\title{
Measurement and evaluation of the performance of an integral abutment bridge deck
}

\author{
Kenneth McGowan \\ West Virginia University
}

Follow this and additional works at: https://researchrepository.wvu.edu/etd

\section{Recommended Citation}

McGowan, Kenneth, "Measurement and evaluation of the performance of an integral abutment bridge deck" (2005). Graduate Theses, Dissertations, and Problem Reports. 1606.

https://researchrepository.wvu.edu/etd/1606

This Thesis is protected by copyright and/or related rights. It has been brought to you by the The Research Repository @ WVU with permission from the rights-holder(s). You are free to use this Thesis in any way that is permitted by the copyright and related rights legislation that applies to your use. For other uses you must obtain permission from the rights-holder(s) directly, unless additional rights are indicated by a Creative Commons license in the record and/ or on the work itself. This Thesis has been accepted for inclusion in WVU Graduate Theses, Dissertations, and Problem Reports collection by an authorized administrator of The Research Repository @ WVU. For more information, please contact researchrepository@mail.wvu.edu. 


\title{
MEASUREMENT AND EVALUATION OF THE PERFORMANCE OF AN INTEGRAL ABUTMENT BRIDGE DECK
}

\author{
By \\ Kenneth McGowan \\ A Thesis \\ Submitted to the College of Engineering and Mineral Resources \\ At \\ West Virginia University \\ In partial fulfillment of the requirements \\ For the degree of \\ Master of Science \\ In \\ Mechanical Engineering \\ Committee Members \\ Dr. Samir N. Shoukry, Chair \\ Dr. Jacky Prucz, MAE \\ Dr. Gergis W. William, CEE \\ Department of Mechanical and Aerospace Engineering,
}

Morgantown, West Virginia

2005 


\section{ABSTRACT \\ MEASUREMENT AND EVALUATION OF THE PERFORMANCE OF AN INTEGRAL ABUTMENT BRIDGE DECK}

\section{Kenneth McGowan}

Many reinforced concrete bridge decks develop problems such as cracking, loss of composite action, and slipping between the reinforcement steel and the concrete, often at very early age, even before the bridge is open to traffic. These are serious problems, and the designs and materials currently in use do not adequately address them. The causes of the problems listed above are most likely constrained drying shrinkage, temperature variation, and over-constraint of the lower surface of the deck by the stay-inplace forms, shear studs, and integral abutments.

This thesis is based upon the instrumentation of an integral abutment bridge, with a reinforced concrete deck on 3-span, continuous steel girders. The bridge is located in Evansville, West Virginia, at the intersection of WV Route 92 South and US Route 50 East. An instrumentation system was developed and installed by Dr. Samir N. Shoukry and his research team to measure the performance of the bridge, including a system of 30 crack meters installed in the deck to detect cracks, strain gages on the girders and embedded in the deck, whose readings can be utilized to determine the degree of composite action of the deck and girders, and sister bars to measure strains in the reinforcement, which can be used to determine the status of the bonding between the reinforcement steel and the concrete deck. Sensor data is collected every 20 minutes and saved. In addition to the data mentioned above, the sensor system also measures the temperature gradient through the deck, the length of the spans, the inclination of the abutments, and girders, and the temperature at each sensor location.

This thesis contains an analysis of the data gathered by the sensors installed in and on Evansville Bridge. Engineering theories and mathematical analysis were used to evaluate the performance of the deck of Evansville Bridge. A technique was developed to detect cracks using the data generated by the crack meters installed in the deck of Evansville Bridge by visually examining the trends of the time-histories of the crack meter displacement reading and temperature. A mathematical model was developed based upon solid mechanics to theoretically predict the strain in the concrete deck assuming it acts as a composite section with the girders; comparing the results of this model with the measured results allows for evaluation of the state of composite action. The status of the bond between the reinforcement and steel was evaluated using correlation between the strain data in the reinforcement and the data from the concrete. It was also determined that the cause of the problems examined was drying shrinkage under constrained conditions, stress due to temperature variation, and differential expansion and contraction due to over-constraint of the bottom surface of the deck. 


\section{TABLE OF CONTENTS}

ABSTRACT $\quad$........................................... ii

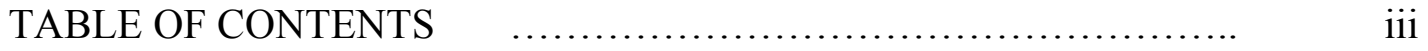

LIST OF FIGURES $\quad$....................................... vi

LIST OF TABLES $\quad$.

\section{CHAPTER 1: INTRODUCTION}

$1.1 \quad$ BACKGROUND $\quad$......................................... 1

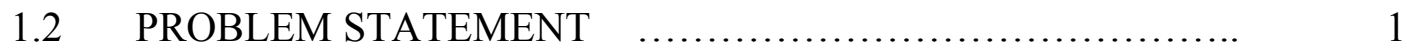

$1.3 \quad$ NEED FOR RESEARCH $\quad$................................. 2

1.4 OBJECTIVES $\quad$......................................... 3

\section{CHAPTER 2: LITERATURE REVIEW}

$2.1 \quad$ INTRODUCTION $\quad$ (........................................ 5

2.2 STRUCTURAL HEALTH MONITORING $\ldots \ldots \ldots \ldots \ldots \ldots \ldots \ldots . \ldots$

2.2.1 NONDESTRUCTIVE TESTING METHODS ........... 7

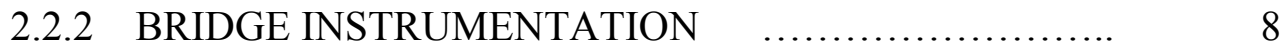

2.3 CRACK DETECTION $\quad$................................. 11

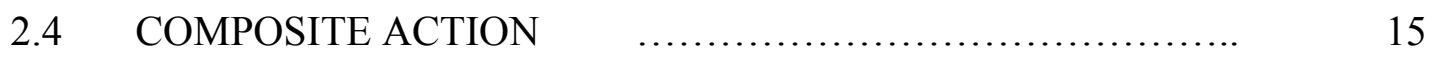

2.5 BOND BETWEEN CONCRETE AND STEEL REINFORCEMENT 18

\section{CHAPTER 3: INSTRUMENTATION OF EVANSVILLE BRIDGE}

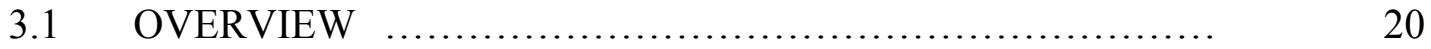

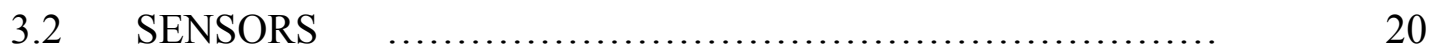

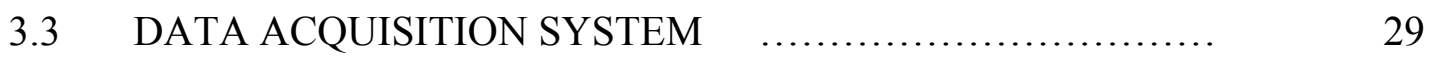

3.4 LABORATORY TESTING OF SENSORS $\ldots \ldots \ldots \ldots \ldots \ldots \ldots . . . \ldots \ldots$

3.4.1 CALIBRATION $\quad$............................... 32

3.4.1.1 CALIBRATION OF VIBRATING WIRE STRAIN 32 GAGES

3.4.1.2 CALIBRATION OF INCLINOMETERS $\quad \ldots . . .34$ 
3.5 INSTRUMENTATION LABELING $\quad$.................... 39

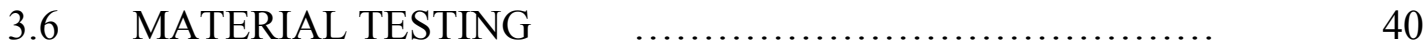

\section{CHAPTER 4: CRACK FORMATION AND DETECTION}

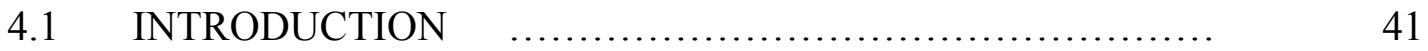

4.2 CAUSES OF CRACKING AT EARLY AGE .............. 41

4.2.1 THERMAL STRESSES DUE TO HYDRATION AND CURING 41

4.2.2 STRAIN AND STRESS IN THE CONCRETE DECK ...... 44

4.2.3 ROLE OF REINFORCEMENT STEEL IN CRACKING .. 53

4.2.4 EFFECTS OF RESTRAINED SHRINKAGE ON EARLY .. 54 AGE CRACKING

$4.3 \quad$ CRACK DETECTION TECHNIQUE $\quad$........................ 61

4.4 RESULTS

4.4.1 POST-CRACKING BEHAVIOR $\quad$....................... 80

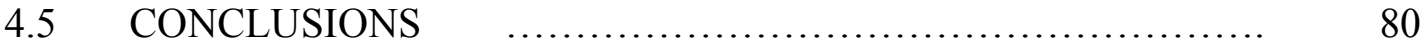

CHAPTER 5: COMPOSITE ACTION OF STEEL GIRDERS AND CONCRETE DECK

$5.1 \quad$ INTRODUCTION $\quad$................................. 81

5.2 EVALUATION OF COMPOSITE ACTION AT EVANSVILLE . 82 BRIDGE

5.3 RESULTS OF COMPOSITE ACTION ANALYSIS $\quad \ldots \ldots \ldots . . . \quad 85$

5.4 CAUSES OF NONCOMPOSITE ACTION ........................ 88

\section{CHAPTER 6: BOND BETWEEN CONCRETE AND STEEL REINFORCEMENT}

$6.1 \quad$ INTRODUCTION [........................................ 91

6.2 EVALUATION OF BOND STATUS $\quad$....................... 91

6.3 RESULTS

6.4 VERIFICATION OF RESULTS _.............................. 100

\section{CHAPTER 7: CONCLUSIONS}

7.1 INSTRUMENATION SYSTEM _.............................. 102 
7.2 BRIDGE STRUCTURE

REFERENCES

104

APPENDIX

A DATA ORGANIZATION

108 


\section{List of Figures}

\section{Chapter 3}

3.1- Instrumentation Plan

3.2- Instruments used to Measure Strain

3.3- Weldable Strain Gage Installed on Top Flange of Girder

3.4- Wire Resistance Embeddment Strain Gages

3.5- Crack Meters Installed in Deck of Evansville Bridge

3.6- Convergence Meter

3.7- Inclinomter, Installed on Lower Flange of Girder B

3.8- Thermistor Tree

3.9- Inside the Instrumentation Shed at Evansville Bridge

3.10- Vibrating Wire Strain Gage Calibration Curve

3.11- Error for a Jewell LCI Inclinometer

3.12- Calibration Curve for LCI Inclinometer

\section{Chapter 4}

4.1- Thermal Map of The Bridge Deck

4.2- Time of Maximum Heat of Hydration

4.4.1-4.4.5a, b- Stress versus Temperature Difference at Midspan and Over the Pier

4.5- Longitudinal Stresses due to Drying Shrinkage 


\section{Chapter 5}

5.1- Shear Studs Attached to a Steel Girder of Evansville Bridge 82

5.2- Illustration of Composite Section $\quad 84$

5.3a-h- Comparison of Calculated and Measured Strains 85

5.4- Change in Span Length and Measured by Crack Meters and 89 Convergence Meters

5.5- Strain Profile through the Deck and Girders at Midspan after 15 Days $\quad 90$

\section{Chapter 6}

6.1a-n- Comparison of Strains in Reinforcement Steel and Concrete Deck 94 


\section{List of Tables}

\section{Chapter 3}

3.1- Strain Gage Calibration Results $\quad 34$

3.2- Material Properties for Concrete Used in Evansville Bridge 40

\section{Chapter 4}

4.1- Crack Detection Results

Chapter 6

6.1- Rebar and Concrete Bonding Status 92

6.2- Correlation Between Strains in Rebar and Concrete 100

\section{Appendix}

A1- Data File Contents for the First 11 Columns 108

$\begin{array}{ll}\text { A2- Sensors Connected to Data Logger 1 } & 110\end{array}$

A3- Sensors Connected to Data Logger 2 111 


\section{CHAPTER 1 \\ INTRODUCTION}

\subsection{BACKGROUND}

Maintenance and repair of bridges is a problem faced universally by departments of transportation worldwide. The costs of keeping America's bridges in safe and serviceable condition are tremendous. The Federal Highway Administration has estimated that $\$ 50$ billion is needed to keep roads and bridges in their current state of repair, and that $\$ 215$ billion is needed to repair all the roadways and bridges that are deficient (Roberts and Shepard, 2000). Deterioration of bridges is particularly troublesome, because repair costs are high, and the safety of motorists depends on the state of repair of bridges. Of the approximately 600,000 bridges in the United States, 200,000 are damaged or of obsolete design (Thompson, et. al., 2000). Deterioration of bridges is often centered in the concrete deck. Several types of damage can occur in bridge decks; of particular interest are cracking, loss of composite action between the concrete deck and the steel girders, and loss of bond between the reinforcement steel and the surrounding concrete in the deck. These problems can all lead to accelerated failure of bridges, and often require costly repairs, so understanding their causes is vitally important to improving bridge construction techniques and designs, and bridge maintenance procedures.

\subsection{PROBLEM STATEMENT}

There are two primary motives behind instrumented monitoring of bridges. The first is to detect damage and deterioration as the structure ages, and the second is to determine the real-life behavior and performance of a bridge, as compared to its assumed or theoretically predicted characteristics. To achieve these ends, half of Evansville Bridge, located in Preston County, West Virginia, where West Virginia Route 92 crosses Little Sandy Creek, was extensively instrumented during the first phase of construction (June 2003). Sensors were installed on the bridge to measure displacements, strains, inclinations, and temperatures. 
Evansville Bridge is an integral abutment three-span continuous steel girder bridge. The bridge is located in Preston County, West Virginia, near the intersection of US route 50 and West Virginia route 92 . Evansville Bridge is skewed at $55^{\circ}$, has a total length of 147 feet, with edge spans of 48.5 feet, and a central span of 50 feet. The bridge is 44 feet wide, with two 12 foot wide traffic lanes, and 8.5 and 9 foot wide shoulders. The concrete of the deck is a minimum of 8 inches thick, and is haunched to 9 inches thick over the girders.

Bridge designers currently rely on several simplifying assumptions to allow them to design a functional and practical structure. In many cases, these simplifying assume strengths for components and loads that may not always be correct. Current theories are unable to accurately predict the true behavior of large and complex structures, especially on a localized scale. By placing sensors on a bridge and measuring its response, it may be possible to restructure and reformulate some of the theories used in bridge design to allow for structures that are safer, last longer, and are more efficient and cost effective.

Current bridge design theories rely on the assumptions that:

1) The bridge exhibits composite action (i.e. the bridge deck and steel girders act as a single composite structural member, provided that shear studs transfer all the shear flow from the deck to the steel).

2) Reinforcing steel rebar is perfectly bonded to the surrounding concrete.

The validity of these assumptions in real-life bridges under the effect of continuous environmental changes needs to be examined.

Also, the formation of cracks at early age and their impact on the bridge's performance needs to be investigated.

\subsection{NEED FOR RESEARCH}

The current method of detection of damage or failure of bridges relies on visual inspection at specified time intervals. Inspectors look for loss of section, cracks, 
structural deterioration and other structural deficiencies to determine the condition of a bridge. There are several key problems with the current method of bridge evaluation. When visual observation is used, the results of the inspection are often dependent on the knowledge, skill, and experience of the inspector. Many defects are not easily detected by the naked eye, some critical areas are obscured from observation, and some key elements, such as reinforcement steel, are not accessible for inspection. Also, some problems can progress very rapidly, and may cause serious failure before they can be detected by the next scheduled inspection. A system of sensors placed throughout the bridge would alleviate the problems associated with visual inspection, and allow most flaws to be detected quickly. The faster a given structural problem can be detected and repaired, the less time and expense is required. Additionally, the mechanisms involved in the development of structural deficiencies can be identified.

The most effective way to correctly characterize the behavior of bridges in the field under actual loading conditions is through extensive instrumentation (placing multiple strain, displacement, and temperature sensors throughout the bridge). Instrumentation was first attempted during the 1960's and 1970's, but until recently, sensor and data acquisition technology has not been capable of reliable, long-term structural monitoring. There have been some limited studies into the phenomena being investigated in this report, but they were limited in scope and duration to such an extent that they were often unable to come to any definitive conclusions about the true state of the bridge structure in question. Through extensive monitoring of the health and performance of bridge structures, it is possible to extend the service life, reduce maintenance costs, and improve the performance of future structures.

\subsection{OBJECTIVES}

The primary objectives of this research are:

1. To analyze the development of cracking at early age, and develop a simple method for detecting cracks based upon data acquired from sensors installed in 
the bridge deck, in order to monitor the development, opening, and steady-state properties of cracks.

2. To determine if the bridge structure exhibits composite action between the steel girders and the concrete deck.

3. To analyze the status of the bond between the reinforcement steel and the concrete deck.

4. To characterize the effects of long-term weather changes and short-term traffic loads on integral abutment bridges. 


\section{CHAPTER 2}

\section{LITERATURE REVIEW}

\subsection{INTRODUCTION}

Monitoring the health of civil infrastructure has become increasingly important as demands placed upon roadways and bridges due to increased traffic and increases in the loads carried by heavy trucks. In light of this, it is necessary to develop methods for analyzing the field performance of bridges throughout their lifetime, with the goal of safely extending their service life. By understanding the mechanisms involved in the deterioration of a bridge, as well as the behavior of the structure under the various loads it is subjected to, it is possible to achieve this goal.

In a steel girder bridge, it is desired that the concrete of the bridge deck and the steel girders act as a cohesive unit. In order to facilitate this, shear studs are welded to the top flanges of the steel girders, and embedded in the concrete of the deck. It is assumed in design and practice that the shear studs provide an adequate bond between the deck and the girders so that they do not act independently of one another. It is also assumed that the reinforcement steel is totally and completely bonded with the surrounding concrete of the deck; this is a vitally important assumption, because the steel reinforcement is necessary to compensate for the concrete's relatively low tensile strength (Nawy, 1997). The mechanism of cracking of bridge decks also requires investigation, since understanding this problem can eventually lead to its correction.

In this chapter, a literature review is presented, which examines previous research in structural health monitoring and bridge instrumentation, as well as methods for detecting cracks, composite action of steel girders and bridge decks, and the bond between steel reinforcement and concrete. 


\subsection{STRUCTURAL HEALTH MONITORING}

Currently, most bridges are visually inspected to determine their state of repair. Typically, a bridge inspection is conducted by a trained examiner, who observes the bridge at close range to determine its condition (Abdel Qader et al, 2003). After inspection, the inspector gives the bridge's various components a ranking based on its observed condition. Typically, the ranking is between 0 for a failed component, and 9 for one in excellent condition (Phares et al., 2001). Visual inspection is often adequate, but has some shortcomings since it is subject to the individual inspector's abilities, the timing of the inspection, and a number of other factors, including the inspector's comfort with heights and moving traffic, and even an inspector's visual acuity (Phares et al., 2001). In a study conducted by the Federal Highway Administration's Nondestructive Evaluation Validation Center (NDEVC), 49 bridge inspectors from 25 state departments of transportation (DOTs) conducted routine inspections on 7 bridges, and in-depth inspections on 3 bridges while being observed by NDEVC scientists (Phares et al., 2001). During the in-depth inspections, it was found that 36\% of the inspectors performed incomplete inspections, and that an in-depth inspection doesn't always yield more information than a routine one (Phares et al., 2001). The study also showed significant variability among inspectors; for example, the deck of one bridge was rated as high as seven by one inspector, and as low as two by another (NDEVC inspectors rated it at 4, and the average rating by inspectors was 4.9) (Phares, et al., 2001).

Clearly, the currently used visual inspection methods do not always yield satisfactory results. Several alternatives to visual inspection have been proposed, including the use of various types of sensors installed in and on a bridge, and nondestructive methods such as laser deflection measurement, ground penetrating radar (GPR), and automated ultrasound testing (AUT), and some imaging methods (Washer, 2003). Automated electronic methods, regardless of the technology used, have the advantage of being independent of the inspectors' skill, and often provide more consistent and accurate results. In addition, these methods often provide insight into the state of internal components of structures that are not accessible to visual inspection. 


\subsubsection{NONDESTRUCTIVE TESTING METHODS}

Nondestructive testing (NDT) is a term used to describe any method of testing a structure that does not cause damage to the structure, yet is still able to evaluate the structures state of repair-its health. Several different types of NDT have been utilized for the examination of the health of bridge structures.

Ground penetrating radar (GPR) has been used as a method of structural evaluation for several years. Scott, et al. (2001) used a prototypical GPR-based system called PERES (Precision Electromagnetic Roadway Evaluation System) to detect delamination cracks and other features (voids, etc) of bridge decks. The PERES system is a part of the HERMES ( High Speed Electromagnetic Roadway Mapping and

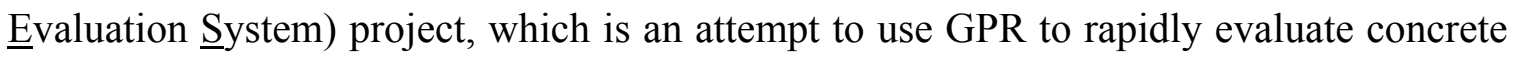
bridge decks using an automated system. The HERMES system is expected to be able to provide evaluation of a bridge deck's condition while traveling across it at highway speed. The research indicated that currently the resolution of the PERES system was not sufficiently high to reliably detect delamination cracks, and that PERES does not have adequate penetration depth and produces too much clutter in its signal. A new HERMES II system was being developed at the time of publication of the original study.

Automated ultrasound testing (AUT) combines ordinary ultrasonic testing methods with computerized data acquisition (Washer 2003). This method is primarily used for inspecting welds in steel bridges during construction, but can be applied for inspection later in the life of the structure as well.

Several other nondestructive methods are presented and reviewed in the section of this literature review on crack detection, including ultrasonic pulse velocity (UPV) and impact echo (IE) testing (Clemeńa et. al., 2000), as well as imaging methods (AbdelQader et al, 2003, Scheffy et al, 1999). Laser measurements have also been used to detect cracks (Lu et al) and measure deflections (Washer, 2003). 
Although they can often accurately and quickly evaluate the health of some of the important components of a bridge structure, the nondestructive evaluation methods above are somewhat limited in scope, and can often only be applied for a limited amount of time to a limited portion of a structure. Most of them cannot be used for continuous or remote monitoring. One way to overcome these limitations is to install a network of sensors throughout a bridge structure. This type of structural health monitoring is covered in the following section of this review.

\subsubsection{BRIDGE INSTRUMENTATION}

There are three types of instrumentation that can be used in structural health monitoring of bridges. The first type uses passive sensors; these sensors require no power to operate, and are only powered upon interrogation when data is acquired (Thompson et. al., 2000). Passive sensors detect peak deflections at monitored locations, and are either mechatronic elements (linear potentiometers designed to retain peak deflections) or TRIP sensors, which consist of a metastable material that has an irreversible reponse to strain (Thompson et. al., 2000). Active systems can be continuously monitored, acquiring real-time data, and require full time power. Sensors used in active systems include vibrating-wire gauges, fiber optics, and electrical resistance gauges (Thompson et. al., 2000). Active systems are less robust than passive systems, because they are vulnerable to power outages, but they provide a much more complete record of structural behavior than passive systems do. The third type of system is a hybrid system, which combines both passive and active sensor technology. Of primary interest for this report are active systems, several of which are reviewed in the following paragraphs.

In 1974, the Nebraska Department of Roads and the University of Nebraska instrumented 2 bridges and a model structure in Nebraska. Holmes, et al. (1974) used electrical resistance strain gages and mechanical strain gages. Additional temperatue and moisture content readings were taken via wells installed in the concrete of the prestressed 
girders and the deck of the instrumented structures. The instrumentation system was relatively extensive, but because there was no remote data acquisition system, the researchers had problems accessing the sensors to acquire data from them. The mechanical strain gages were more accurate for long-term readings than the wire resistance gages, but they were found to be delicate instruments, and were highly sensitive to misuse and rough handling (Holmes, et al., 1974). The researchers found the electrical resistance gages adequate, but some problems were encountered with them, especially with the insulation, which was intended to prevent environmental damage and signal loss. The researchers were concerned with measuring the effects of creep and shrinkage on prestressed girders, and they reported moderate success in doing so with the instrumentation system described above (Holmes et al., 1974)

In the years following the Nebraska Department of Roads project, several bridges have been instrumented. In most cases, the researchers were attempting to characterize the structure's response to a specific loading condition, or to analyze the performance of a specific component, and because of this, the sensor network placed was not extensive. For example, in Salt Lake City, Utah, researchers placed accelerometers and seismometers on an overpass bridge on Interstate 15 to determine its seismic (dynamic) response (Petty, 2002). In 2002, The Dormeus Avenue Bridge in New Jersey was instrumented to measure only its deflection (using linear variable displacement transducers (LVDTs), and Laser Doppler Vibrometers (Nassif, et al, 2002). In Minnesota, Jajich et al. (2003) instrumented the girders of a bridge with 16 strain gages to evaluate the effect of fatigue loading on the welds attaching the stiffeners to the web and used string potentiometers to measure differential deflections at the diaphragms. Wotton Bridge in Quebec, Canada was instrumented with Fabry-Perot fiber optic strain gages in order to facilitate comparison between a part of the bridge which was constructed using fiber-reinforced polymer (FRP) reinforcement and a part of the bridge constructed with steel reinforcement (El-Salakawy et al., 2003). Strains gages were bonded to the reinforcement, embedded in the concrete of the bridge deck, and bonded to the surface of the concrete girders; the study found that the FRP reinforcement performed in a nearly identical fashion to steel reinforcement (El-Salakawy et al., 2003). 
Lawver et al. (2000) instrumented part of an integral abutment bridge in Minnesota, and data was collected from construction through 2 years in service. The researchers instrumented one end pile and one middle pile with arc-weldable strain gages to measure bending and compression in the piles. Lawver et al. (2000) installed tiltmeters, extensometers, and a total station to measure abutment movement; they discovered that the primary cause of abutment movement is seasonal changes in length of the span due to temperature variation. The earth pressure behind the abutment walls was measured. In order to determine the effect of the approach panel on movement of the bridge, Lawver et al. monitored strain in the reinforcement steel of the approach slab using spot-weldable steel reinforcement strain gages. Data was collected remotely on certain days throughout the year to measure daily trends on different types of days (i.e. cold, cloudy days and warm, sunny days) (Lawver et al., 2000). Additionally, a live load test was conducted with loaded trucks to determine the effects of traffic loading on the bridge; in this test, convergence meters were used to measure the relative displacement between the girders and the ground, and 3 embedment strain gages in each of the girders were used to measure strains, which were used to calculate the moments induced by the loading; the results of this study indicated that the bridge was behaving as 3 independent spans instead of one continuous span as is assumed in design (Lawver et al., 2000). In this study, data was not collected often enough to understand the day-to-day real life performance of the bridge, nor was the instrumentation truly extensive enough to totally characterize the bridge's performance.

In 2002, Civjan et al. (2004) instrumented a bridge in Massachusetts. The bridge was monitored for a total of 16 months. In all, 85 channels of instrumentation were installed on the bridge, including earth pressure cells, joint meters, tiltmeters, temperature gages, strain gages, and thermistors. Joint meters were used to measure longitudinal and transverse displacement of the bridge structure, relative rotation of the abutments was measured using two tiltmeters on each abutment, the earth pressure behind the abutment walls was measured with earth pressure cells, and strains in the piles supporting the abutments and in the exterior girders were measured with strain gages. Temperature was 
measured on the underside of the bridge deck, and each instrument had its own embedded thermistor to measure local temperatures. Data was collected every six hours with a CR10X Campbell Scientific datalogger. The primary objective of this study was to monitor the response of the bridge to seasonal temperature variations (Civjan et al., 2004). Even though the instrumentation was extensive, no sensors were installed in the deck of the bridge, making it difficult to characterize the structure's total behavior.

There have only been a few attempts at instrumentation on the scale necessary to truly determine the total, in-use performance of a bridge. One such instrumentation system was installed on the US route 127 (Hamilton Avenue) bridge in Cincinnati, Ohio. The researchers from the Cincinnati Infrastructure Institute of the University of Cincinnati installed an extensive network of sensors on the bridge, including vibrating wire strain gages on the girders and embedded in the deck, inclinometers, and extensometers to measure static events, and wire resistance strain gages on the girders and embedded in the deck to measure dynamic behavior. This system was designed for long-term monitoring, and attempted to characterize the bridge's behavior completely (Levi, et al, 1999).

\subsection{CRACK DETECTION}

Cracking is a major problem associated with concrete bridge decks. Cracking occurs not only at later stages of the life of a slab due to normal wear and stress, but also at very early age. According to a study conducted by Wiss, Janney, Elstner Associates, Inc. for the NCHRP, longitudinal tensile stresses are the cause of transverse cracking in concrete bridge decks; the stresses are caused by temperature variation, restrained shrinking, and traffic loads (Krauss and Rogalla, 1996). The primary cause of elevated stresses leading to cracking was found to be drying shrinkage under restrained conditions.

Abdel-Qader et al. (2003) proposed a method for the detection of cracks that utilized an imaging system as part of an automated crack detection algorithm. The idea of this system was to detect edges in the image. An edge typically represents a crack. In 
order to detect edges in a given image, several methods were used. The first proposed method was the Sobel method (Parker 1997), which uses the gradient of image intensity. The next proposed method was the Canny (Canny 1986) method, which uses a smoothed image, from which the gradient magnitude is determined. Fourier Transform (Cooley and Tukey, 1965) and Fast Haar Transform (Alageel and Abdel-Qader, 2002) methods were also used. Each method was used on a sample of 50 images of concrete bridge decks, 25 of which were known to be healthy, uncracked bridge decks, and 25 of which were known to be deteriorating. A MATLAB code was used to read an image, perform the transformation required in each method, and based upon the measured edge intensity and a threshold value, cracked or uncracked status was determined (Abdel Qader et al., 2003). The threshold was the average value of the intensity of all pixels in the images. The study found that the Fast Haar Transform provided the best results, with an $86 \%$ correct detection rate. The Fourier Transform was one of the poorest performing methods, with a 64\% detection rate (Abdel Qader et al., 2003).

Another form of digital image analysis was used to detect cracks by Scheffy et al. (1999). The researchers used digital imaging techniques to convert images of concrete surfaces into data on the location, orientation, and length of cracks in pavement test sections. Images were digitally corrected and enhanced using Optimas imaging software, and a composite image consisting of several photographs was constructed for the entire test spectrum. The images were then calibrated in such a manner that distances in the image corresponded to real-life distances; researchers were then able to identify cracks, as well as measure their width, length, and orientation (Scheffy et al., 1999). The crack detection method used in this research appears to be primarily an enhanced form of visual inspection.

A study conducted for the Virginia Department of Transportation evaluated several nondestructive testing methods for use in detecting defects and damage in concrete pavements. The methods examined included surface ultrasonic pulse velocity (UPV), impact-echo testing (IE), and the use of a seismic pavement analyzer (SPA) (Clemeńa, et al., 2000). Surface UPV measures the velocity of a longitudinal 
compression wave as it travels through the structure being tested. Defects such as cracks, delaminations, and alkali-silica reactivity cause variations in the velocity of the pulse. The pulse velocity can be used to calculate the elastic modulus of the material, which can be used to determine its condition. Clemeńa, et al. found that UPV was simple to perform, and required a single, relatively inexpensive, commercially available instrument. They also determined that the development of a mechanized, automated version of the UPV instrument is necessary before it can be successfully used for widespread measurements of the condition of concrete pavement. Clemeńa, et al. tested the effectiveness of UPV for crack detection, and found that while it was occasionally able to detect fine cracks usually missed by visual inspection, it often did not. Overall, UPV test results were correct 82 percent of the time, but in sections where cracking was only beginning to occur, and cracks were not large, the accuracy dropped to only 68 percent. Impact echo testing is also based upon the propagation of stress waves through the concrete slab being examined; in an IE test, a transient stress pulse is initiated into the concrete by impacting its surface with a spherical steel ball. The stress pulse is reflected off of slab boundaries, as well as cracks and other defects within the concrete. A piezoelectric transducer is used to detect the reflections. Clemeńa, et al (2000) determined that IE testing was not effective for detecting microscopic cracks, and that the accuracy of this type of test varied considerably. In some test sections, the results were as accurate as 84 percent, but in others, accuracy was as low as 38 percent. The final method evaluated by Clemeńa, et al. was the use of an instrument called a seismic pavement analyzer, which makes use of an IE system. Clemeńa, et al., had difficulty determining how well the SPA device worked, or how accurately it detected cracking. The researchers also noted that both UPV and IE tests can be used for long term monitoring.

Kuang et al. (2003) used plastic optical fibers (POFs) to detect cracks and measure deflections in concrete beams subjected to bending loads. The researchers drew several conclusions regarding the use of plastic optical fibers for damage detection in civil structures; among these were that plastic optical fibers have several advantages over glass optical fibers. POFs are cheaper ( $\$ 0.13$ per meter or less), easier to terminate and 
couple, and more resistive to fracture than glass fibers (Kuang et al., 2003). Additionally, only basic solid-state equipment was required to use POFs as sensors. The operating principle of a POF-based sensor is based upon modulation of light intensity, so sophisticated signal interrogation techniques are not necessary (Kuang et al., 2003). In the study conducted by Kuang et al., $1 \mathrm{~mm}$ diameter, step-index POFs were used. The fibers were initially "sensitized" by removing their protective cladding. Without the cladding, the fiber loses more light to the environment through evanescent penetration; this loss of light is increased when the fiber is bent in one direction, and decreased if the fiber is bent in the opposite direction. The POF sensors were tested on two types of concrete specimens: a scale model of a concrete beam and a full-scale steel-reinforced concrete beam. The sensors were attached to the specimens via adhesive bonding, and then the specimens were subjected to 3 and 4 point bending tests. As the specimens were loaded, the sensors' response changed steadily, until cracking occurred. When a crack was initiated, Kuang et al. (2003) observed a sharp change in the rate of attenuation of light intensity. The researchers also found that the sensor was able to detect deflection of the structure after cracking had initiated, as well as crack propagation. Kuang et al.'s research indicates that plastic optical fibers have a high degree of reliability and a high rate of detection of cracks.

Ground Penetrating Radar (GPR) has been used in several studies to detect cracks in pavements and bridge decks. GPR works by emitting electromagnetic waves into the concrete surface, and is well known as a non-contact, rapid and safe technique for crack detection. Halabe et al. (1994) successfully used GPR to detect surface cracks on concrete structures. Scott, et al. (2001) used a prototypical GPR-based system called PERES (Precision Electromagnetic Roadway Evaluation System) to detect delamination cracks in bridge decks. The research indicated that currently the resolution of the PERES system was not sufficiently high to reliably detect delamination cracks.

Lu et. al. $(* * *)$ used lasers to detect and evaluate cracks in pavements. In the study they conducted for the Florida Department of Transportation, $\mathrm{Lu}$ et al. aimed to develop a system that was able to dynamically and automatically detect a surface crack 
and measure its depth. In order to do this, they employed two laser sensors and a distance sensor to obtain data on cracks, and a neural network was developed to analyze the data and estimate the depth of the crack (Lu et. al., ****). Lu et al. found the laser sensor system very good for detecting surface cracks, with detection rates over $90 \%$ in all test sections.

All of the crack detection methods reviewed are undoubtedly useful for detecting and measuring cracks in bridge decks, but unfortunately, none of them provide sufficient additional information about the state of the bridge structure to determine the causative factors contributing to the detected cracks. In order to do this, additional measurements, such as strain, stress, temperature, etc, are required.

\subsection{COMPOSITE ACTION}

In the design of steel girder bridges, composite action between the concrete deck and the girders is assumed to minimize the deflection, reduce bending stress in the steel girder, and allow for the reduction of the steel girders' cross sections. A lack of composite action can have serious consequences with regard to the overall serviceability and longevity of a bridge. Several studies into the state of composite action of bridge structures have been conducted, and some alternative methods to improve and insure composite action in bridges have been proposed.

Researchers from the Virginia Transportation Research Council (Brown et al., 2003) conducted a study of a bridge across the New River on Interstate 81 to determine, among other things, if it was performing acceptably with regard to composite action. Two parallel bridge structures where examined; each structure consists of ten spans, with the southbound bridge being 1657.5 feet in length, and the northbound bridge being 1599.5 feet in length. The bridges were constructed using partial depth precast panels, with the remainder of the deck being cast-in-place. The structure was in a state of disrepair, with spalling occurring in the cast in place layer of the deck, some prestressing strands were exposed, and there was growing concern about the deterioration of the 
structural capacity of the bridge, and in particular the degree of composite action between the deck and the steel girders. Prior to the study being discussed here, the bridge had been evaluated in August of 2000; the strain in the steel girders was monitored at midspan while the bridge was loaded with a tandem axle dumptruck of known weight and dimensions. Load tests were conducted at highway speeds. In August of 2002, the bridge was examined again in a similar manner, and the acquired strain data was used to determine the state of the composite action of the bridge. Strain was measured at the top and bottom flanges of the girder, and this data was used to estimate the location of the girder's neutral axis. These results were compared with results obtained in the August 2000 study to determine how much the structure had deteriorated. The field results were also compared with calculated results. Calculations were carried out assuming a range of degrees of composite action, varying from complete composite action to complete noncomposite action. The calculations revealed that as the degree of composite action decreases, the depth of the neutral axis (as measured from the top of the deck) decreases. The study determined that the average neutral axis location is deeper than is to be expected for a fully bonded composite system, and is in fact in the range predicted for partial or full loss of bond between the precast panels and the girders, and possibly some cracking of the cast-in place deck sections. The results of this study did not definitively confirm the loss of composite action, but they did show that the contribution of the deck to the overall structural capacity is much less than anticipated (Brown et al., 2003).

Researchers at the Bridge Structure Division of Kawada Industries, Setsunan University, and the Osaka Institute of Technology in Japan have recently attempted to devise a method of ensuring that composite action occurs by modifying the shear studs used to connect the bridge deck to the steel girders (Kitagawa et. al., 2001). The research project determined that the primary cause of bridges not exhibiting composite action stems from increased tensile stress in the concrete at the time of curing due to drying shrinkage, which causes localized damage around the shear stud, which in turn results in imperfect bonding between the concrete and the shear stud. The proposed design, known as a Post Rigid System, incorporates a traditional shear stud encased in a cold-setting epoxy resin mortar. The mortar used was time-setting; it remains gelatinous and allows 
relative motion between the shear studs and the concrete prior to hardening, but becomes rigid and does not allow relative motion after hardening. The hardening time of the resin mortar can be adjusted as necessary. The goal of the redesigned shear studs was to provide non composite action during construction, which removes the stresses ordinarily developed due to drying shrinkage. This system was successfully used in Shiratori Bridge, and the results indicated that the improved shear studs have shear strength similar to normal shear studs both before and after the resin hardens. Additionally, the slippage prior to construction, when the resin is in a gelatinous state, is much greater than the slippage after the resin hardens. After hardening, the resin-encased stud performs nearly identically to a normal shear stud with regard to slippage (Kitagawa et al.).

In a report on Composite slab design, Nagy and Szatmari (1998) of the Technical University of Budapest, noted that composite slabs are structurally desirable because they exploit the high tensile strength of steel members and the high compressive strength of concrete. That is due to the fact that the concrete provides resistance to buckling, which is a problem with relatively slender steel members, and the steel prevents the concrete from rupturing under tensile loads, since the tensile strength of concrete is relatively low. The authors noted that while the chemical bond between concrete and steel can be very strong (on the order of $0.45 \mathrm{MPa}$ ), it cannot be counted on by designers to provide composite action, because the strength of the bond is very dependent on the quality of the surface finish on the steel, any coatings applied to the steel, and on surface cleanliness. It was also noted that the rupture of a joint between chemically bonded steel and concrete structural members is very sudden. Based upon these findings, the authors recommend that mechanical and/or friction connectors be used to ensure a bond between the concrete slab and its supporting steel girders. Shear studs were recommended as the connectors between steel and concrete structural members, and it was noted that the use of shear studs greatly improves the ultimate load that can be supported by a steel/concrete composite structure (Nagy and Szatmari, 1998). 


\subsection{BOND BETWEEN CONCRETE AND STEEL REINFORCEMENT}

Steel reinforcement helps to provide tensile strength to a concrete structure, which is vitally important, since concrete alone has low strength in tension. In order for steel reinforcement to be effective, there must be a bond between the steel reinforcement and the surrounding concrete. According to Haddad and Ashteyate (2001), this bond is comprised of three components: chemical adhesion, friction, and mechanical interlock between the ribs of the steel bar and the concrete. Several studies have been conducted to investigate the bond between steel reinforcement and the concrete surrounding it.

Weathersby (2003) conducted a study in which the bond between steel reinforcement and concrete was examined. The study was largely focused on determining the dynamic interaction between the reinforcement and the concrete, and examined the effects of concrete confinement, bar deformation, and bar diameter on bond slip, as well as the influence of loading rates, which were varied from quasi-static to impact levels. Strains were measured along the steel reinforcement using Micromeasurements resistance strain gages, and strains in concrete were measured using Extrinsic Fabry-Perot Interferometer fiber-optic strain gages. A finite element analysis was conducted using experimental parameters to determine the value of chemical adhesion and to compare experimental results with analytical values. A total of thirtythree pullout tests were performed, using quasi-static, dynamic, and impact loads. Test specimens were constructed by casting a single steel bar in the center of center of a concrete matrix. It was found that chemical adhesion is 960 psi for quasi static loading, 2600 psi for dynamic loading, and 3200 psi for impact loading; in all cases, deformation of the steel bar accounted for $70-77 \%$ of the total resistance to pullout. It was found that smooth bars were more susceptible to pull-out than deformed bars, and that loading rate had no effect on the failure mode, except in the case of 20-inch diameter specimens with \#8 bars, where the failure mode changed from radial cracking of the specimen to yielding of the steel bar when the loading rate was increased from quasi-static to dynamic. Generally, specimens with deformed bars failed by radial cracking of the concrete, and specimens with smooth bars failed by bar pull-out. As bar diameter increased, failure loads increased in the dynamic and impact tests, but decreased for the quasi-static tests. 
This research examined bonding between steel reinforcement and concrete only in a laboratory setting, so it was useful in demonstrating the causes of bond failures, but it did not examine the bonding between steel and concrete in real structures.

Haddad and Ashteyate (2001) studied the effect of the addition of synthetic fibers to concrete on the corrosion of steel reinforcement and the bond between steel and concrete. Among their findings was that bond strength was initially improved by corrosion of steel reinforcement, until the corrosion became bad enough to cause cracking in the surrounding concrete, which led to decreased bond strength. Additionally, it was noted that bond strength was improved by as much as $87 \%$ in the latter stages of corrosion by the addition of synthetic fibers. The results of this study help to illustrate the primary cause of bond slip (corrosion of steel bars), and also suggest a possible solution (addition of fibers). 


\section{CHAPTER 3 \\ INSTRUMENTATION OF EVANSVILLE BRIDGE}

\subsection{INTRODUCTION}

In June 2003, Evansville Bridge was instrumented by Dr. Samir N. Shoukry and his research team. In this chapter, a description of the instrumentation system and its components is presented.

The instrumentation system implemented at Evansville Bridge was designed to measure the histories of strains, temperatures, relative displacement of supports, girder slopes, and the abutments' relative inclinations. The data collected by this instrumentation system provides a complete record of the bridge's actual performance in service, which can be used to determine the state of repair of the bridge.

\subsection{SENSORS}

A total of 232 sensors were installed in several locations on Evansville Bridge to monitor the structure's response to traffic loads and variations in temperature. In order to measure the bridge's performance, four parameters were monitored:

1) Strain

2) Displacement

3) Inclination

4) Temperature.

Strains were measured using strain gages; displacements were measured with displacement transducers, inclination with inclinometers, and temperature with thermistors. Figure 3.1 shows a layout of the instrumentation system used in the deck of Evansville Bridge. 


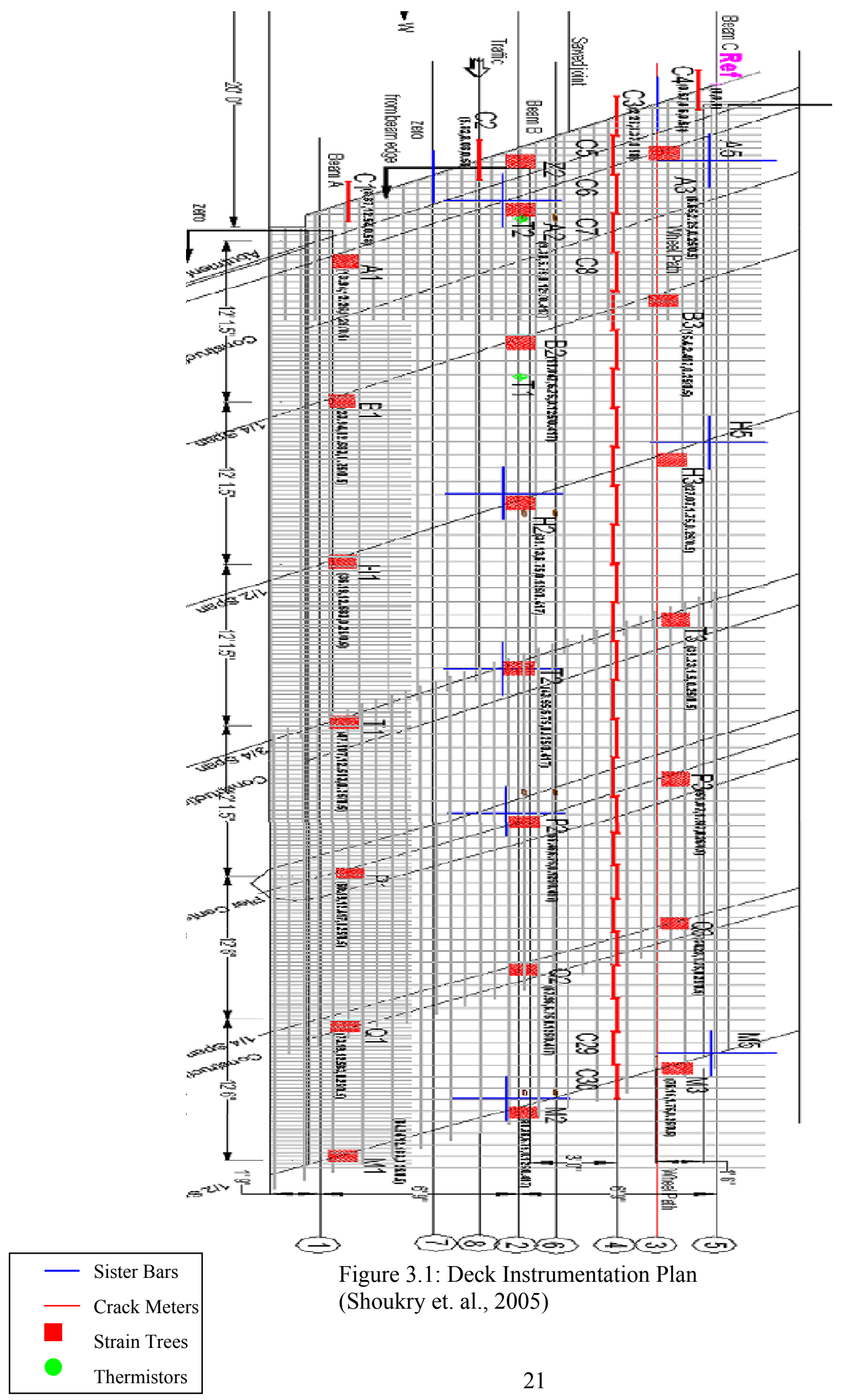


Two different types of strain gages were utilized to capture the strain distributions present in Evansville Bridge: vibrating wire gages were used to measure long-term strains due to static loading and environmental effects, and wire resistance strain gages were used to measure the short-term, dynamic strains, caused by traffic passing over the bridge.

Vibrating wire embedment strain gages were placed in 22 locations, with 5 or 6 gages at each location in tree form ( 6 gages is ideal, but only 5 could be placed at some locations due to space constraints). A strain gage tree is made up of a total of 6 gages, with gages in the $\mathrm{X}, \mathrm{Y}$ and $\mathrm{Z}$ directions at both the top and the bottom of the deck, as shown in figure 3.2. These gages aim to capture the triaxial state of strain caused by environmental effects throughout the bridge deck. Geokon manufactures the VCE 4200 vibrating wire strain gages used for embedment in the bridge deck. The VCE 4200 strain gage has a gage length of four inches, a midrange of 2500 microstrain, and a sensitivity of one microstrain (Geokon, 1996). The electronic excitation coil is detachable, which makes installation simpler and more convenient. A thermistor is provided with each gage (located in the detachable plucking coil) to allow for temperature compensation, since the coefficients of thermal expansion of the gages and the concrete they were placed in differ. The gages were initially secured in place with nylon cable ties, and were later bonded to the reinforcement steel using epoxy adhesive (JB weld). 


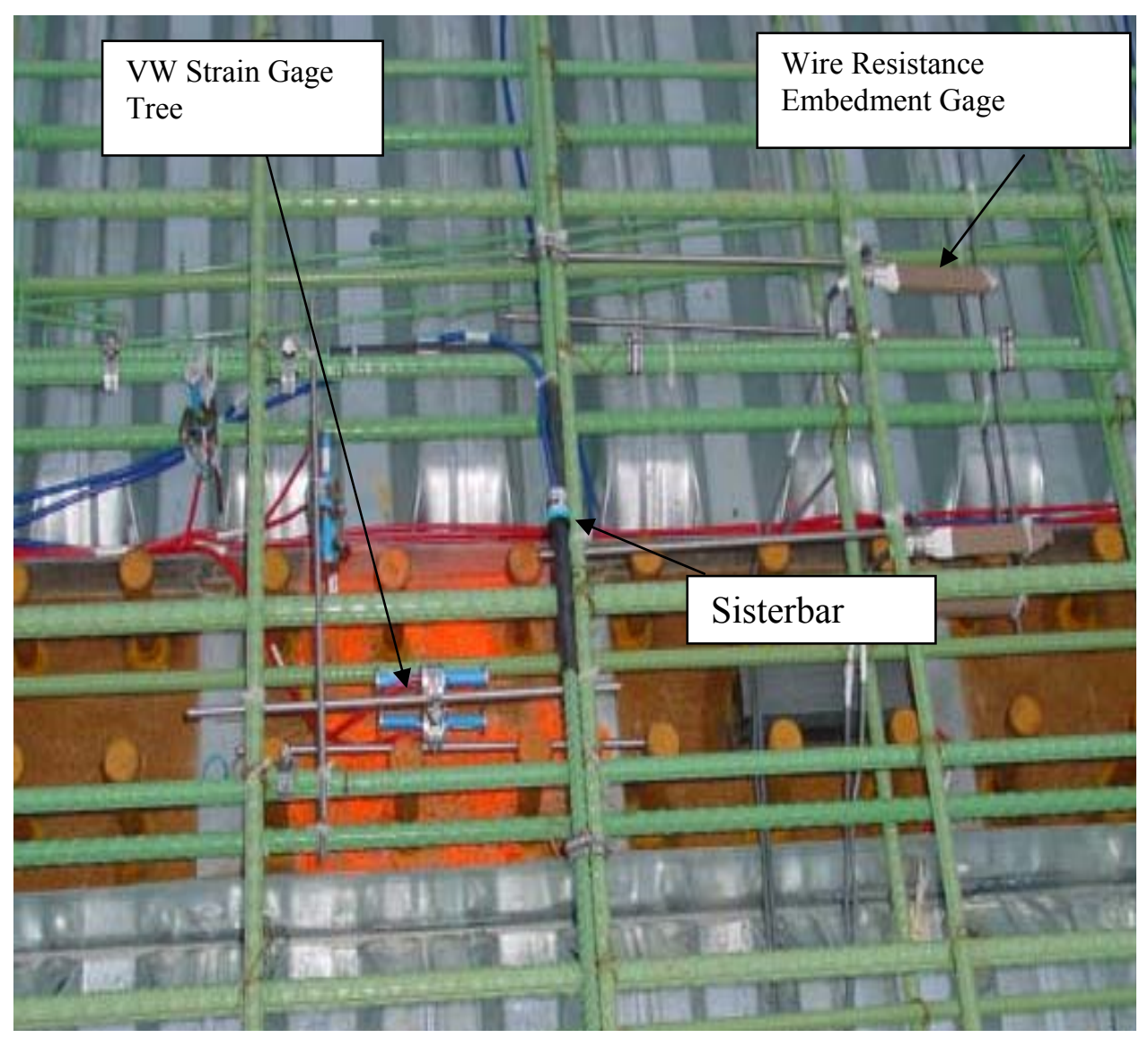

Figure 3.2: Instruments Used to Measure Strains (photo courtesy of Dr. Shoukry, WVU)

Vibrating wire sister bars were placed at the same locations as the strain gage trees to measure the strain in the top reinforcement steel. Sister bars were mounted in the longitudinal and transverse directions at eight locations, in a similar manner to that illustrated in figure 3.2. The sister bars used were Geokon model 4911 sister bars, which consist of a 7.75 inch section of high strength steel, in which a vibrating wire sensing element, a plucking coil, and a thermistor are placed, welded between two 23.375 inch sections of reinforcement steel (Geokon, 1996). The total length of the sister bar is 54.5 inches, and it has a 2500 microstrain range, with a sensitivity of 0.4 microstrain (Geokon, 1996). The sister bars were tied to the reinforcement bars in the bridge deck using stainless steel hose clamps at the ends and at one-third of their length, to avoid applying force to the gage. 
In order to measure the strains in the steel girders, a total of eight weldable strain gages were used. Gages were placed in four locations, with two gages (top and bottom of the girder) at each location. The gages were mounted near the abutment, at half span, at the pier, and at the midpoint of the middle span. Geokon model VSM 4000 strain gages were used; these gages are 5.875 inches long, have a midrange of 2500 microstrain, and one microstrain sensitivity (Geokon, 1996). The electronic plucking coil is detachable, similar to the VCE 4200. A thermistor is provided in the plucking coil for temperature measurement. The VSM 4000 gage is not welded directly to the girder, as welding would cause distortion of the gage and would likely destroy its effectiveness. Instead, two mounting blocks are provided with the gage; one has a single cone point set screw, and one has two oval point set screws. In order to mount the gage, the surface of the girder must first be free of rust, dirt or oil; therefore the surface was cleaned using an angle grinder. After cleaning the surface of the girder, the mounting blocks were fixed to the end flanges of the gage, and the block positions were marked on the girder. The gage was then replaced with a spacer, and the mounting blocks were held in place firmly with a jig. The blocks were then arc welded to the surface of the girder. The strain gage was then mounted in the end blocks, and covered to protect it from environmental hazards. A typical weldable strain gage is shown installed on the girder in figure 3.3

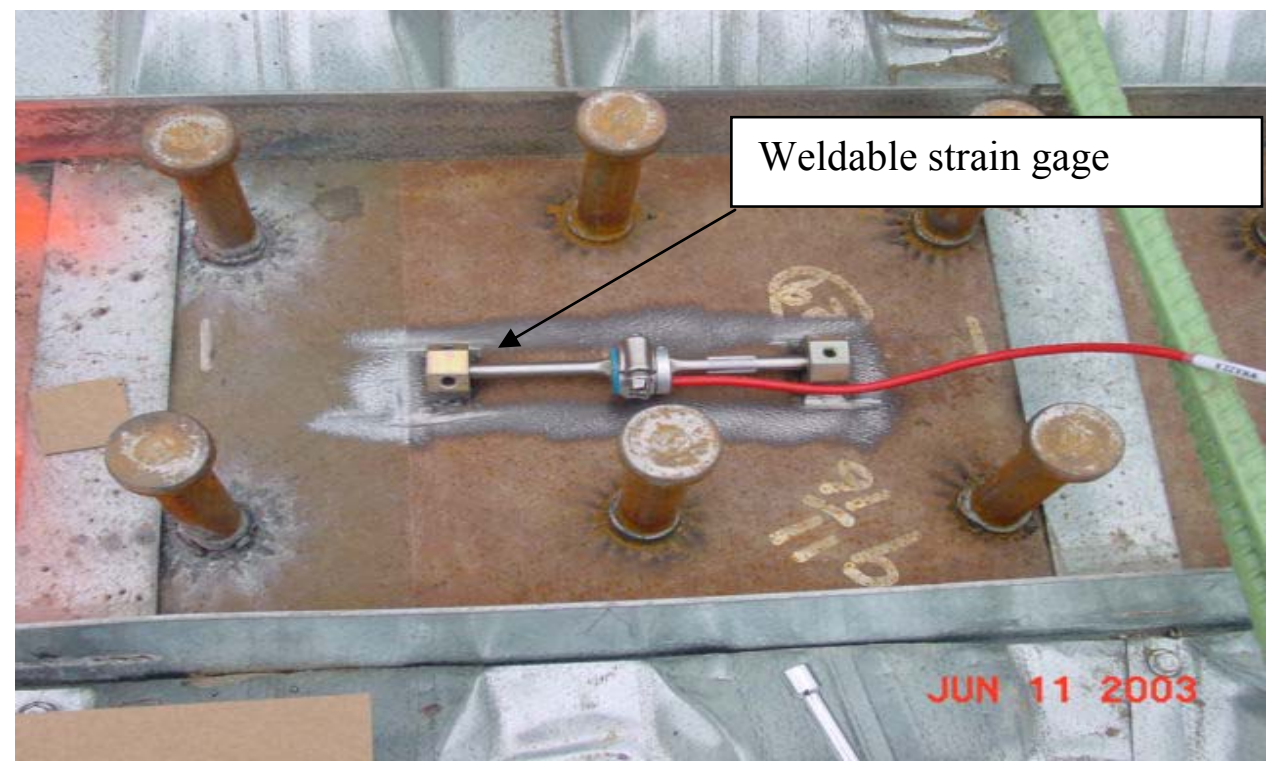

Figure 3.3: Weldable Strain Gage Installed on the Top Flange of a Girder (photo courtesy of Dr. Shoukry, WVU) 
To measure the dynamic response of the bridge, 16 wire resistance type embedment strain gages were installed near the vibrating wire strain gage trees. These gages were installed in eight locations, with two gages at each location. One gage was placed at the top reinforcement of the deck, and one was placed at the bottom reinforcement. The wire resistance strain gages used are from Micro Measurements, and are designed for concrete embedment. Their model number is EGP-5-120. The gages are constructed of karma alloy, and have a resistance of 120 ohms (Micro Measurements). Each gage is mounted on a carrier, and cast into a proprietary polymer cement body five inches in length. The cement body protects the delicate strain gage from damage due to concrete pouring, moisture, and corrosion. Temperature compensation is automatic with these gages. The resistance strain gages were installed similarly to the VCE 4200 gages; they were first attached to the reinforcement steel using nylon wire ties, and were later bonded to the rebar using JB weld. A typical installation of resistance-type embedment strain gages is shown in figure 3.4.

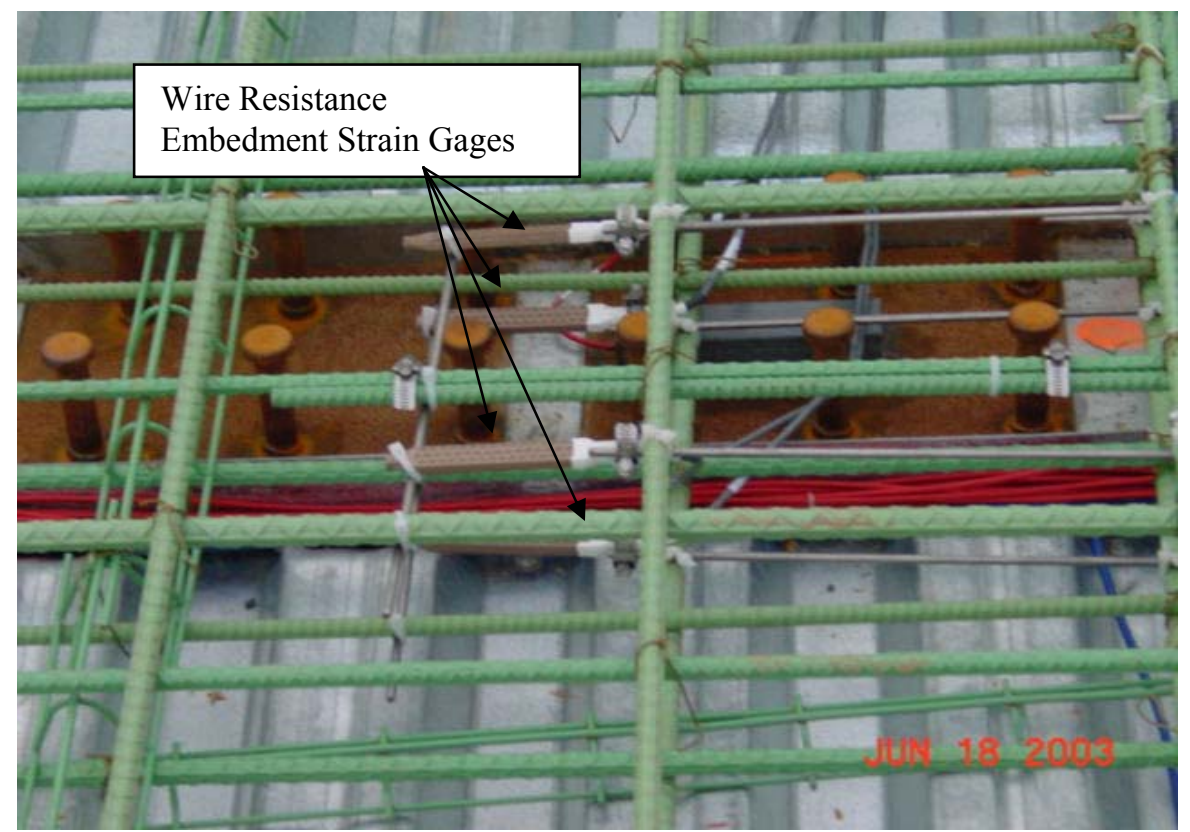

Figure 3.4: Wire Resistance Embedment Strain Gages (photo courtesy of Dr. Shoukry, WVU)

Two different displacement transducers were used on Evansville Bridge: crackmeters and convergence meters. The crack meters were used to measure crack openings 
and axial deformations in the concrete deck. Convergence meters were used to measure relative motion between the bridge supports (abutments and piers).

In total, 30 crack meters were placed on the bridge to measure crack growth and axial deformation along the wheel path. Four were placed in the construction joint between the approach slab and the deck, and the remaining 26 were placed in series through half the length of the bridge. The crack meters used in Evansville Bridge were Geokon model 4430 deformation meters. These displacement transducers can be embedded in series along an axis through the concrete, to give the deformation pattern along that axis. The model 4430 transducer is made up of a vibrating wire sensing element in series with a precision music wire spring, which is coupled to a movable shaft. As the shaft moves in or out of the body of the sensor, the spring and the vibrating wire are stretched, which changes their tension. The change in tension results in a change in the frequency of vibration of the wire, which can be measured (Geokon, 1996). A crack meter installation is illustrated in figure 3.5.

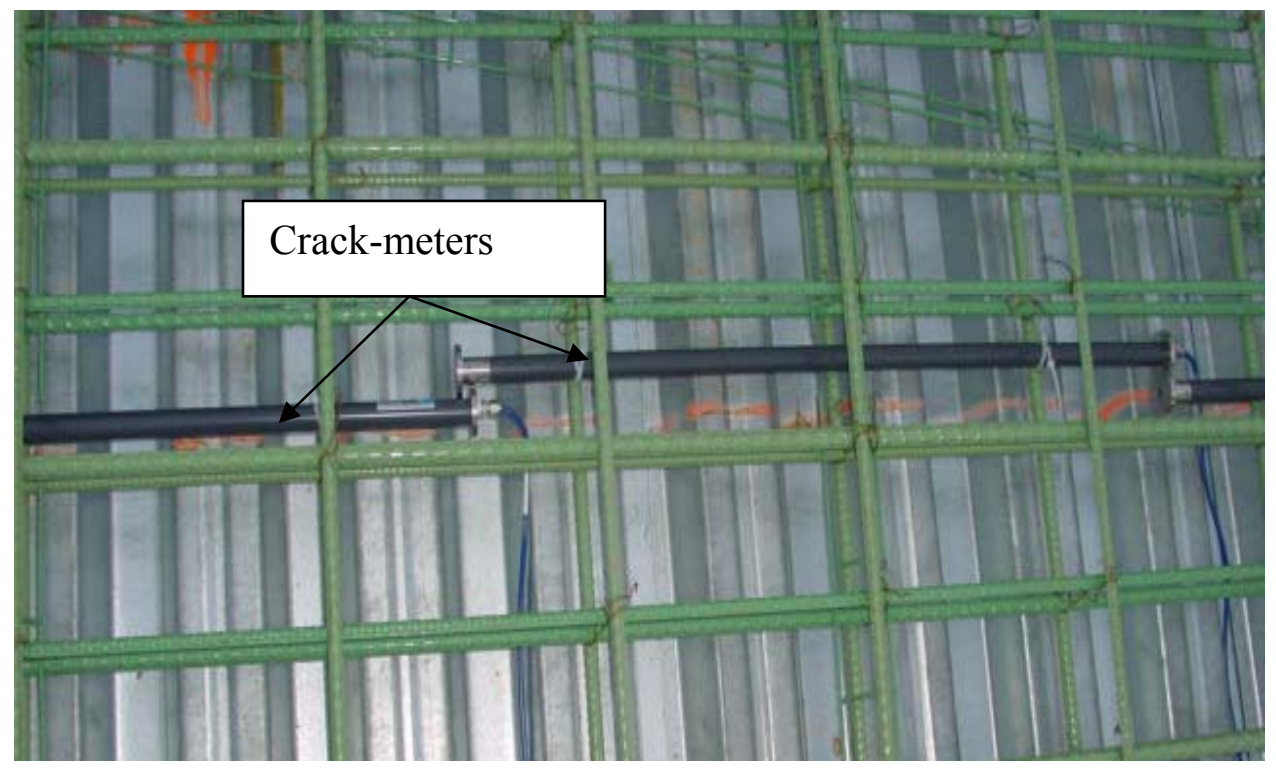

Figure 3.5: Crack Meters Installed in Deck of Evansville Bridge (photo courtesy of Dr. Shoukry, WVU) 
Two convergence meters, placed between the abutment and pier 1, and piers 1 and 2, were used to measure relative movement between the abutments and piers. The convergence meters used were Geokon model 4425 vibrating wire convergence meters. They are designed to measure deformation between two fixed anchor points. The model 4425 convergence meter consists of a vibrating wire sensing element in series with a heat-treated, stress-relieved spring. The spring is connected to a six-millimeter diameter connecting rod. The operating principle is similar to that of the Geokon model 4430 transducer (Geokon, 1996). The mounting procedure for the convergence meter is as follows: first, holes are drilled in the concrete for the two anchor points, and the anchor points are affixed in the holes. A turnbuckle assembly was attached to the convergence meter, and carbon fiber connecting rods were linked together to fit between the two fixed endpoints using the supplied swagelok fittings. The rods were then connected to the sensor using swagelok fittings, and finally a swagelok eyehook was attached to the carbon rod and hooked to the anchor point. The convergence meter as installed at Evansville bridge is shown in figure 3.6.

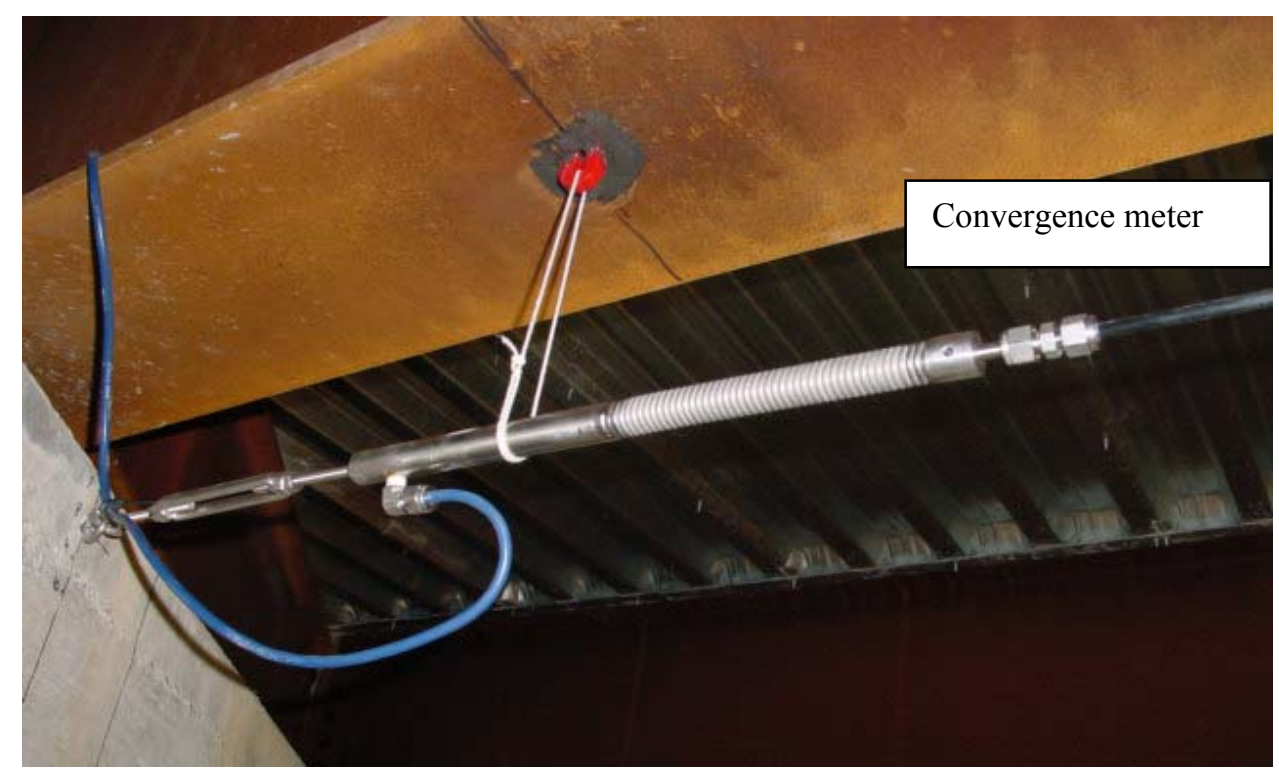

Figure 3.6: Convergence Meter (photo courtesy of Dr. Shoukry, WVU)

Inclinometers were used to monitor changes in the inclination of the girders. A total of seven inclinometers were mounted on the bottom flange of girder B along the 
edge span, between pier 1 and mid-span, as shown in figure 3.7. The inclinometers used were Jewell LCI inclinometers. The sensing element in the Jewell LCI is called a torquer, and it operates as follows: the torquer is intentionally unbalanced in the plane of allowable rotation, and a torque is developed on it in proportion to the unbalance of the mechanism and the angular input. An optical position detector, whose output is compared to a reference voltage, detects the angular motion of the torquer. The difference between the output of the position detector and the reference voltage is sent as an error signal to a servo amplifier, and the servo amplifier current is applied to the torquer in opposition to the tilt torque or angular acceleration. The output of the servo amplifier is directly proportional to the acceleration applied in dynamic cases, or the tilt in static cases. The Jewell LCI inclinometer is sensitive to tilts of less than one microradian, and its output is an analog voltage (Jewell Instruments). The inclinometers were mounted to the bottom flange of the girder using epoxy adhesive after the steel surface had been ground and cleaned with acetone.

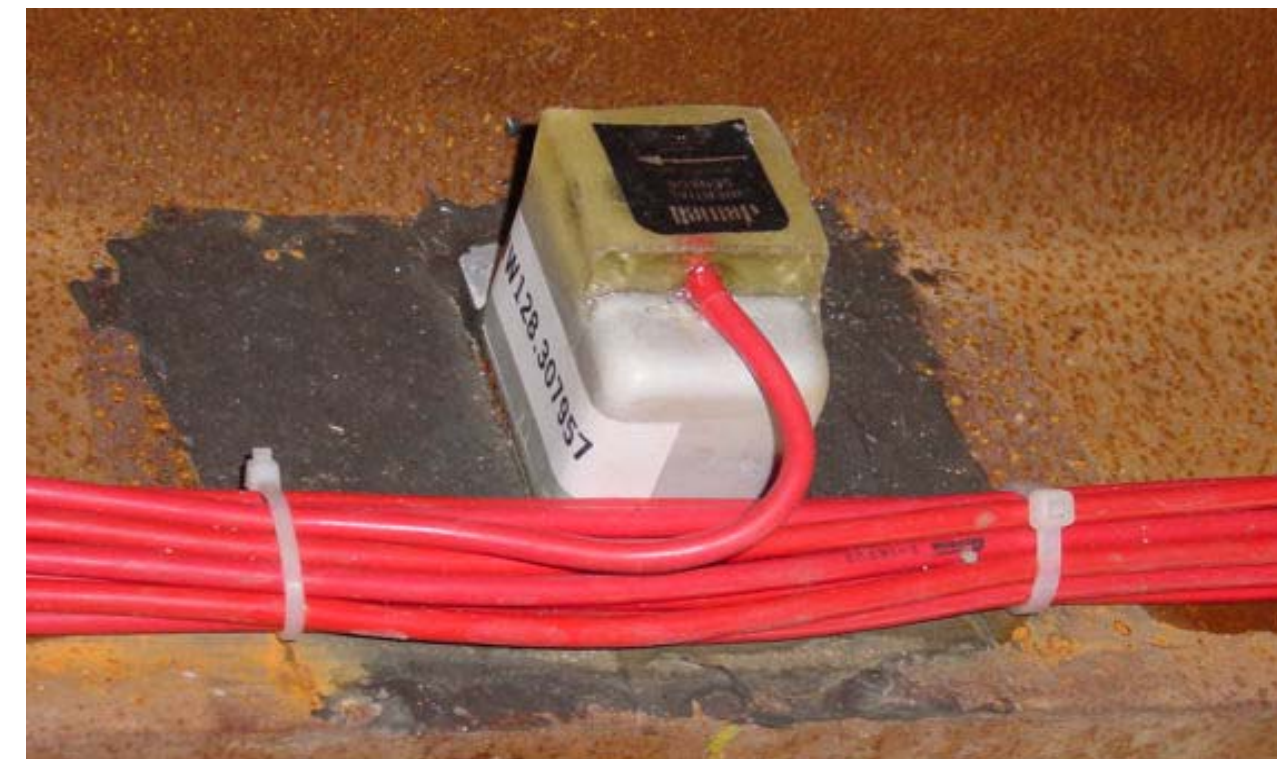

Figure 3.7: Inclinomter, Installed on Lower Flange of Girder B (photo courtesy of Dr. Shoukry, WVU)

To measure the temperature distribution through the deck's cross section, two thermistor trees, consisting of 17 thermistors mounted on an 8-inch long, 1-inch diameter 
PVC tube, were used. Each tree was constructed as follows: eight thermistors were placed in the topmost inch of the tube, and the rest were placed at one-inch intervals along the remainder of the tube, as shown in figure 3.8. A thermistor is designed so that its resistance decreases as temperature rises.

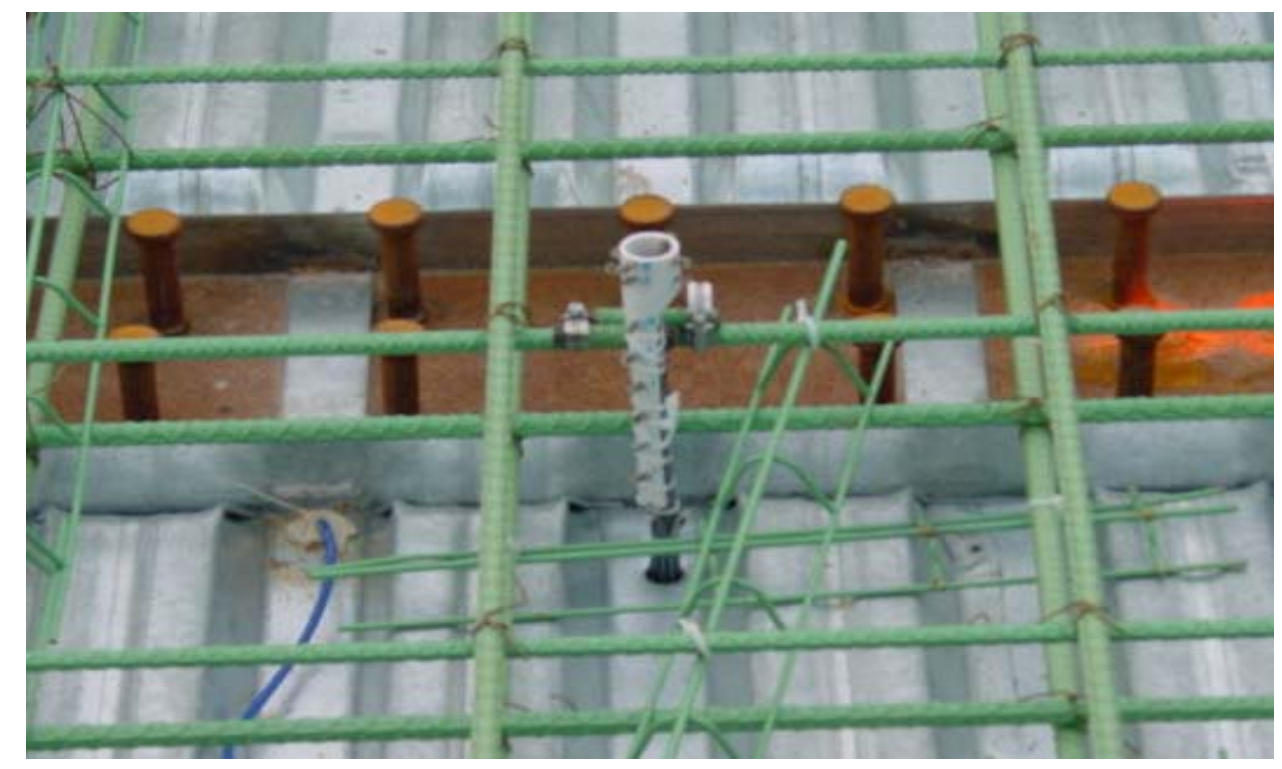

Figure 3.8: Thermistor Tree (photo courtesy of Dr. Shoukry, WVU)

\subsection{DATA ACQUISITION SYSTEM}

The data acquisition system used at Evansville bridge to gather and store the strain, displacement, and temperature data generated by the sensors consists of three basic components: data loggers, muliplexers, and interfaces.

The data loggers used at Evansville Bridge are Campbell Scientifics CR10X measurement and control modules (Campbell Scientific, 1997). These data loggers are fully programmable, and feature non-volatile memory and a back-up battery. Each unit is contained in a compact, stainless steel, sealed cabinet. The standard memory for the $\mathrm{CR} 10 \mathrm{X}$ is $128 \mathrm{~KB}$ of flash electronically erasable programmable read-only memory and $128 \mathrm{~KB}$ of static random access memory. Used in conjunction with up to eight multiplexers, each data logger can acquire data from as many as 128 channels for 16- 
channel multiplexers, or 256 channels for 32 channel multiplexers. The CR10X requires a 12 VDC power supply. A PC or the Campbell Scientifics CR10KD keyboard display is required to communicate with the CR10X through its I/O port. The CR10X data logger was programmed using Campbell Scientifics' multilogger software prior to collecting data (Canary Systems, 1997).

Geokon model 8032 muliplexers were used at Evansville Bridge. These multiplexers can be used as 16 channel multiplexers, with four conductors per channel, or 32 channel multiplexers with two conductors per channel. Each mulitplexer unit contains a terminal board for gage connections, and a multiplexing switchboard to switch gages (Geokon, 2001). With the exception of the thermistors, each of the sensors installed at Evansville Bridge requires four conductors per channel. The vibrating wire gages require two wires to read the frequency response of the vibrating wire element, and two to transmit the signal from the thermistor that is integral to each gage. The inclinometers require 4 wires because two are required to power the gage, and two are required to transmit the signal. Thermistors only require two wires to transmit their signal.

The interface system used with the data acquisition system was a Canary Systems multi sensor interface, which allows multiple sensors with various inputs and outputs to be connected to and controlled by a CR10X data logger (Canary Systems, 1997). This interface allows up to eight multiplexers to operate with the CR10X. The microcontroller in the multi sensor interface communicates with the CR10X via a 26-pin connector, and is powered through a three pin connector below the data logger connector. The multi sensor interface is connected to the multiplexers with 8 10-pin connectors on the interface.

The dataloggers and multiplexers in use at Evansville bridge are housed inside a small vinyl storage shed, as shown in figure 3.9, both to protect them from the elements and to allow easy access to them for collection of data, as well as inspection, repair, and maintenance of equipment. Originally, standard $\mathrm{AC}$ power was used in conjunction with $\mathrm{AC}$ power adapters to provide power to the equipment, but the electrical service installed 
at Evansville Bridge was temporary, and was removed after construction was completed. After the removal of the AC power source, the data acquisition system was powered by a system of deep-cycle marine batteries (12V DC output), which are charged by a solar panel. This system requires little maintenance, and has proven more reliable even than the $\mathrm{AC}$ power, which is prone to interruptions in remote rural areas.

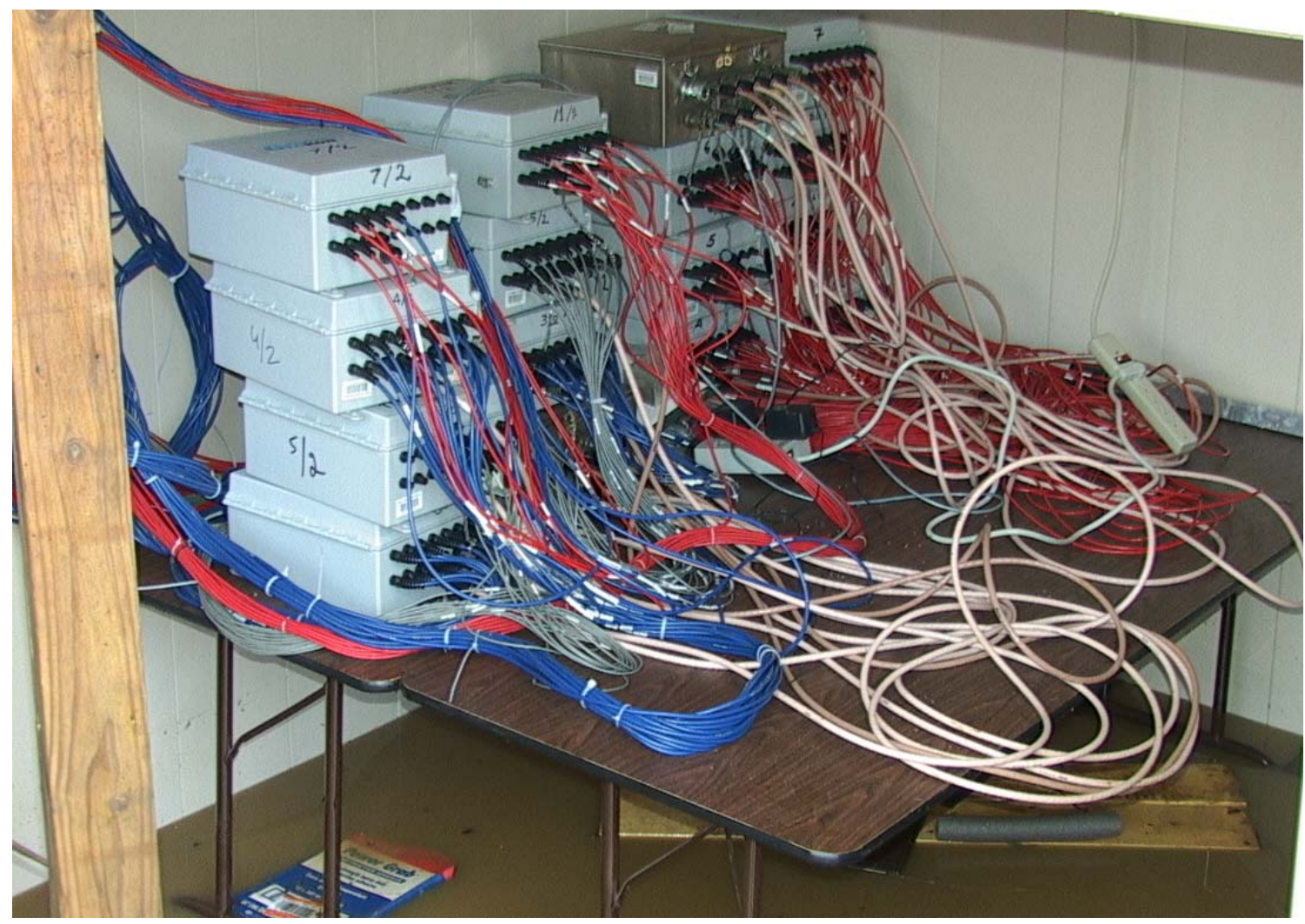

Figure 3.9: Inside the Instrumentation Shed at Evansville Bridge (photo courtesy of Dr. Shoukry, WVU)

\subsection{LABORATORY TESTING OF SENSORS}

All sensors were checked in the laboratory prior to installation on the bridge. A preliminary check is advisable for all types of sensors to detect faulty gages, using a GK 403 readout box and in some instances a datalogger as well. The GK 403 can store strain readings and also apply calibration factors to convert readings to engineering units. After the preliminary test, sensors were calibrated. 


\subsubsection{CALIBRATION}

Calibration is a means of determining or correcting the accuracy and precision of a measuring device, usually by adjusting it to match or conform to a well-known and constant measure. It is also used to determine the sensitivity and resolution of the device. Calibration was performed in the laboratory for each of the sensors installed in and on Evansville Bridge.

\subsubsection{CALIBRATION OF VIBRATING WIRE STRAIN GAGES}

Each of the vibrating wire strain gages was calibrated prior to installation. A Geokon model VSM-4000 strain gage will be used as an illustrative example of the calibration process. This model is designed to be attached to steel surfaces by arc welding. The measuring coil is external to the gage, and is attached to the signal cable. The VSM-4000 was used in conjunction with a Geokon GK-403 Readout Box, which provides the necessary voltage pulses to pluck the wire, and converts the resulting frequency reading directly into a strain value (in microstrains).

\section{$\underline{\text { Calibration Procedure }}$}

In order to properly calibrate the VSM-4000 strain gage, the following steps must be taken:

1) The signal cable is attached to the strain gage using a hose clamp, and then the gage is mounted in the test machine by sliding the flanges on its ends into the clamps on the machine. The set screw on the right end is tightened, but the left screw is left loose, for reasons to be explained later.

2) After the gage is placed into the test machine, the signal wires are connected to the GK-403 Readout Box. The colors of the wires correspond to the colors of the leads from the test machine. The black and red wires transmit the strain signal, and the green and white wires transmit a temperature signal from the thermistor that is integral to the strain gage. The blue wire is used as a shield drain.

3) Next, a position transducer is set into the special hole in the right end of the test machine. The position transducer must be connected to plus and minus fifteen 
volts at the terminals marked $+15 \mathrm{~V}$, and $-15 \mathrm{~V}$, the Output Return (marked $\mathrm{O} / \mathrm{P}$ return), must be connected to ground, and the Output terminal must be connected to a digital voltmeter. The voltages and ground are supplied by a DC power supply. The ground of the digital voltmeter is connected to the ground of the power supply.

4) The position transducer is then adjusted in its mounting hole until its voltage output is between 3 and 3.5 volts (in this instance it was approximately 3.25 volts).

5) After the signal connections are made, the strain gage mounting procedure is completed. This is accomplished by watching the strain reading while applying force (by pushing) on the sliding end (left side) of the mount. The set screw is tightened when the strain reading was approximately 1200 microstrains.

6) After the gage has been mounted properly, the calibration can begin. The tension in the gage was adjusted using the jig handle, which screws into the knurled brass nut, the tension was adjusted until the reading was 1000 microstrains with the switch on the readout in position $\mathrm{C}$.

7) After setting the initial value, the voltage output of the position transducer and the strain reading on the readout were recorded. This procedure was repeated for values of approximately 1500, 2000, 2500, and 3000. (For a more complete test, readings of 3500 and 4000 should have been taken).

The following calculations must be performed in order to determine the calibration factor of the strain gage. First, both the strain readings and the voltages from the position transducer must be zeroed by subtracting the first value (1000 microstrains and the corresponding transducer voltage), from each of the succeeding values. Next, the strain and voltage readings must be converted to a deformation in inches. From the Geokon Calibration manual, the equation for converting the strain gage reading (with the readout box in position C) is $\operatorname{Pos} C \times 5.875 \times 10^{-6}$. The voltage from the position transducer was converted to displacement by multiplying the voltage reading by the constant $0.02 \mathrm{in} / \mathrm{V}$. The deformation measured by the displacement transducer is assumed to be the correct value; and when it is plotted against the deformation measured by the strain gage, the 
slope of the resulting line (0.9528) is the calibration factor of the gage. Table 3.1 and figure 3.9 show the results of the experiment.

Table 3.1: Strain Gage Calibration Results

\begin{tabular}{|l|l|l|l|l|l|}
\hline $\begin{array}{c}\text { Microstrain } \\
(\text { from GK- } \\
403) \\
(\mu \varepsilon)\end{array}$ & $\begin{array}{c}\text { Displacment } \\
\text { Transducer } \\
\text { Reading (V) }\end{array}$ & $\begin{array}{c}\text { Zeroed } \\
\text { Microstrain }\end{array}$ & $\begin{array}{c}\text { Zeroed } \\
\text { Displacement } \\
\text { Transducer } \\
\text { Reading }\end{array}$ & $\begin{array}{c}\text { Actual } \\
\text { Displacement }\end{array}$ & $\begin{array}{c}\text { Measured } \\
\text { Displacement }\end{array}$ \\
\hline 1002.5 & 3.7454 & 0 & 0 & 0 & 0 \\
\hline 1499.3 & 3.3374 & 496.8 & 0.138 & 0.00276 & 0.0029187 \\
\hline 1999.3 & 3.1976 & 996.8 & 0.2778 & 0.005556 & 0.0058562 \\
\hline 2504.5 & 3.0560 & 1502.0 & 0.4194 & 0.008388 & 0.0088425 \\
\hline 3002.9 & 2.9154 & 2000.4 & 0.5600 & 0.0112 & 0.01175235 \\
\hline
\end{tabular}

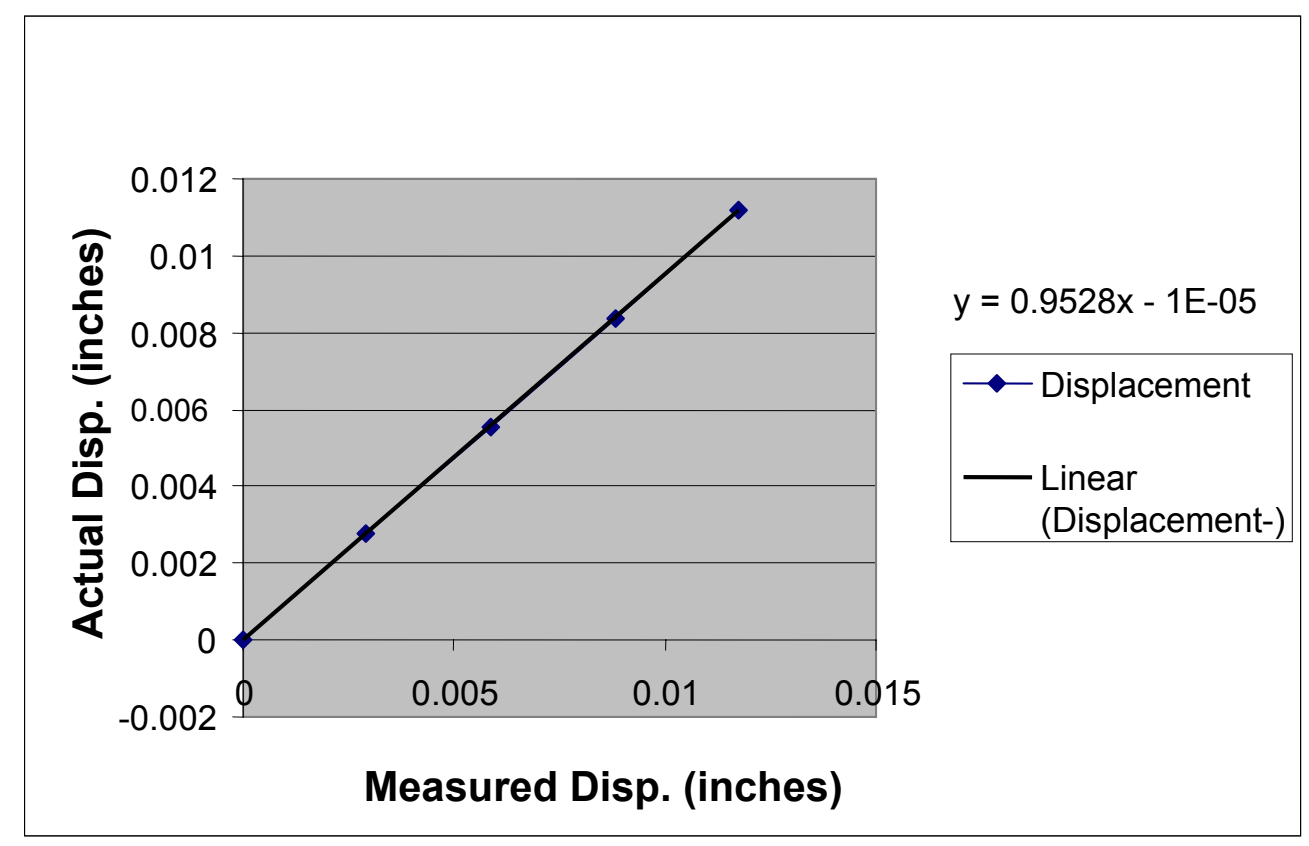

Figure 3.10: Vibrating Wire Strain Gage Calibration Curve

\subsubsection{CALIBRATION OF INCLINOMETERS}

An inclinometer responds to angular displacement by producing an output voltage. In the case of the Jewell inclinometers (both LCI and LCF) models, the voltage range is +5 to -5 volts. The example inclinometers calibrated for this report had an 
angular input range of +-14.5 degrees. In reality, the sensing element in an inclinometer does not respond to angles; it responds to the effect of gravity upon it, which is affected by the angle at which the instrument is tilted. Because of the trigonometric relationship between the gravitational force on an object and the angle at which it rests, the voltage output of an inclinometer is proportional to the sine of the angle it is placed at, rather than the angle itself.

The output of the inclinometer can be measured using both a digital voltmeter and a CR10X datalogger in conjunction with a Geokon Model 8032 multiplexer. The angles are generated using a 10 inch sine bar and block gages.

\section{Calibration Procedure}

In order to properly calibrate a Jewell LCI series inclinometer, the following steps must be taken. First, the instrument must be supplied with electrical power and its output measured. This can done in two ways; a digital voltmeter and DC power supply can be used to measure the output and power the inclinometer, or a datalogger and multiplexer can be used. It is useful to calibrate the instrument using both systems, in order to be certain that the datalogger and multiplexer arrangement, which will be used in the field, provides a comparable level of accuracy to that of the voltmeter and power supply configuration.

The following procedure is used to operate an inclinometer using a digital voltmeter and DC power supply: first, the power supply must be configured to supply the correct voltage. This is done by placing a jumper between the negative terminal of output A and the positive terminal of output B. Then, the voltage must be adjusted using the knobs until the voltage gage reads approximately $12 \mathrm{~V}$. The output of the power supply can then be verified using the digital voltmeter. There should be 24 volts potential between the positive terminal of A and the negative terminal of B (both outputs should supply $12 \mathrm{~V}$ ). After the power supply has been set, the inclinometer can be connected. Terminal $\mathrm{A}$ on the inclinometer must be connected to $+12 \mathrm{~V}$ (the positive terminal of output A on the power supply) using the black wire in the shielded connection cable. 
Terminal $\mathrm{B}$ on the inclinometer must be connected to $-12 \mathrm{~V}$ (the negative terminal of output B on the power supply) using the red wire in the shielded connection cable. Terminal $\mathrm{C}$ must be connected to the positive voltage input terminal of the voltmeter (using the red wire with an alligator clip on its end). Terminal D must be connected to the ground of the power supply, as must the negative (black) input terminal of the voltmeter.

The procedure for connecting an inclinometer to a multiplexer and datalogger is as follows: first, the datalogger and multiplexer must be configured. The configuration procedure is as follows: first, connect the RS232 port on the datalogger to the port on the computer, then open the multilogger software. Next, select COM1 in the tree on the left side of the multilogger software window. Then click Add in the toolbar at the top of the window; in the window that opens, select CR10X Datalogger and click Accept. In the window that opens after Accept has been clicked, fill in the field marked Datalogger ID with an integer value (i.e. 1,2,3,etc). Then click Save in the toolbar at the top of the display window. In the window that opens, select Create a New Configuration File, and then click Accept. In the window that opens, fill in the field under Interval type, single interval, with an integer value in seconds (a value in the range of 10-30 seconds is appropriate in this case). After the interval has been set, click on the Program menu at the top of the page and select Multiplexers. In the window that opens, select MUX 1, and specify the model as Geokon 8032, and specify the gage type as multisensor. Next, click the Edit Channels button, and in the window that opens, select the Gage Type as tiltmeter, the Make as Geokon, and the Model as 6200. No other fields must be modified, so click accept. After the window closes, click Accept in the Configure Multiplexers window. The configuration of the multiplexer and datalogger is now complete.

After the multiplexer and datalogger have been configured, the inclinometer can be connected to the multiplexer. Connect the mulitplexer to the MUX1 connector on the datalogger using the supplied cable. Then, connect the inclinometer to channel 1 of the multiplexer as follows: connect terminal A to terminal $1 \mathrm{H}$ of the multiplexer using the black wire in the shielded cable, connect terminal B to terminal $1 \mathrm{~L}$ of the multiplexer 
using the the red wire in the shielded cable, connect terminal $\mathrm{C}$ to $2 \mathrm{H}$ in the multiplexer using the white wire in the shielded cable, and connect terminal $\mathrm{D}$ to $2 \mathrm{~L}$ in the multiplexer using the green wire in the shielded cable. To begin measurement of the inclinometer's output, simply click Start in the toolbar at the top of the Multilogger window.

After the inclinometer has been connected to either the voltmeter and power supply or the multiplexer, readings can be taken. The inclinometer can be subjected to various angles throughout its operating range using a sine bar and block gages. The inclinometer is attached to the sine bar using two-sided tape on the raised portion that is at a right angle to the bar. The inclinometer should be oriented such that the arrow that indicates its sensitive axis points along the length of the sine bar. After affixing the inclinometer to the sine bar, block gages must be placed under the cylindrical bar on the right end of the sine bar to produce a positive angle, and under the left end to produce a negative angle. The required blocks to produce the desired angle can be determined by utilizing the trigonometric relationship for sine (opposite over hypotenuse); the length of the sine bar (10 inches) is known, and the desired angle is known, so the height required to produce the desired angle can easily be calculated.

The determination of the required block gages to be placed under the end of the sine bar is best illustrated by an example. For example, suppose the desired angle is 5 degrees. The height can be found by multiplying the sine of 5 degrees $(0.08716)$ by the length of the sine bar ( 10 inches). The resulting required height is 0.8716 inches. The block gages required to produce this height are $0.1006,0.101,0.170$, and 0.500 inches.

After the inclinometer has been subjected to angles throughout its operating range, and the resulting voltages (as measured by the datalogger and the digital voltmeter) have been recorded, the voltage readings must be converted to angles. This is accomplished using the following formula: Angle (degrees) $=\sin ^{-1}((\mathrm{Vo}-\mathrm{Ko}) / \mathrm{K} 1)$. Where Vo is the measured voltage, Ko is the bias of the sensor in volts (provided in the data sheet that accompanies the sensor), and $\mathrm{K} 1$ is the scale factor. The scale factor is 
calculated by dividing the full range output of the sensor (available on the data sheet) by the range of the sensor in $\mathrm{g}$. The range of the sensor in $\mathrm{g}$ is equal to the sine of its range in degrees. For inclinometers with a +-14.5 -degree range the range in $\mathrm{g}$ is equal to the sine of 14.5 , or $0.25 \mathrm{~g}$. As an example, an LCF-100-14.5 inclinometer (serial number 2030649) has a scale factor of 19.904, as calculated by dividing its full range output of 4.976 volts by $0.25 \mathrm{~g}$ (the scale factor has units of $\mathrm{V} / \mathrm{g}$ ). The scale factor can be verified by plotting the output voltage of the inclinometer versus the sine of the angles it was subjected to. The scale factor is the slope of the resulting line.

Of particular interest is the error between the know angle and the angle indicated by the inclinometer. Figure 3.11 shows the results from an LCI inclinometer with serial number 52960.

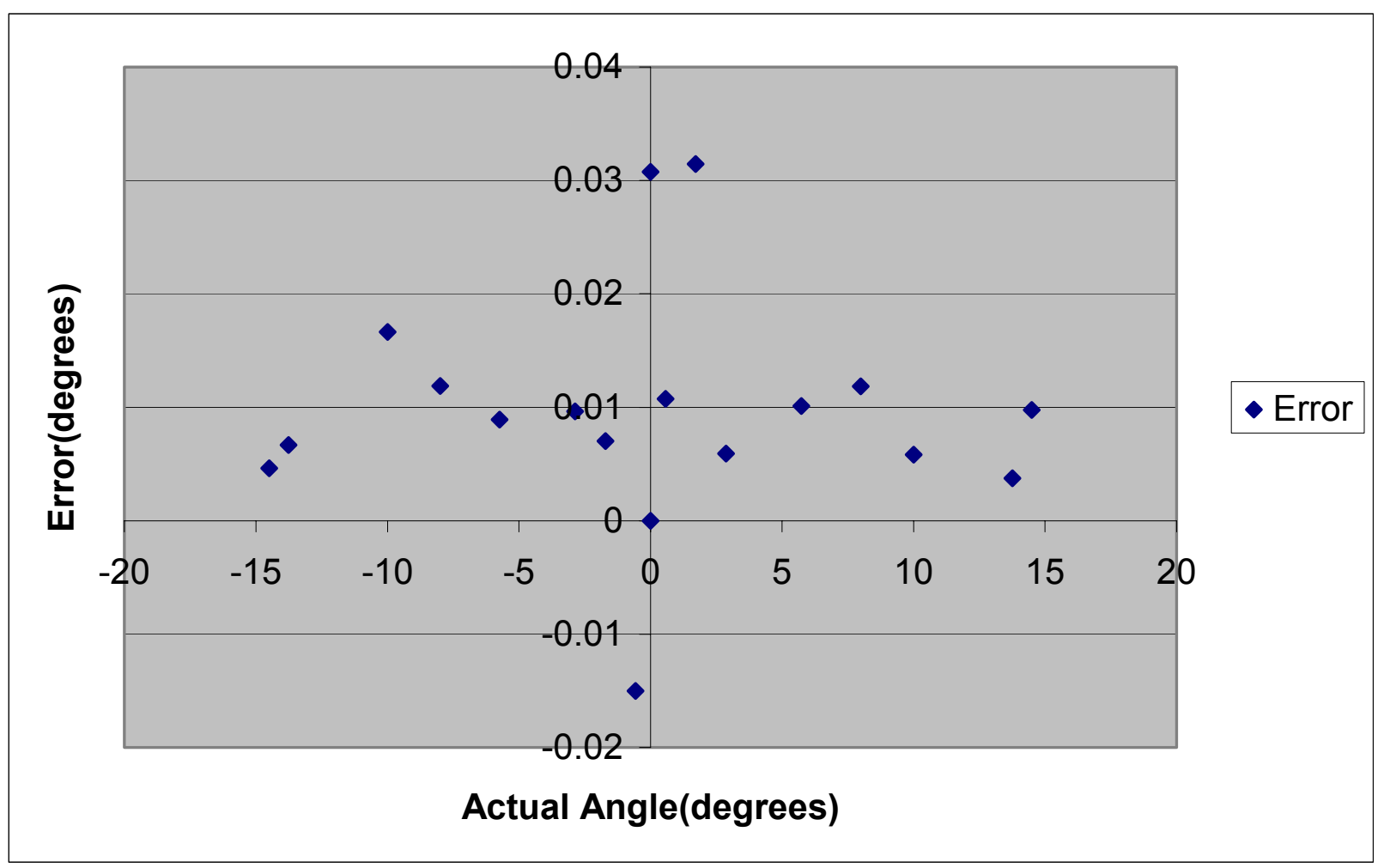

Figure 3.11: Error for a Jewell LCI Inclinometer

As can be seen, errors are typically in the range of a few hundredths of a degree or less, which is higher than ideally desired errors, but within acceptable ranges. Figure 3.12 shows a sample calibration curve from an inclinometer. 


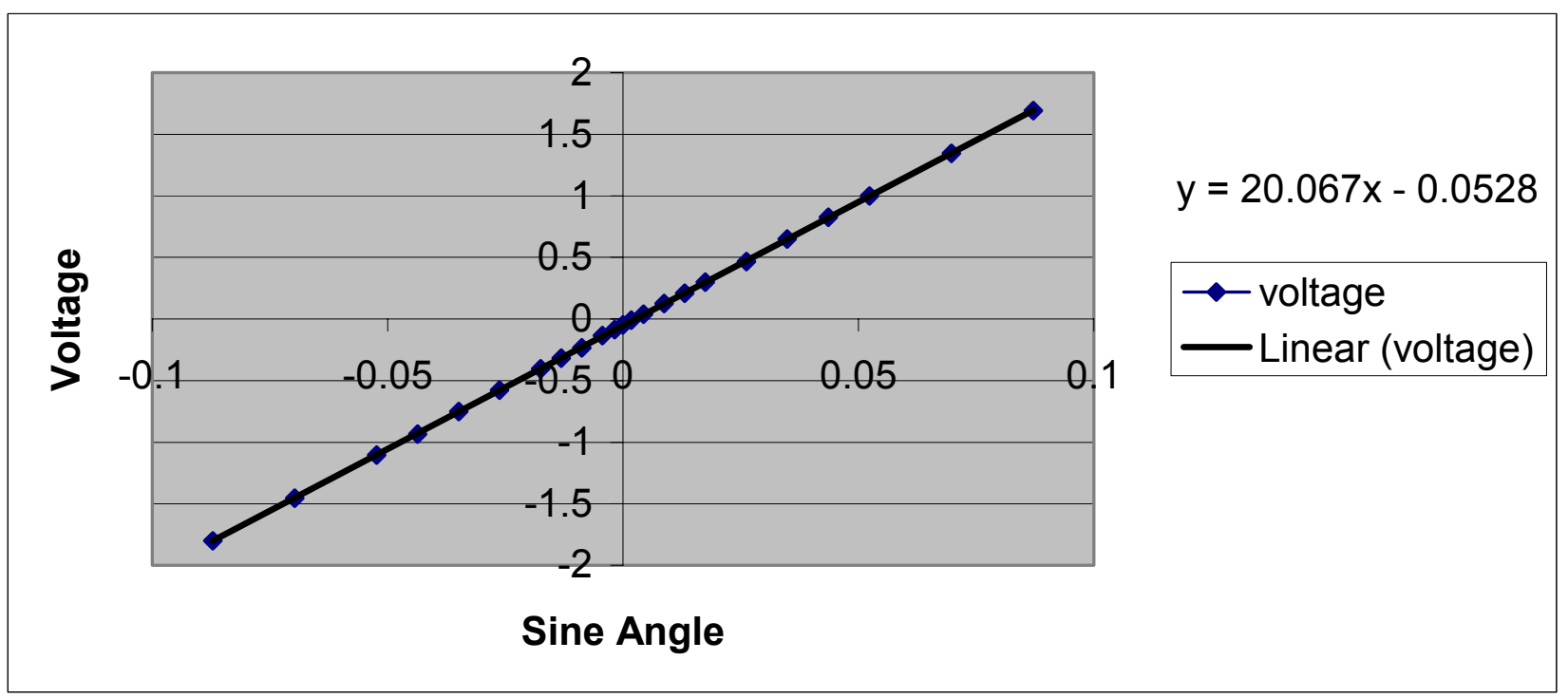

Figure 3.12: Calibration Curve for LCI Inclinometer.

The scale factor provided by the manufacturer for this inclinometer is 20.056 . The slope of the line on the above plot is 20.067, which is in close agreement with the provided value, as it should be.

Similar Calibrations were carried out for each of the sensors installed at Evansville Bridge by other members of the research team.

\subsection{INSTRUMENTATION LABELING}

All the sensors and cables that are installed in the field are labeled in the laboratory based on their position. A unique code was used that depends on the type of sensor, its girder position, its direction, and its serial number.

The three girders in the span 1 were labeled as A, B and C. The gages within each girder were further identified by gage type, location and direction. For example Vibrating wire gages were labeled as $\mathrm{V}$, Thermistors were labeled as $\mathrm{T}$, and Inclinometers were labeled as I, weldable as W and Embedment as E. 
The directions are classified as Wheel path (W), Perpendicular to wheel path (P), Vertical to the wheel path $(\mathrm{V})$. Then by its positions like $\mathrm{X}, \mathrm{Y}, \mathrm{Z}$ positions and its location in those positions as explained in Table 3.3. i.e. top or bottom. Followed by dot and its serial number or batch number. For example: SWA20.25161 represents, Sister bar (S) in the wheel path (W) direction at the abutment (A), I-beam number 2 (2) on top the slab (0) with serial number (25161). A full description of the labels used for each type of sensor as well as the organization of the acquired data is contained in appendix A.

\subsection{MATERIAL TESTING}

Several concrete cylinders were cast from the concrete used in the bridge deck, and were tested in the laboratory to determine the actual engineering properties of the concrete used in Evansville Bridge. Tests were performed to determine the elastic modulus, Poisson's ratio, and coefficient of thermal expansion. The results of the material testing for elastic modulus and Poisson's ratio are shown in table 3.1, and the average coefficient of thermal expansion based upon testing of three cylinders was found to be be $11.2616 \times 10^{-6}$ per $^{\circ} \mathrm{C}$.

Table 3.2: Material Properties of Concrete used in Evansville Bridge

\begin{tabular}{|l|l|l|}
\hline $\begin{array}{c}\text { Concrete Age } \\
\text { (days) }\end{array}$ & $\begin{array}{c}\text { Modulus of } \\
\text { Elasticity, E } \\
\text { (psi) }\end{array}$ & \multicolumn{1}{|c|}{$\begin{array}{c}\text { Poisson's } \\
\text { Ratio, } \mathbf{v}\end{array}$} \\
\hline 2 & 3367064 & 0.193036 \\
\hline 4 & 3786918 & 0.202757 \\
\hline 18 & 4058325 & 0.239454 \\
\hline 28 & 4174813 & 0.2434 \\
\hline 60 & 5053188 & 0.3089 \\
\hline 96 & 5225915 & 0.310612 \\
\hline
\end{tabular}




\section{CHAPTER 4}

\section{CRACK FORMATION AND DETECTION}

\subsection{INTRODUCTION}

One of the most frequently encountered problems in bridge construction is the cracking of concrete in the deck. Cracking often occurs at very early ages, before the bridge is open to traffic. Many attempts have been made to characterize the causes of cracking and predict when cracking may occur. One of the objectives of the Evansville Bridge project is to determine the onset of cracks, how they propagate, and what causes cracking.

To detect and measure cracks in the deck of Evansville Bridge, 26 crack meters (deformation meters) were placed in series along the wheelpath, and an additional 4 were placed in the construction joint between the approach slab and the bridge deck. The data acquired from the crack meters can be used to determine whether cracks are present at each of the 26 crack meter locations. Therefore, a methodology was developed for interpreting the crack meter data.

\subsection{CAUSES OF CRACKING AT EARLY AGE}

Cracking occurs when longitudinal stress exceeds the modulus of rupture of the concrete. The primary loading experienced by Evansville bridge is due to varying temperatures. Loading conditions vary significantly over each day as temperatures change, causing the bridge's components to expand and contract. In this section, the causative factors leading to cracking will be investigated.

\subsubsection{THERMAL STRESSES DUE TO HYDRATION AND CURING}

The largest temperature variations occur during the initial pouring of concrete. Due to the exothermic reaction of the cement with water, the temperature of the concrete increases initially during hydration and curing. This temperature increase causes the 
concrete to expand, leading to increased tensile strain. As the exothermic reaction slows (10-12 hours after pouring), the concrete cools and starts to shrink. The concrete is delivered in several trucks; differences in the thermal properties of the concrete in different trucks cause different maximum temperatures and strains to occur in different sections of the deck, at different times. Figure 4.1 shows a thermal map of the bridge deck, and figure 4.2 is a map indicating the time of maximum heat of hydration. 


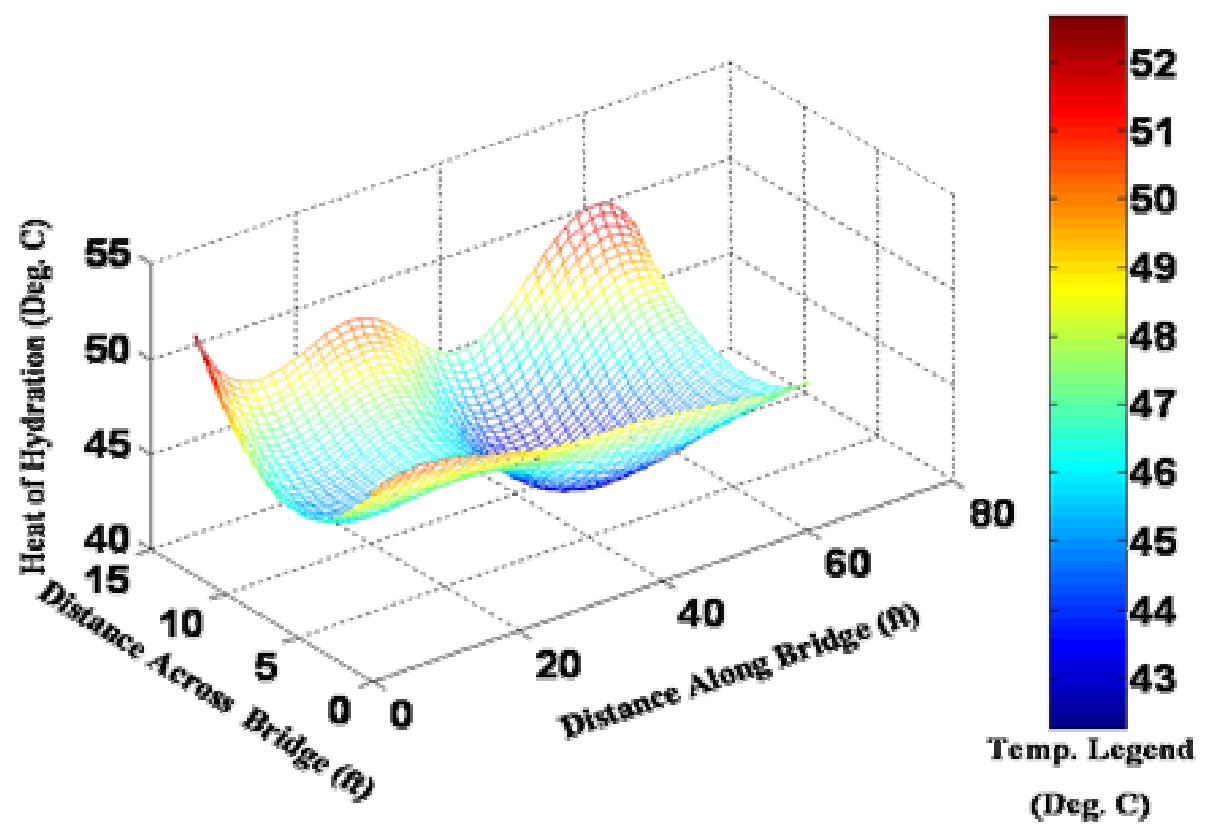

Figure 4.1 Thermal Map of the Bridge Deck (Shoukry et. al., 2005)

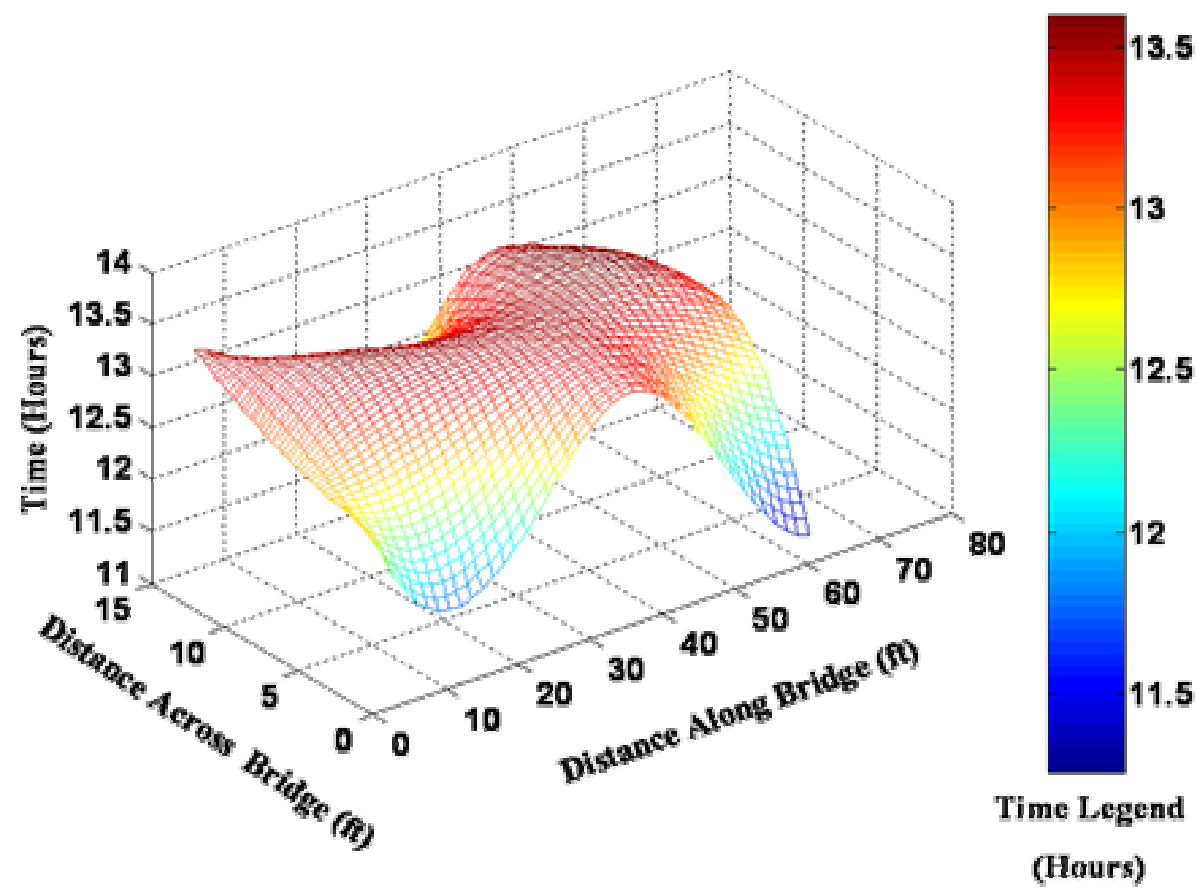

Figure 4.2 Time of Maximum Heat of Hydration (Shoukry et. al., 2005)

Current design practices assume temperatures are uniform throughout the deck, and vary only with depth (Imbsen, et. al., 1985). This leads to elevated stresses that are 
not accounted for. The difference in temperature was $12{ }^{\circ} \mathrm{C}$, which lead to a 100 microstrain difference in strain. These differences are responsible for added thermal stresses that can contribute to premature cracking of the deck.

\subsubsection{STRAIN AND STRESS IN THE CONCRETE DECK}

As indicated in the literature review, Cracking is primarily caused by elevated tensile stresses, which are due to restrained shrinkage and environmental effects. In order to determine if stresses reached high enough levels to cause cracking in the deck of Evansville Bridge, stresses were calculated based upon the measured data from the instruments installed in the bridge.

At Evansville Bridge, strains were measured using vibrating wire strain gages embedded in the deck. An analysis of the stress and strain was conducted to determine if stresses have reached high enough levels to cause cracking. In order to calculate the stresses present in the deck of Evansville bridge, the three dimensional version of Hooke's law was utilized:

$$
\sigma_{x}=\frac{E}{(1+v)(1-2 v)}\left[\varepsilon_{x}(1-v)+v\left(\varepsilon_{y}+\varepsilon_{z}\right)-(1+v) \alpha \Delta T\right]
$$

Where:

$\sigma_{\mathrm{x}}$ is stress in the $\mathrm{x}$ (longitudinal) direction,

E is Young's Modulus,

$\varepsilon_{\mathrm{x}}, \varepsilon_{\mathrm{y}}$, and $\varepsilon_{\mathrm{z}}$ are strains in the $\mathrm{x}, \mathrm{y}$ (transverse), and $\mathrm{z}$ (vertical) directions,

$v$ is Poisson's ratio,

$\alpha$ is the coefficient of thermal expansion, and

$\Delta \mathrm{T}$ is the change in temperature. 
The strength of the concrete was calculated based on the results obtained from laboratory testing of concrete cylinders using the following equation:

$$
S=S_{u} \frac{\sqrt{k\left(t-t_{0}\right)}}{1+\sqrt{k\left(t-t_{0}\right)}}
$$

Where:

$\mathrm{S}$ is strength at time $\mathrm{t}$,

$\mathrm{Su}$ is ultimate tensile strength,

$\mathrm{k}$ is the rate constant, which was determined experimentally, and $t_{0}$ is the age at the start of strength development.

Figures 4.3.1-4.3.21 show plots generated using equations 4.1 and 4.2. 

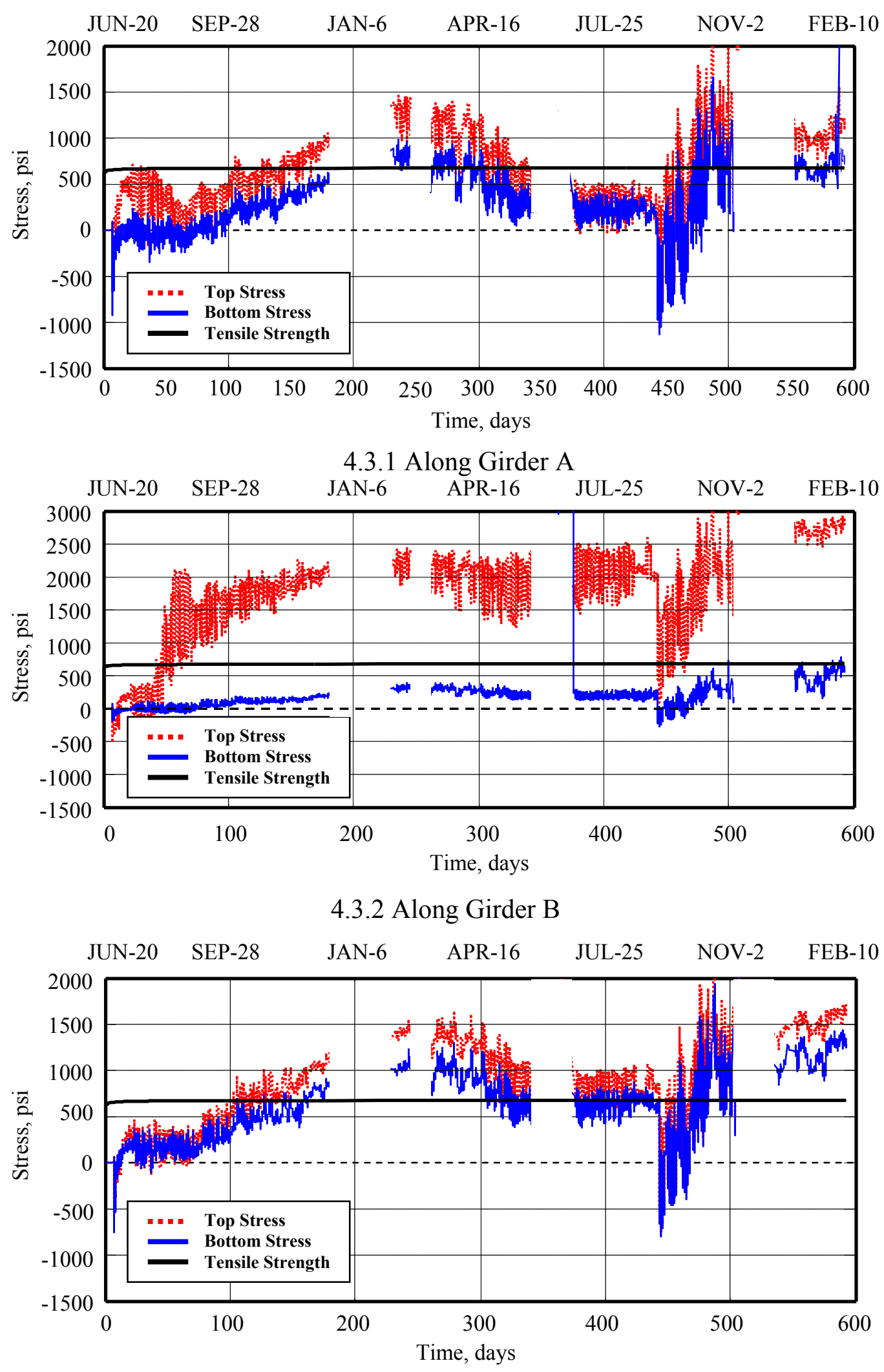

\subsubsection{Along Girder C}

Figures 4.3.1-4.3.3 Time-History of Longitudinal Stresses at Abutment. 


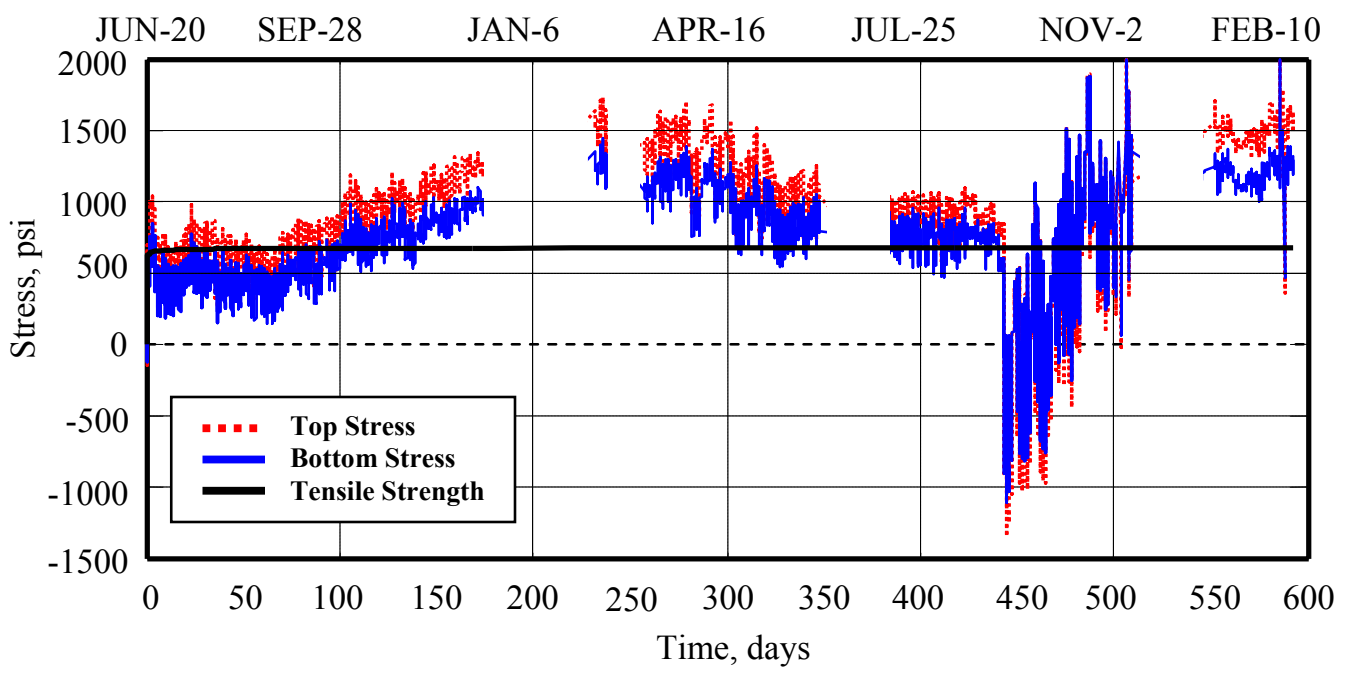

4.3.4 Along Girder A

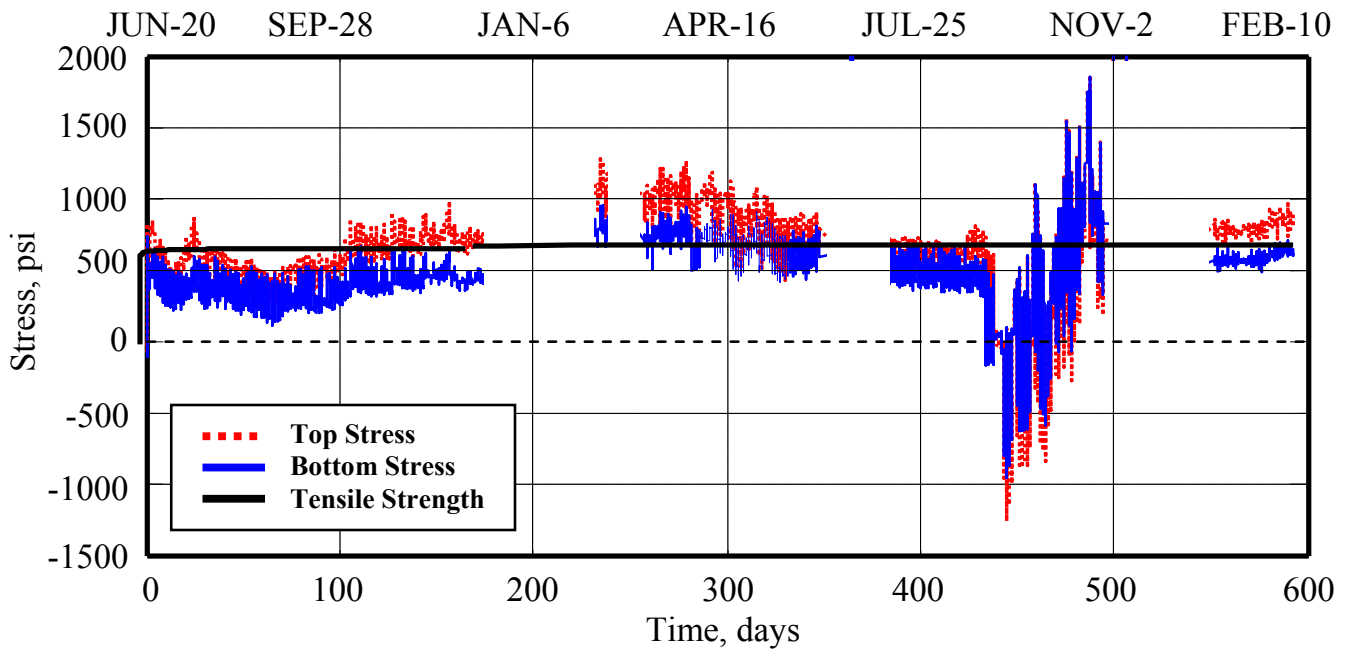

4.3.5 Along Girder B

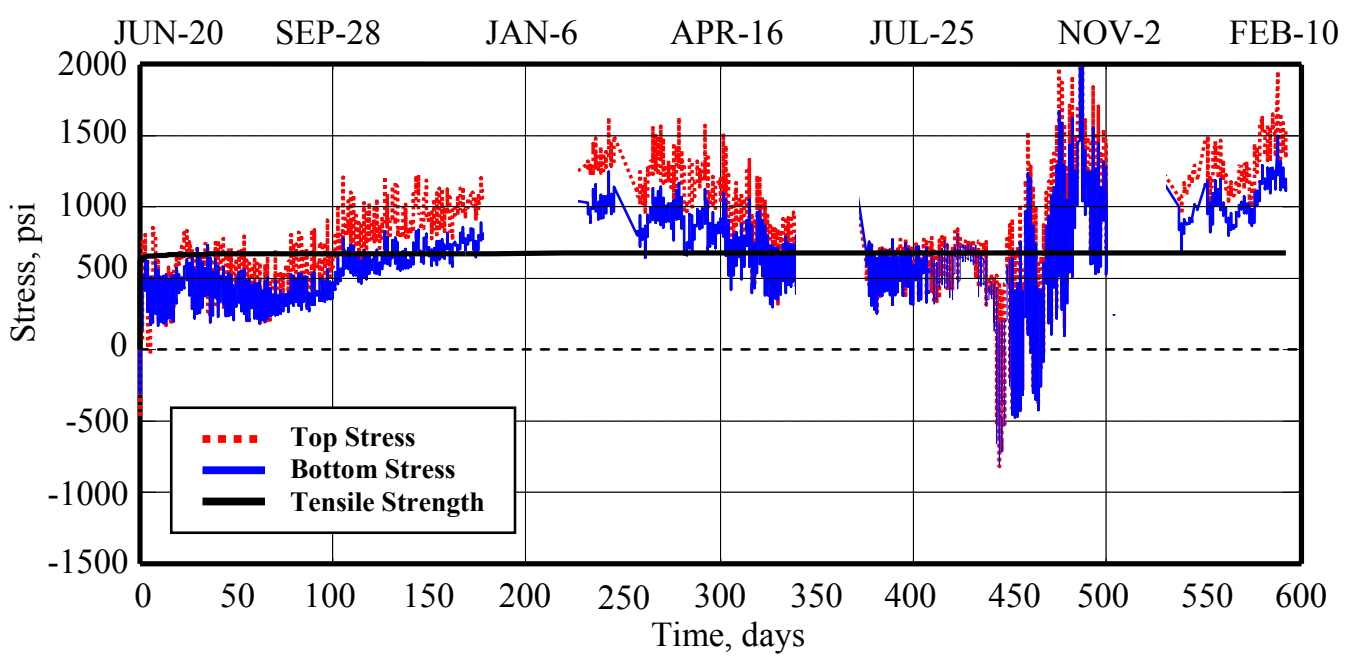

4.3.6 Along Girder C

Figures 4.3.3-4.3.6 Time-History of Longitudinal Stresses at 1/4 Span \# 1 . 


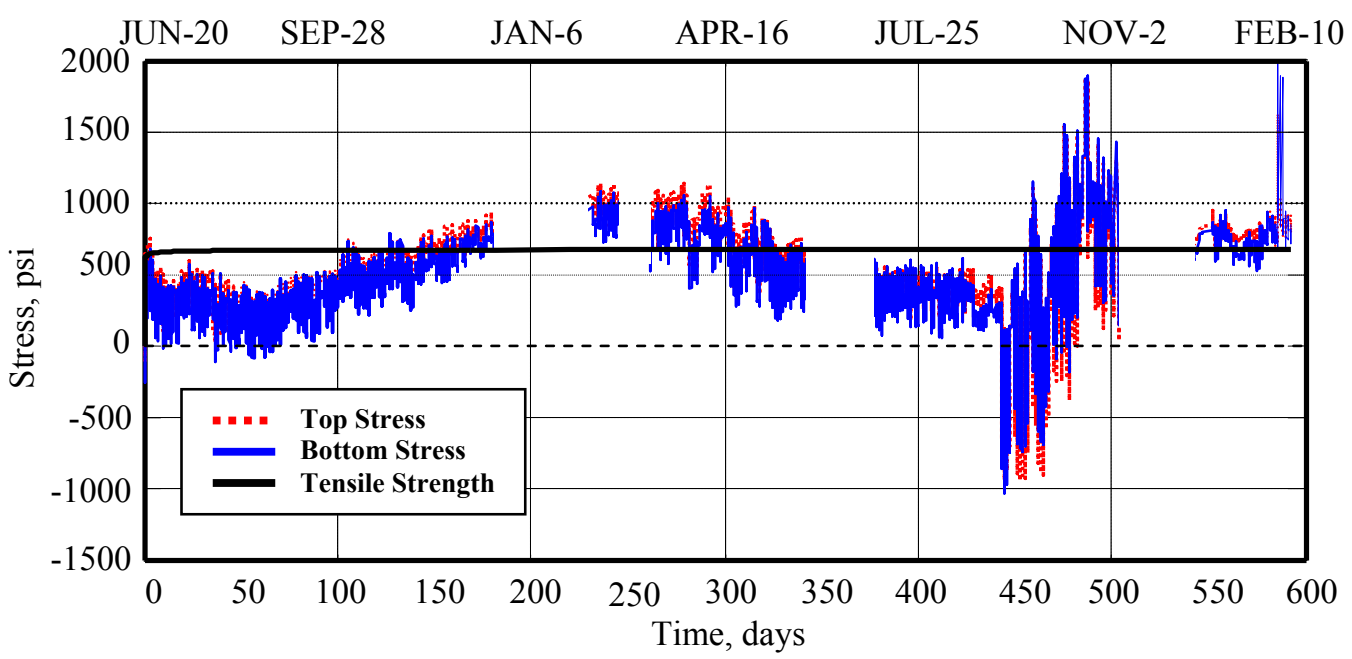

4.3.7 Along Girder A

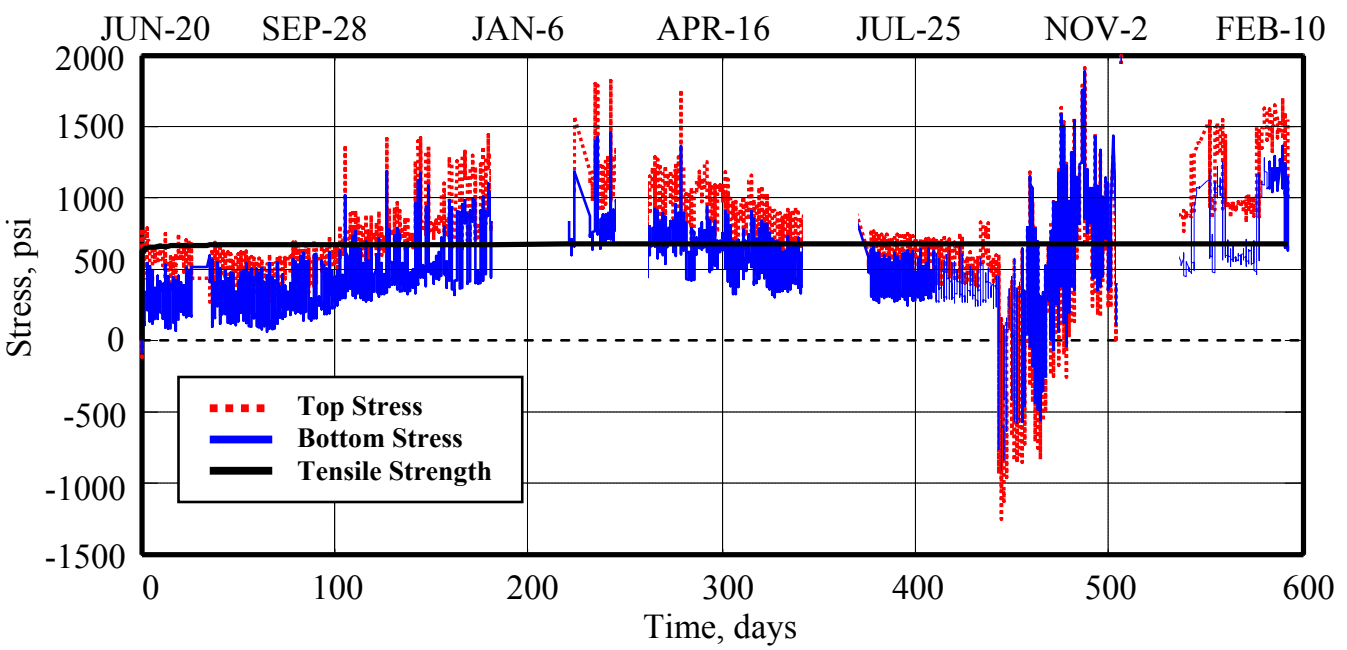

4.3.8 Along Girder B

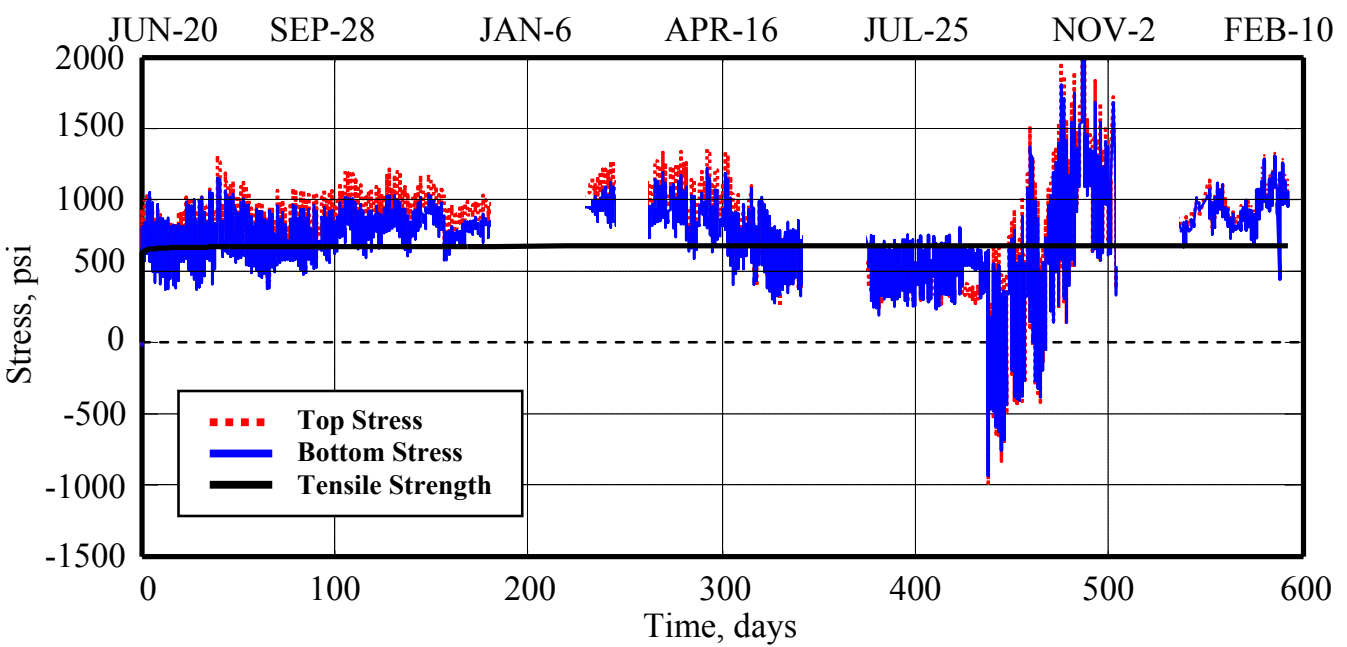

4.3.9 Along Girder C

Figures 4.3.7-4.3.9 Time-History of Longitudinal Stresses at Mid Span \# 1. 


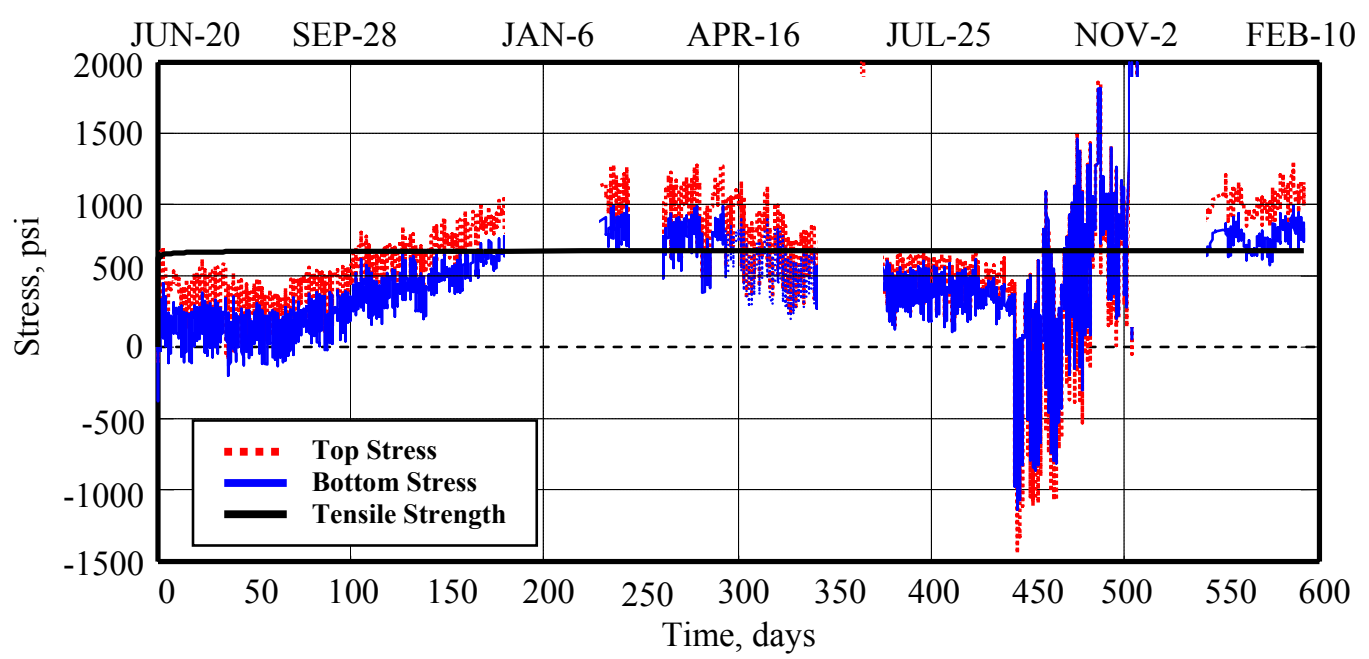

4.3.10 Along Girder A

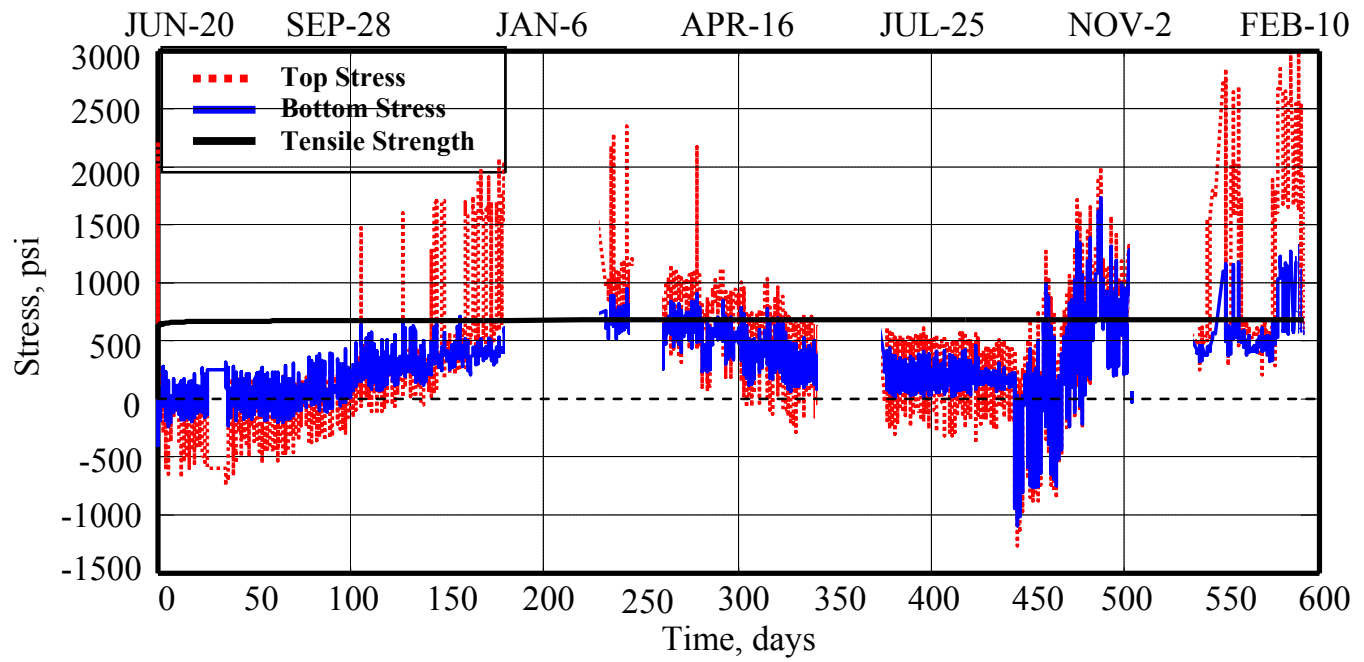

4.3.11 Along Girder B

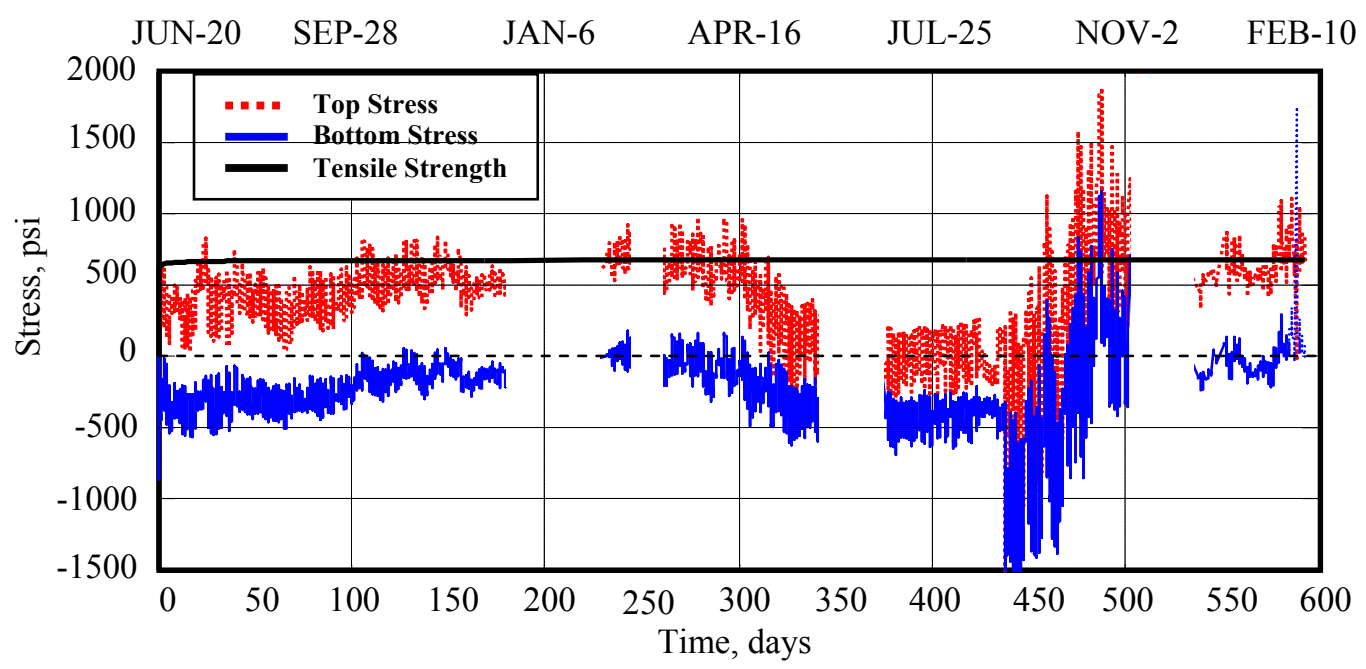

4.3.12 Along Girder C

Figures 4.3.10-4.3.12 Time-History of Longitudinal Stresses at 3/4 Span \# 1 . 


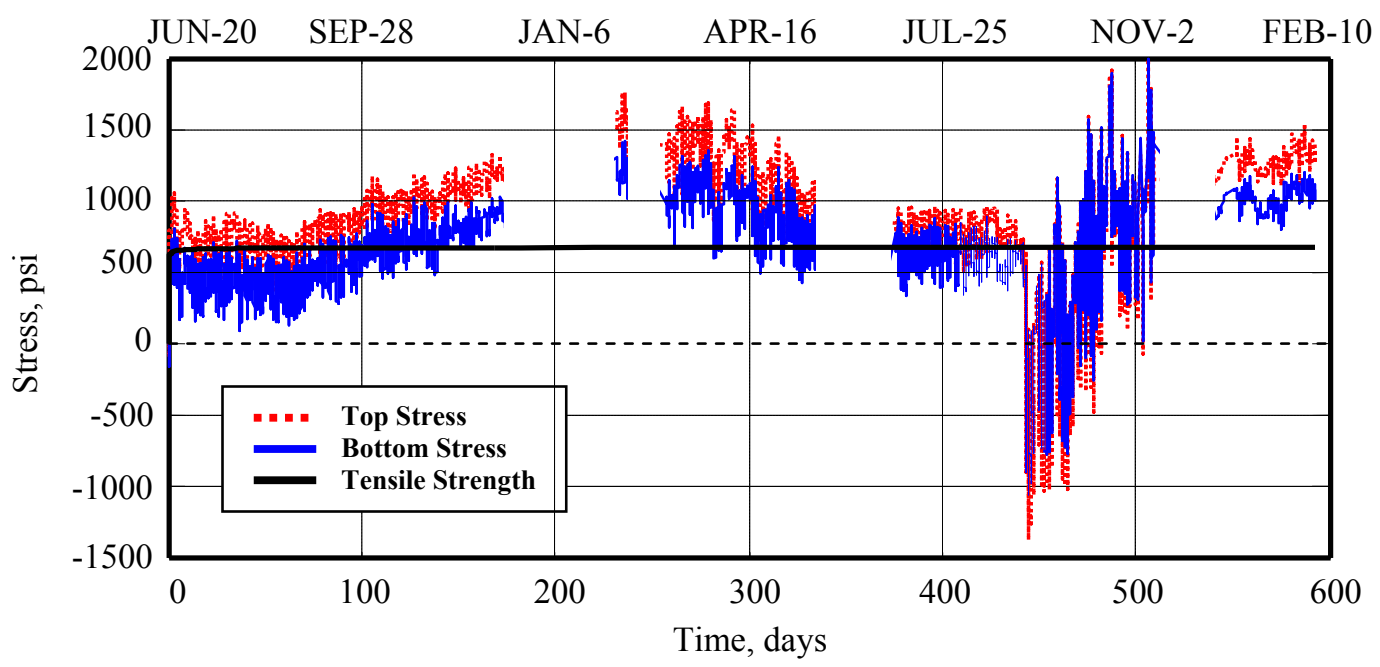

4.3.13 Along Girder A

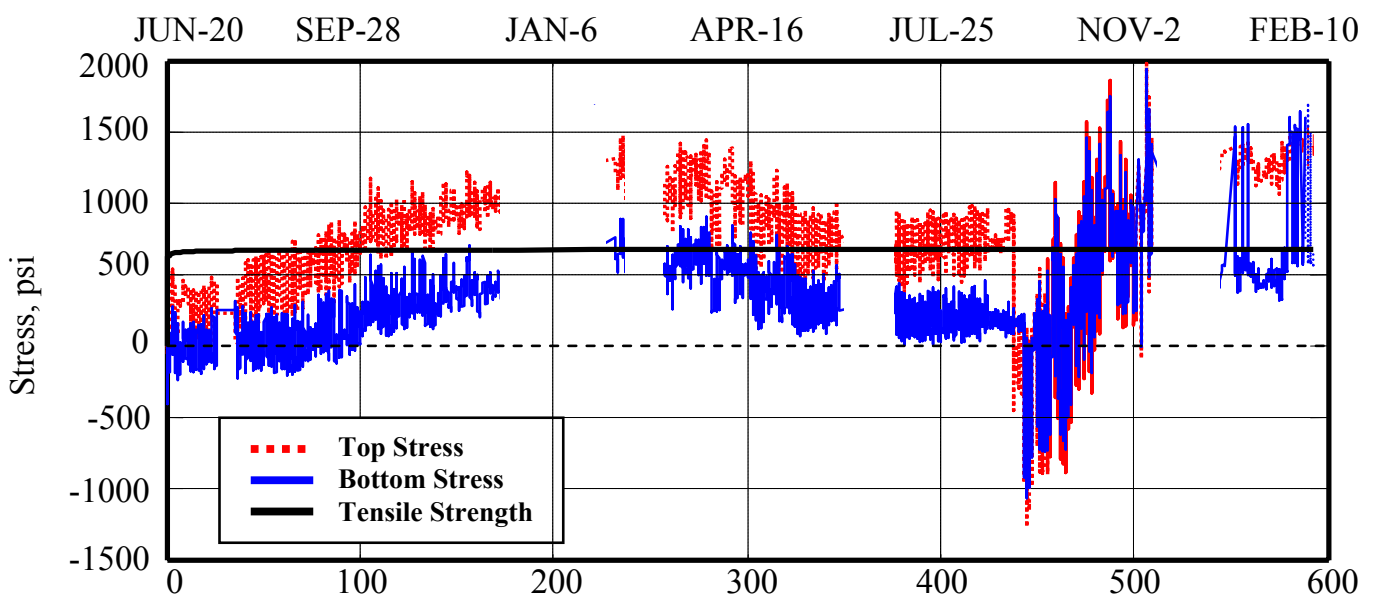

Time, days

4.3.14 Along Girder B

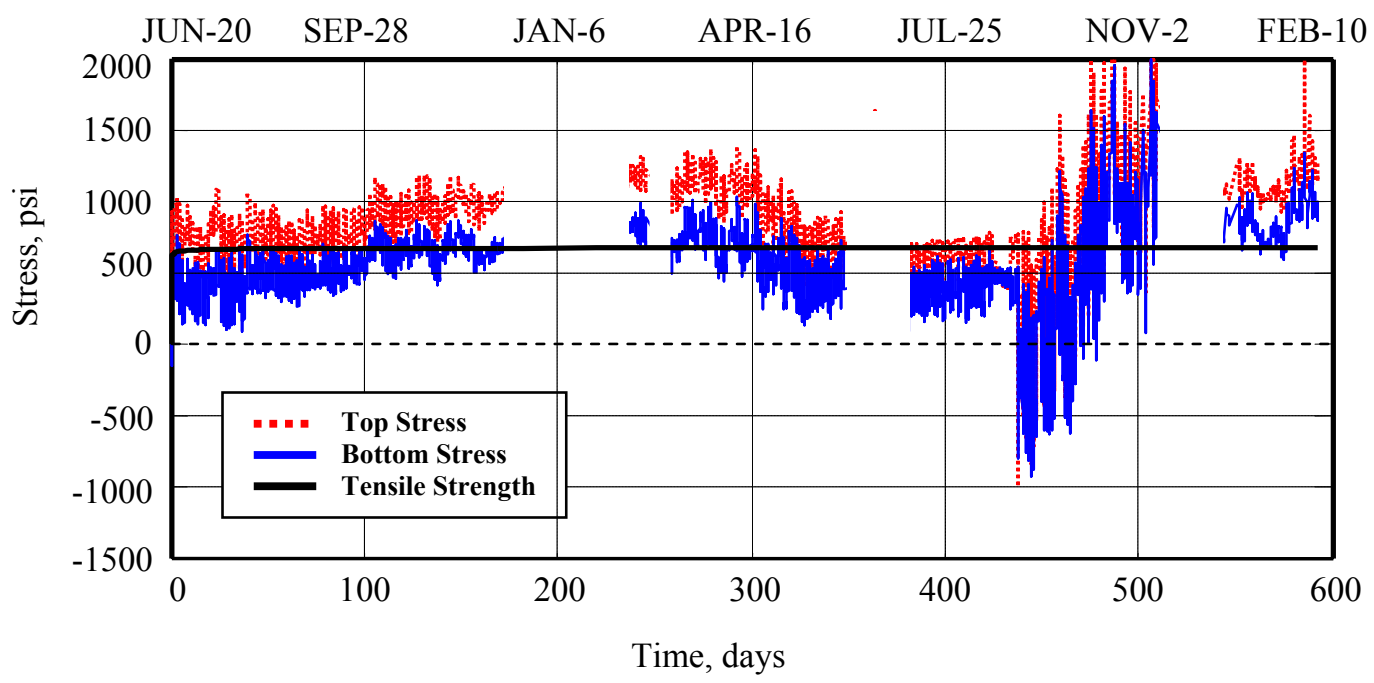

4.3.15 Along Girder C

Figure 4.3.13-4.3.15 Time-History of Longitudinal Stresses Over the Pier. 


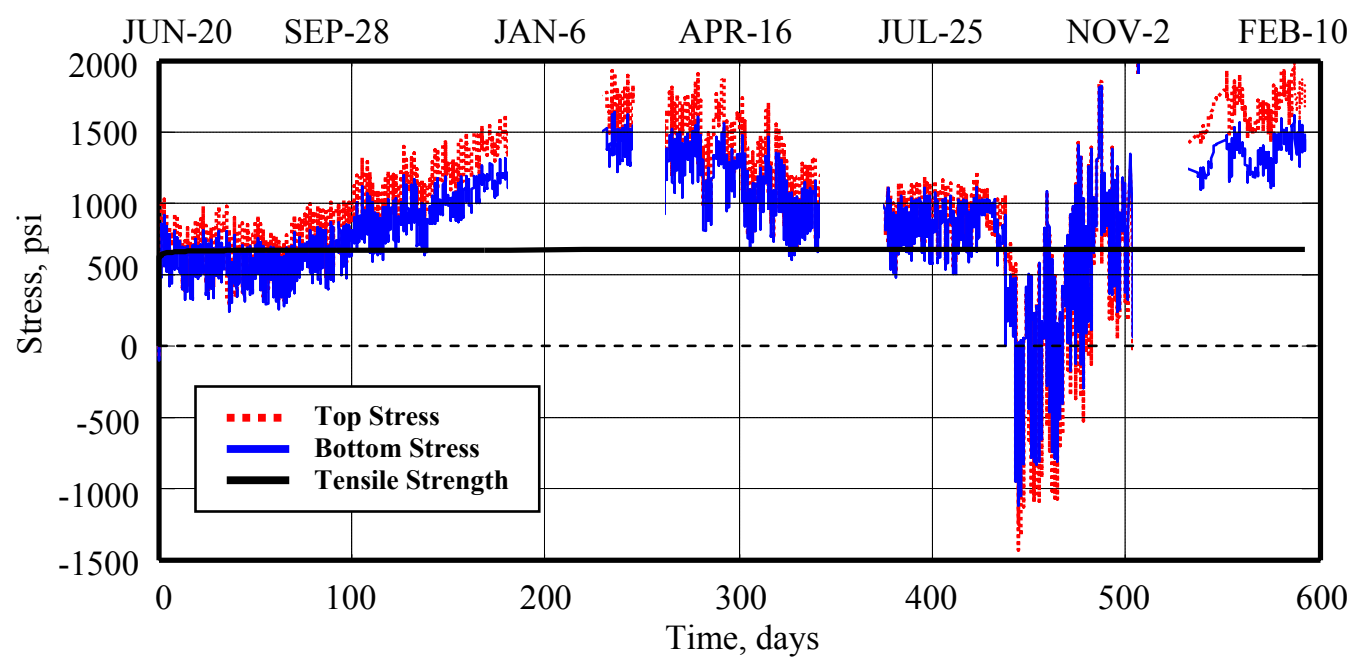

4.3.16 Along Girder A

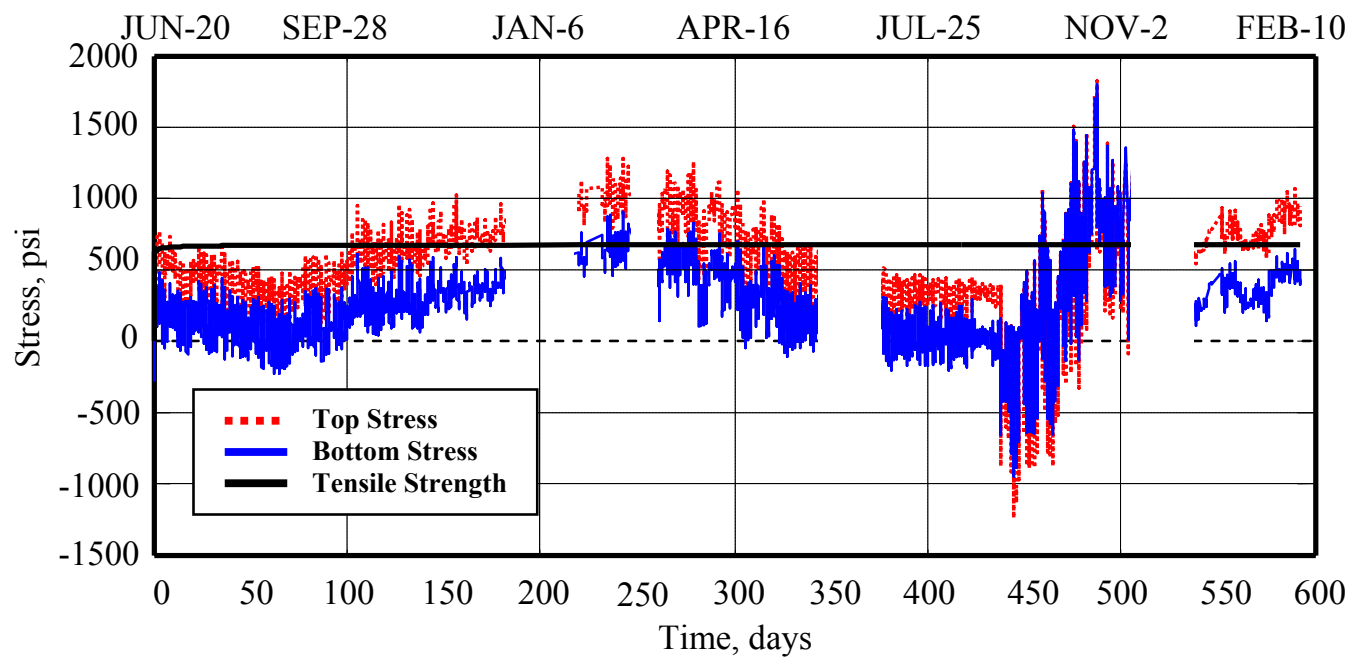

4.3.17 Along Girder B

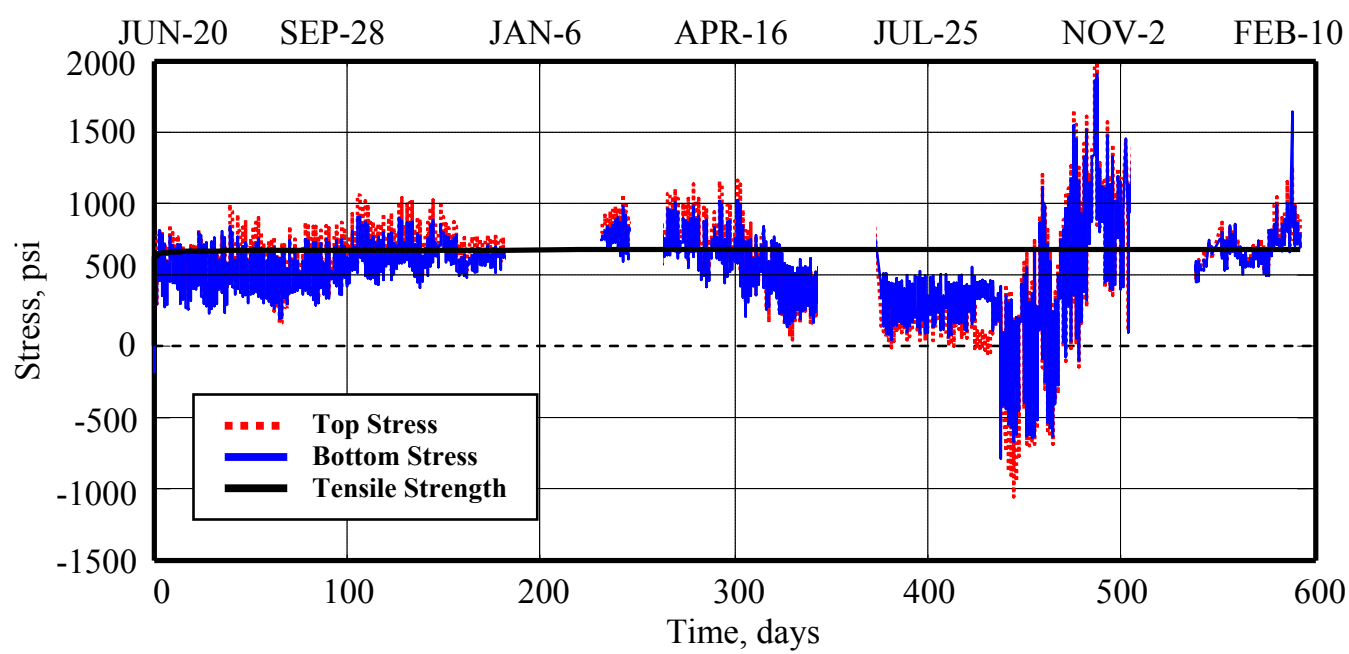

4.3.18 Along Girder C

Figure 4.3.16-4.3.18 Time-History of Longitudinal Stresses at 1/4 Span \# 2 . 


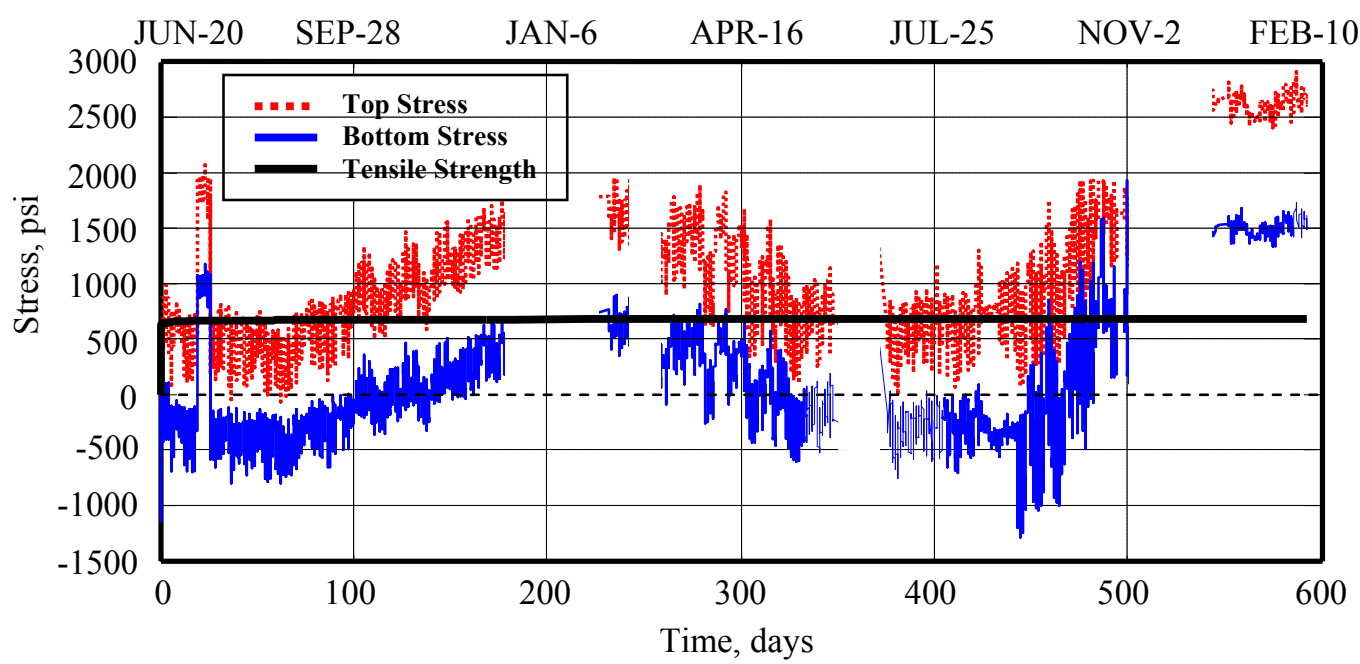

4.3.19 Along Girder A

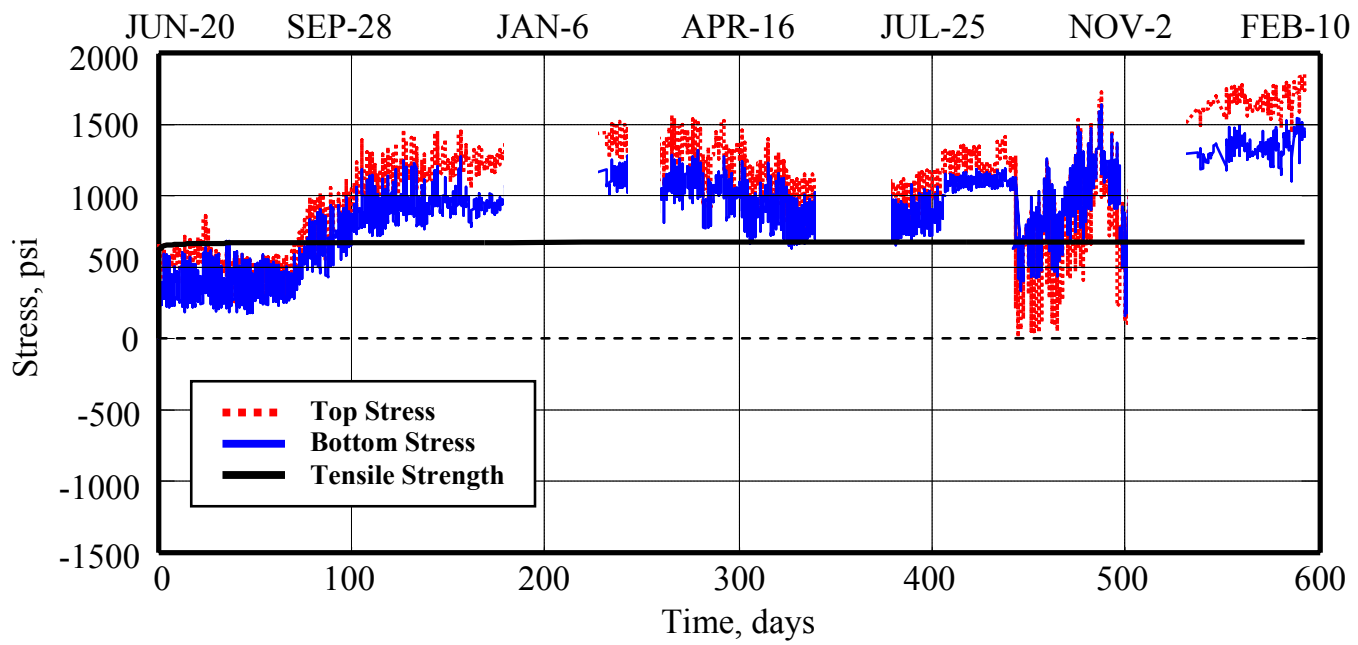

4.3.20 Along Girder B

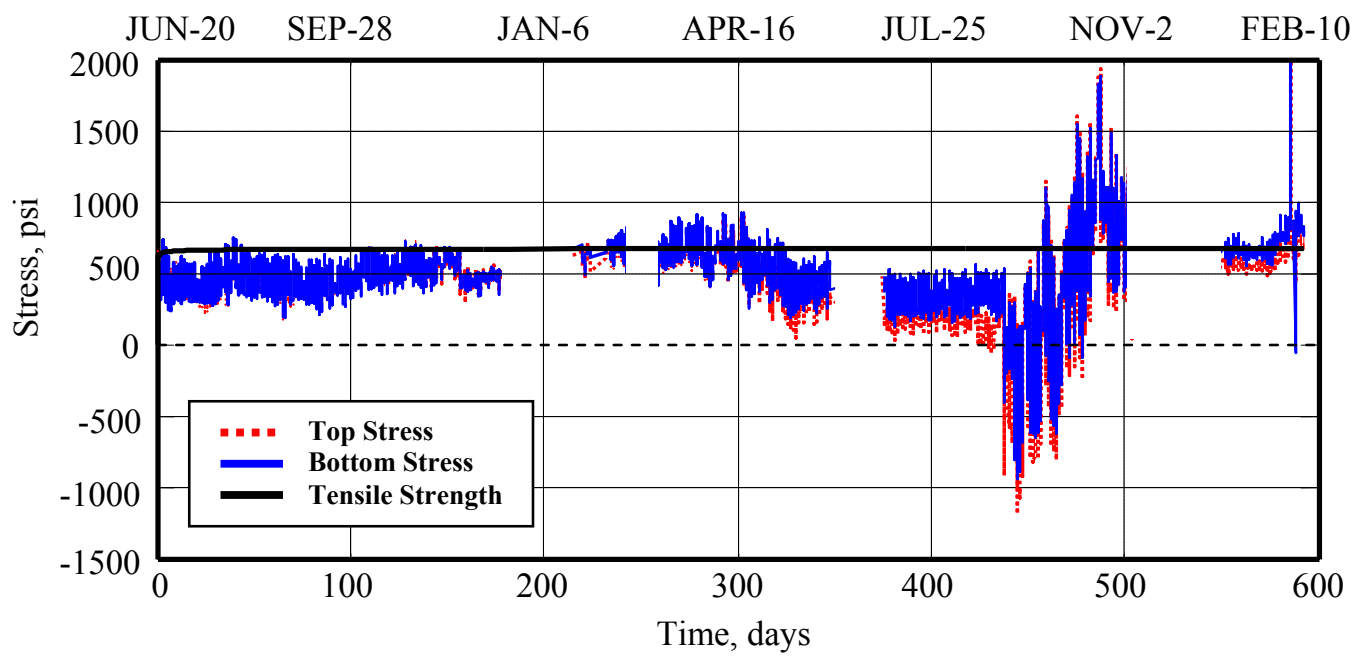

4.3.21 Along Girder C

Figure 4.3.19-4.3.21 Time-History of Longitudinal Stresses at Mid Span \# 2 . 
Based upon the stresses calculated from the measured strains, it is quite obvious that stress levels have surpassed those necessary to cause cracking. Stress levels were high enough to cause cracking at all locations. Based upon the results of the stress analysis, it is quite likely that extensive cracking has occurred throughout the deck of Evansville Bridge.

\subsubsection{ROLE OF REINFORCEMENT STEEL IN CRACKING}

In bridge design, it is assumed that the reinforcement steel and the concrete of the bridge deck are bonded together completely. It is vital that the reinforcement steel be bonded with the concrete. This phenomenon is discussed in detail in Chapter 6; it was determined that in some cases there may be some relative slipping between the reinforcement and the concrete.

To help prevent the concrete from cracking, steel reinforcement is added in the areas of maximum flexural stress. If the design yield strength, $f_{y}$, exceeds $40,000 \mathrm{psi}$, the AASHTO Standard Specifications for Highway Bridges (2002) recommend that the the

reinforcement steel's stress, $f_{s}$, should not exceed the value given by the following equation:

$$
f_{s}=\frac{Z}{\left(A d_{c}\right)^{1 / 3}} \leq 0.6 f_{y}
$$

where:

$A$ is the effective tension area, in square inches, of concrete surrounding the tension reinforcement and having the same centroid as the reinforcement steel. For calculation purposes the thickness of clear concrete cover used to compute $A$ should not exceed 2 inches.

$d_{c}$ is the distance measured from the extreme tensioned fiber and the center of the steel rebar in inches. For calculation purposes the thickness of clear concrete cover used to compute $d_{c}$ should not exceed 2 inches.

$Z$ is a quantity which should not exceed 170 kips per inch for members in moderate conditions, and 130 kips per inch for members in severe exposure conditions. 
In Evansville Bridge the clear concrete cover over the top reinforcement is 2.5 inches, which means the distance $d_{c}$ is 3.25 inches. The spacing between longitudinal steel reinforcement is 12 inches in the mid-spans and 6 inches over the abutments and piers. Substituting these values into Equation 4.3 and taking $\mathrm{dc}=2$ inches, the maximum allowable stresses in the longitudinal steel rebar are $28.4 \mathrm{ksi}$ in the mid spans and 35.77 ksi over the piers.

The stresses in the reinforcement (calculated based upon strains measured with sister bars) do not exceed the maximum allowable stresses calculated using equation 4.3. However, this did not prevent early age cracking of the bridge deck. The stress level in the reinforcement is two to three times that recorded in the surrounding concrete, but if a bond exists between the rebar and the concrete, the stress ratio should be equal to steel/concrete modular ratio $\left(\mathrm{E}_{\mathrm{s}} / \mathrm{E}_{\mathrm{c}}=30,000 \mathrm{ksi} / 4,500 \mathrm{ksi}=6.6\right)$. The low stresses in the steel reinforcement indicate that the concrete deck is over reinforced, which causes abrupt cracking of the concrete deck. The excess reinforcement is caused by the steel stay-in-place forms and girders carrying much of the tensile stress in the bridge. The stay-in-place forms constrain the lower surface of the deck, causing differential shrinkage and contraction across the slab's thickness. The large concrete cover over the longitudinal reinforcement results in the formation of transverse cracks at early age as the stresses at the slab top exceed the concrete modulus of rupture as presented in Figures 4.2.1-4.2.19. One solution to overcome this problem is casting the deck with a thin concrete cover of one inch, and overlaying the deck at a later stage with fine aggregate concrete. This technique is currently used in casting long bridges.

\subsubsection{EFFECTS OF RESTRAINED SHRINKAGE ON EARLY AGE CRACKING}

If a given slab of concrete undergoes a cyclic temperature change in which the net temperature change $(\Delta \mathrm{T})$ is equal to zero, the residual stress will be zero. If there are other volumetric changes than those due to temperature, then the net stress change will 
not be zero (there will be residual stress). Therefore, if stress is plotted against temperature change, the intercept $(\Delta \mathrm{T}=0)$ is equal to the magnitude of stress due to other factors, and the slope of the line is equal to the stress that is caused by temperature change. The other volumetric changes mentioned above are due to the concrete shrinking as it dries.

In order to examine the phenomenon described above as it occurs at Evansville Bridge, plots of stress versus temperature change were created at ages of $1,3,7,14$, and 28 days in two locations (mid-span \#1 and the pier). These plots are shown in figures 4.4.14.4.5 $\mathrm{a}$ and $\mathrm{b}$. 


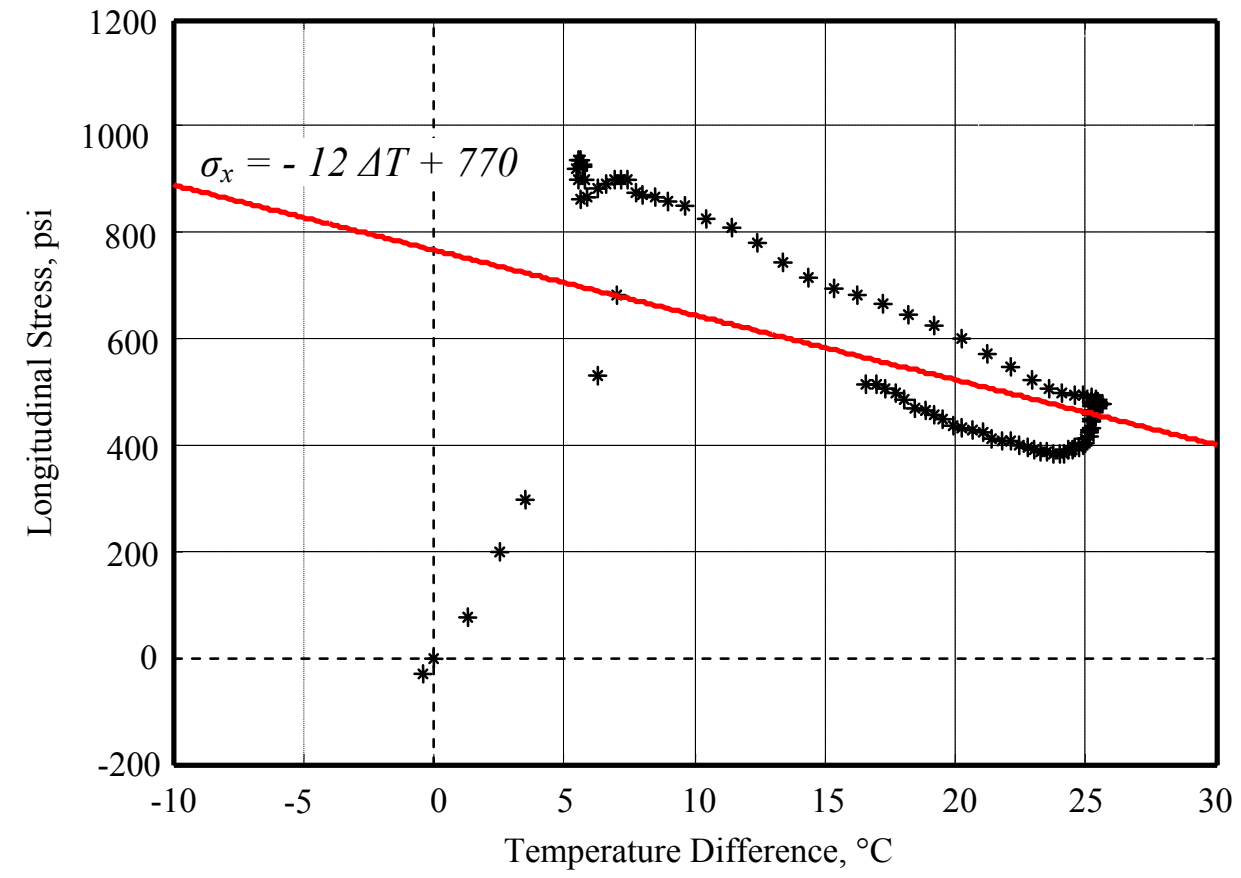

a. At Mid Span \# 1

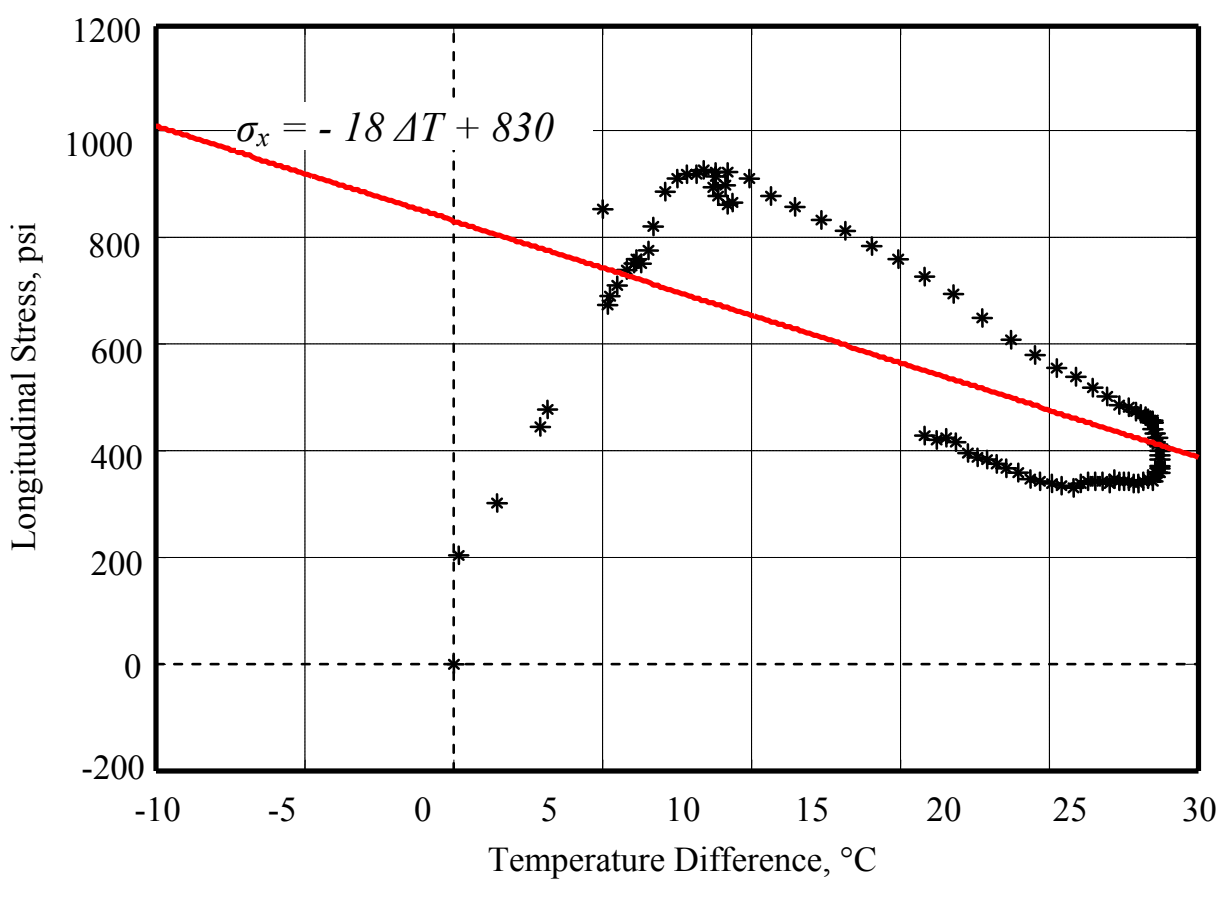

b. Over the Pier

Figure 4.4.1 Stress Versus Temperature Change During the First Day (Shoukry et. al., 2005). 


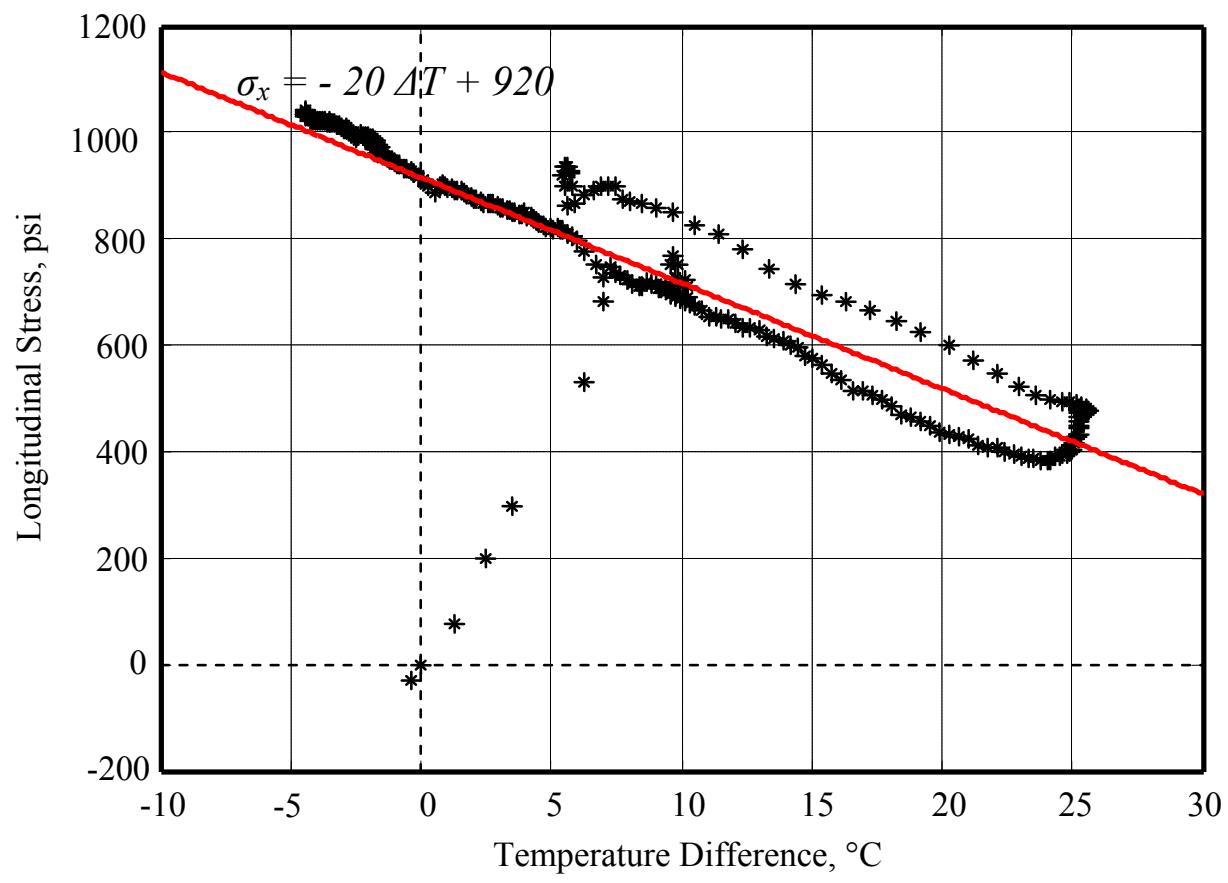

a. At Mid Span \# 1

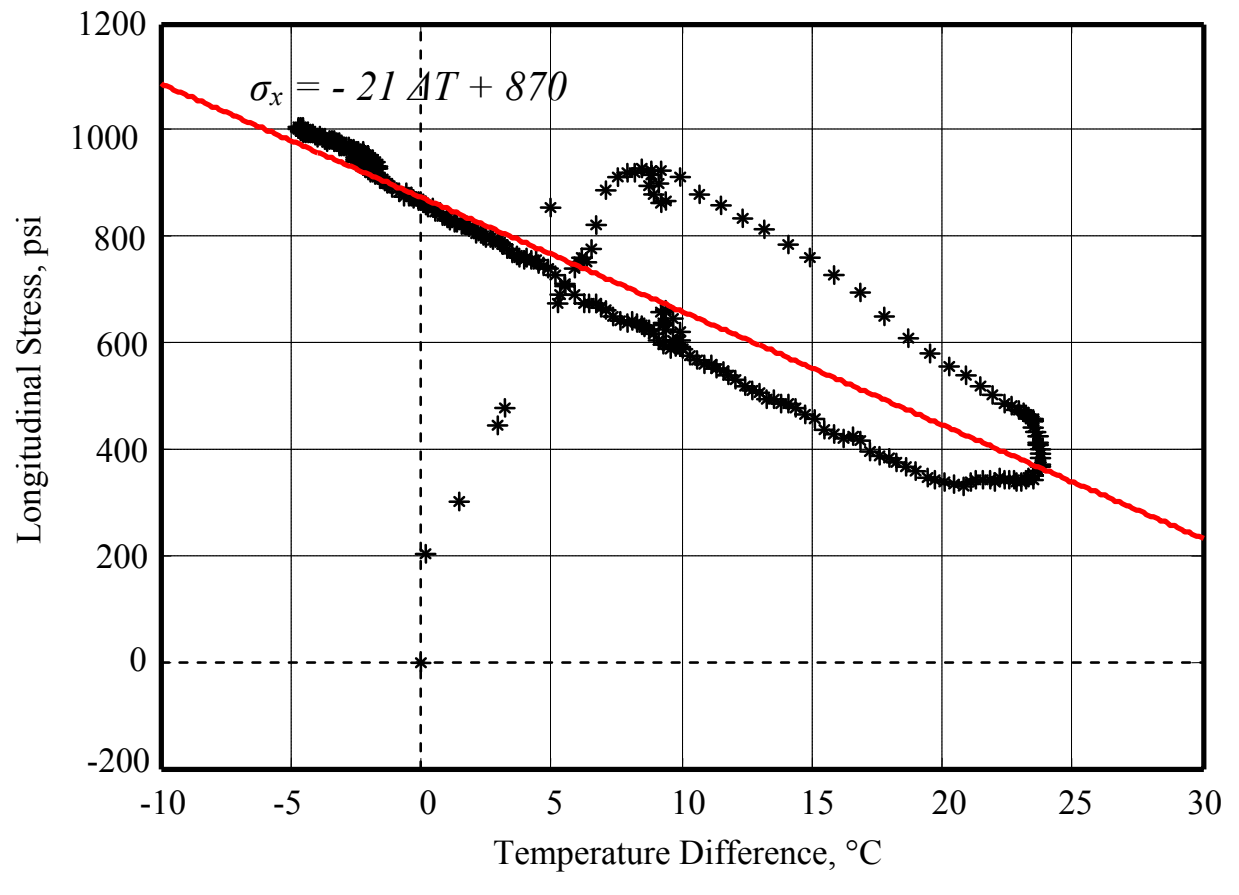

b. Over the Pier

Figure 4.4.2 Stress Versus Temperature Change After Three Days. (Shoukry et. al., 2005) 


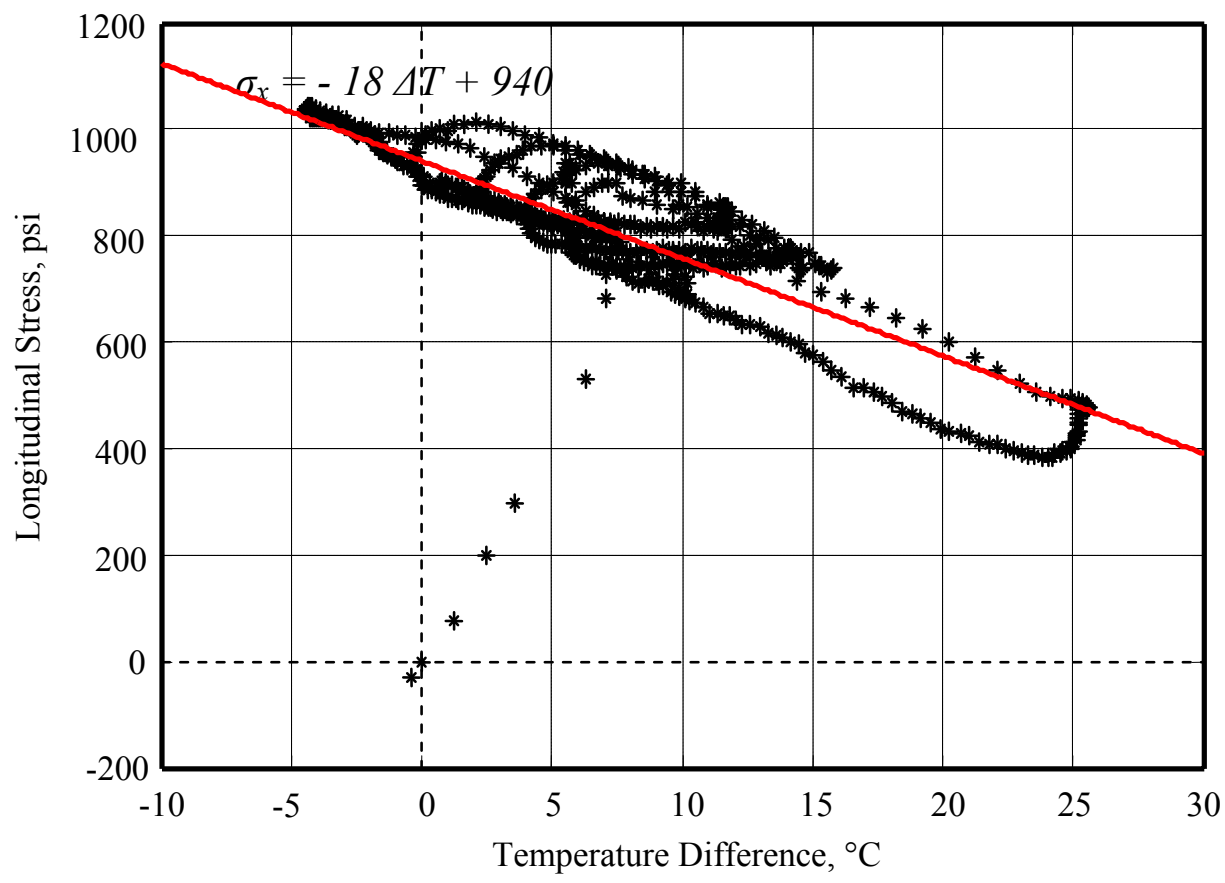

a. At Mid Span \# 1

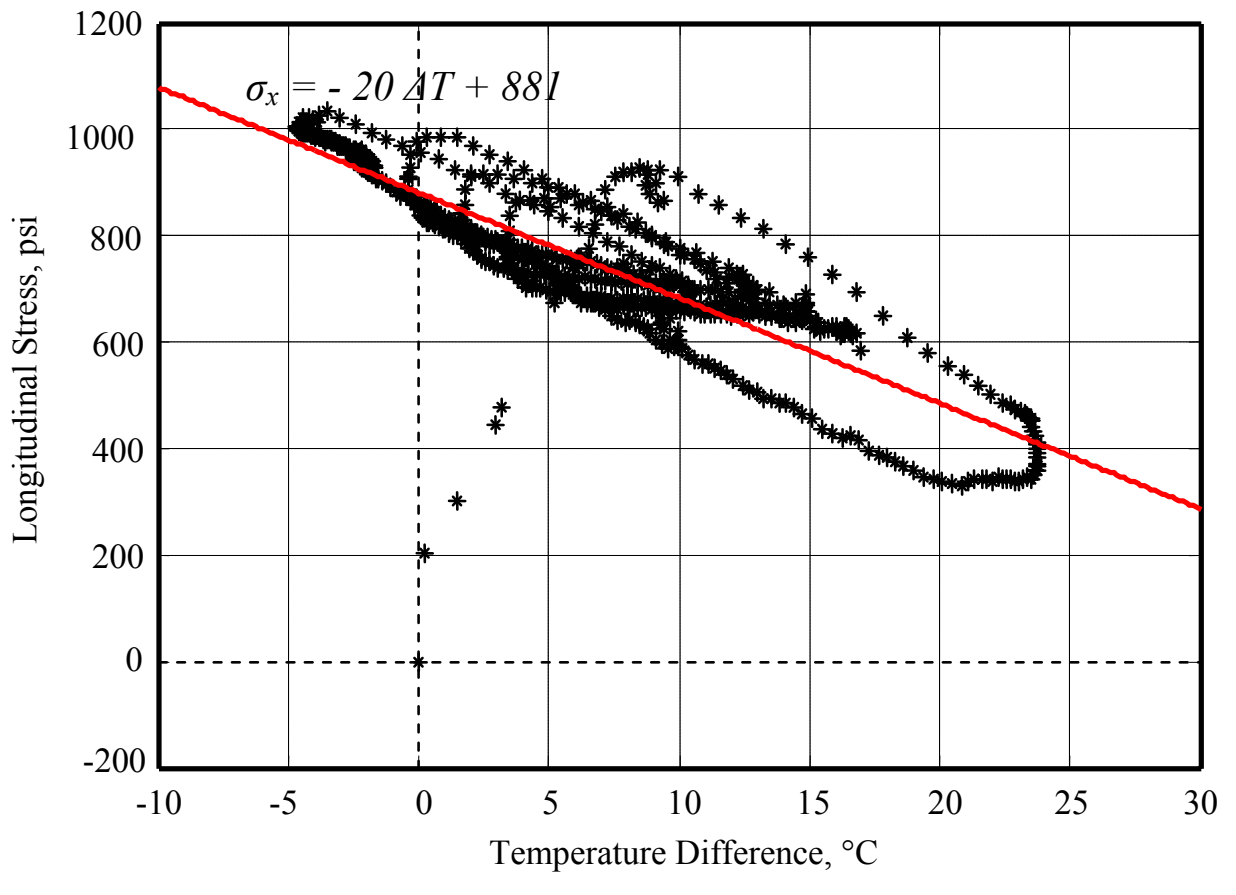

b. Over the Pier

Figure 4.4.3 Stress Versus Temperature Change After Seven Days. (Shoukry et. al., 2005) 


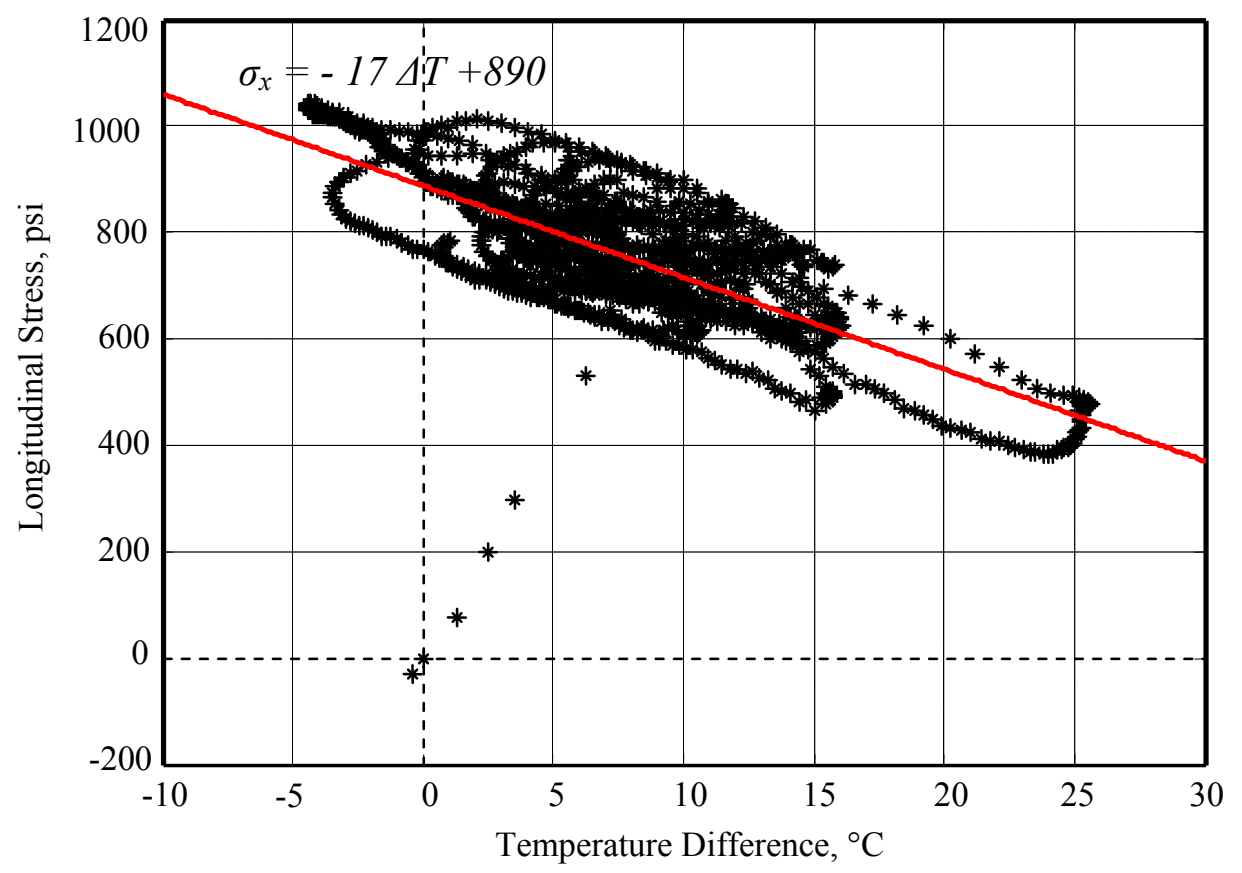

a. At Mid Span \# 1

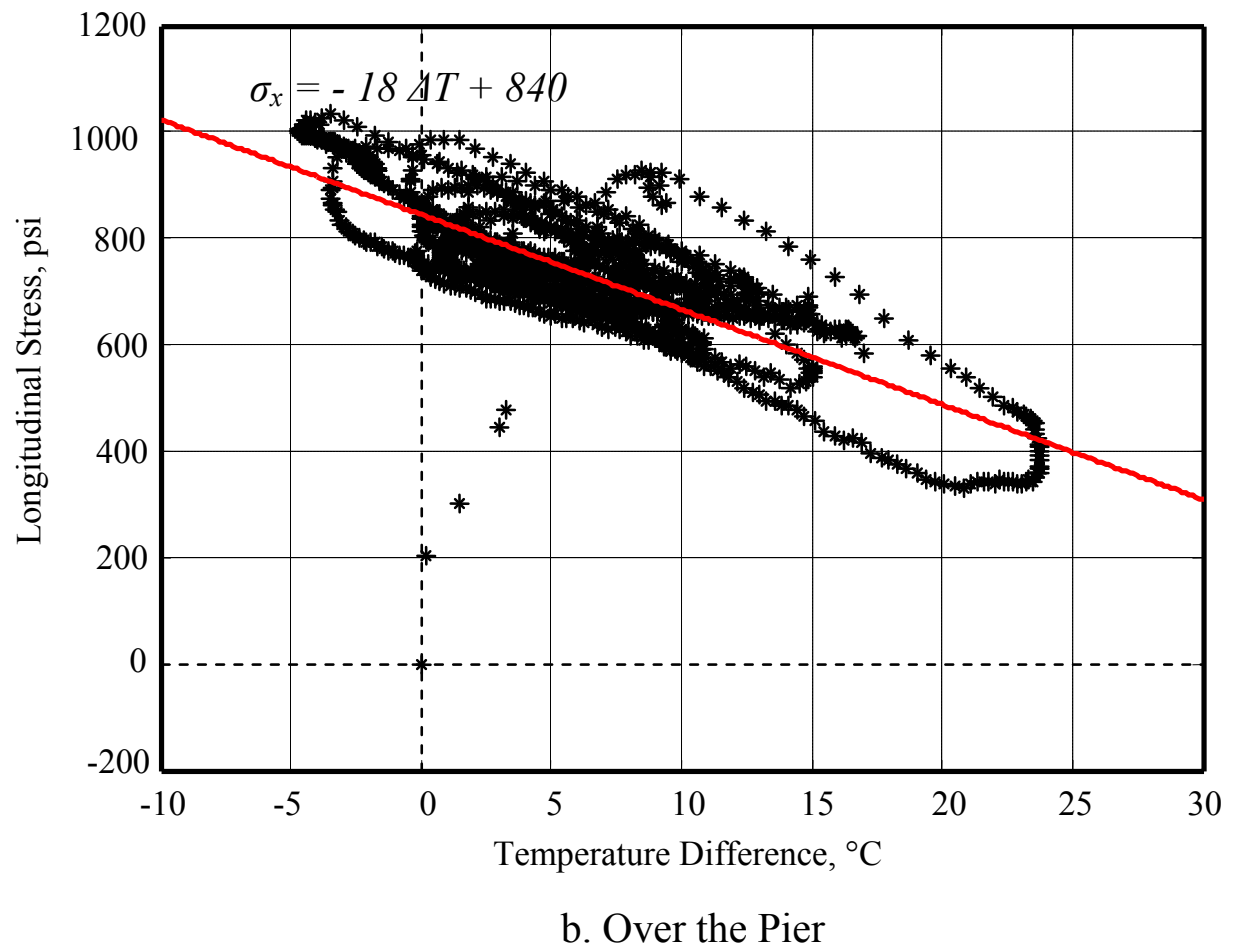

Figure 4.4.4 Stress Versus Temperature Change After 14 Days.

(Shoukry et. al., 2005) 


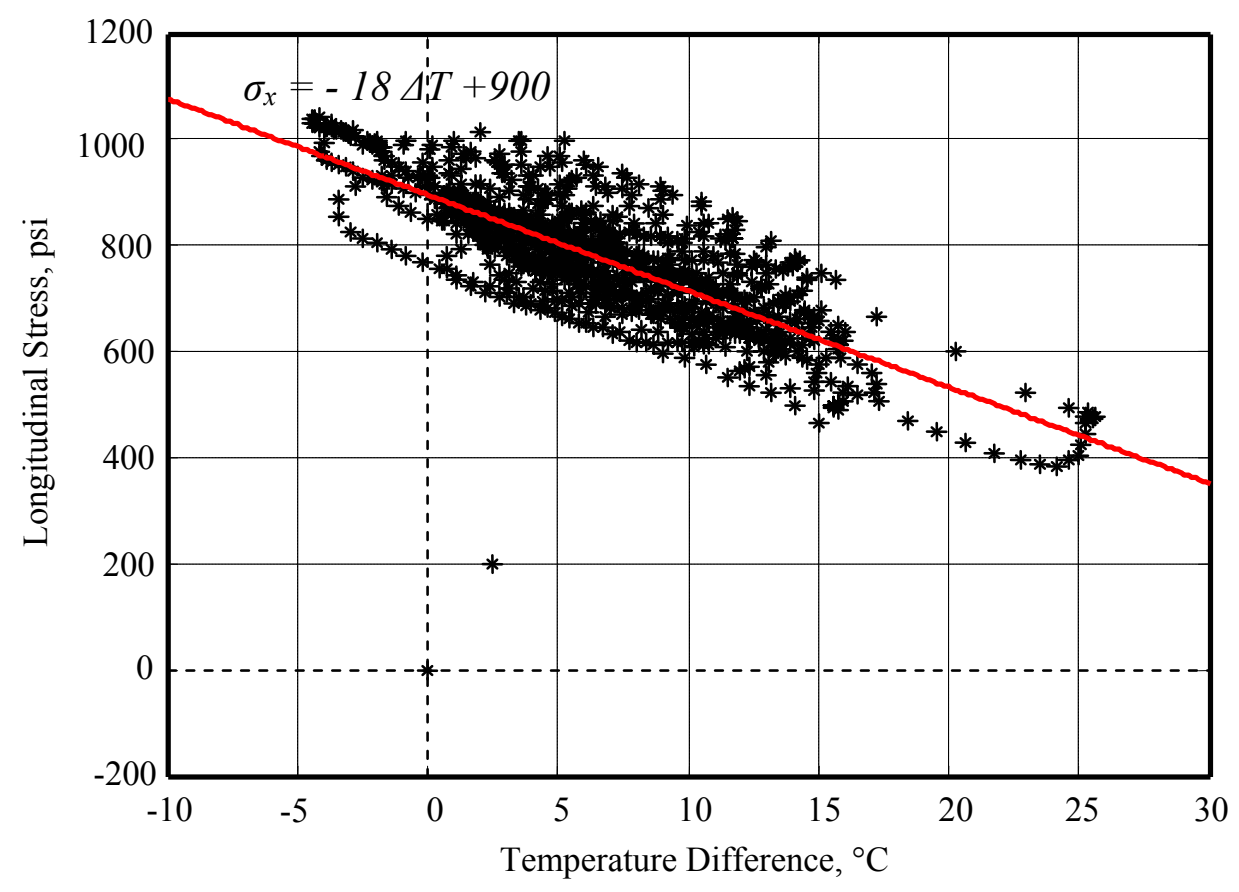

a. At Mid Span \# 1

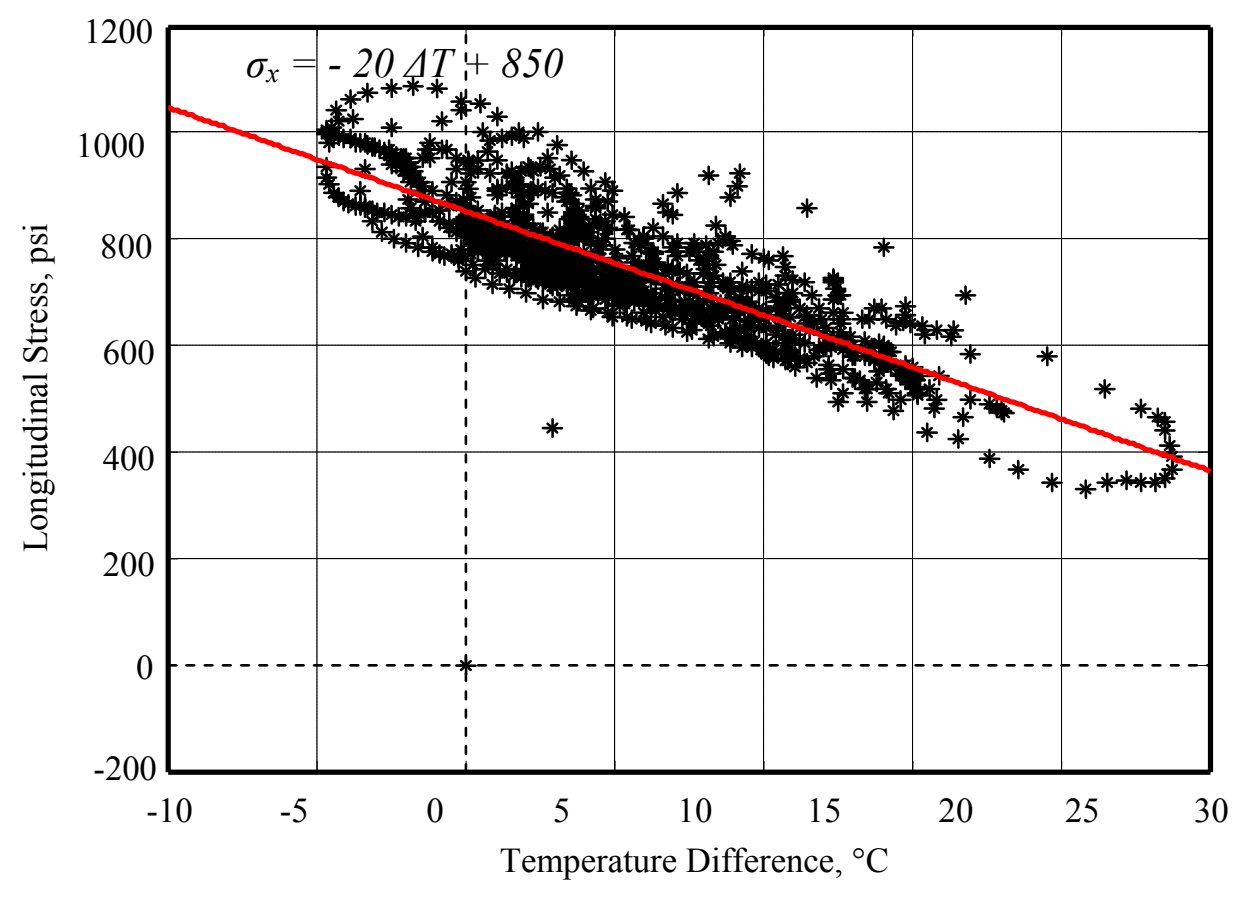

b. Over the Pier

Figure 4.4.5 Stress Versus Temperature Change After 28 Days.

(Shoukry et. al., 2005) 
Using the data from the above plots, it is possible to generate time histories of the stresses to due restrained shrinkage, as shown in figure 4.4. The stresses exceed the modulus of rupture of concrete during the first day after casting; at this point the bond between the concrete and the steel reinforcement is weak, which means that the reinforcement provides very little tensile strength, and the concrete can't sustain the stresses, which leads to cracking.

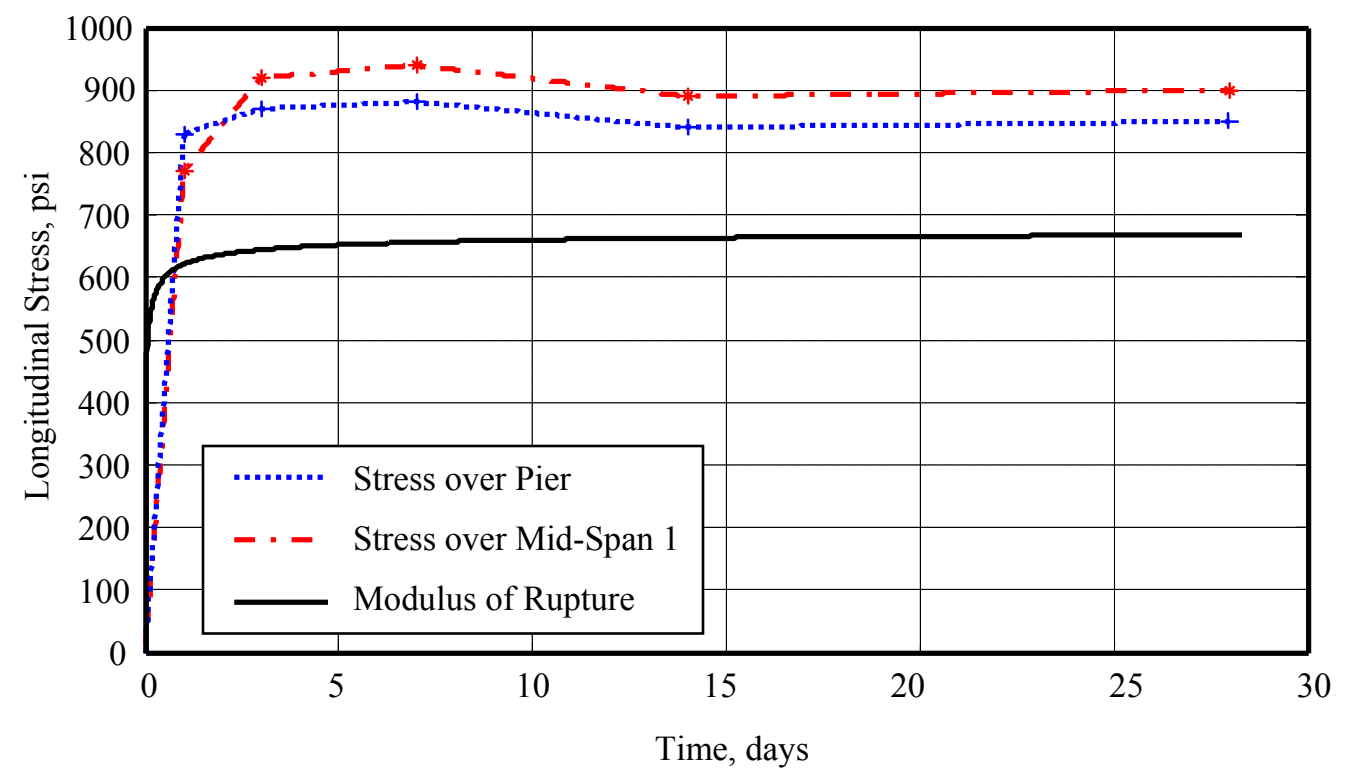

Figure 4.5 Longitudinal Stresses Due to Drying Shrinkage.

\subsection{CRACK DETECTION TECHNIQUE}

The crack meters installed on Evansville bridge measure the relative displacement between their two endpoints, in addition to temperature. The method devised to determine whether the concrete of a bridge deck is cracked is based upon the displacement and temperature data collected over time. The crack detection algorithm takes advantage of the behavior of concrete in response to changing temperatures. Concrete expands in response to increasing temperatures, and contracts in response to decreasing temperature. Displacement and temperature are related by the following equation:

$$
\Delta=c \alpha \Delta T
$$


Where:

$\Delta$ is displacement.

$\mathrm{c}$ is a constant that depends on the constraint of the structure and is equal to 1 free structures, and 0 for fully constrained structures.

$\alpha$ is the coefficient of thermal expansion, and

$\Delta \mathrm{T}$ is the change in temperature

Because of this, the deflection and the temperature data, when examined with respect to time, should exhibit the same trends. The concrete expands as temperature increases, which means that the displacement, as measured by the crack meter embedded in the concrete slab, should increase with increasing temperature if the slab is undamaged. If the slab is cracked, its behavior resembles that of two independent slabs. The two portions of the cracked slab expand and contract separately under temperature variation. Taken to extremes, cracking causes the cracked section to behave like two sections with a joint between them. This means that a crack meter whose length extends through a crack will generate displacement readings nearly opposite to one in an undamaged section. The displacement reading will increase as temperature decreases, because the two portions of the cracked slab will pull away from one another, opening the crack between them and stretching the crack meter that is embedded in both portions of the slab. Conversely, the reading of a crack meter in a cracked slab will decrease as temperature increases, because the two parts of the slab will expand and the crack will close, compressing the crack meter. These concepts are illustrated in figure 4.6. 


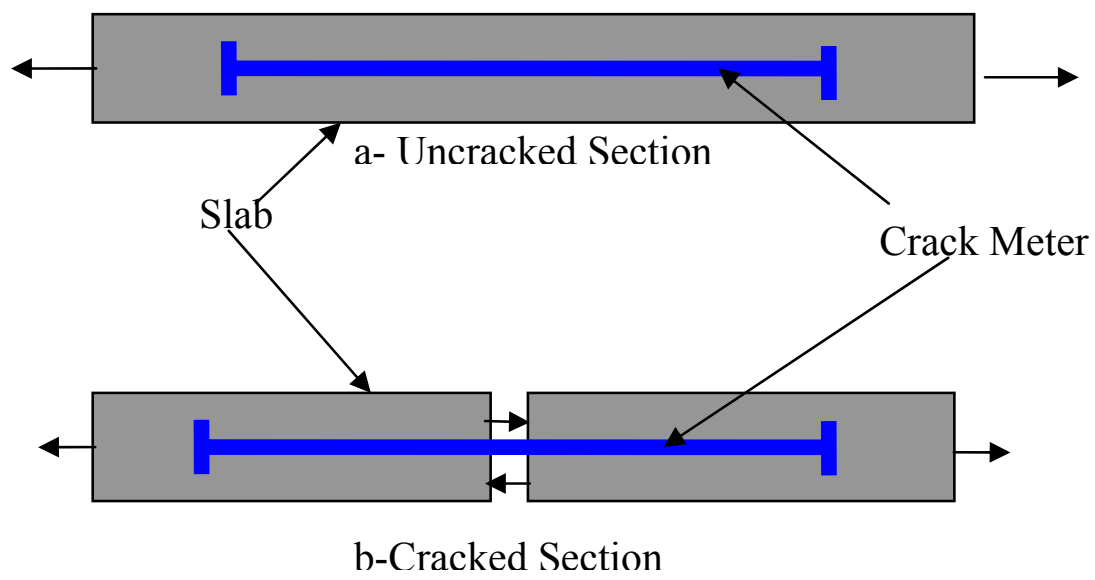

Figure 4.6: Idealized Slab Response to Increasing temperature

\subsection{RESULTS}

In order to determine whether the bridge deck is cracked at the location of a given crack meter, a short section of data (120 days worth) was plotted versus time. By observing the trend of the data, it is possible to determine if a crack is present. If the displacement reading increases with decreasing temperature, then a crack is very likely present. These short plots are shown in figures 4.7.1-4.7.30 a and $\mathrm{b}$. 


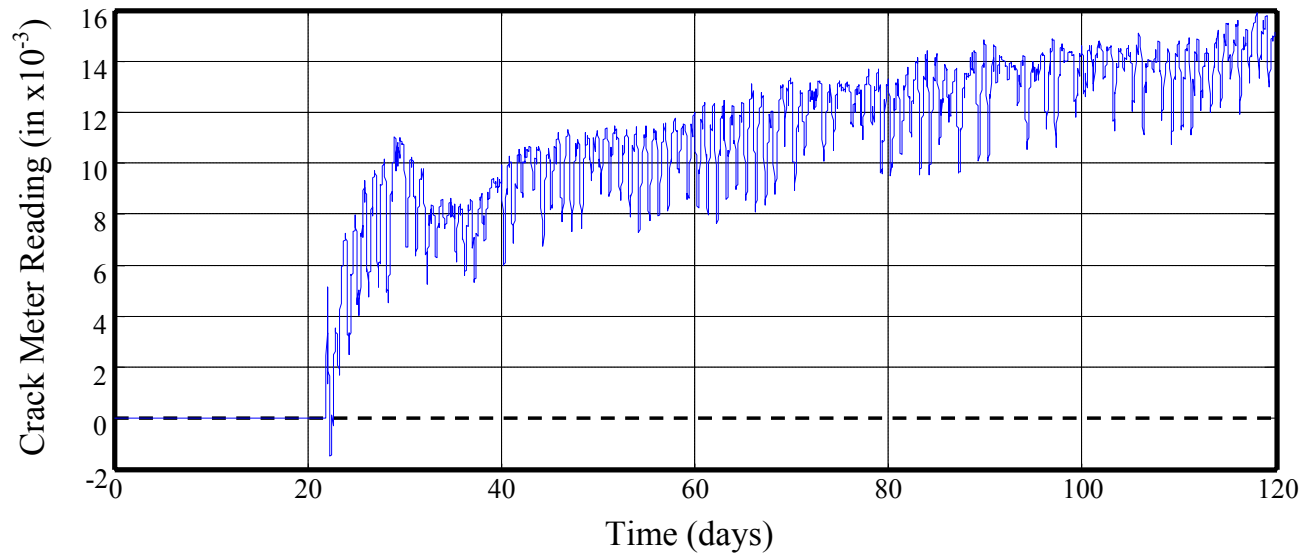

Figure 4.7.1a: Displacement Reading, Crack Meter 1

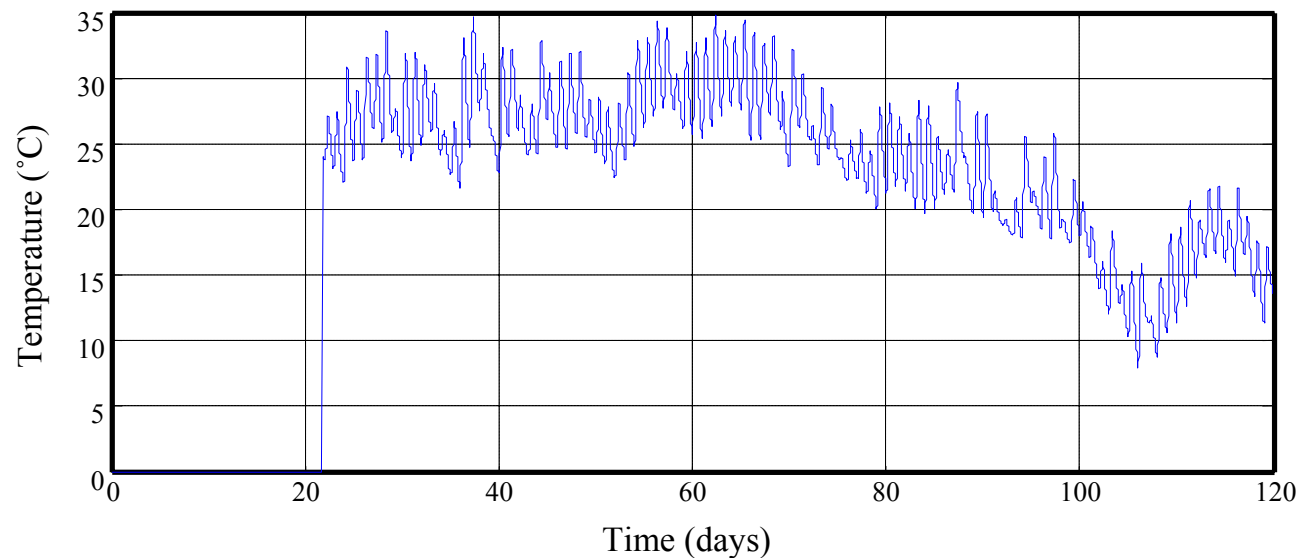

Figure 4.7.1b: Temperature Reading, Crack Meter 1

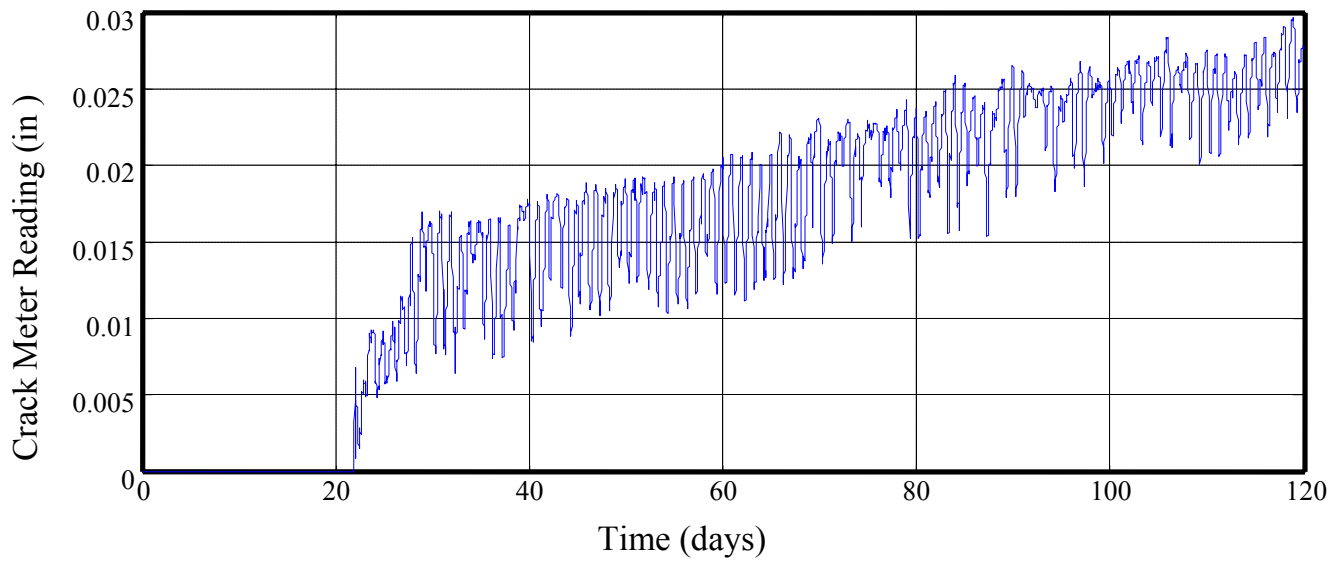

Figure 4.7.2a: Displacement Reading, Crack Meter 2

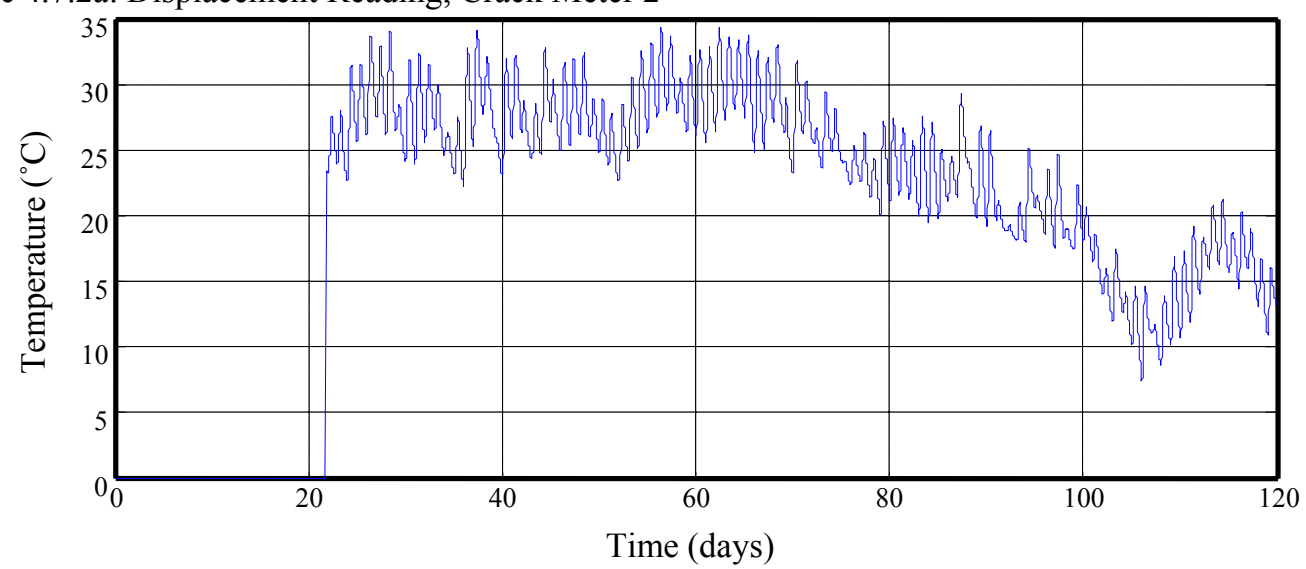

4.7.2b: Temperature Reading, Crack Meter 2 


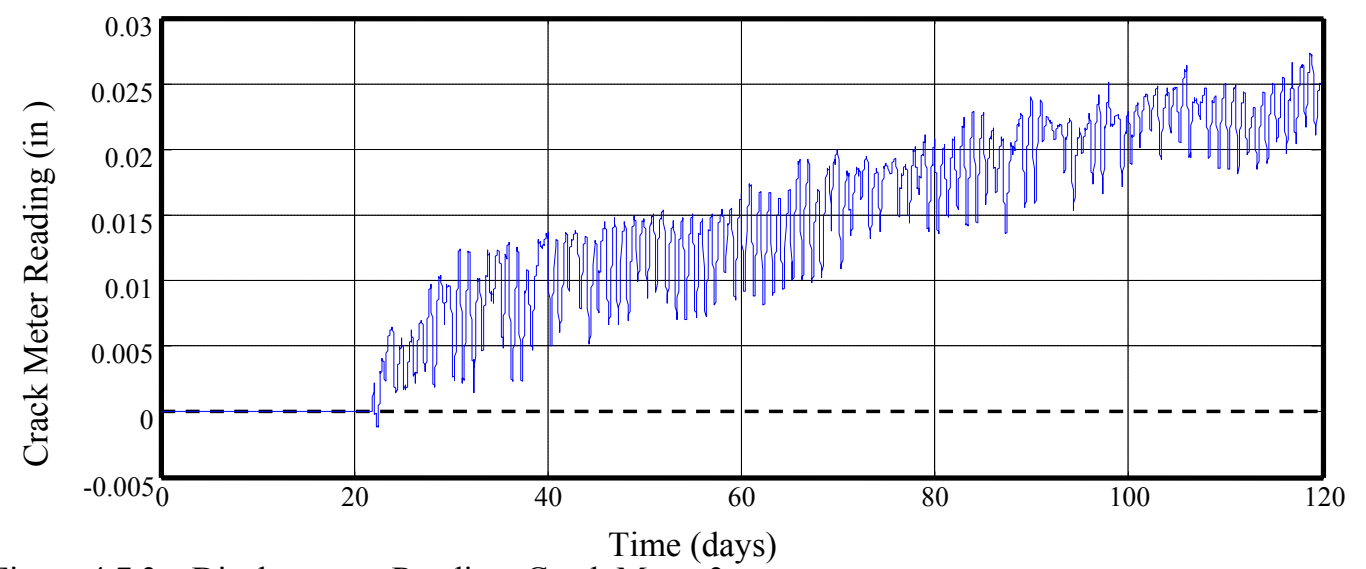

Figure 4.7.3a: Displacement Reading, Crack Meter 3

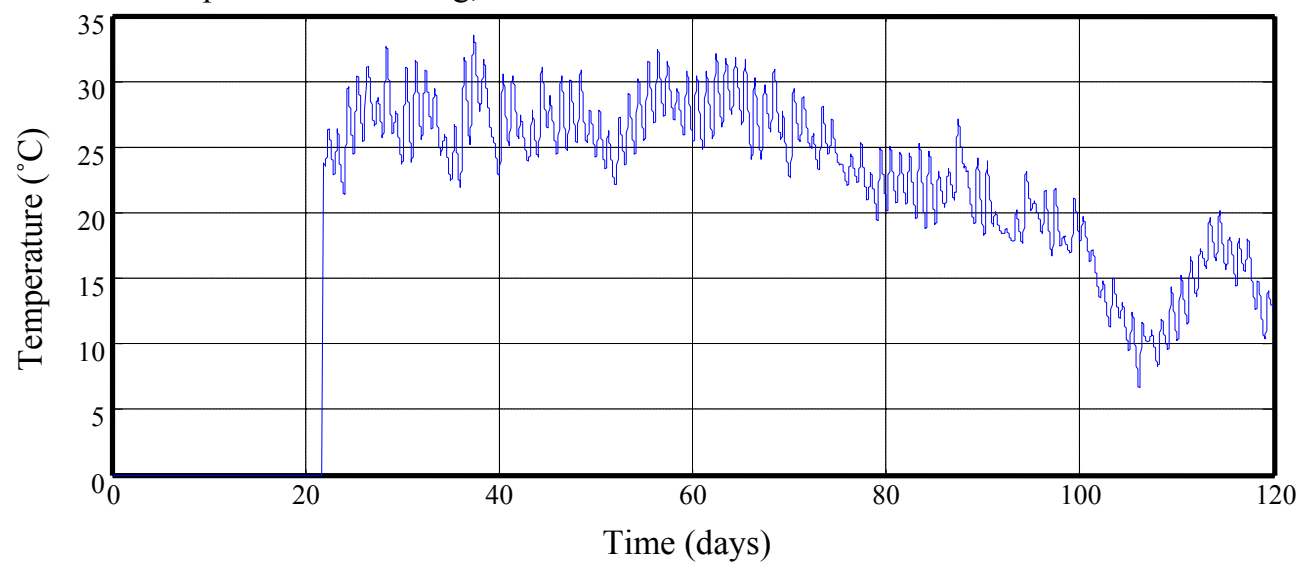

Figure 4.7.3b: Temperature Reading, Crack Meter 3

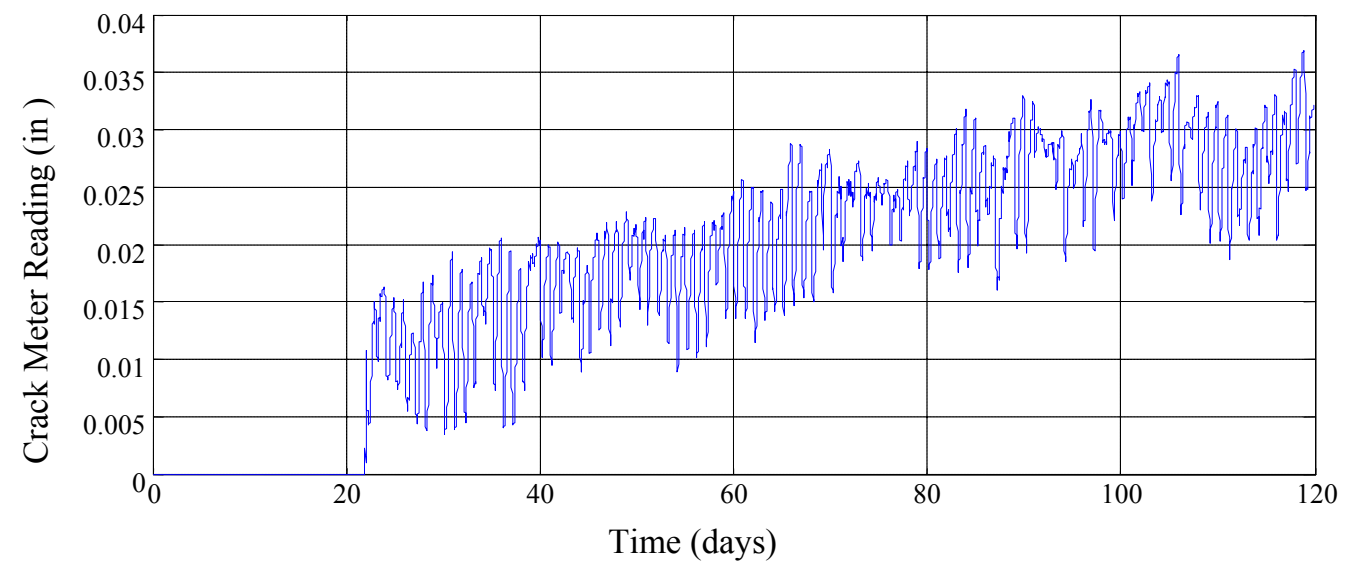

Figure 4.7.4a: Displacement Reading, Crack Meter 4

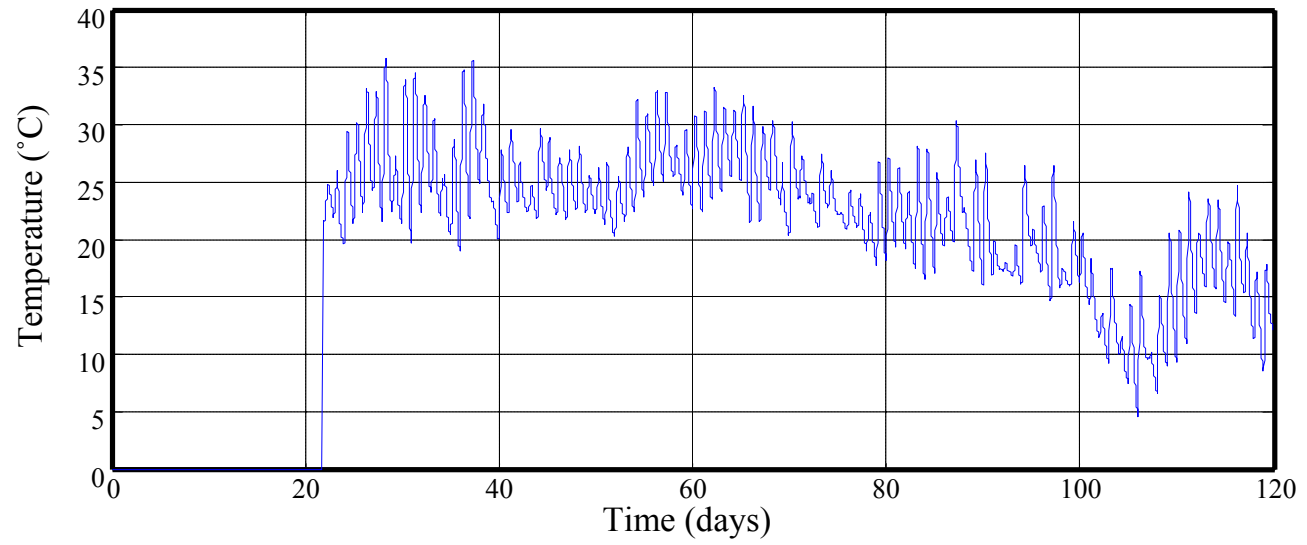

Figure 4.7.4b: Temperature Reading, Crack Meter 4 


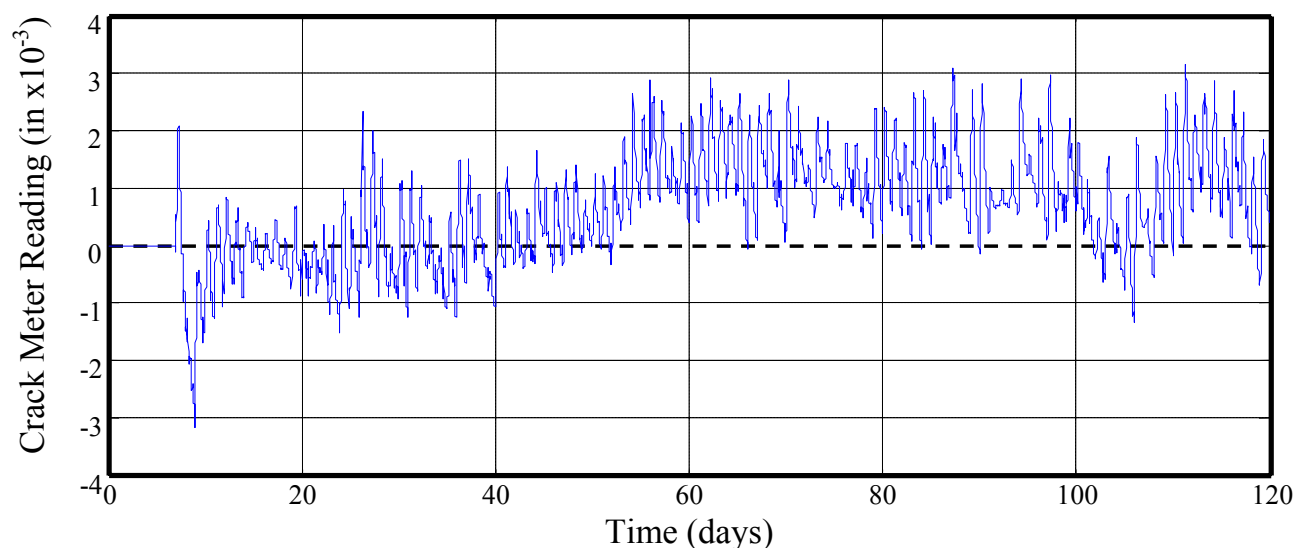

Figure 4.7.5a: Displacement Reading, Crack Meter 5

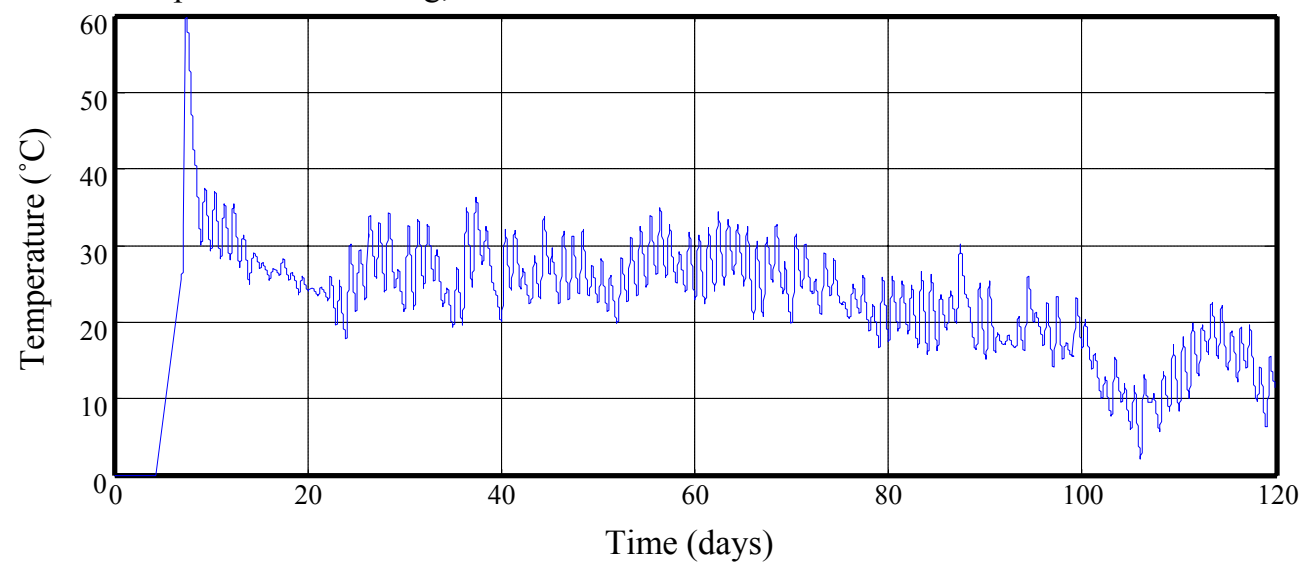

Figure 4.7.5b: Temperature Reading, Crack Meter 5

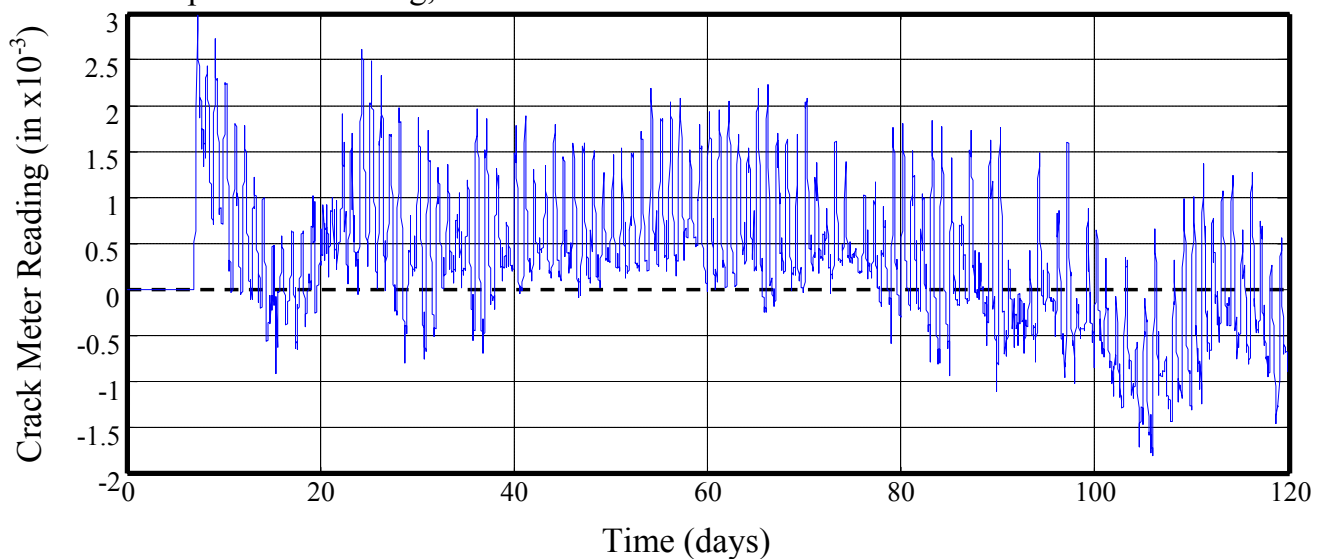

Figure 4.7.6a: Displacement Reading, Crack Meter 6

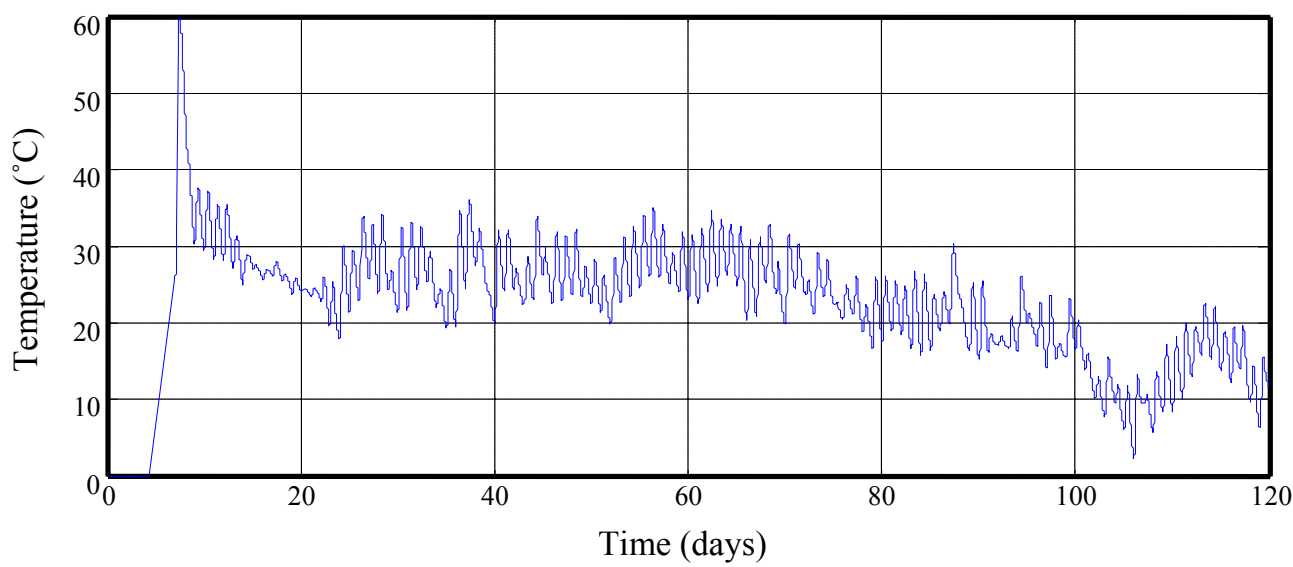

Figure 4.7.6b: Temperature Reading, Crack Meter 6 


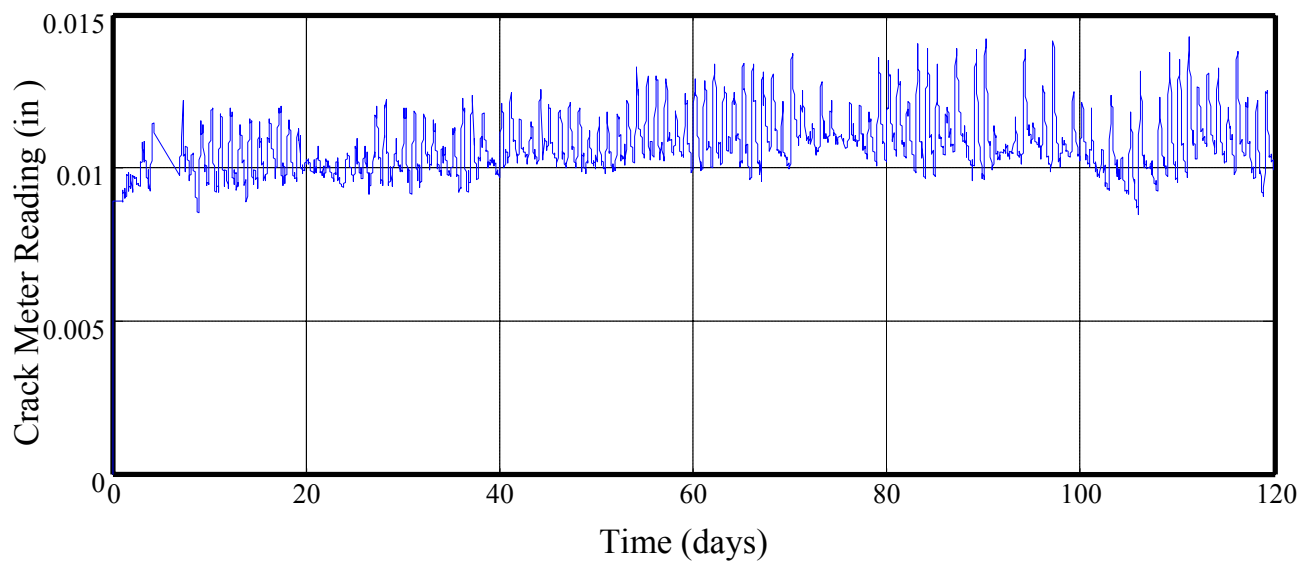

Figure 4.7.8a: Displacement Reading, Crack Meter 8

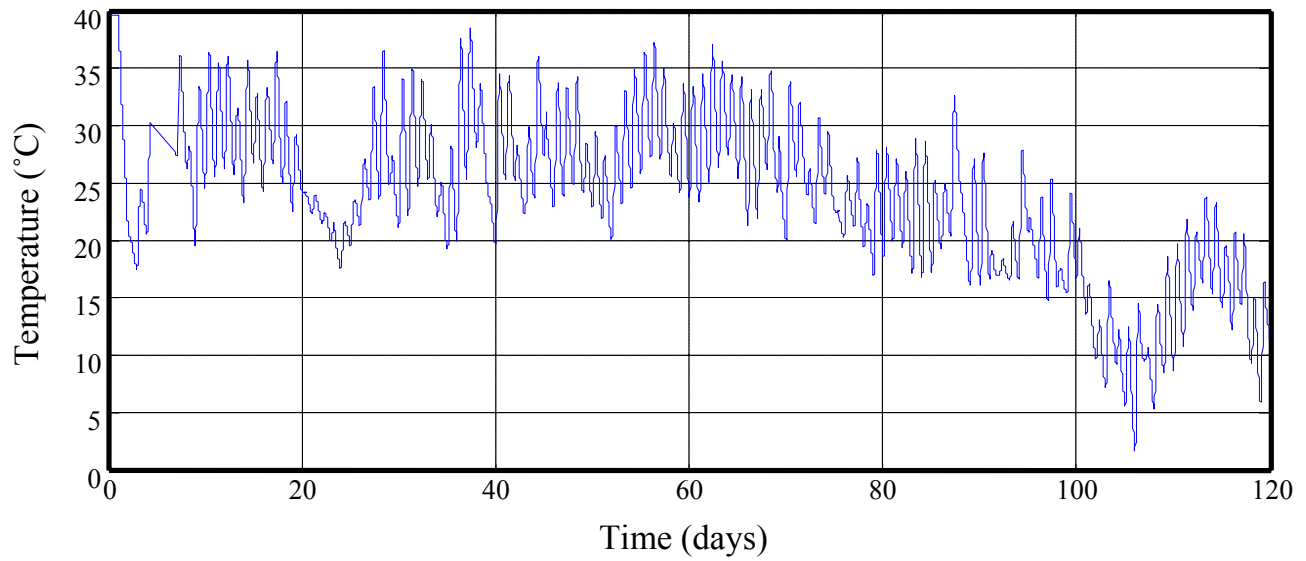

Figure 4.7.8b: Temperature Reading, Crack Meter 8

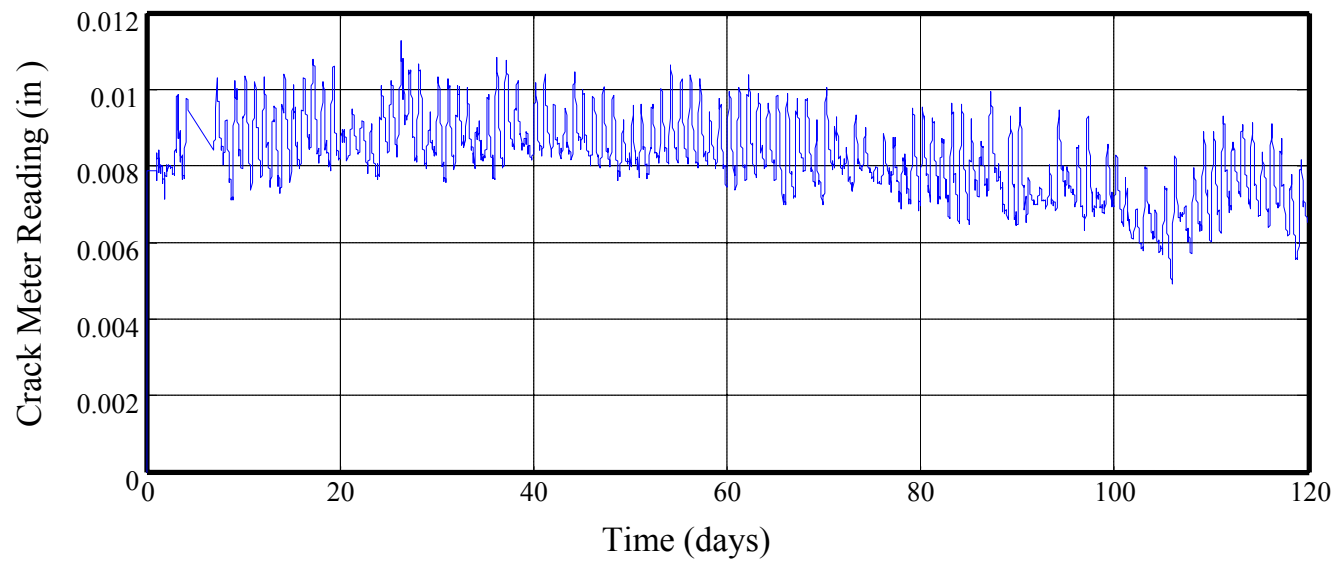

Figure 4.7.9a: Displacement Reading, Crack Meter 9

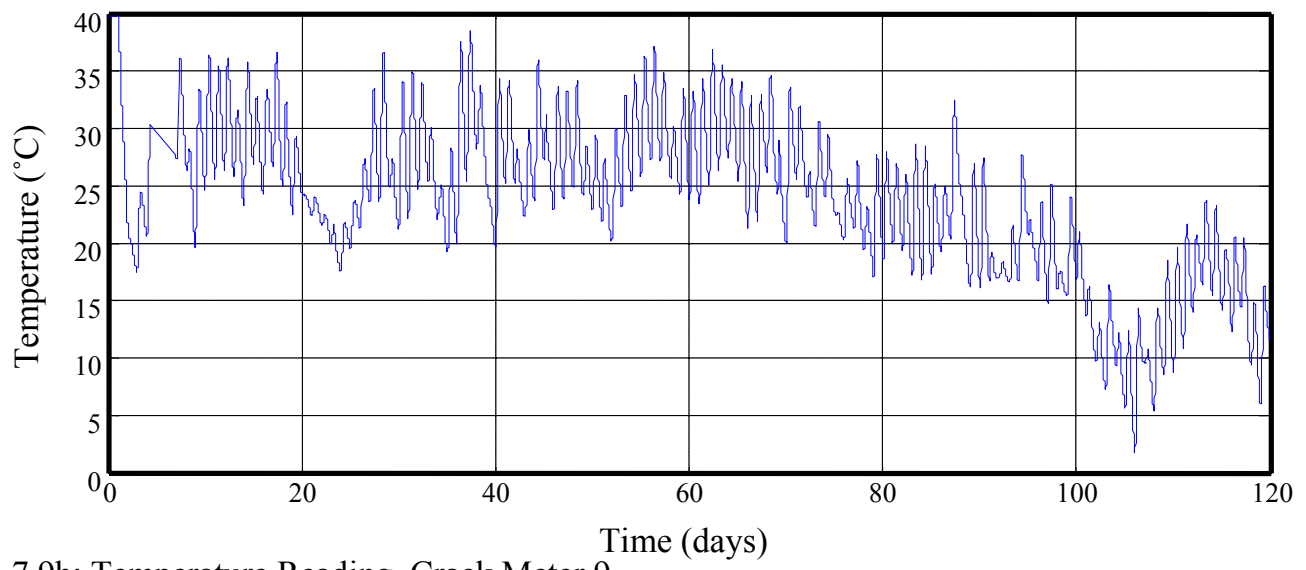

Figure 4.7.9b: Temperature Reading, Crack Meter 9 


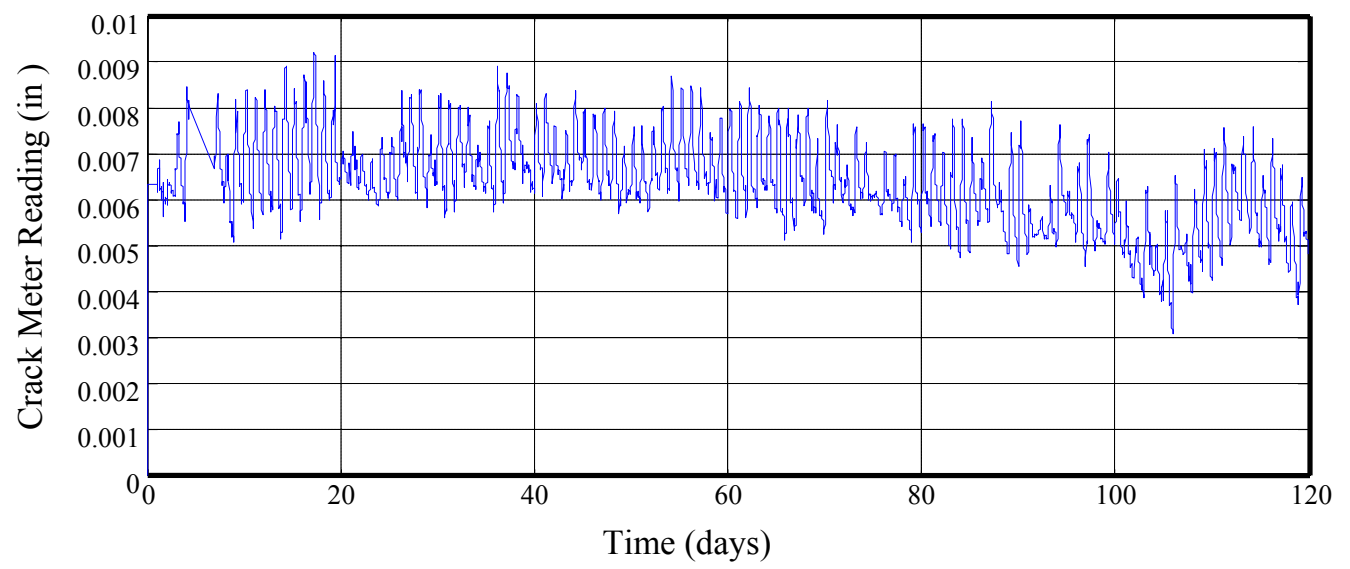

Figure 4.7.10a: Displacement Reading, Crack Meter 10

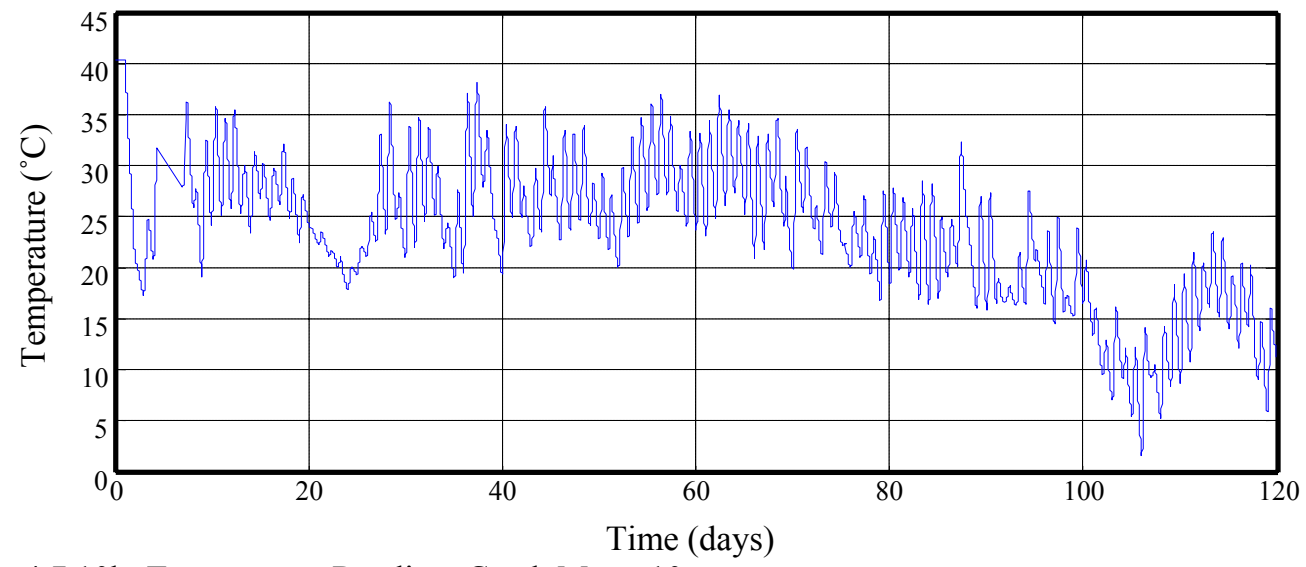

Figure 4.7.10b: Temperature Reading, Crack Meter 10

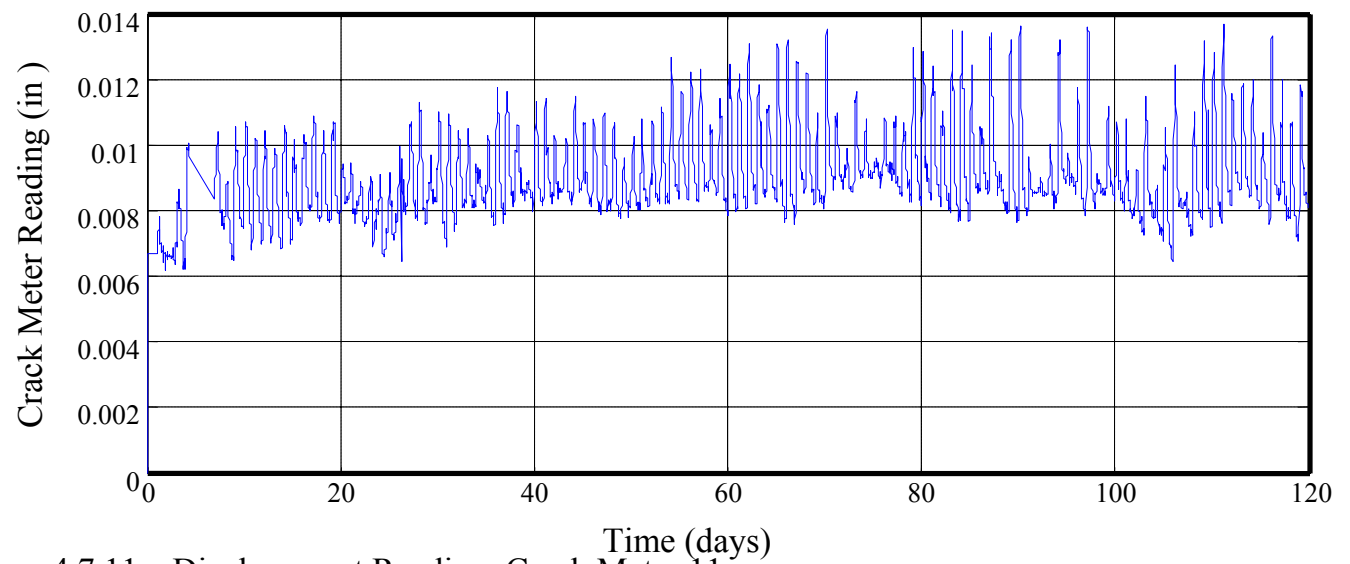

Figure 4.7.11a: Displacement Reading, Crack Meter 11

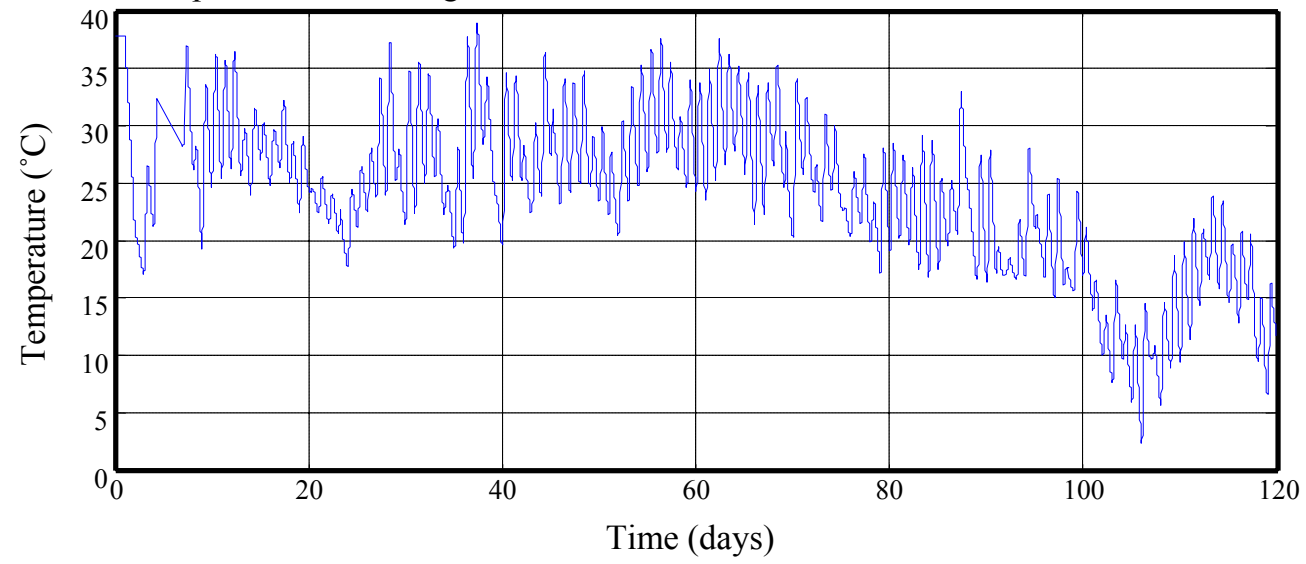

Figure 4.7.11b: Temperature Reading, Crack Meter 11 


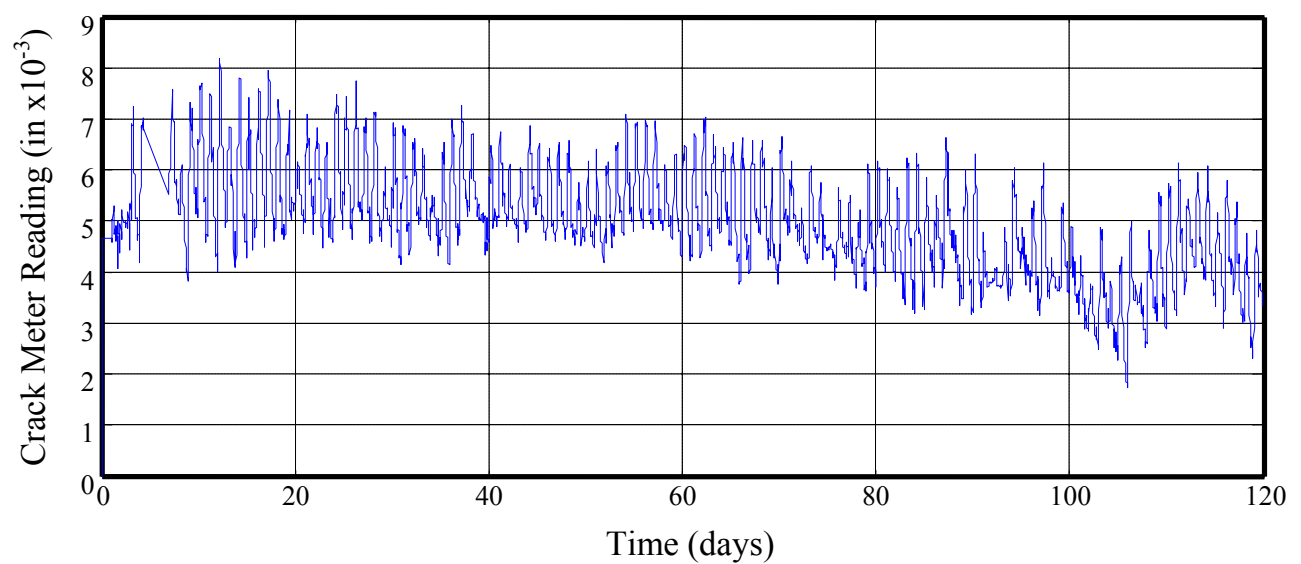

Figure 4.7.12a: Displacement Reading, Crack Meter 12

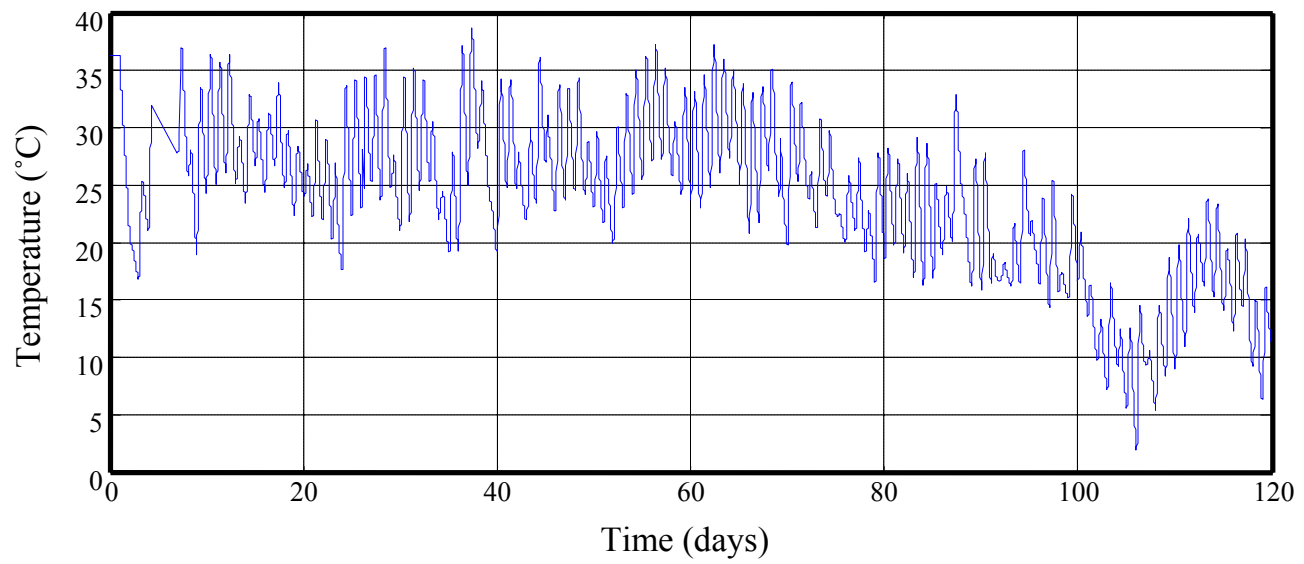

Figure 4.7.12b: Temperature Reading, Crack Meter 12

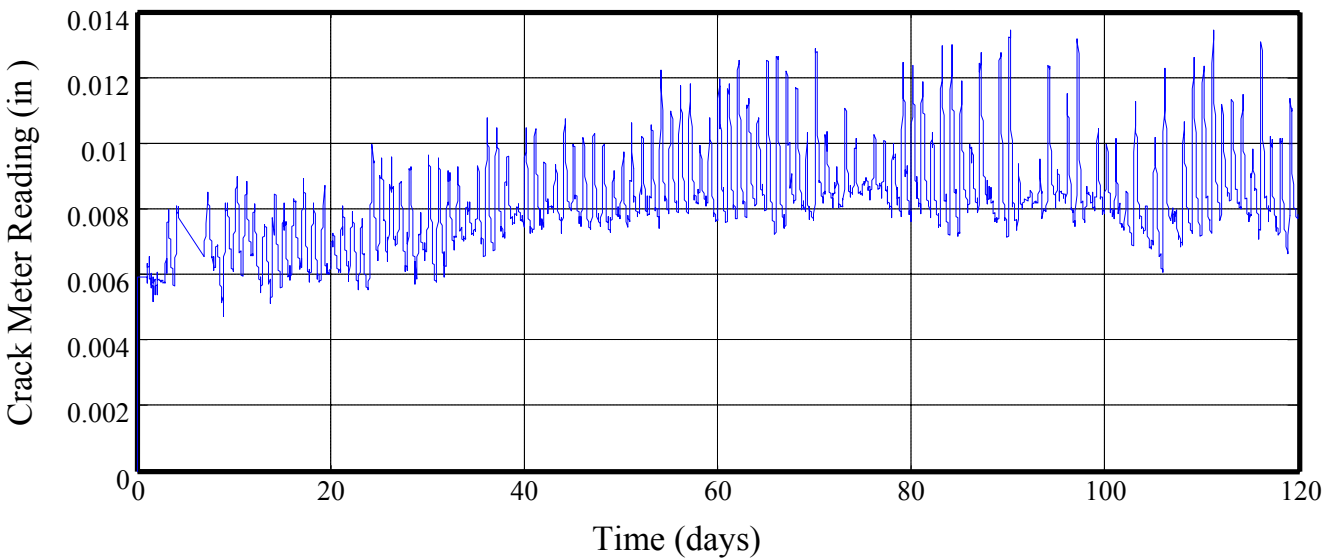

Figure 4.7.13a: Displacement Reading, Crack Meter 13

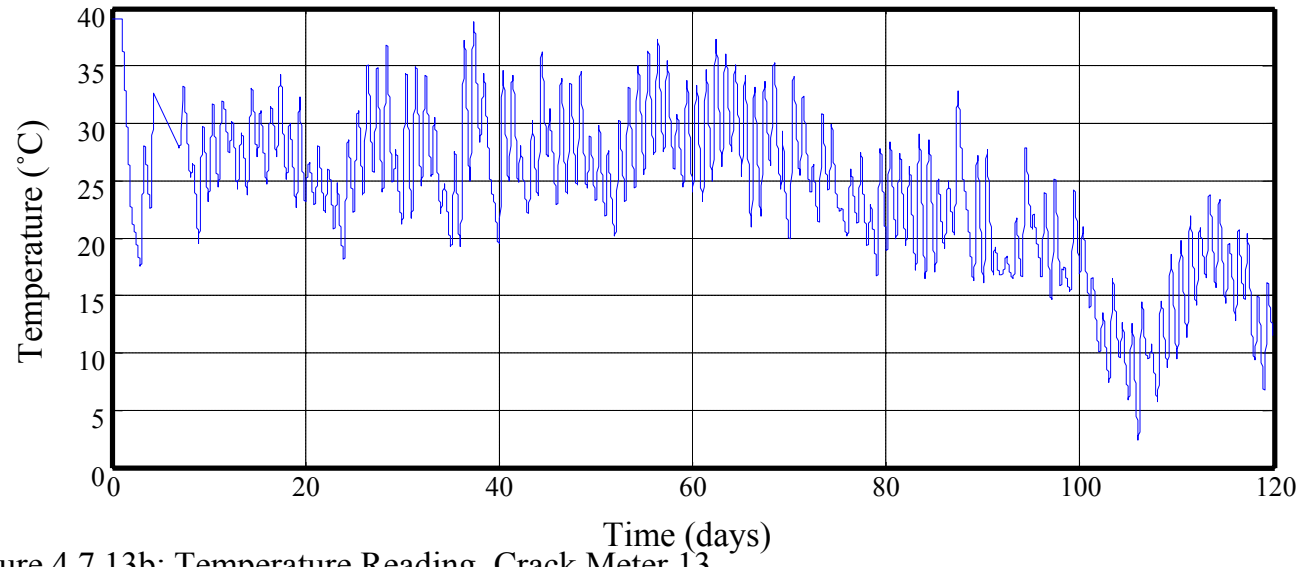

Figure 4.7.13b: Temperature Reading, Crack Meter 13 


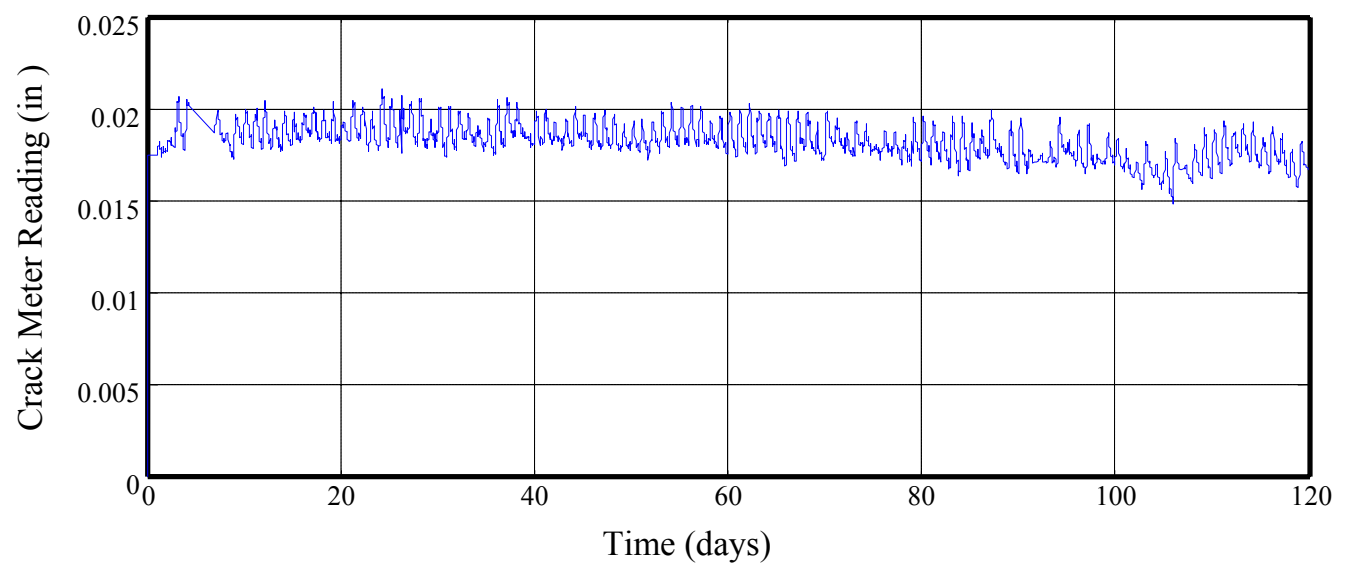

Figure 4.7.14a: Displacement Reading, Crack Meter 14

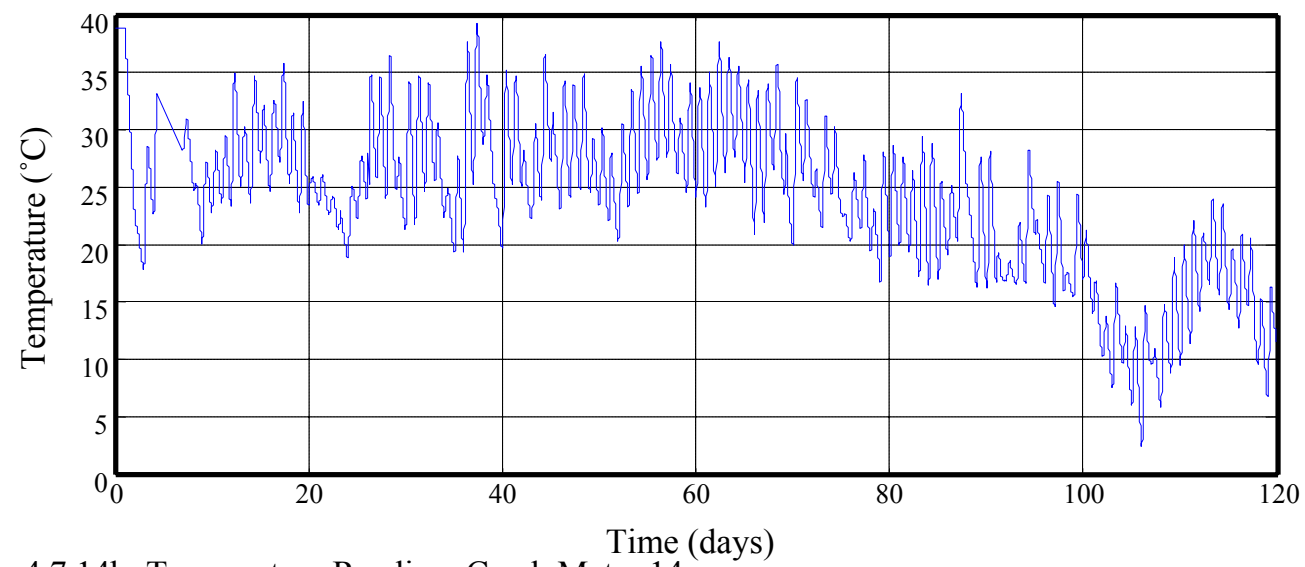

Figure 4.7.14b: Temperature Reading, Crack Meter 14

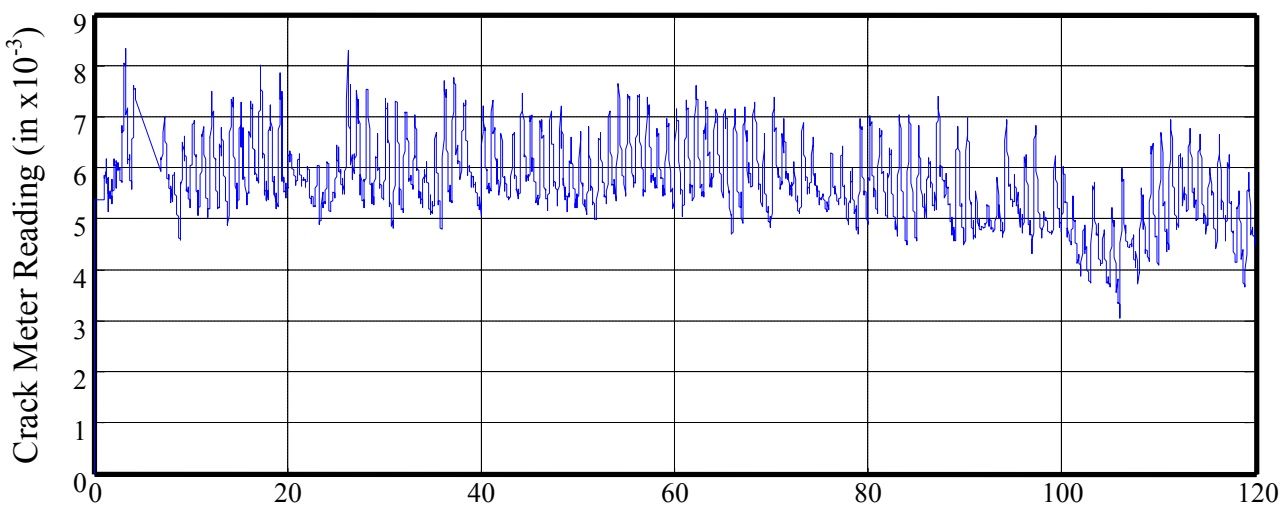

Time (days)

Figure 4.7.15a: Displacement Reading, Crack Meter 15

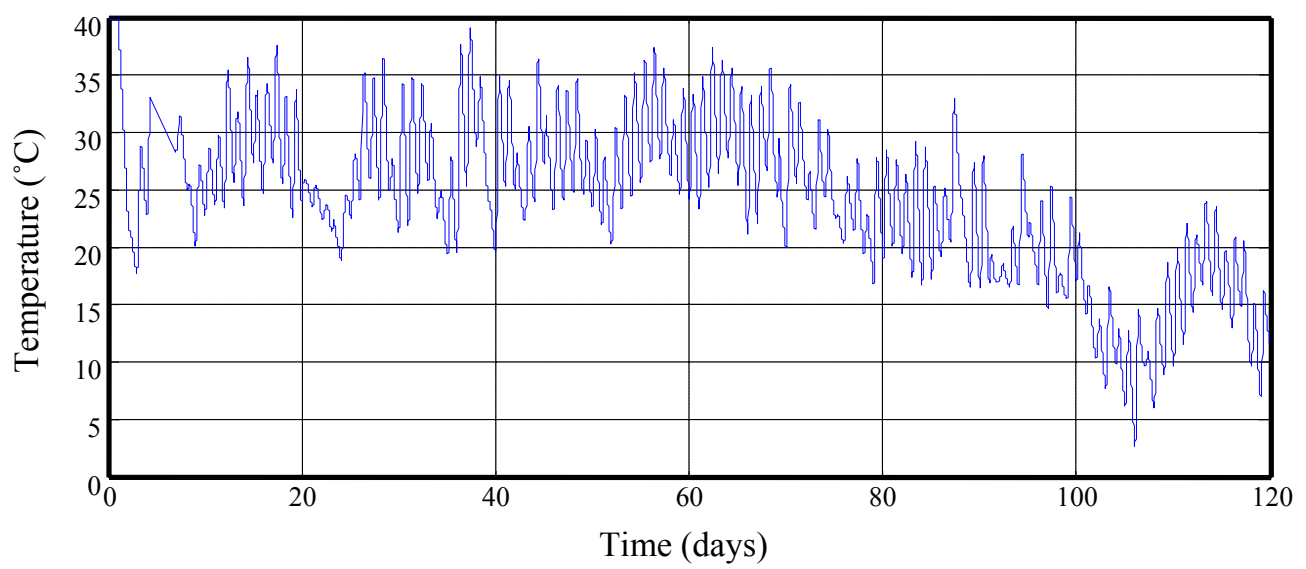

Figure 4.7.15b: Temperature Reading, Crack Meter 15 


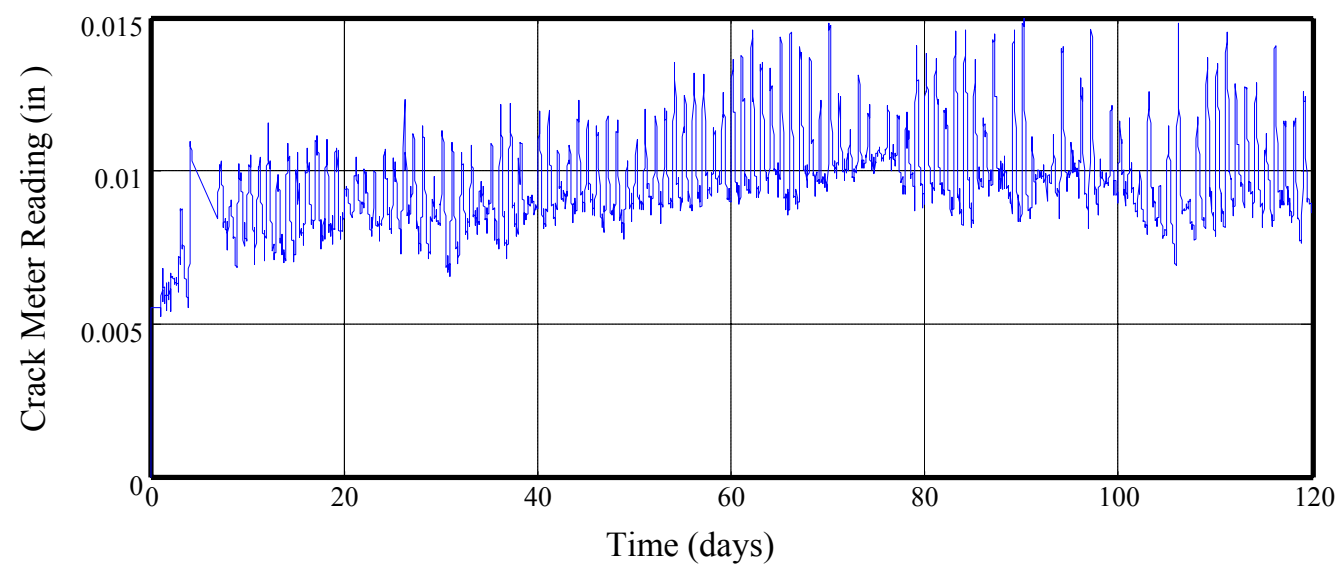

Figure 4.7.16a: Displacement Reading, Crack Meter 16

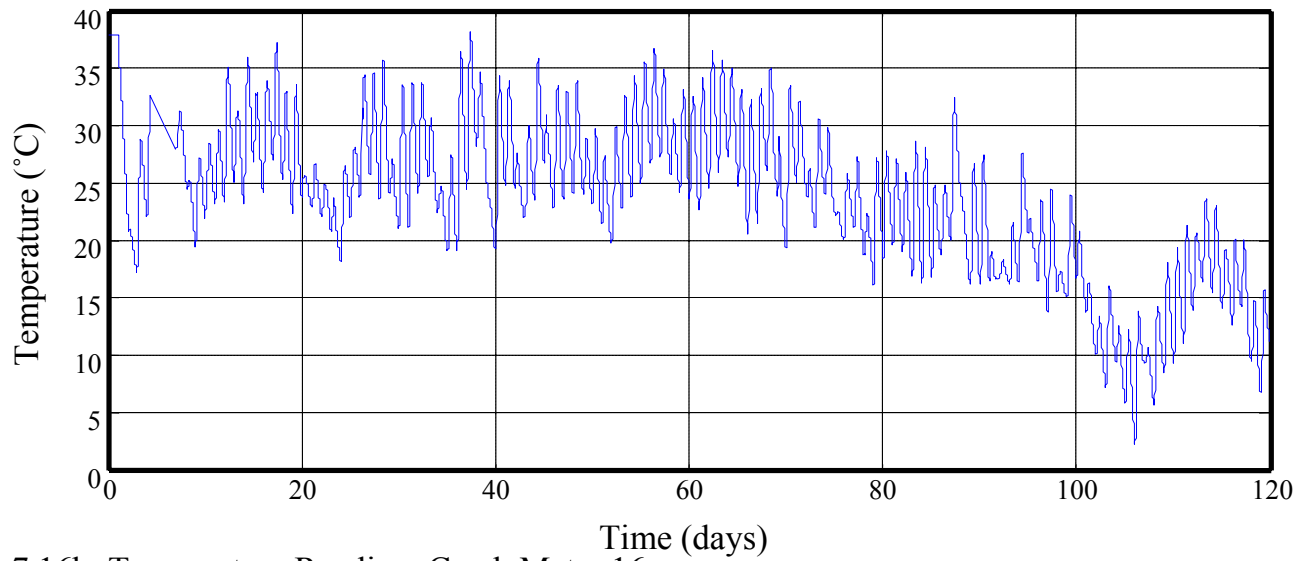

Figure 4.7.16b: Temperature Reading, Crack Meter 16

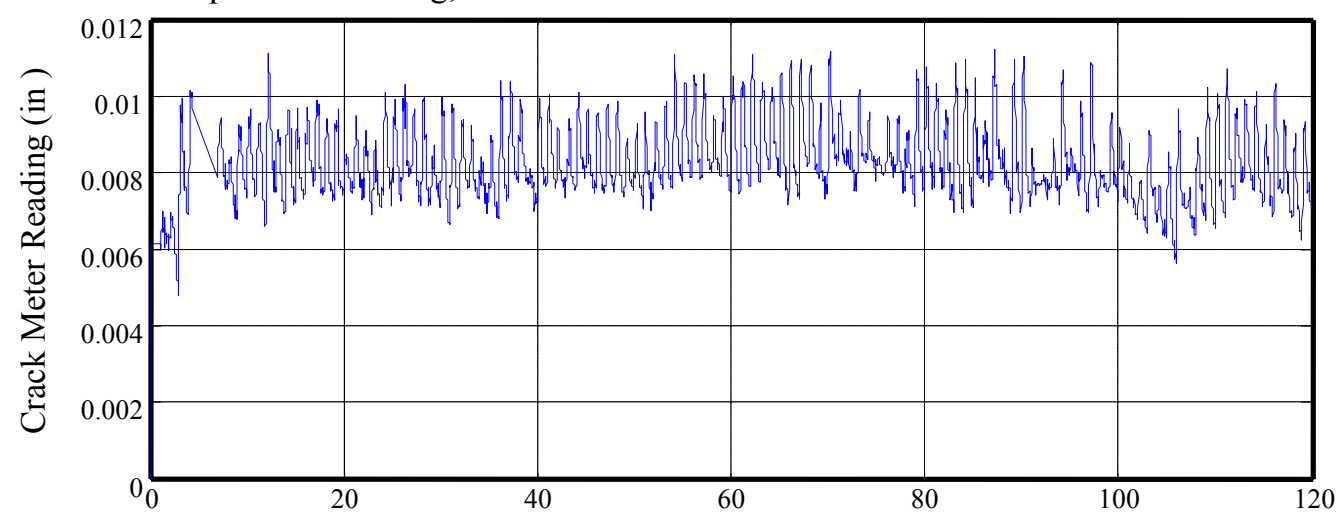

Time (days)

Figure 4.7.17a: Displacement Reading, Crack Meter 17

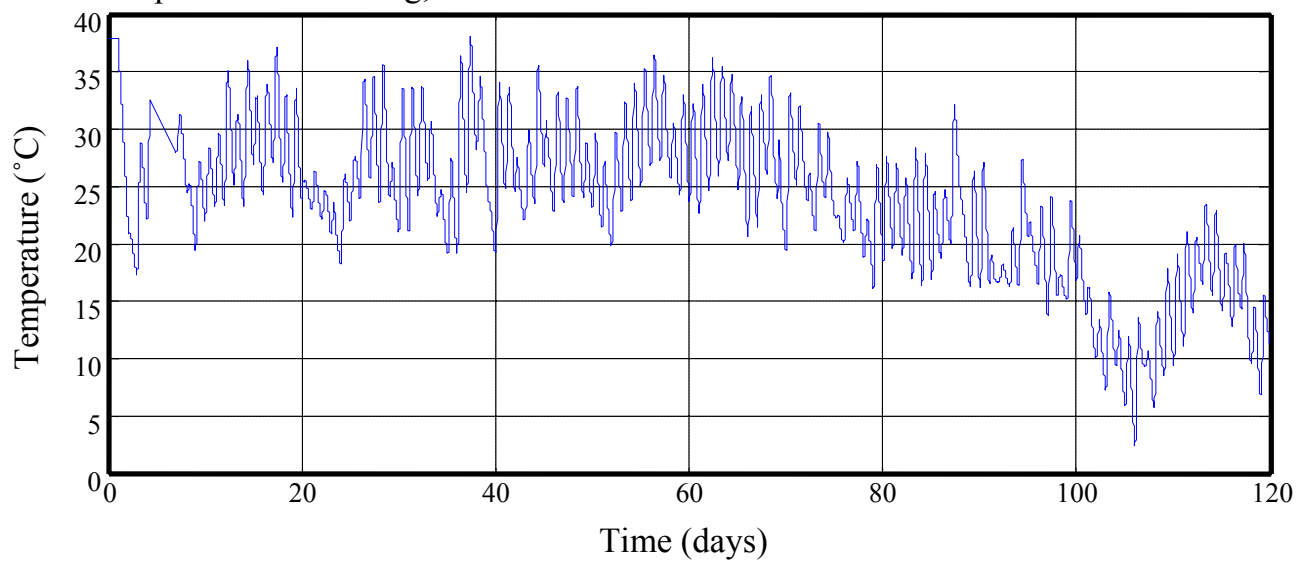

Figure 4.7.17b: Temperature Reading, Crack Meter 17 


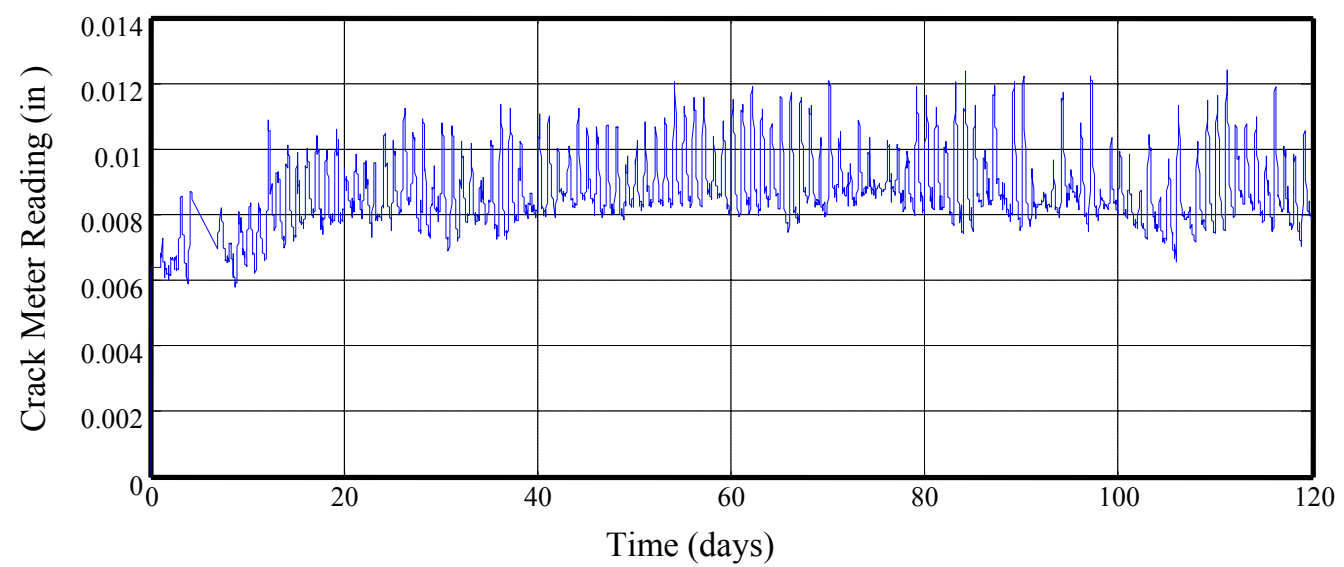

Figure 4.7.18a: Displacement Reading, Crack Meter 18

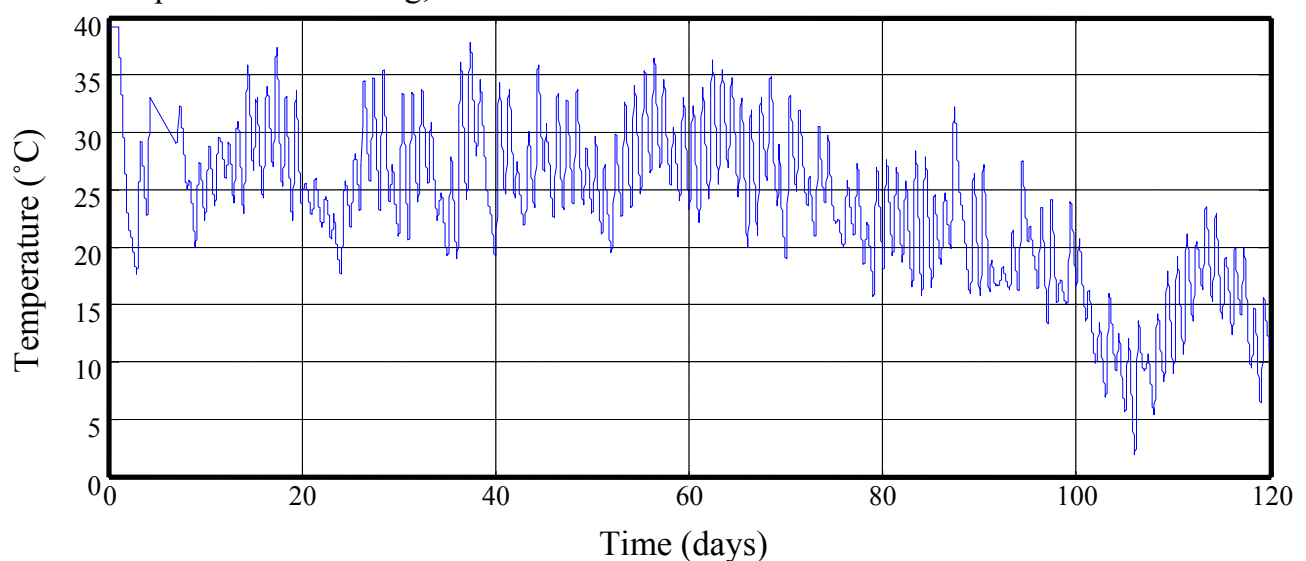

Figure 4.7.18b: Temperature Reading, Crack Meter 18

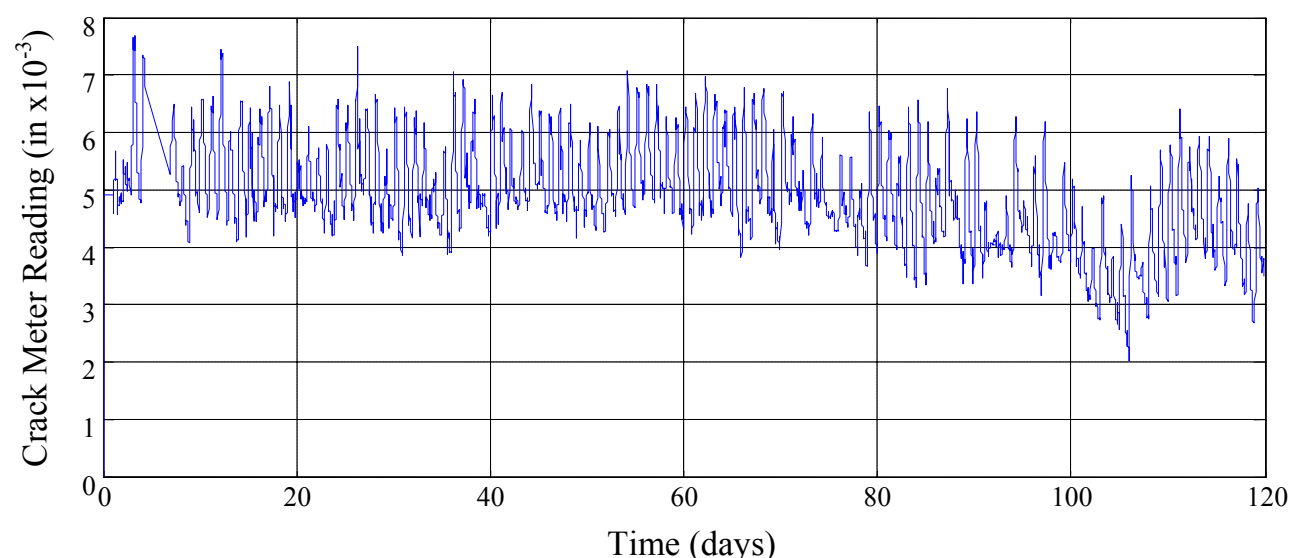

Figure 4.7.19a: Displacement Reading, Crack Meter 19

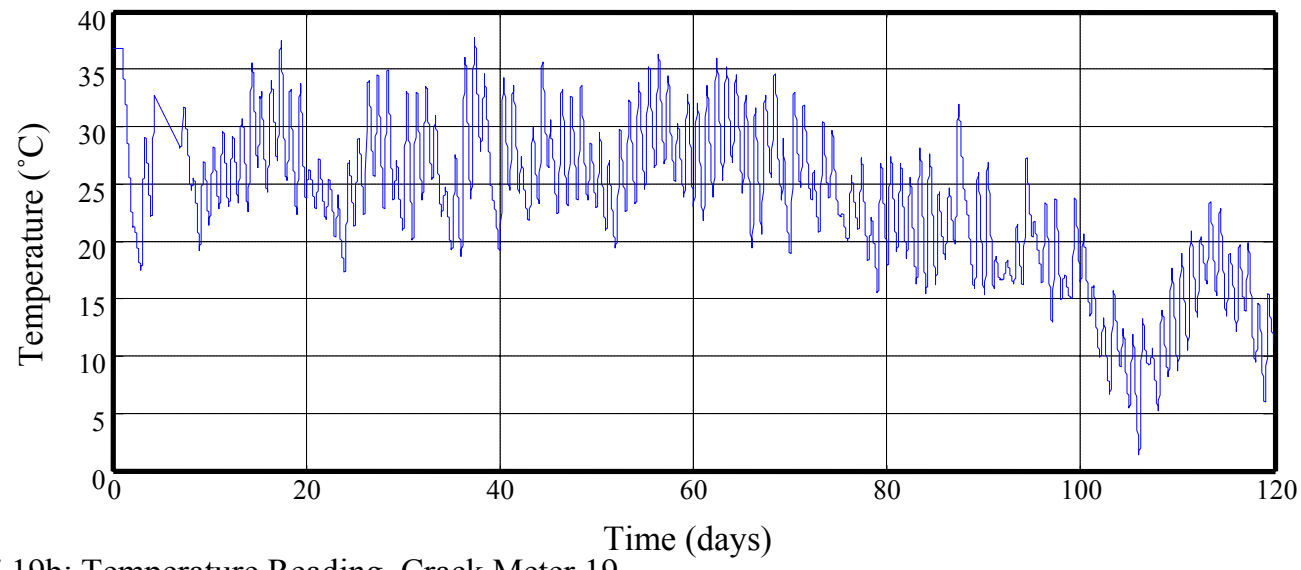

Figure 4.7.19b: Temperature Reading, Crack Meter 19 


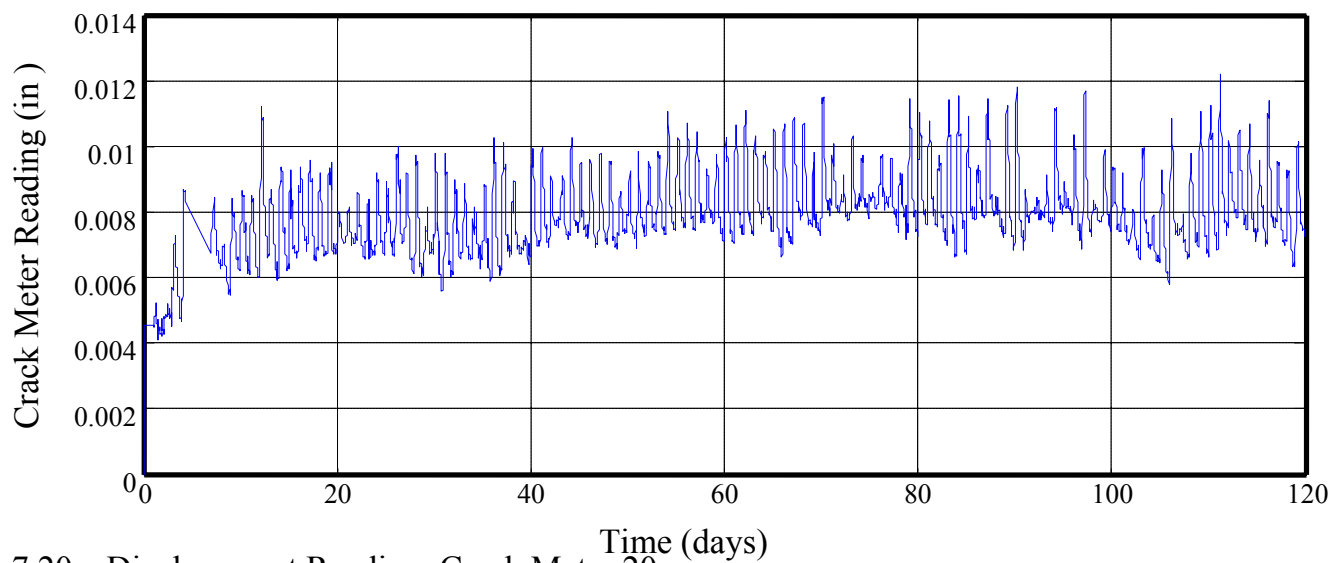

Figure 4.7.20a: Displacement Reading, Crack Meter 20

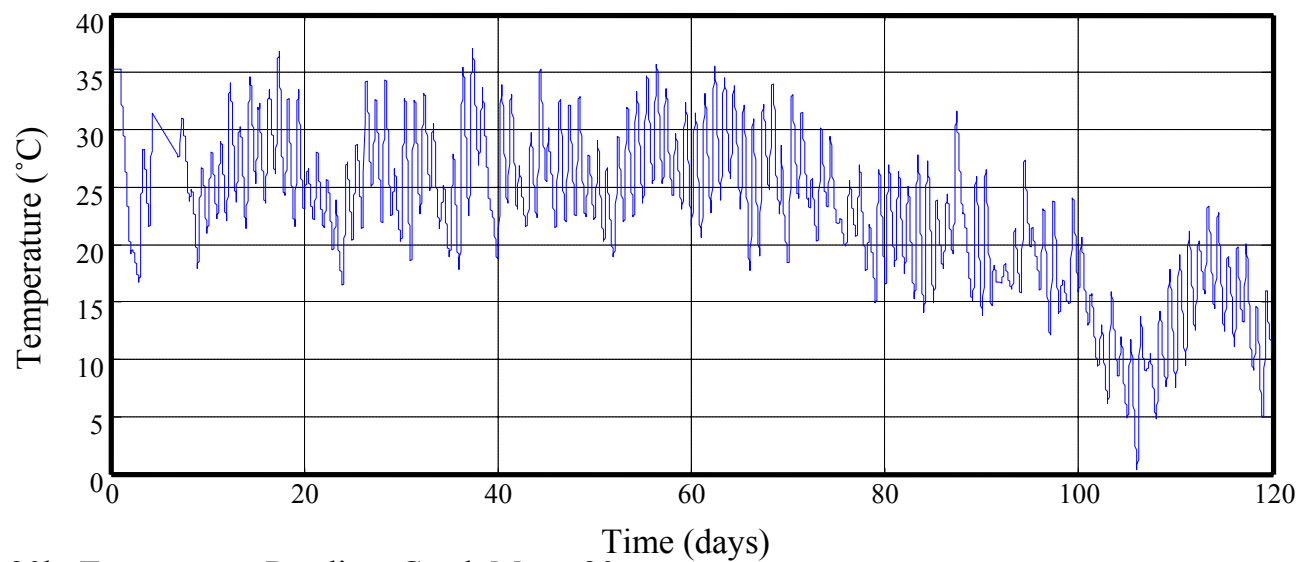

Figure 4.7.20b: Temperature Reading, Crack Meter 20

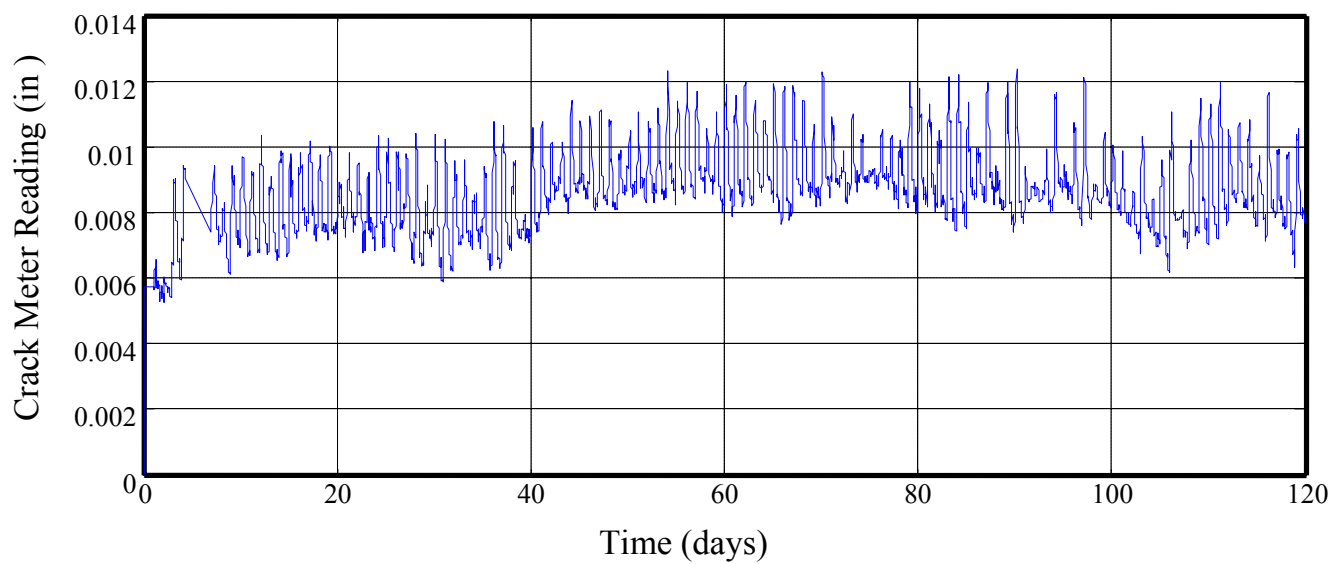

Figure 4.7.21a: Displacement Reading, Crack Meter 21

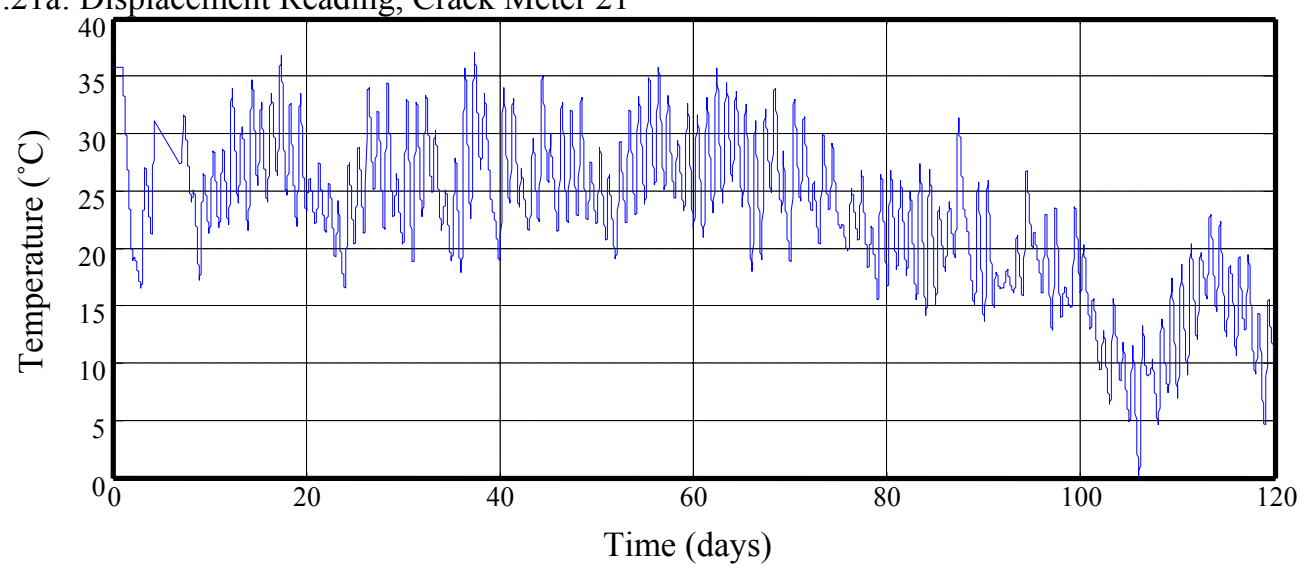

Figure 4.7.21b: Temperature Reading, Crack Meter 21 


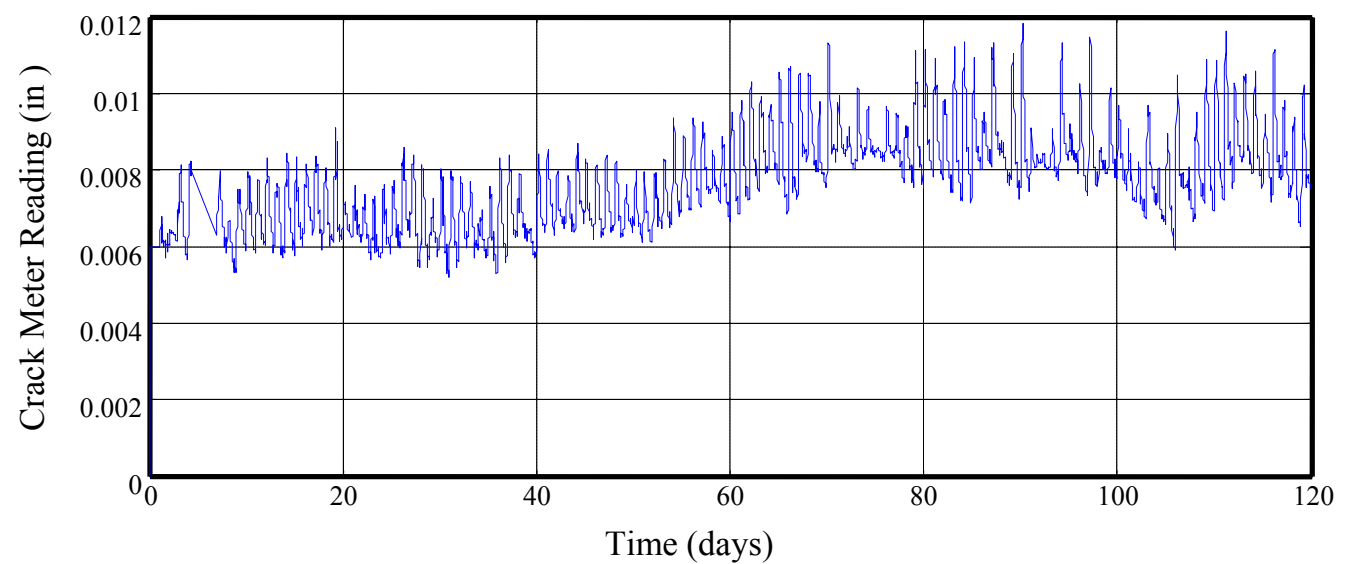

Figure 4.7.22a: Displacement Reading, Crack Meter 22

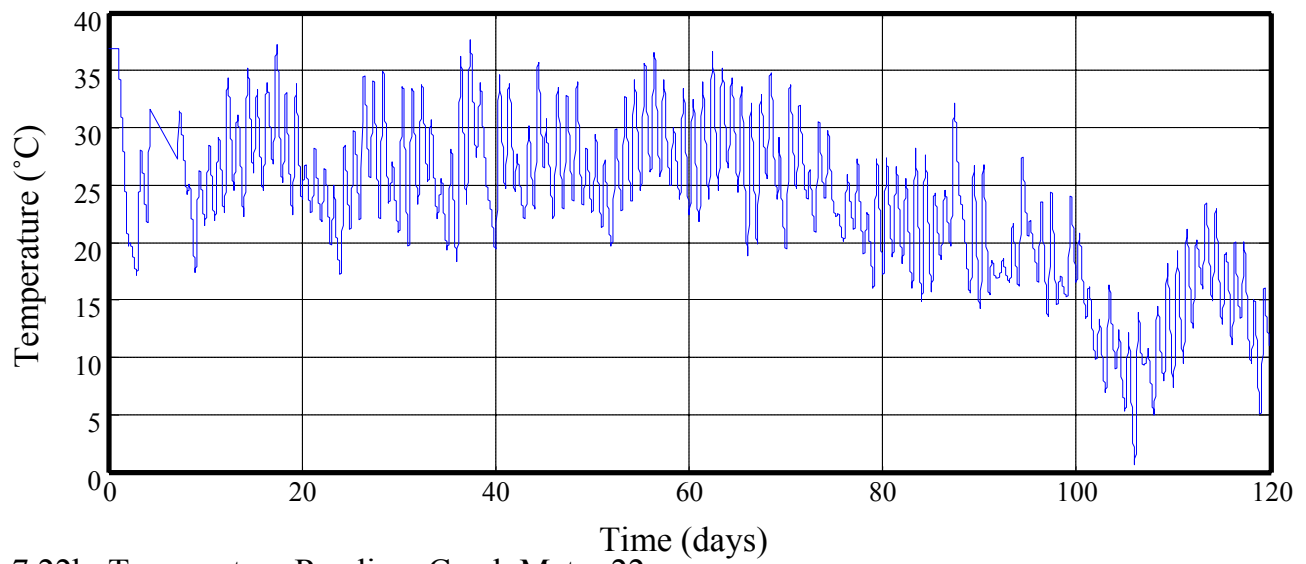

Figure 4.7.22b: Temperature Reading, Crack Meter 22

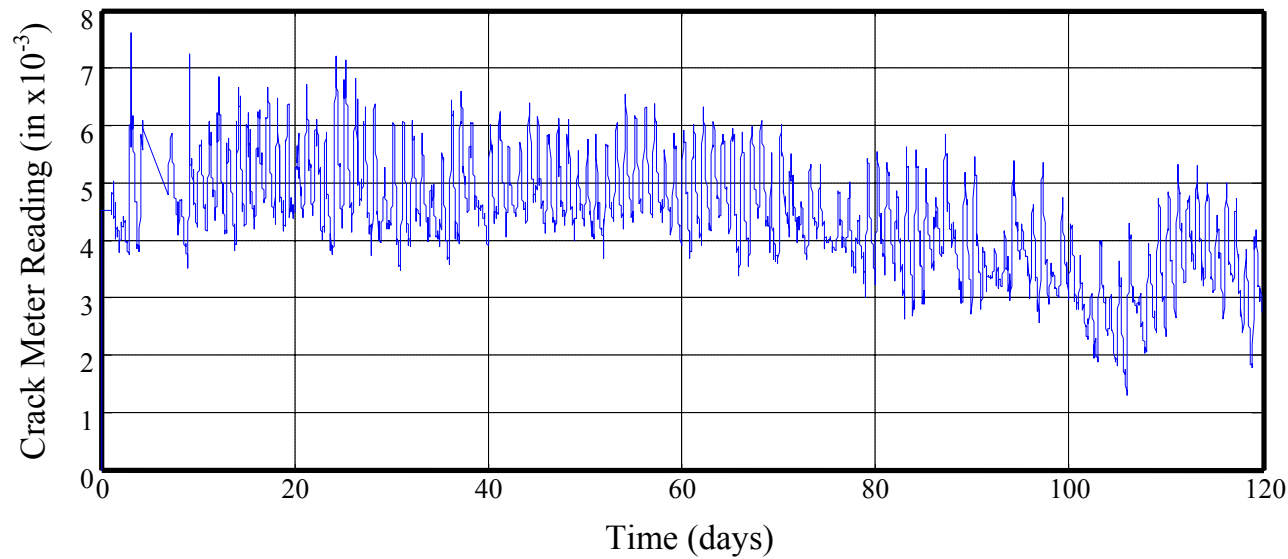

Figure 4.7.23a: Displacement Reading, Crack Meter 23

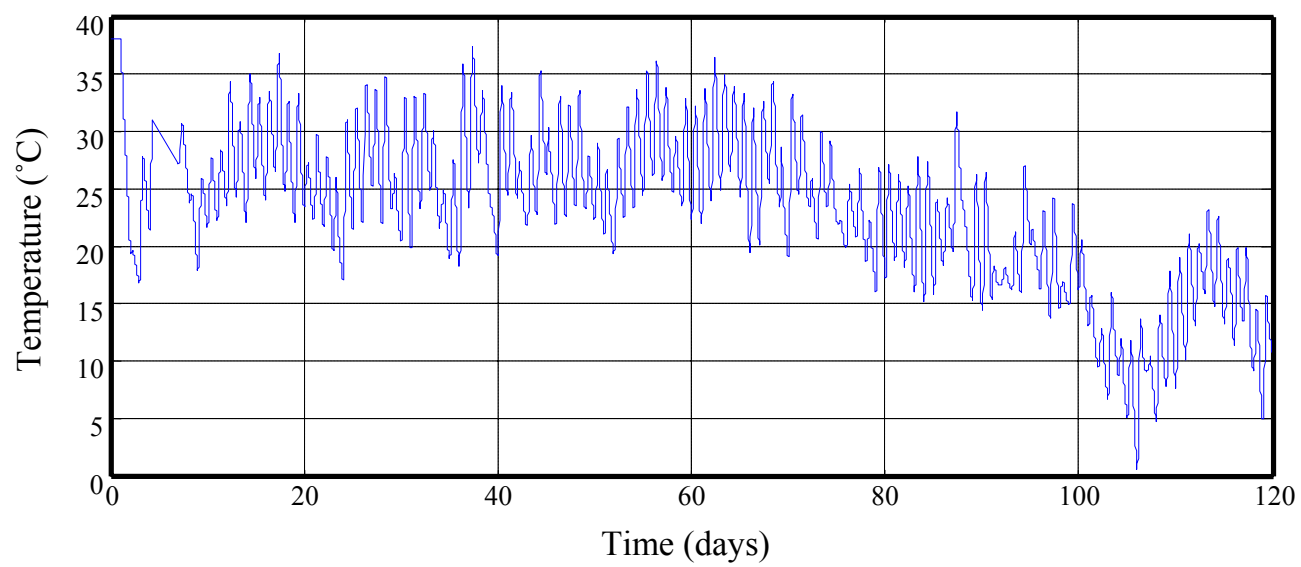

Figure 4.7.23b: Temperature Reading, Crack Meter 23 


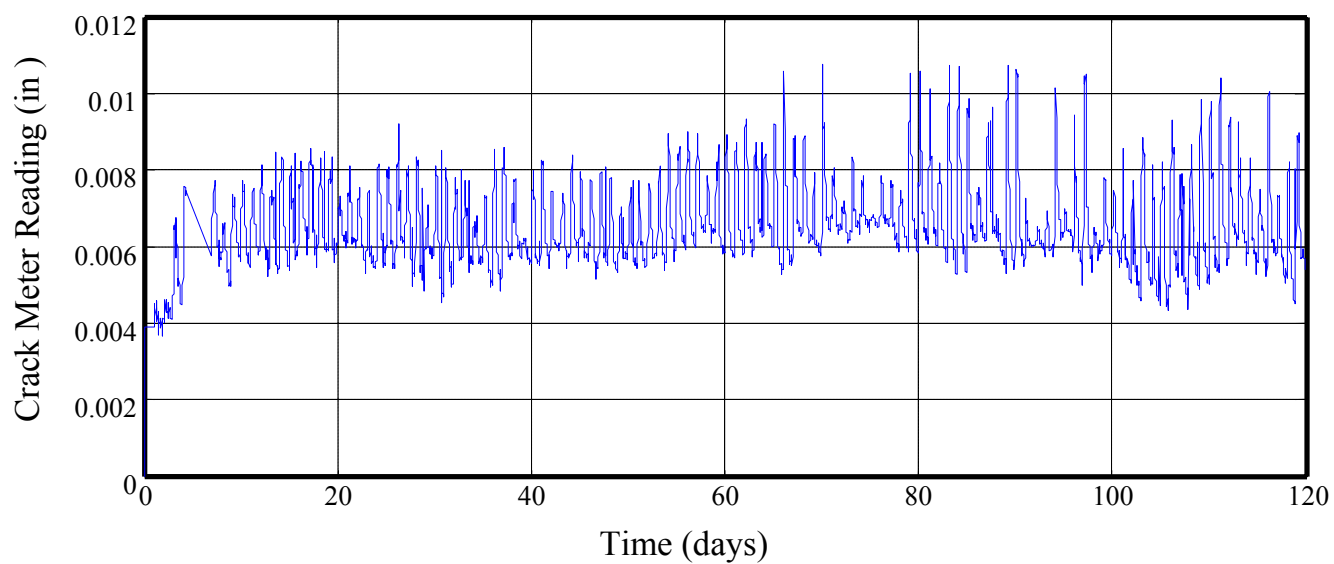

Figure 4.7.24a: Displacement Reading, Crack Meter 24

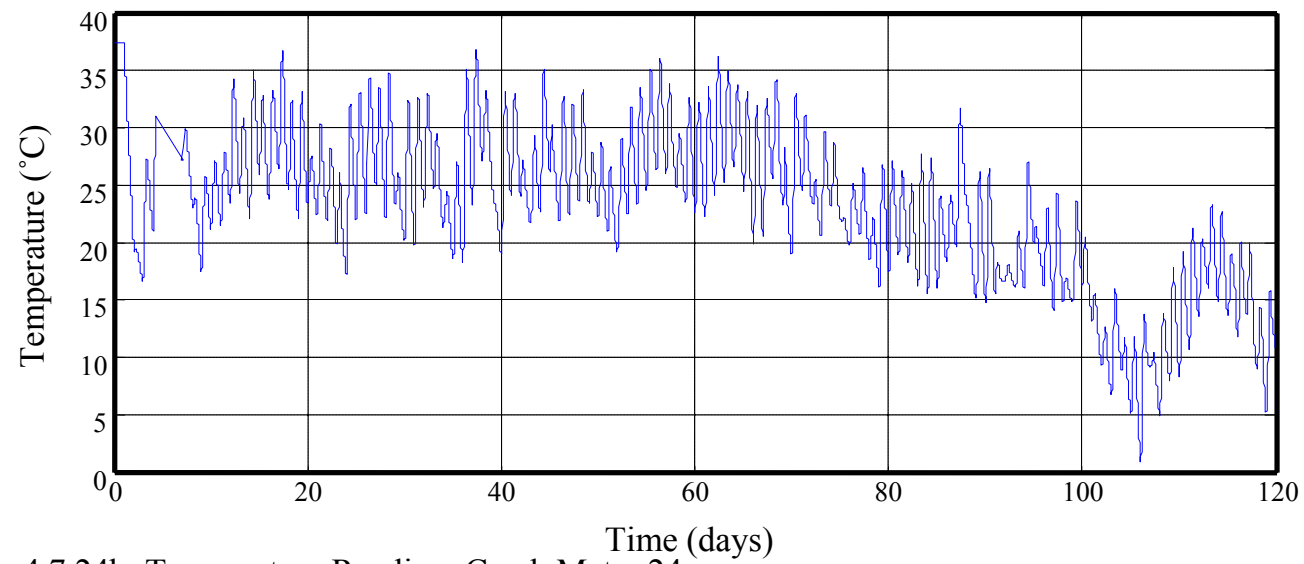

Figure 4.7.24b: Temperature Reading, Crack Meter 24

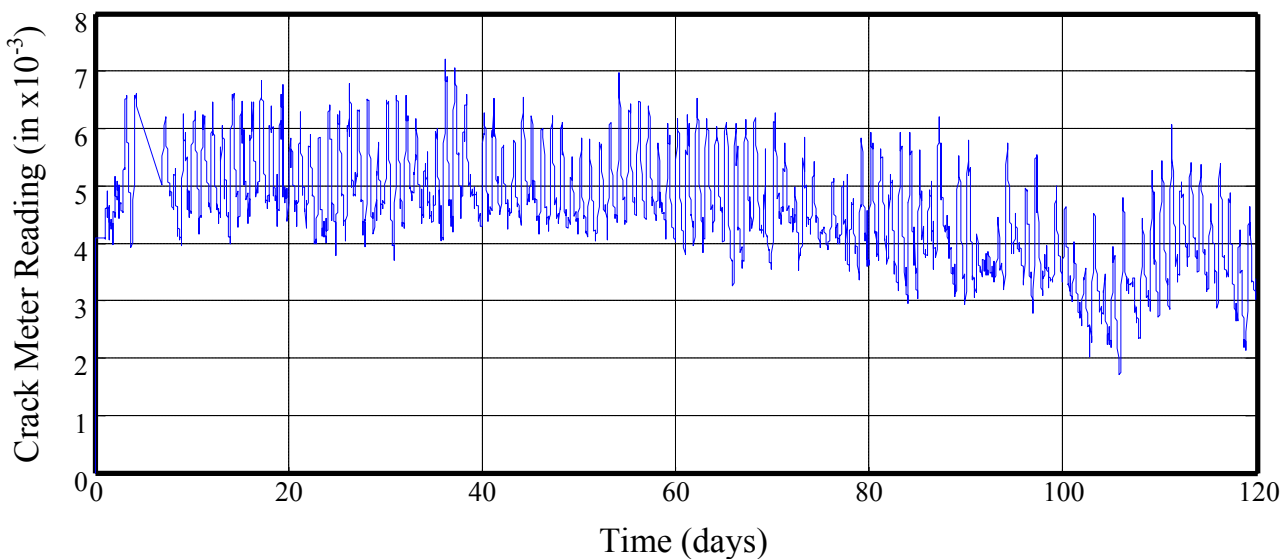

Figure 4.7.25a: Displacement Reading, Crack Meter 25

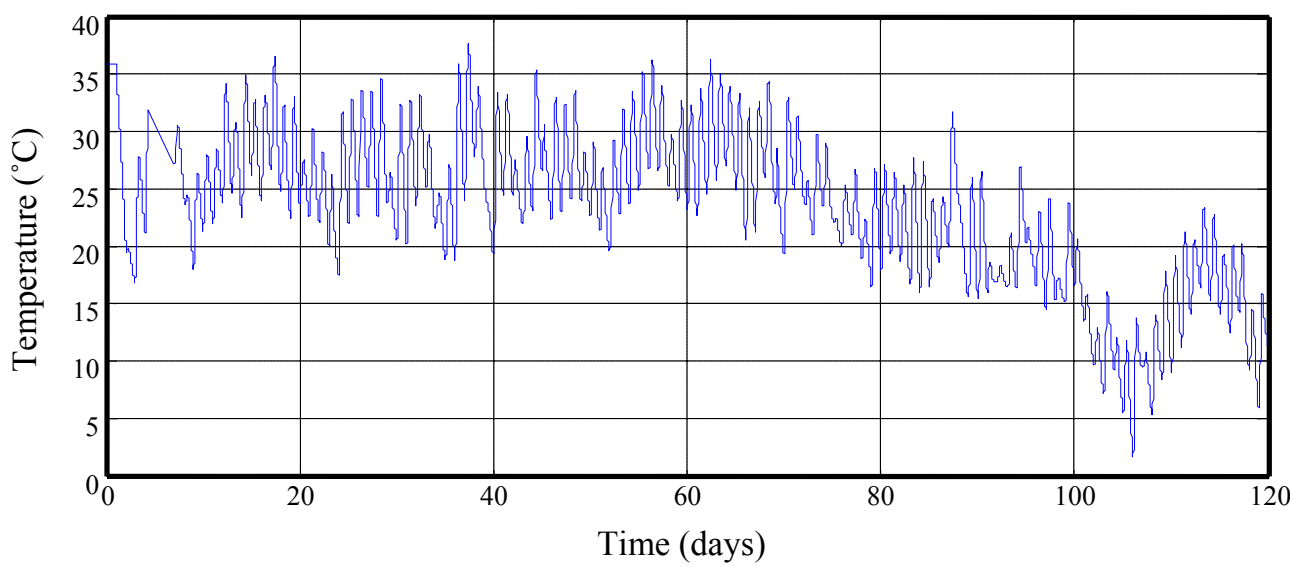

Figure 4.7.25b: Temperature Reading, Crack Meter 25 


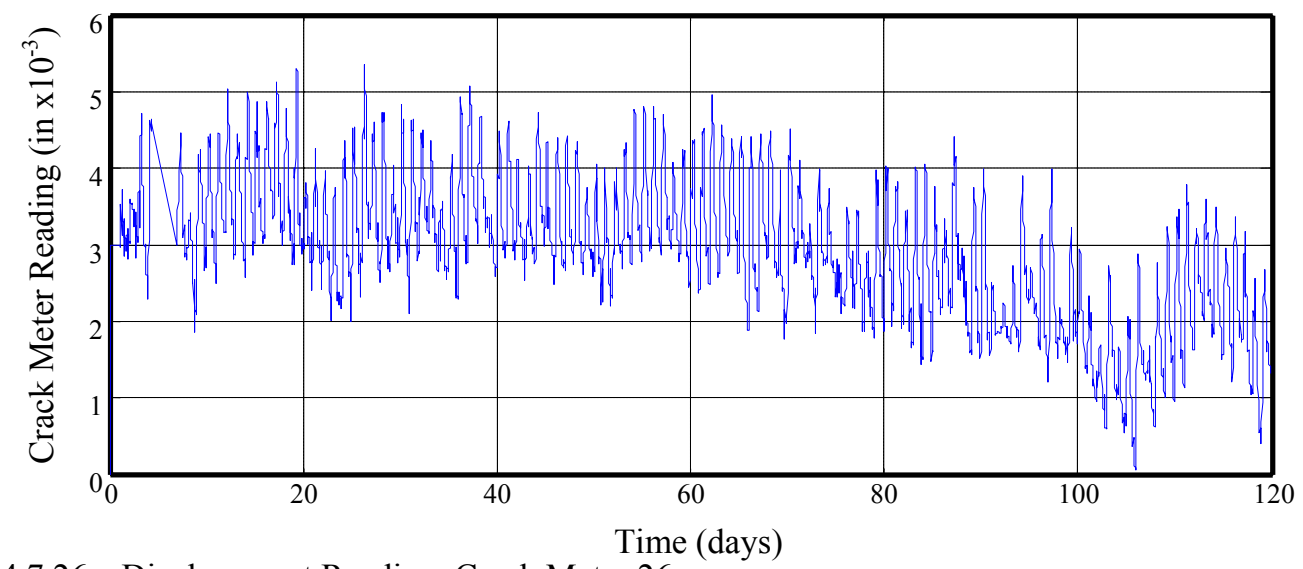

Figure 4.7.26a: Displacement Reading, Crack Meter 26

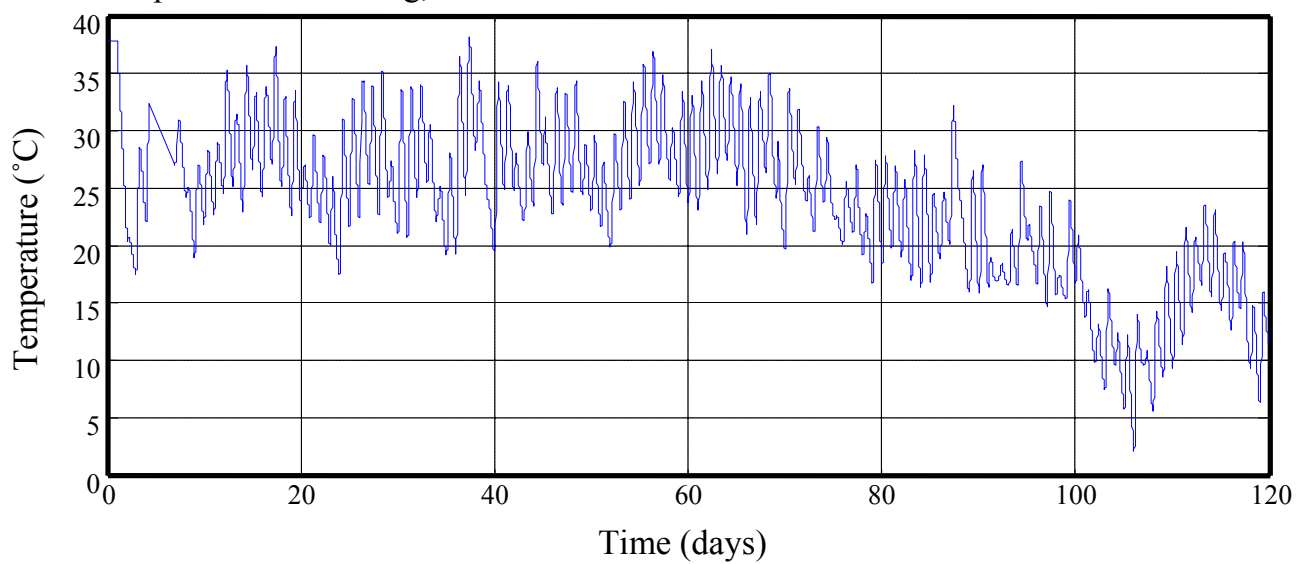

Figure 4.7.26b: Temperature Reading, Crack Meter 26

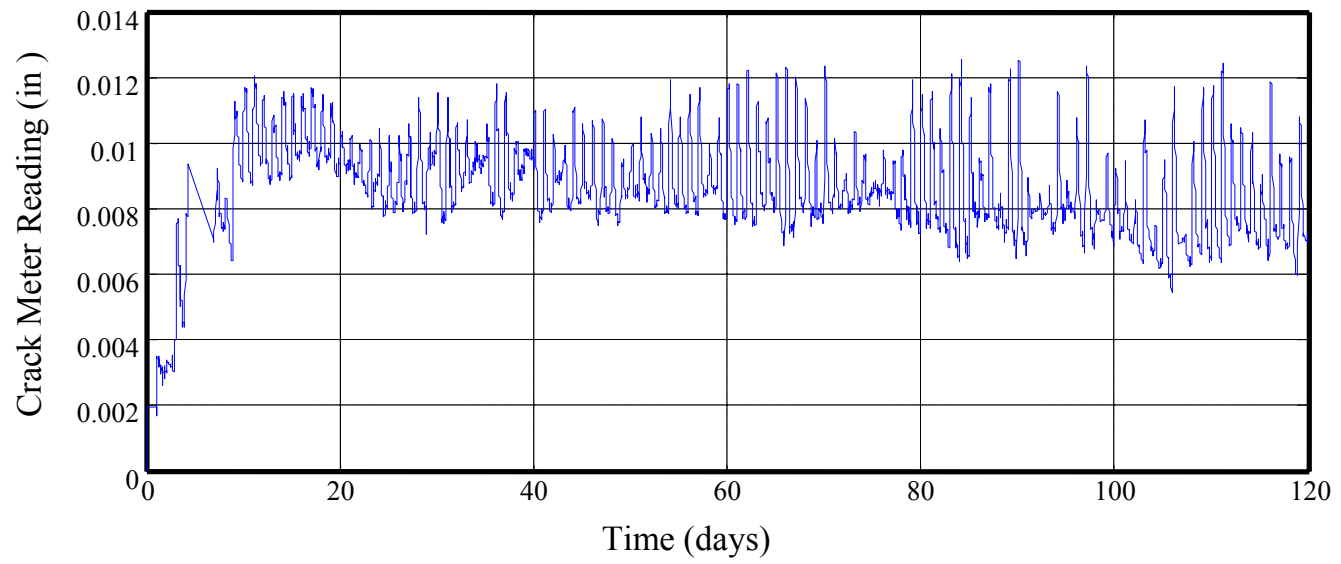

Figure4.7.27a: Displacement Reading, Crack Meter 27

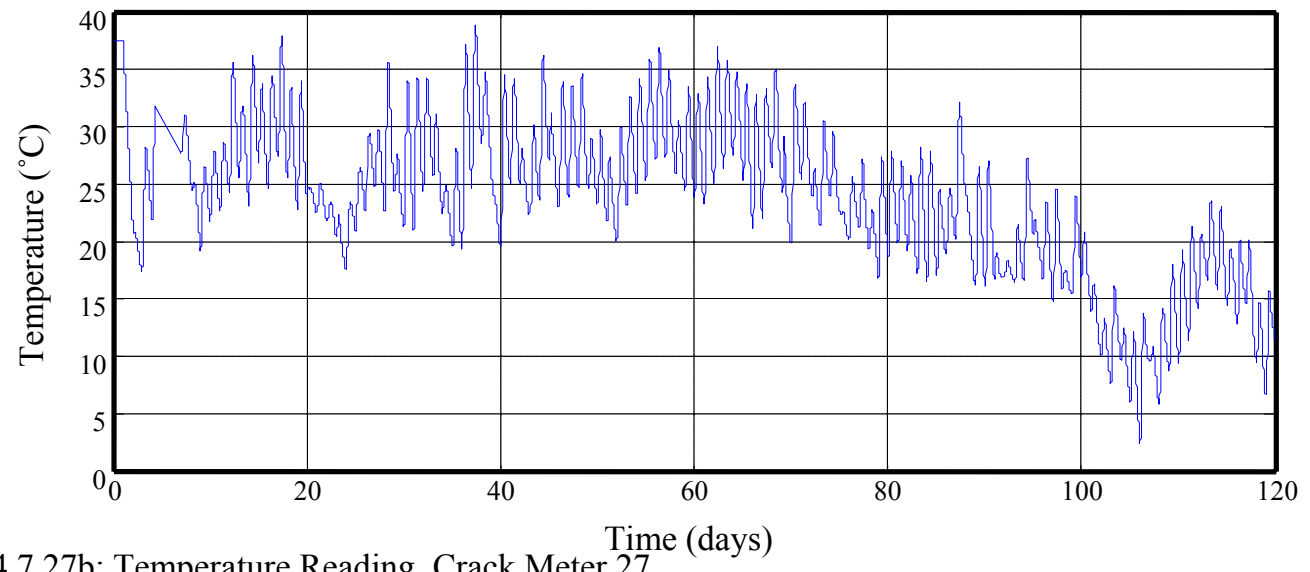

Figure 4.7.27b: Temperature Reading, Crack Meter 27 


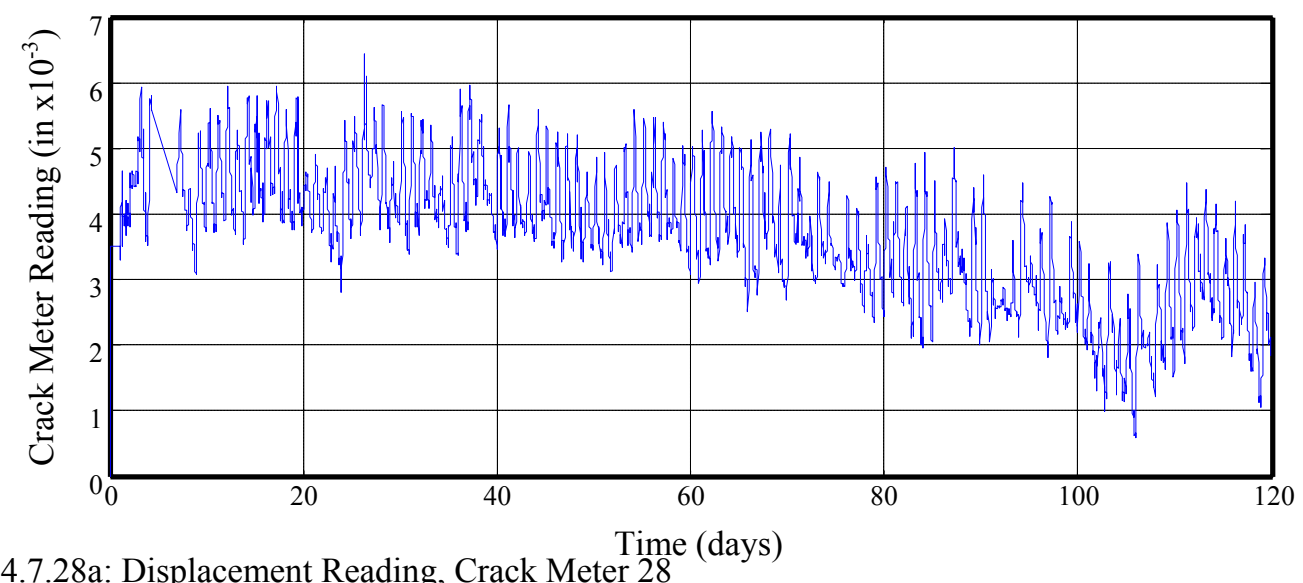

Figure 4.7.28a: Displacement Reading, Crack Meter 28

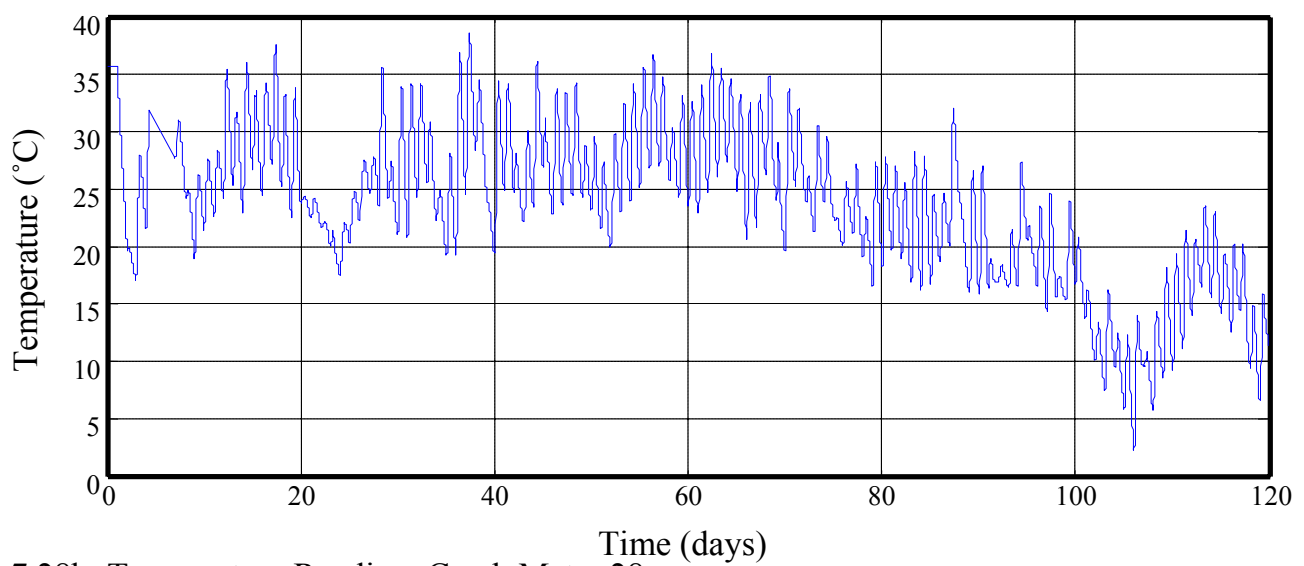

Figure 4.7.28b: Temperature Reading, Crack Meter 28

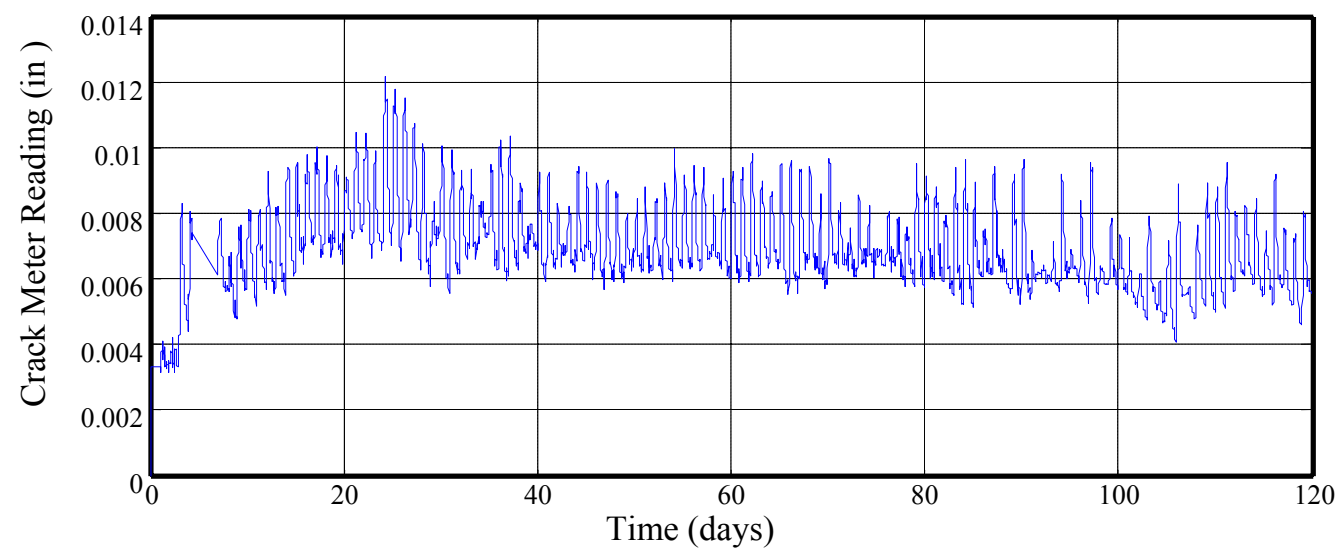

Figure 4.7.29a: Displacement Reading, Crack Meter 29

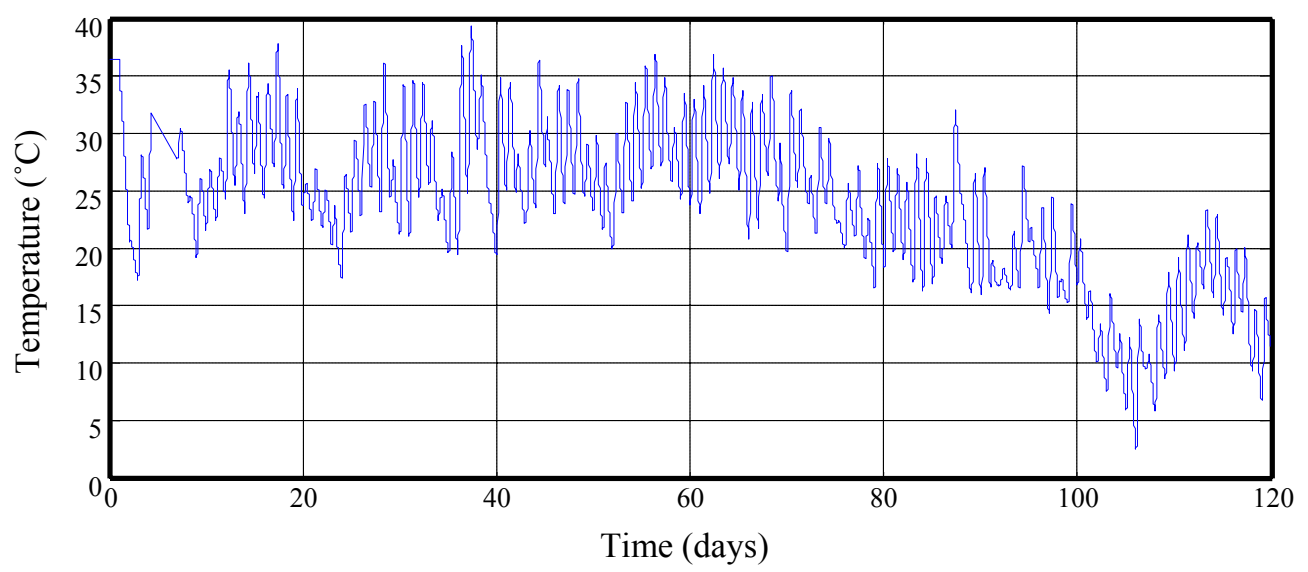

Figure 4.7.29b: Temperature Reading, Crack Meter 29 


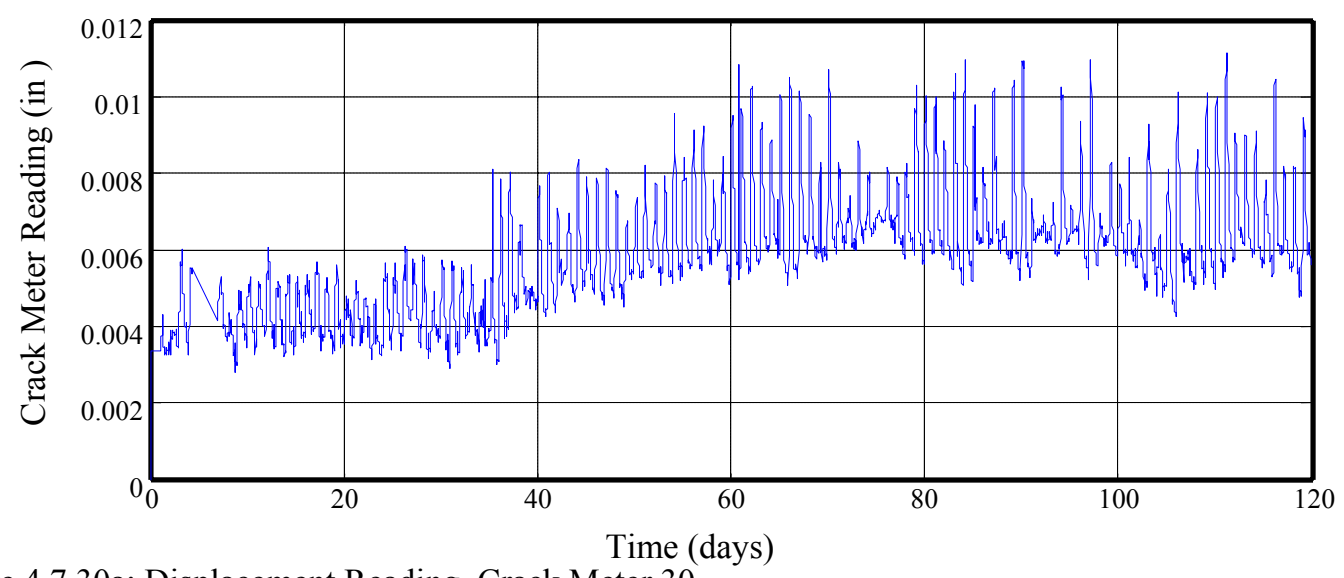

Figure 4.7.30a: Displacement Reading, Crack Meter 30

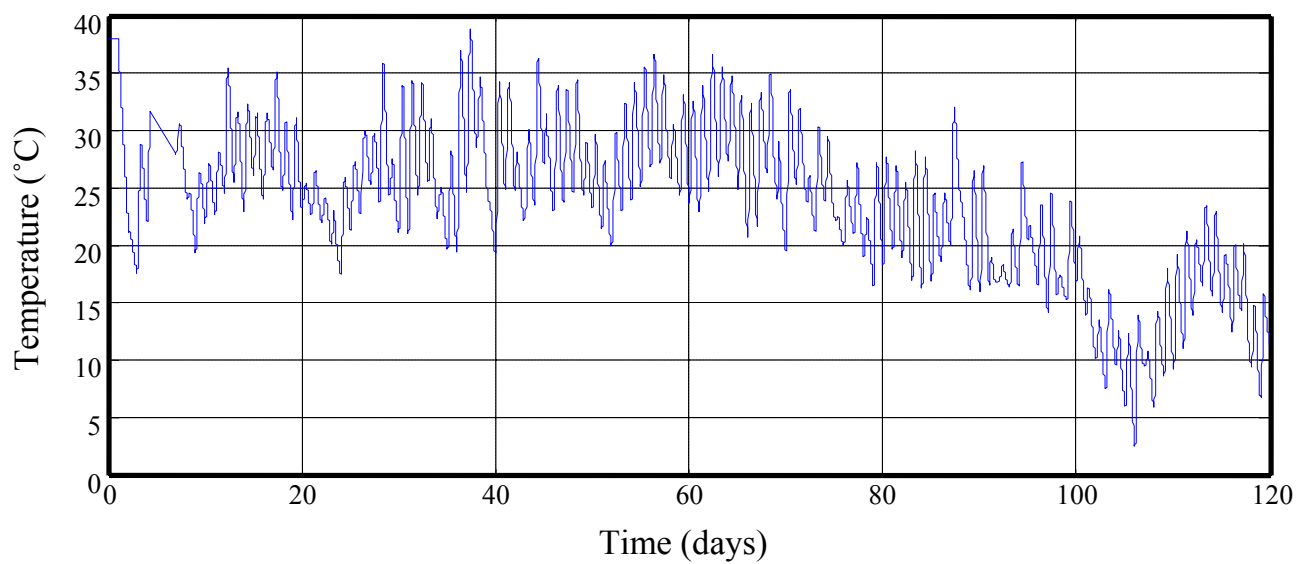

Figure 4.7.30b: Temperature Reading, Crack Meter 30

Figures 4.7.1-4.7.30a, b: Time-History Plots of Crack Meter Reading and Temperature

The results of the visual analysis of the plots presented above are presented in table 4.1, and figure 4.8. 
Table 4.1: Crack Detection Results

\begin{tabular}{|c|c|}
\hline $\begin{array}{c}\text { Crack Meter } \\
\text { Number }\end{array}$ & Condition \\
\hline 1 & Joint \\
\hline 2 & Joint \\
\hline 3 & Joint \\
\hline 4 & Joint \\
\hline 5 & Cracked \\
\hline 6 & Uncracked \\
\hline 7 & Bad Sensor \\
\hline 8 & Cracked \\
\hline 9 & Uncracked \\
\hline 10 & Uncracked \\
\hline 11 & Cracked \\
\hline 12 & Uncracked \\
\hline 13 & Cracked \\
\hline 14 & Uncracked \\
\hline 15 & Uncracked \\
\hline 16 & Cracked \\
\hline 17 & Cracked \\
\hline 18 & Cracked \\
\hline 19 & Uncracked \\
\hline 20 & Cracked \\
\hline 21 & Cracked \\
\hline 22 & Cracked \\
\hline 23 & Uncracked \\
\hline 24 & Cracked \\
\hline 25 & Uncracked \\
\hline 26 & Uncracked \\
\hline 27 & Cracked \\
\hline 28 & Uncracked \\
\hline 29 & Uncracked \\
\hline 30 & Cracked \\
\hline & \\
\hline
\end{tabular}




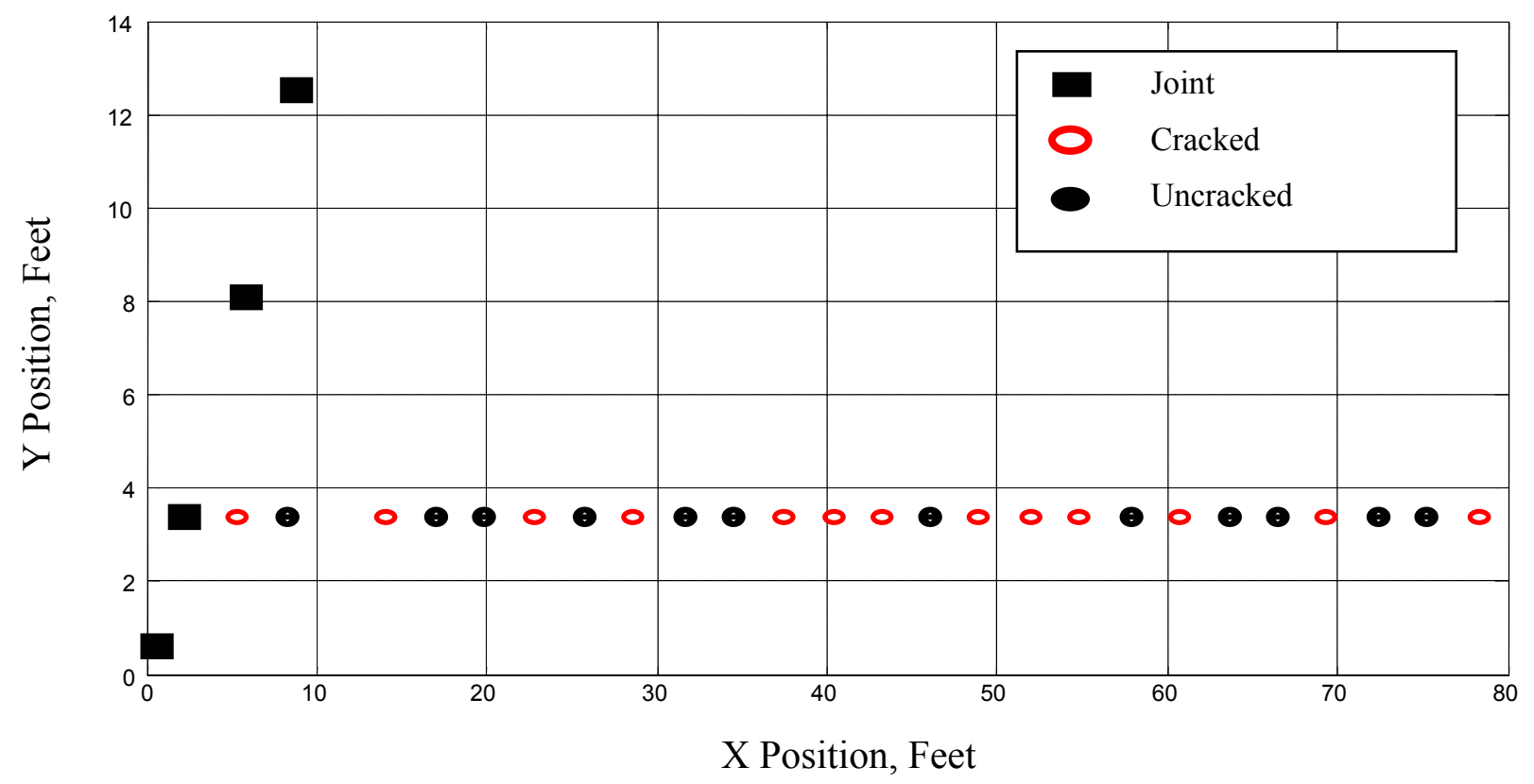

Figure 4.8: Map of Bridge Deck Showing Sensor Locations and Cracks Detected

\subsubsection{POST-CRACKING BEHAVIOR}

The original intent east $\mathrm{p}$ use the crack meters to detect the onset of cracking, and afterwards to monitor the growth of cracks. This was not possible, due to the constraints placed upon the concrete by the stay-in-place forms, the shear studs, and the longitudinal reinforcement. The crack meter reading begins to follow a similar trend to temperature some time after cracking occurs, which indicates that the reading is then following the behavior of the steel components of the structure instead of the concrete deck.

\subsection{CONCLUSIONS}

Extensive cracking has occurred at Evansville Bridge, beginning at early age. The stresses due to drying shrinkage and temperature variation are much higher than those induced by traffic loads, because of the over-constrained condition of the deck. Current design does not account for this, and because of this, cracking at early age occurs. 


\section{CHAPTER 5}

\section{COMPOSITE ACTION OF STEEL GIRDERS AND CONCRETE DECK}

\subsection{INTRODUCTION}

Composite action plays a vital role in the performance of steel girder bridges. Composite action means that the steel girders and the concrete deck are connected together in such a manner that they act as a single, cohesive unit. This allows for enhanced strength of the bridge structure, because the deck contributes to the bending stiffness of the bridge, instead of merely causing added stress in the girders because of its weight as it would if composite action were not present; a deck section that employs composite action can be designed with a lighter and shallower girder than a noncomposite section (Spiegel and Limbrunner, 1980). Additionally, concrete is strong in compression, whereas still girders are susceptible to buckling due to compressive loading. Concrete is relatively weak in tension, whereas the steel girders are strong in tension. Composite action is a means of compensating for the relative weaknesses of one component of the bridge by taking advantage of the relative strengths of the other component.

The chemical bond between concrete and steel is not adequate to tie the concrete and steel together for composite action, therefore a mechanical connector is required. Shear studs are added to the top surface of the upper flange of the steel girders to connect the concrete deck and the girders, as shown in figure 5.1; it is assumed that the shear studs effectively tie the deck to the girders, so that they act as a composite unit. The role of the shear studs is to prevent relative motion (slip) between the upper surface of the girder and the lower surface of the deck; the load on the studs is in the form of horizontal shear (Spiegel and Limbrunner, 1980). In this chapter, the presence of or lack of composite action in Evansville Bridge will be evaluated. 


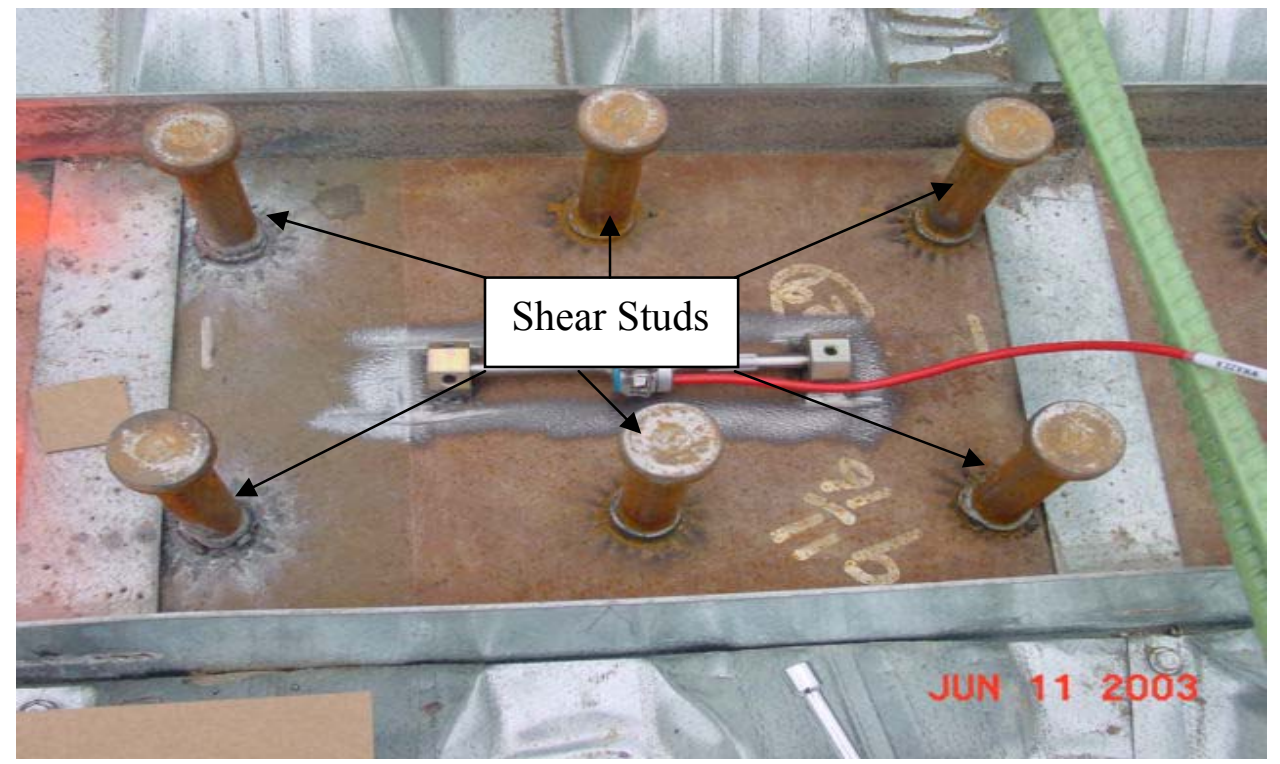

Figure 5.1: Shear Studs Attached to a Steel Girder of Evansville Bridge. (photo courtesy of Dr. Shoukry, WVU)

\subsection{EVALUATION OF COMPOSITE ACTION IN EVANSVILLE BRIDGE}

In order to evaluate the state of composite action of the bridge, the measured results obtained through the strain gages mounted in the bridge deck and on the surface of the steel girders were compared with theoretically predicted results. The theoretical results were calculated based upon an assumption of complete composite action and an uncracked deck condition. In order to determine the degree of composite behavior of Evansville Bridge's deck and girders, a formula for the theoretically predicted strain in the bridge deck was developed. The standard equation for a beam loaded with bending and axial loads was used as follows:

$$
\varepsilon=\frac{P}{A E}+\frac{M c}{E I}
$$

Where:

$\varepsilon$ is strain,

$\mathrm{P}$ is axial force,

A is the effective area of the composite section,

E is Young's modulus, 
$\mathrm{M}$ is Moment,

$\mathrm{c}$ is the distance of the point of interest from the neutral axis, and

I is the effective moment of inertia of the composite section

If Equation 5.1 is applied at the top and the bottom of the girders, it is possible to solve the resulting system of equations for the axial force, $\mathrm{P}$ and the moment, $\mathrm{M}$. The resulting rearranged equations are as follows:

$$
\begin{array}{ll}
P=\left[\varepsilon_{t}-\frac{M c_{t}}{I_{t} E_{s}}\right] A_{t} E_{s} & 5.2 \\
M=\frac{\left(\varepsilon_{b}-\varepsilon_{t}\right) I_{t} E_{s}}{c_{t}-c_{b}} & 5.3
\end{array}
$$

Where:

$\varepsilon_{\mathrm{b}}$ and $\varepsilon_{\mathrm{t}}$ are the measured strains at the bottom and the top flanges of the girders, respectively,

$c_{t}$ and $c_{b}$ are the distances from the neutral axis to the top and bottom flanges of the girder, respectively,

$I_{t}$ is the effective moment of inertia of the composite section,

$\mathrm{E}_{\mathrm{s}}$ is the Young's Modulus of Steel,

$A_{t}$ is the effective area of the composite section,

$\mathrm{P}$ is the axial force, and

$\mathrm{M}$ is the moment.

$I_{t}$ and $A_{t}$ are both effective properties of the composite section, and are calculated according to the composite rule of mixtures, as follows:

$$
X_{t}=X_{A}+\frac{X_{B}}{m}
$$

Where:

$\mathrm{X}_{\mathrm{t}}$ is the total section property, $\mathrm{X}_{\mathrm{A}}$ is the property of the stronger constituent (steel), $\mathrm{X}_{\mathrm{B}}$ is the property of the weaker constituent (concrete), and $\mathrm{m}$ is the ratio of the elastic modulus of the stronger material and the weaker one.

Figure 5.2 shows a diagram of the composite section and a possible idealization of the stress and strain distributions. 


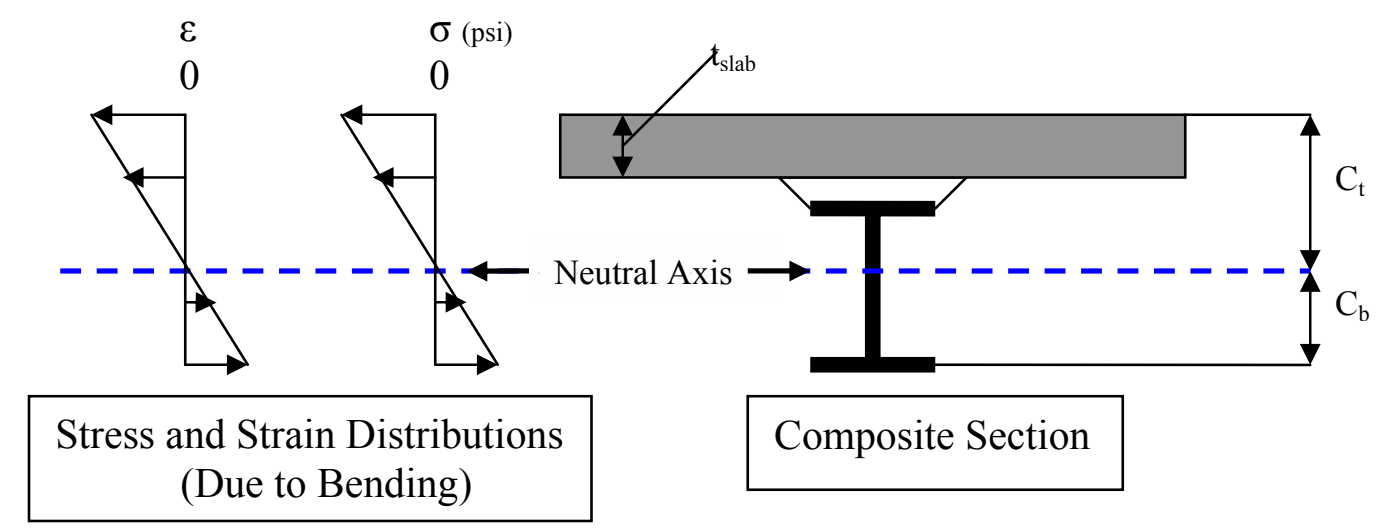

Figure 5.2: Illustration of Composite Section

The strain data, as measured with the vibrating wire strain gages installed on the steel girders at the top and bottom flanges, were substituted into equations 5.2 and 5.3 to determine the actual loading condition (moment and axial force) to which Evansville Bridge is subjected.

After the moment and the axial force have been determined, the expected strains in the concrete deck can be calculated using Equation 5.1, which assumes complete composite action. The calculated strains are then compared to the strains measured by the vibrating wire strain gages embedded in the concrete deck. If the concrete deck and steel girders of Evansville Bridge exhibit composite behavior, the theoretically predicted results, as calculated with the above equations and the field-measured strains should be the same. If the theoretically predicted results for strain in the concrete are significantly different, then it can be assumed that the steel girders and concrete deck do not act as a composite section.

A MATLAB code was written to calculate the theoretically predicted strain using equations 5.1-5.3, and generate time-history plots of both the theoretically predicted and the measured strains in the concrete deck. There are vibrating wire strain gages installed on the girders at the abutment, at half-span, at the first pier, and at mid span. Plots were 
generated at each location for the strain at the top and bottom of the deck slab, for a total of eight time history plots, which include over 400 days worth of data, as illustrated in figures $5.3 \mathrm{a}$ to $5.3 \mathrm{~h}$.

\subsection{RESULTS OF COMPOSITE ACTION ANALYSIS}

As can be seen in figures 5.1a through 5.1h, composite action does not develop at all locations. Figure 5.1a, which shows the strain at the top of the slab at the abutment, does not show composite action for more than the first few days, whereas the strains at the bottom of the slab in the same location (figure 5.1b) do indicate composite action. Only the abutment consistently shows composite action. Composite action is indicated sporadically at mid span. The quality of the composite action of the concrete deck and the steel girders does not appear to improve as the concrete ages and cures.

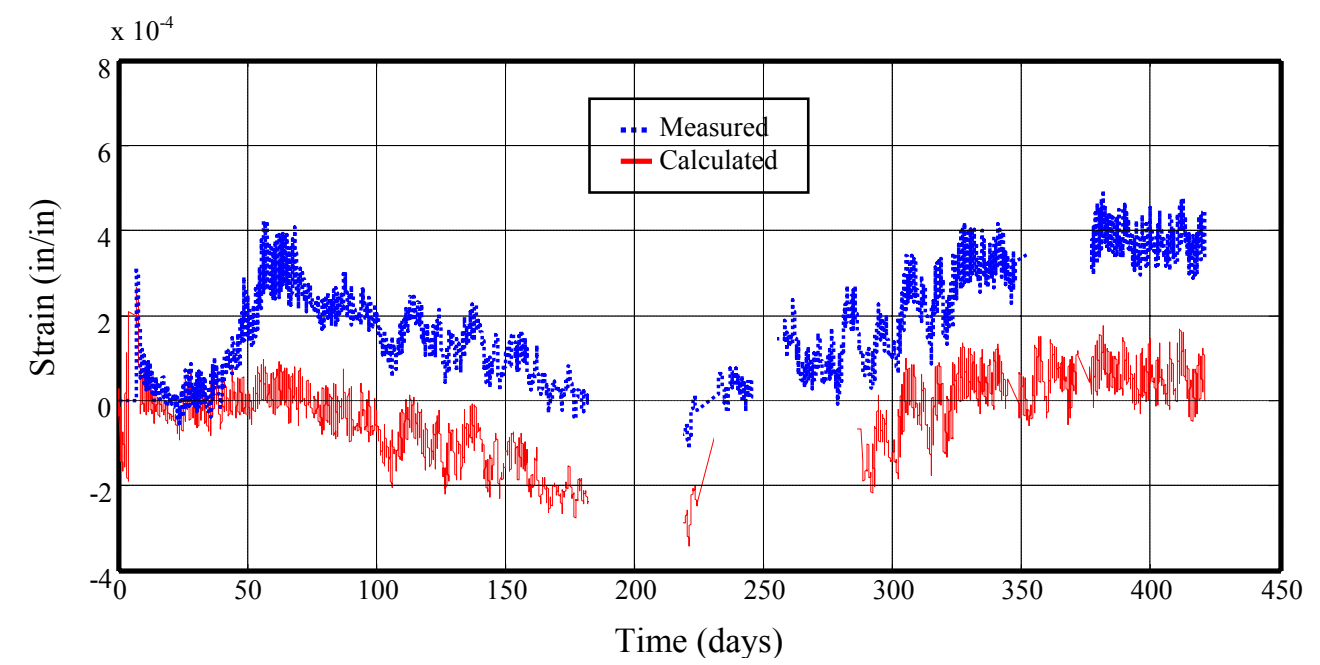

a) Calculated and Measured Strains at Top of Slab at the Abutment 


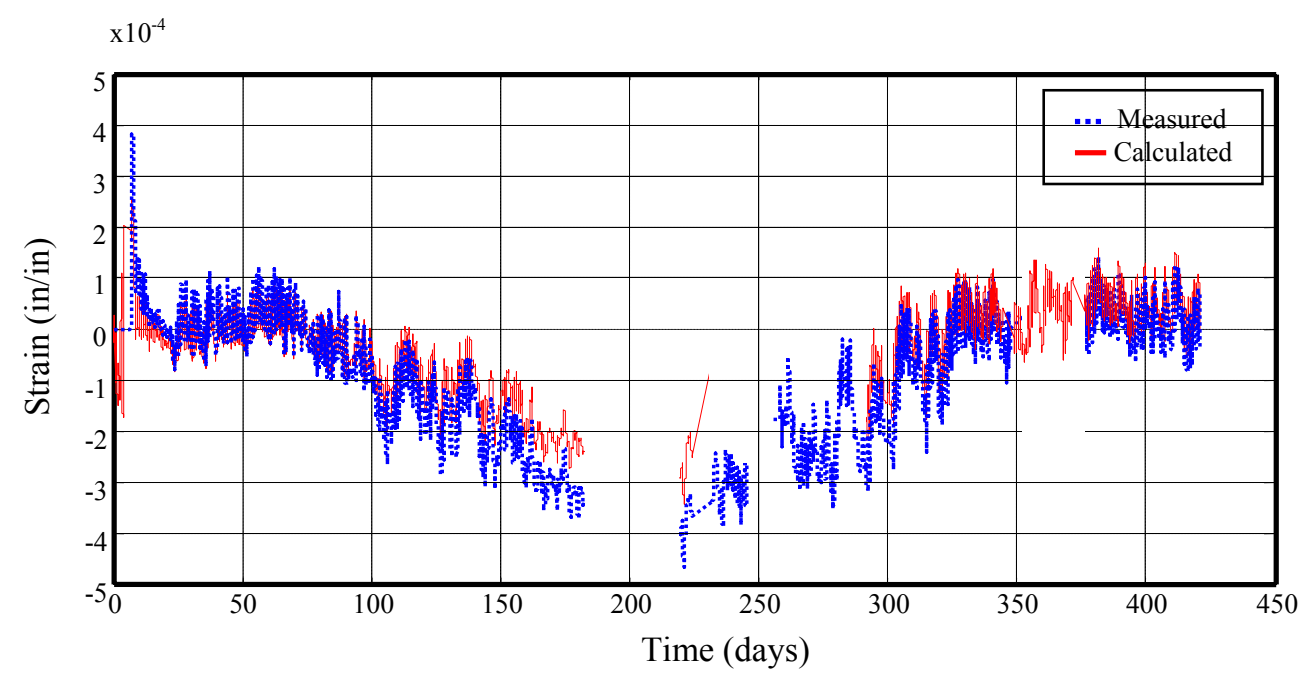

b) Calculated and Measured Strains at Bottom of Slab at the Abutment

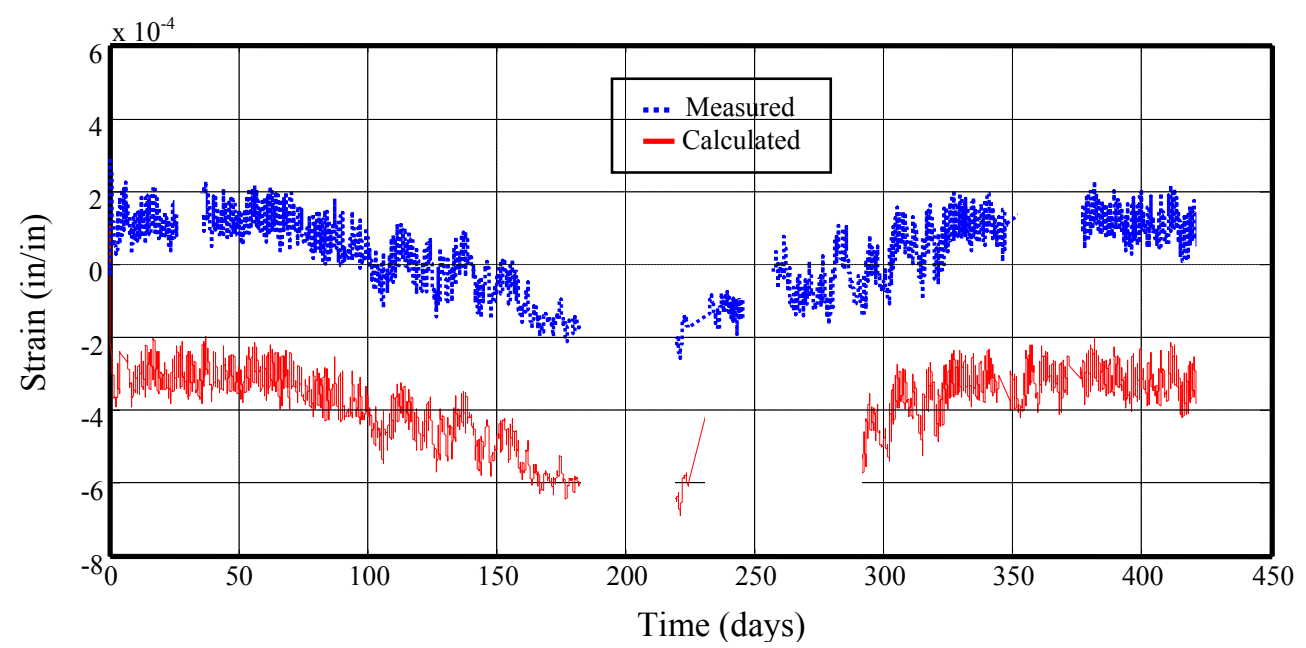

c) Calculated $\underset{x 10}{\operatorname{an}}$ and Measured Strains at Top of Slab at Half-span

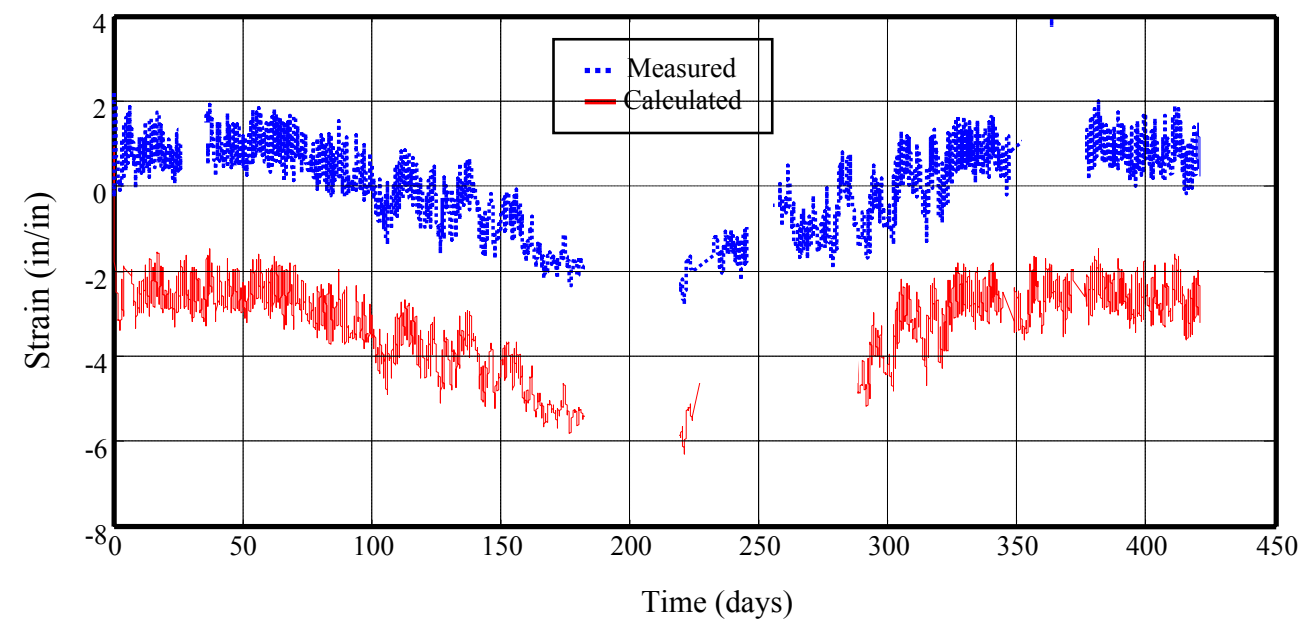

d) Calculated and Measured Strains at Bottom of Slab at Half-span 


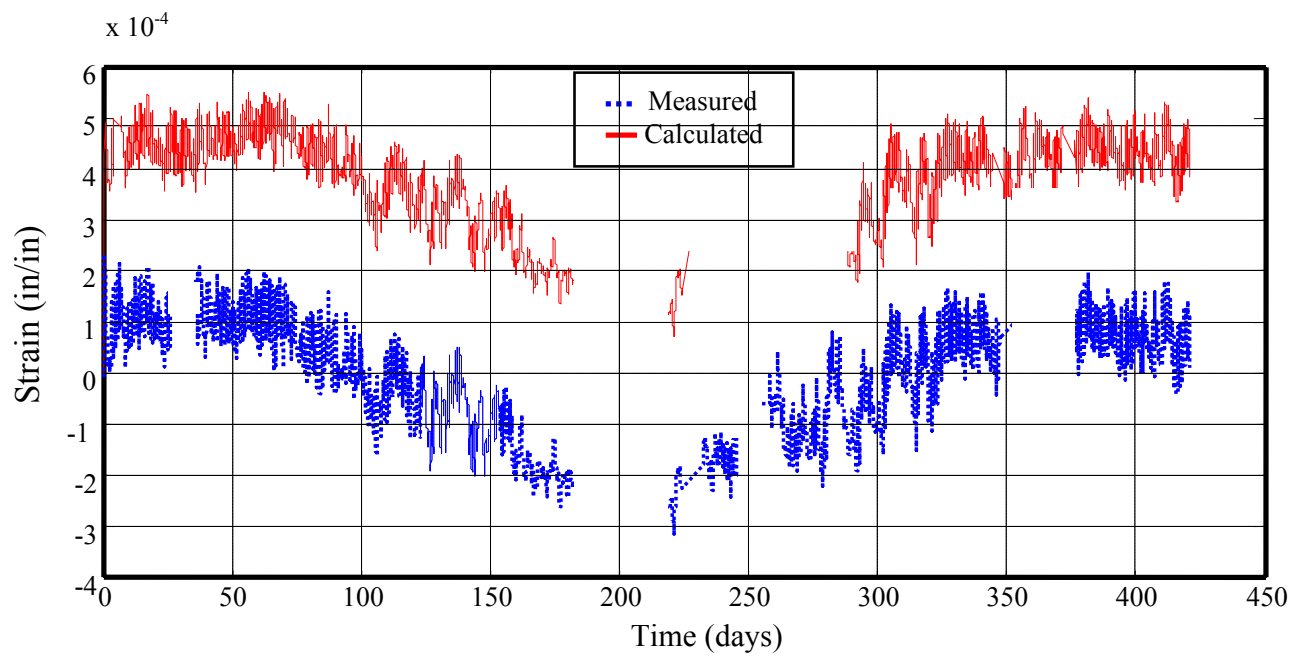

e) Calculated and Measured Strains at Top of Slab at the Pier

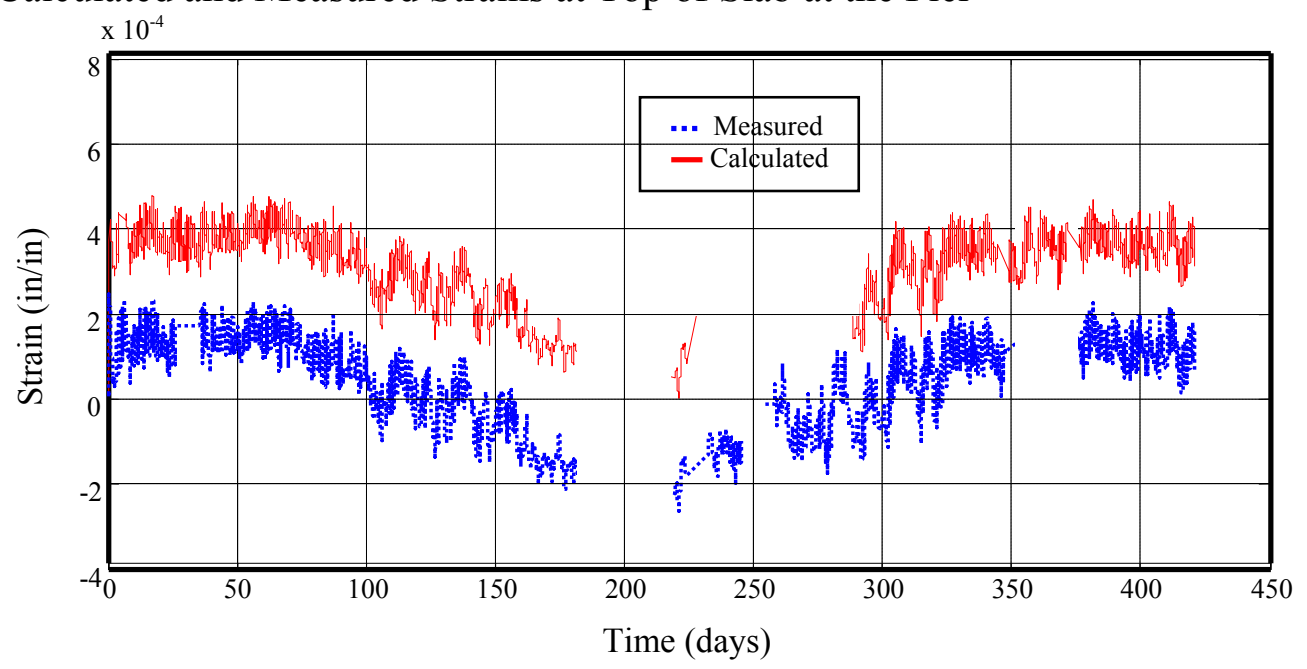

f) Calculated and Measured Strains at Bottom of Slab at the Pier

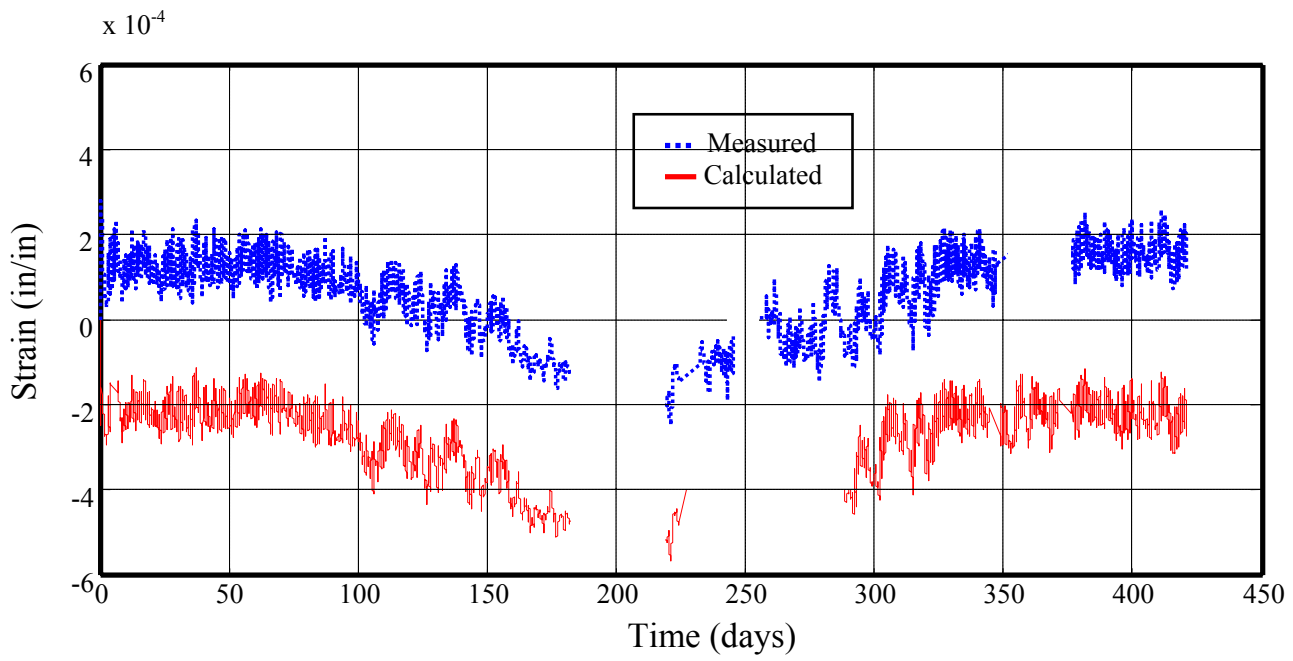

g) Calculated and Measured Strains at Top of Slab at Mid Span 


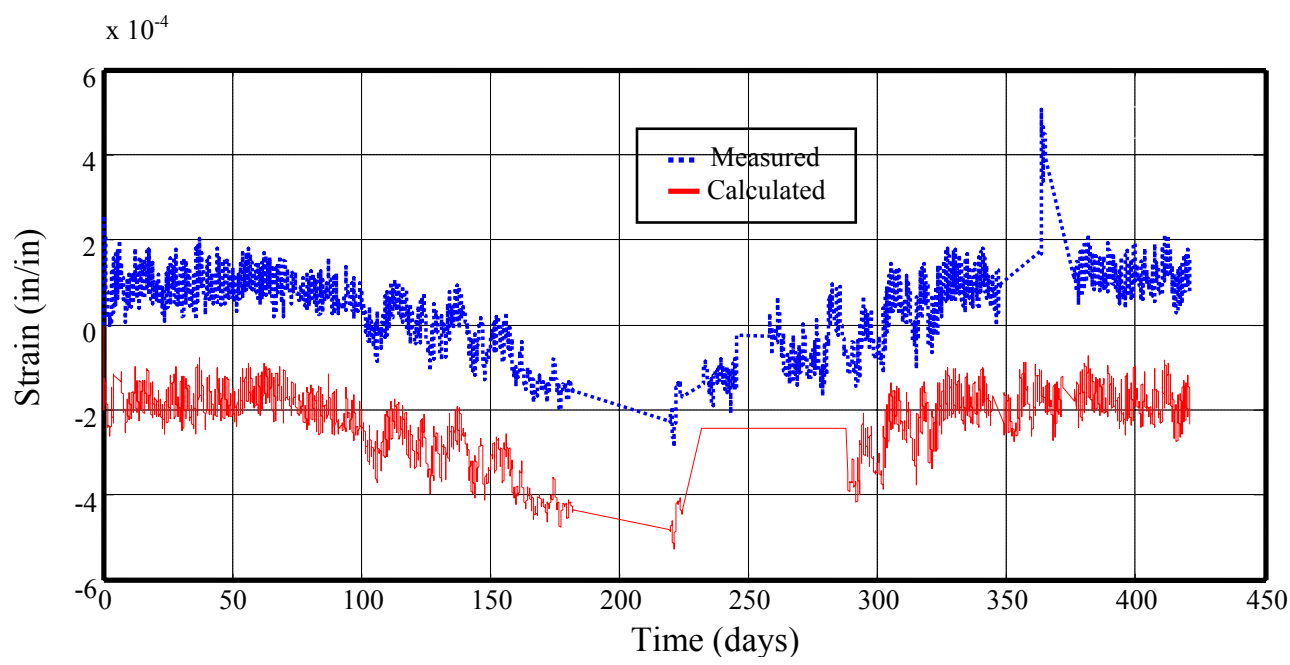

h) Calculated and Measured Strains at Bottom of Slab at Mid Span

Figure 5.3a-h: Comparison of Calculated Measured Strains

\subsection{CAUSES OF NONCOMPOSITE ACTION}

Noncomposite action is indicated based upon the analysis of data from Evansville Bridge. The most likely cause of this is the extensive stress around the shear studs, generated by drying shrinkage, which leads to cracking of the concrete around the shear studs. This cracking weakens or destroys the bond and the mechanical interlock between the shear studs and the concrete deck. This phenomenon has been observed in other bridge decks, as indicated by Kitagawa et. al. It has already been established in Chapter 4 that high stresses developed during drying at Evansville Bridge.

Constraint of the lower surface of the bridge deck causes curling, since the upper surface of the concrete is freer to expand and contract. This curling effect contributes to the noncomposite behavior of the deck and girders of Evansville Bridge by causing additional stresses in the vertical direction on the interface between the concrete and the shear studs. Figure 5.4 illustrates the curling effect. 


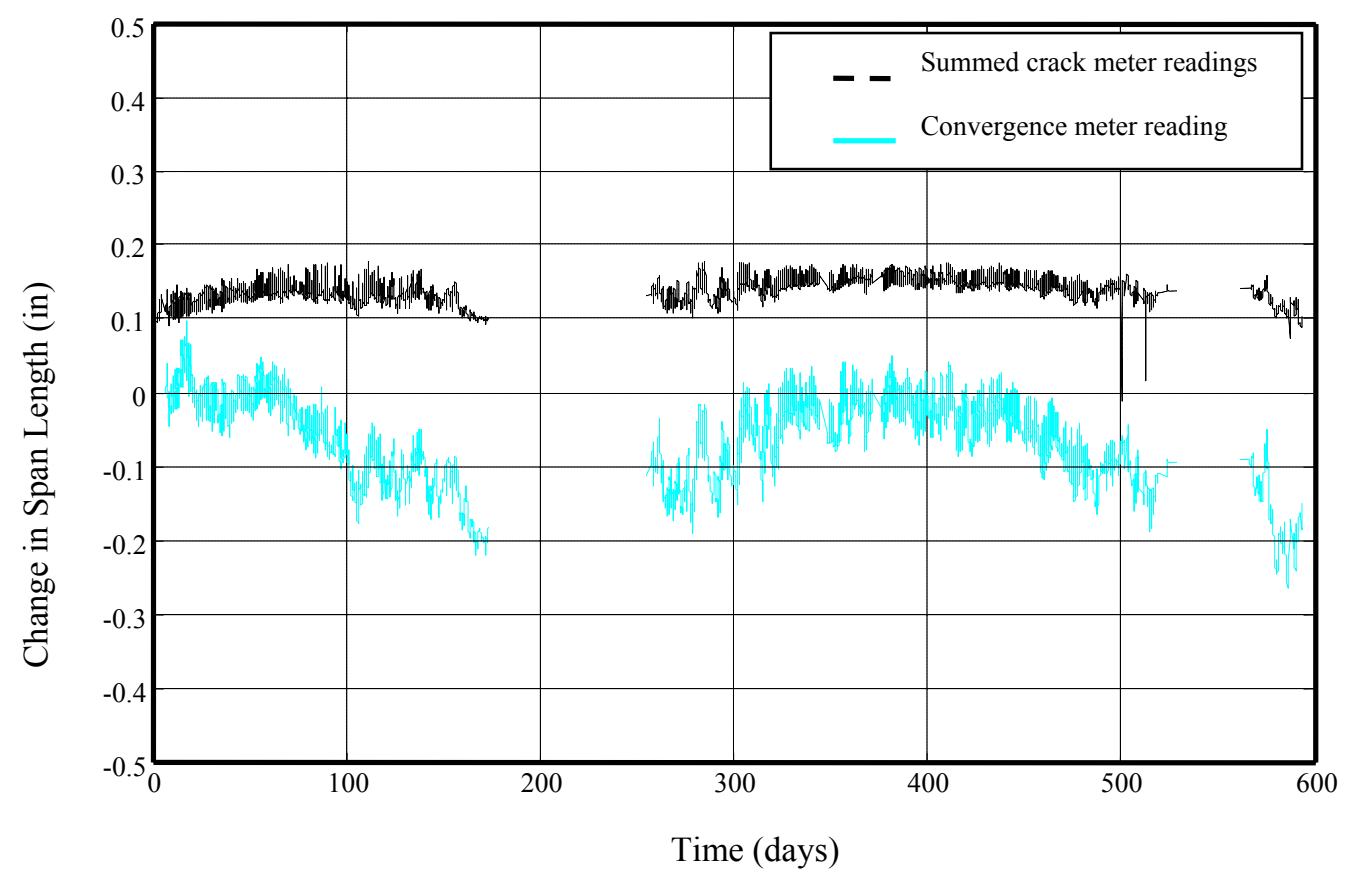

Figure 5.4: Change in Span Length as Measured by Crack Meters and Convergence Meters

The convergence meter measures span length by the relative motion of the abutment and the pier; this is effectively the change in length of the girders. The crack meters measure span length as the change in length of the deck. If the deck and the girders behave as a composite unit, the two span lengths should be equal. They are not equal, and the fact that the summation of the crack meter readings is always positive indicates that the deck has curled to some degree. Additional evidence of the curling phenomenon is shown in the strain profiles. Strain profiles indicate that although the girders deflect downward due to dead loads (the weight of the concrete deck and the weight of the girders themselves), the concrete deck exhibits upward curling. Some examples of measured strain profiles are shown in figure 5.5. Similar plots of strain profiles for the other instrumented locations are similar. None of them show a continuous, linear profile that should be present if composite action occurs. 


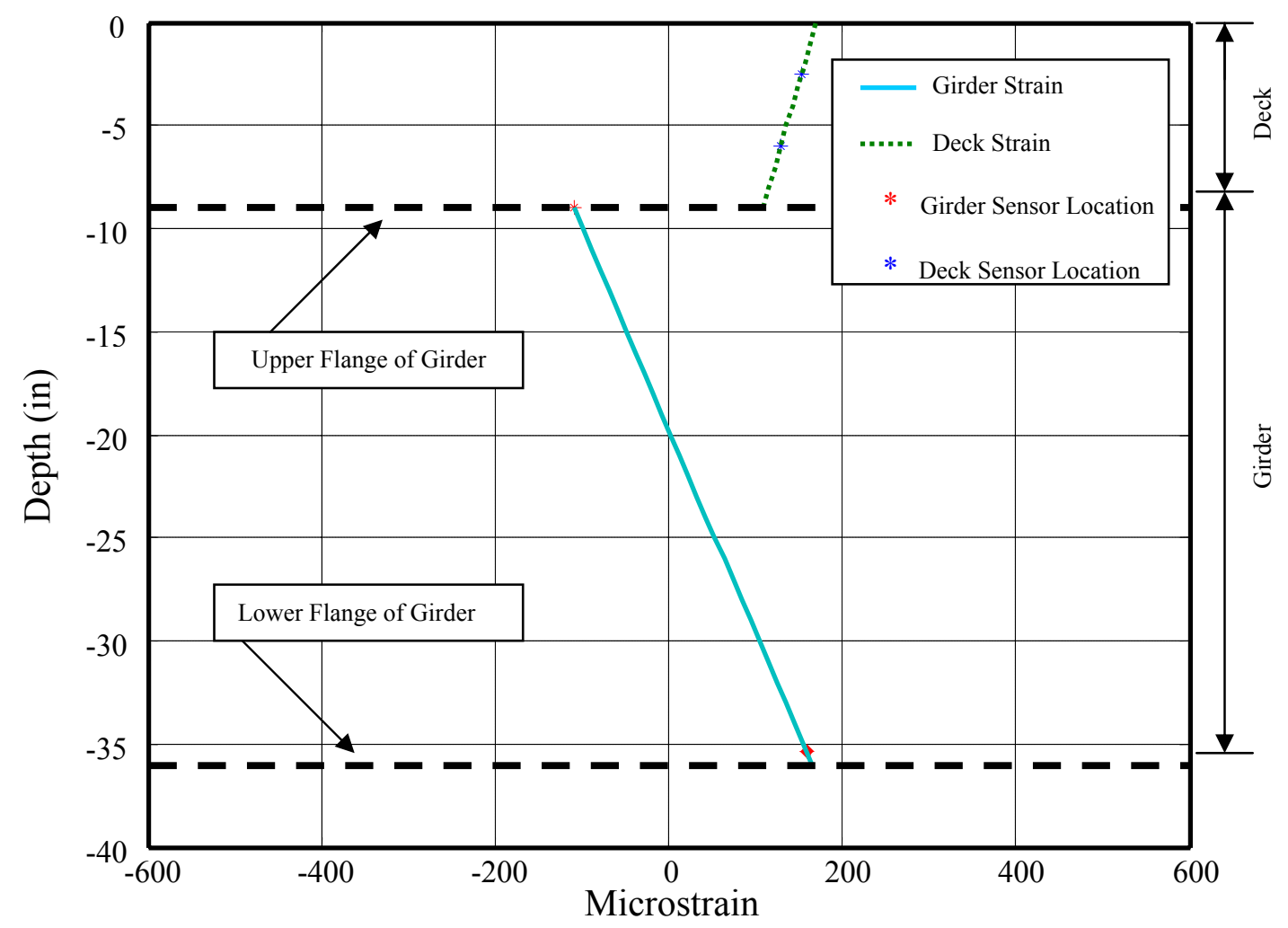

Figure 5.5: Strain Profile through the Deck and Girders at Midspan After 15 Days

It is apparent from the measured data and the analysis of this data that complete composite action does not occur between the concrete deck and steel girders of Evansville Bridge. 


\section{CHAPTER 6}

\section{BONDING OF REINFORCEMENT STEEL WITH CONCRETE IN THE DECK OF EVANSVILLE BRIDGE}

\subsection{INTRODUCTION}

In the design of bridges, it is naturally assumed that the reinforcement steel and the concrete of the bridge deck are perfectly bonded together. It is vital that the reinforcement steel be bonded with the concrete, because the reinforcement steel provides the bulk of the tensile strength of a concrete structure, since concrete has relatively low tensile strength (Spiegel and Limbrunner, 1980). In order to enhance bonding and provide a mechanical interlock between the reinforcement steel and the concrete, the surface of steel bars used to reinforce concrete is deformed with a pattern of ribbed projections (Spiegel and Limbrunner, 1980).

\subsection{EVALUATION OF BOND STATUS}

In order to determine if the reinforcement is bonded to the concrete as assumed, a series of time history plots of the strain in the reinforcement steel and the concrete were created. Plots were created in seven locations. At each location, the strain in the concrete of the deck was measured in three orthogonal directions at the top and the bottom of the deck slab using Geokon VCE 4200 Vibrating Wire Strain Gages; strain in the reinforcement was measured using Geokon Model 4911 Sister Bars.

\subsection{RESULTS}

As shown in Figure 6.1, some of the plots indicated that some degree of debonding has occurred, but overall, the reinforcement appears to be well bonded to the concrete of the bridge deck. The reinforcement steel along the direction of the wheelpath exhibits a lesser degree of bonding, which is likely due to the higher stresses in this direction. Figures $6.1 \mathrm{a}$ through $6.1 \mathrm{~s}$ show the measured strains in the reinforcement steel 
and in the concrete deck plotted versus time. Plots were generated for strains in both the longitudinal (wheel path) direction and transverse direction. Table 6.1 shows details of the condition of the rebar-concrete bond at each location, as estimated by a visual inspection of the plotted strains.

Table 6.1 Rebar and Concrete Bonding Status

\begin{tabular}{|l|l|l|}
\hline Direction & Location & Condition \\
\hline Along Wheelpath & Abutment, Beam B & Debonded \\
\hline Transverse to Wheelpath & Abutment, Beam B & Bonded \\
\hline Along Wheelpath & $1 / 2$ Span, Beam C & Bonded \\
\hline Transverse to Wheelpath & $1 / 2$ Span, Beam C & Debonded \\
\hline Along Wheelpath & $1 / 2$ Span, Beam B & Bonded \\
\hline Transverse to Wheelpath & $1 / 2$ Span, Beam B & Bonded \\
\hline Along Wheelpath & $3 / 4$ Span, Beam B & Bonded \\
\hline Transverse to Wheelpath & $3 / 4$ Span, Beam B & Bonded \\
\hline Along Wheelpath & Pier, Beam B & Imperfectly Bonded \\
\hline Transverse to Wheelpath & Pier, Beam B & Bonded \\
\hline Along Wheelpath & Midspan, Beam C & Bonded \\
\hline Transverse to Wheelpath & Midspan, Beam C & Bonded \\
\hline Along Wheelpath & Midspan, Beam B & Bonded \\
\hline Transverse to Wheelpath & Midspan, Beam B & Bonded \\
\hline
\end{tabular}




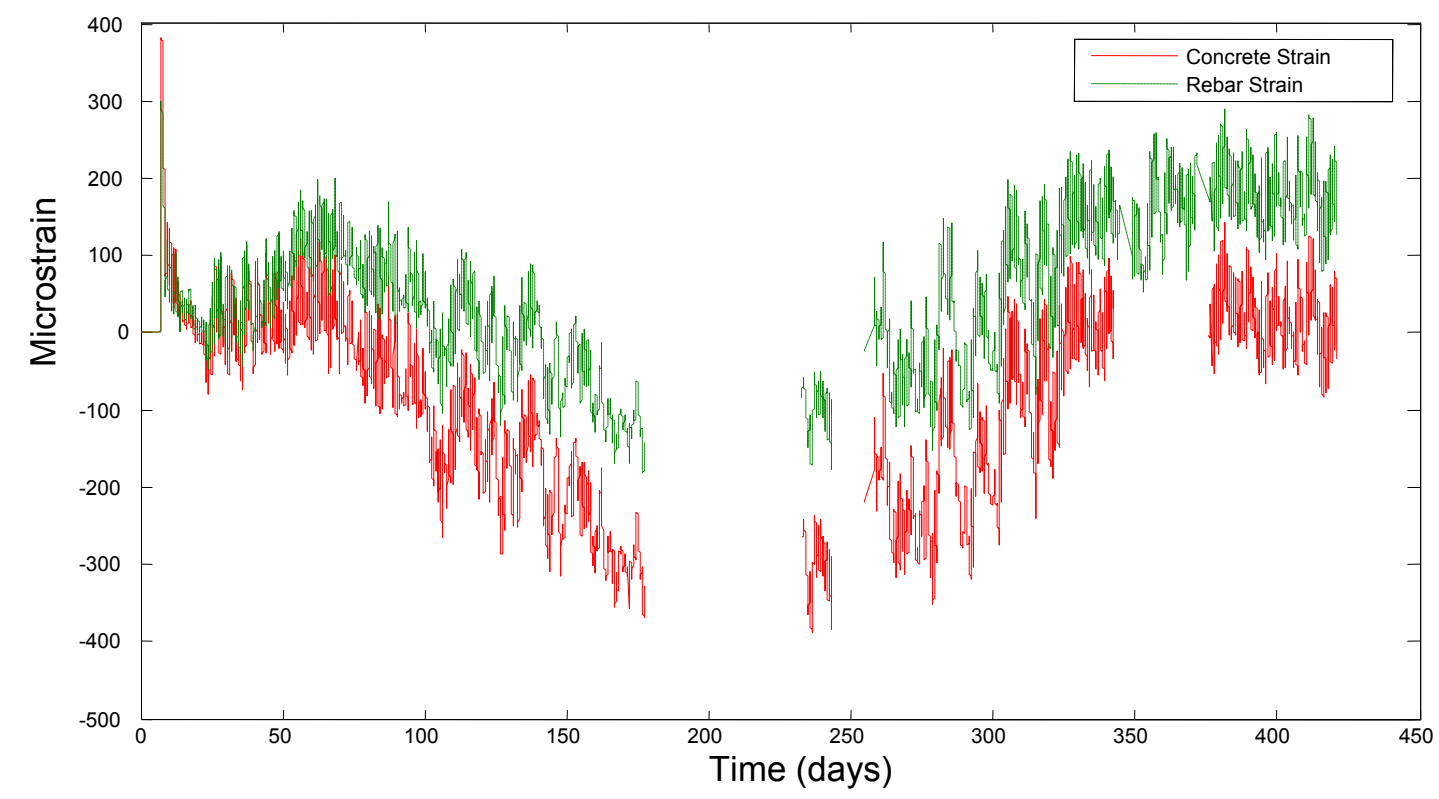

a) Strain in Wheelpath Direction at Abutment along Beam B

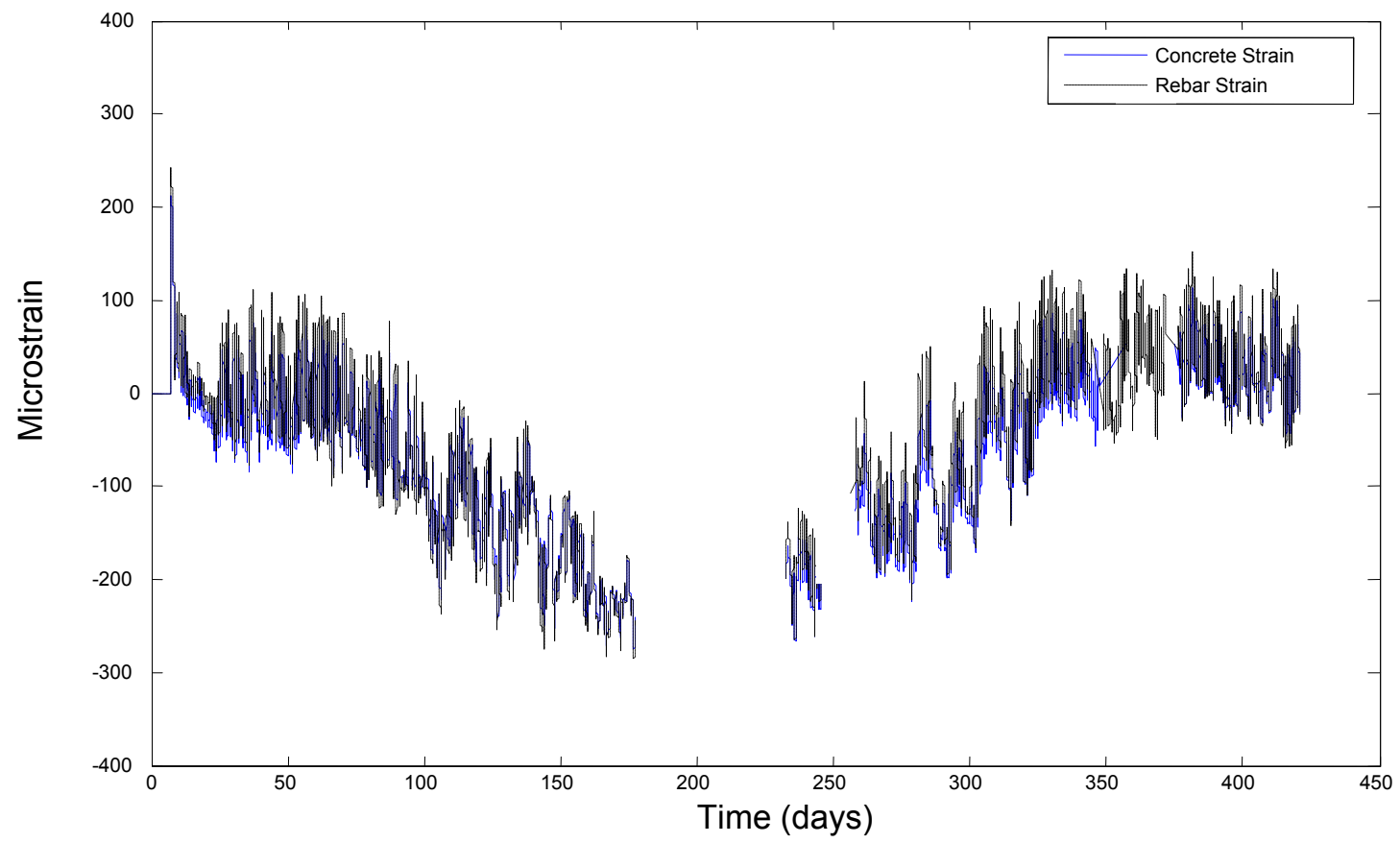

b) Strain in Transverse Direction at Abutment Along Beam B 


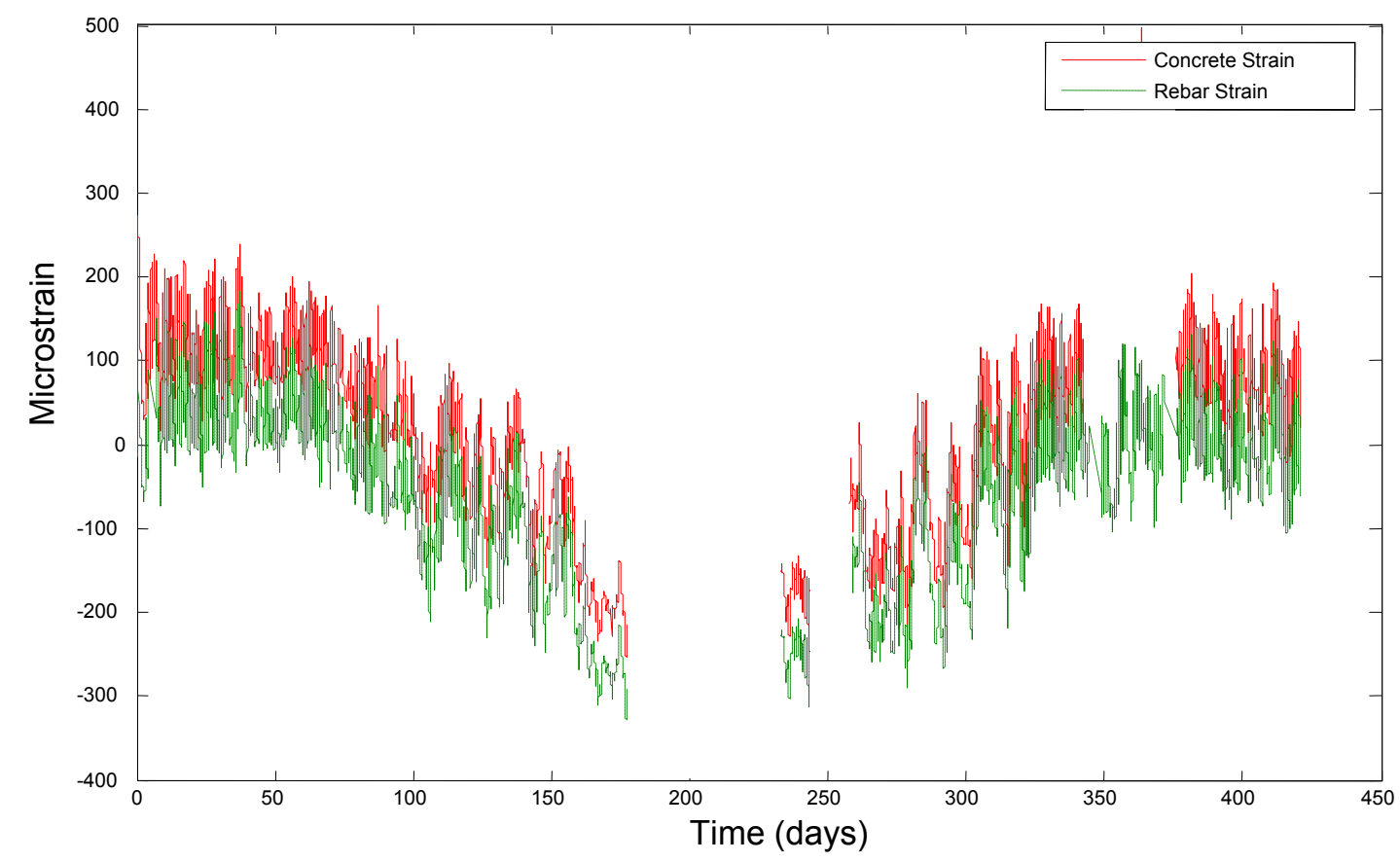

c) Strain in the Wheelpath Direction at $1 / 2$ Span, Along Beam C

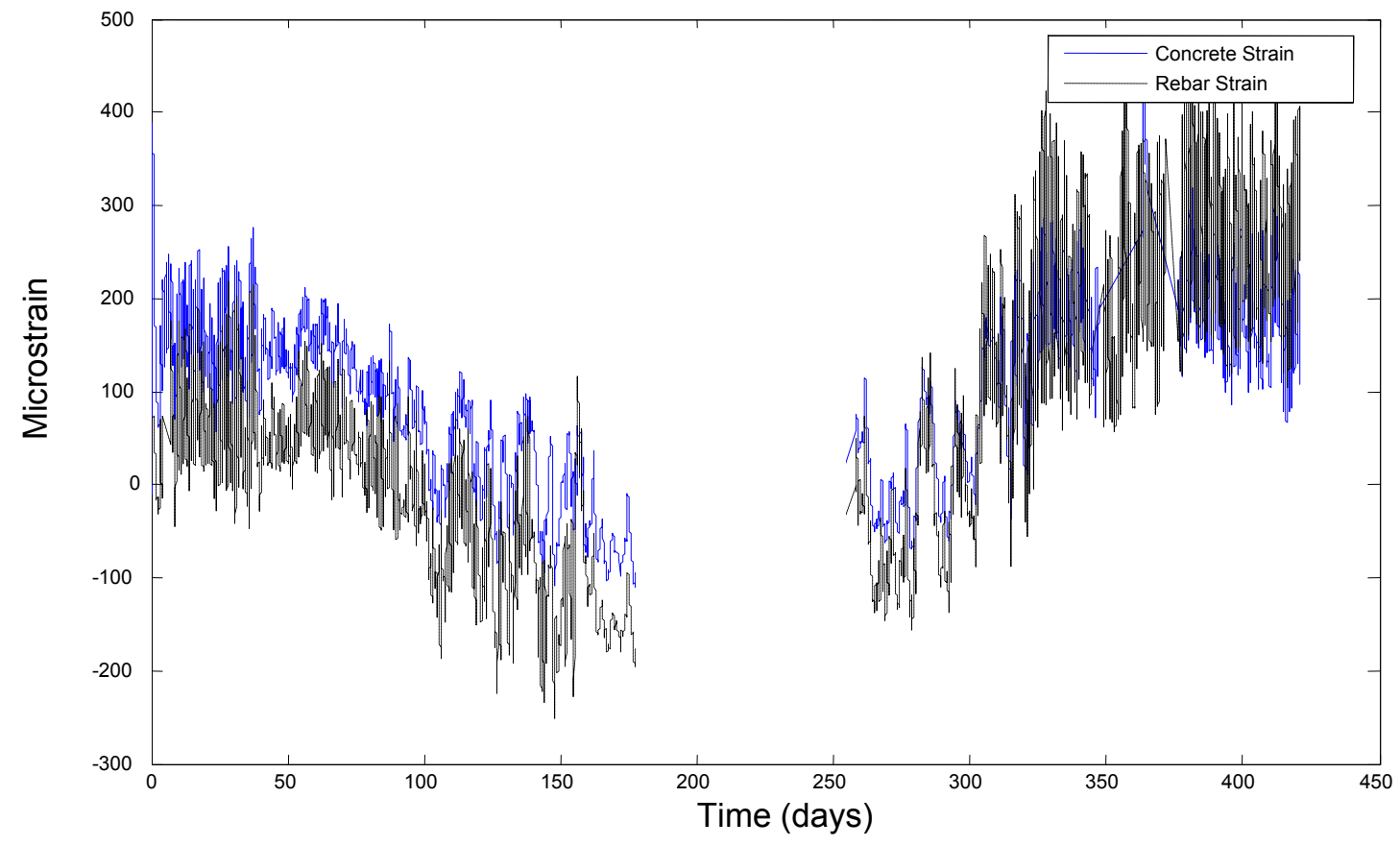

d) Strain in the Transverse Direction at $1 / 2$ Span, Along Beam C 


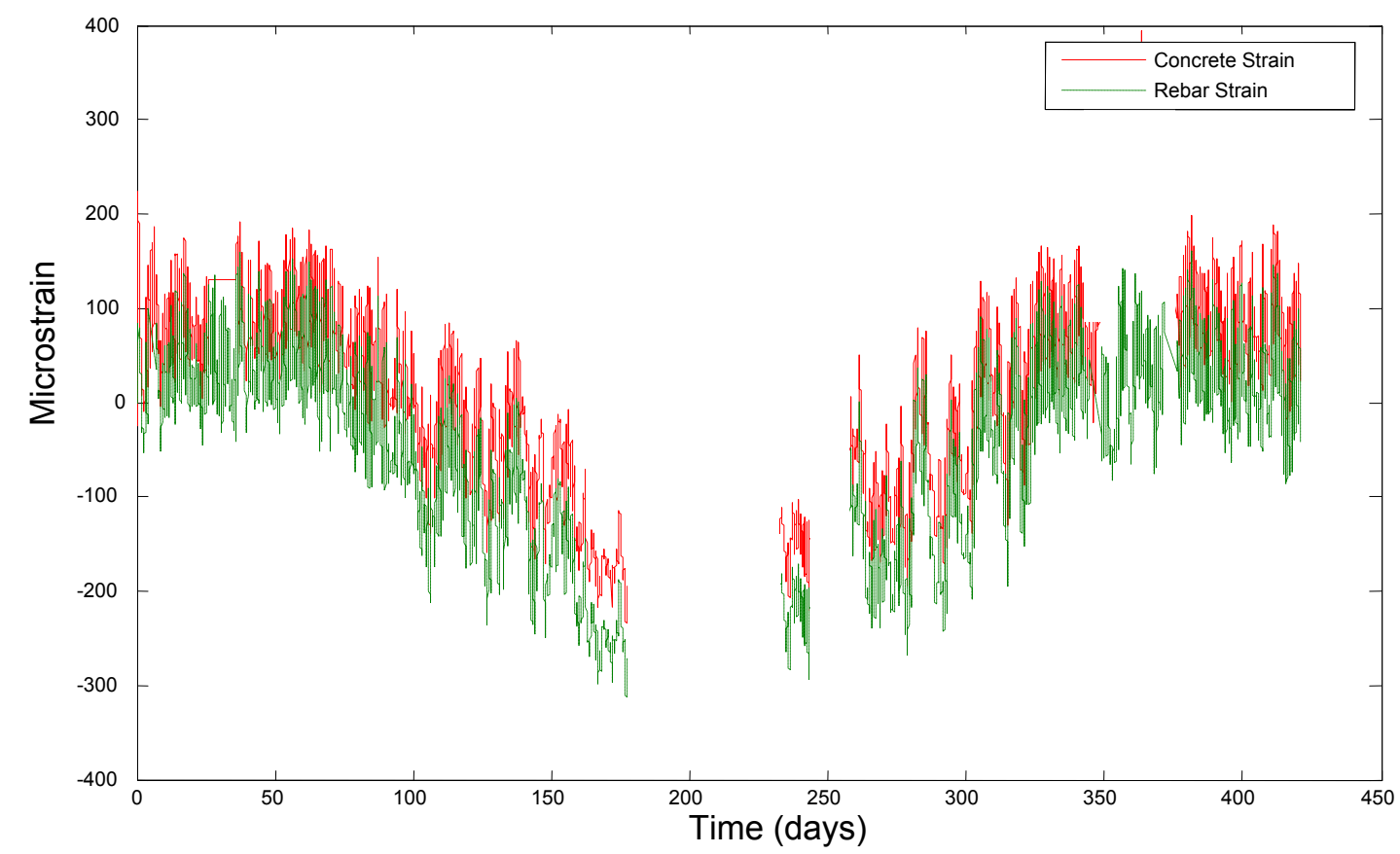

e) Strain in the Wheelpath Direction at $1 / 2$ Span, Along Beam B

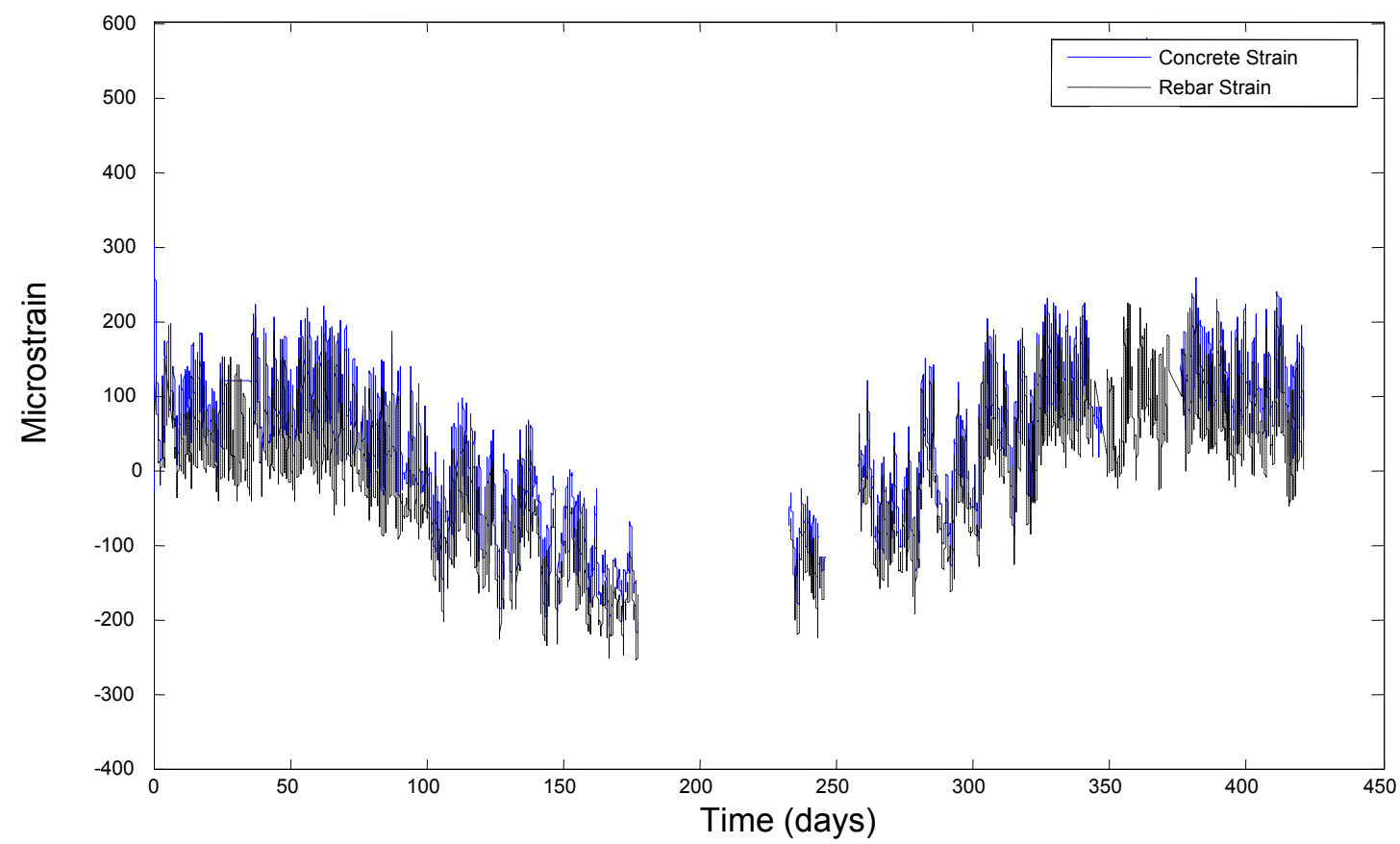

f) Strain in the Transverse Direction at $1 / 2$ Span, Along Beam B 


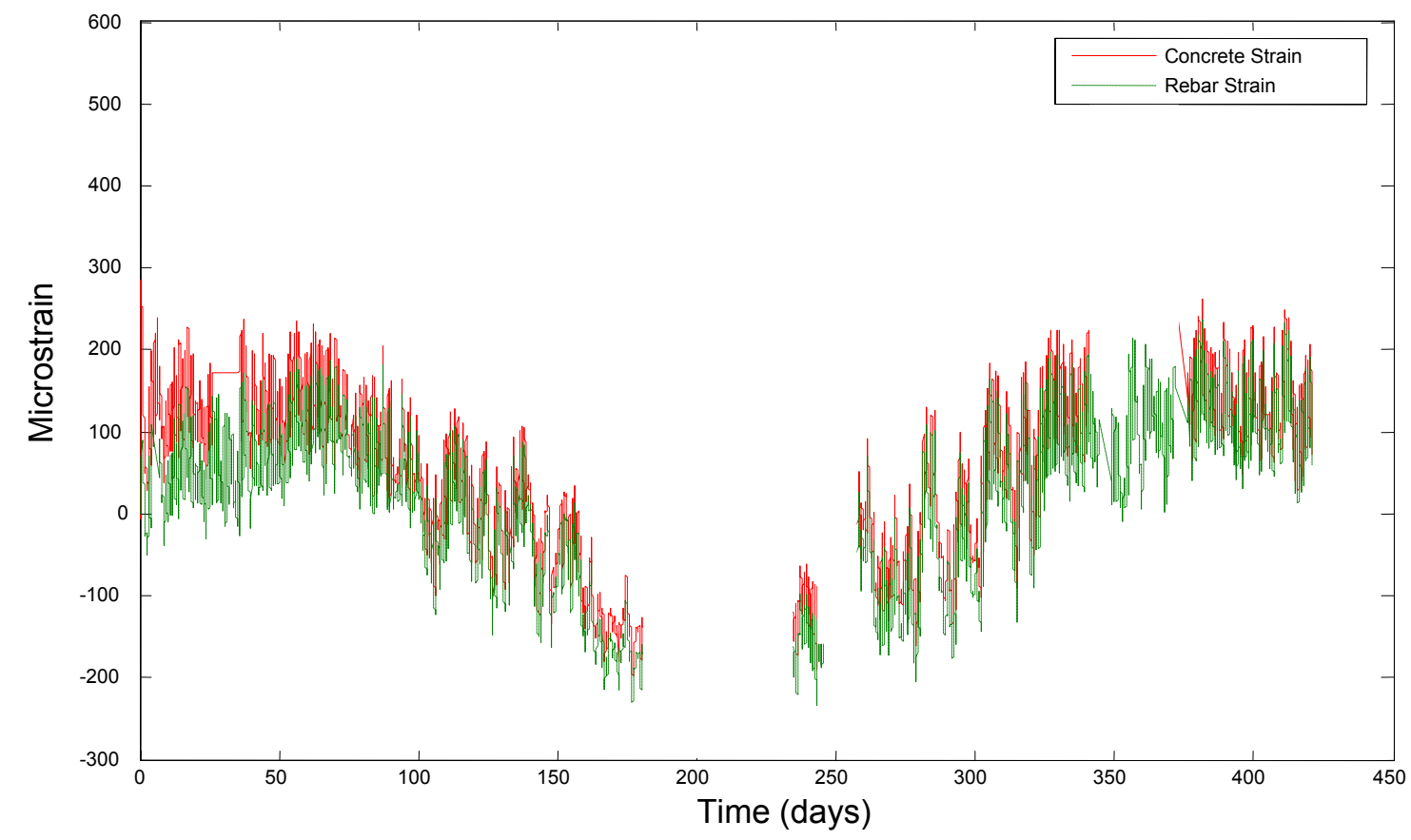

g) Strain in the Wheelpath Direction at $3 / 4$ Span, Along Beam B

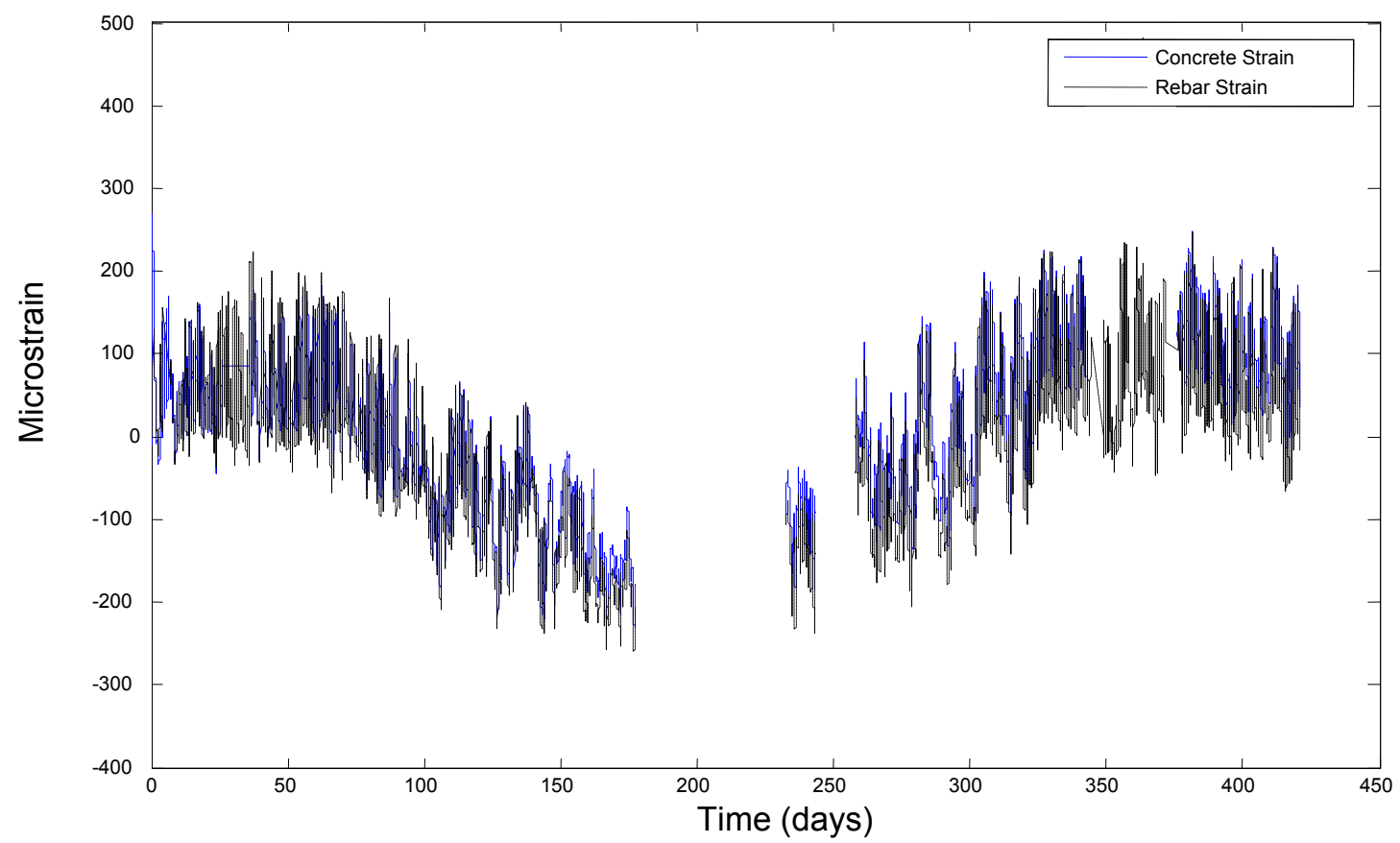

h) Strain in the Transverse Direction at $3 / 4$ Span, Along Beam B 


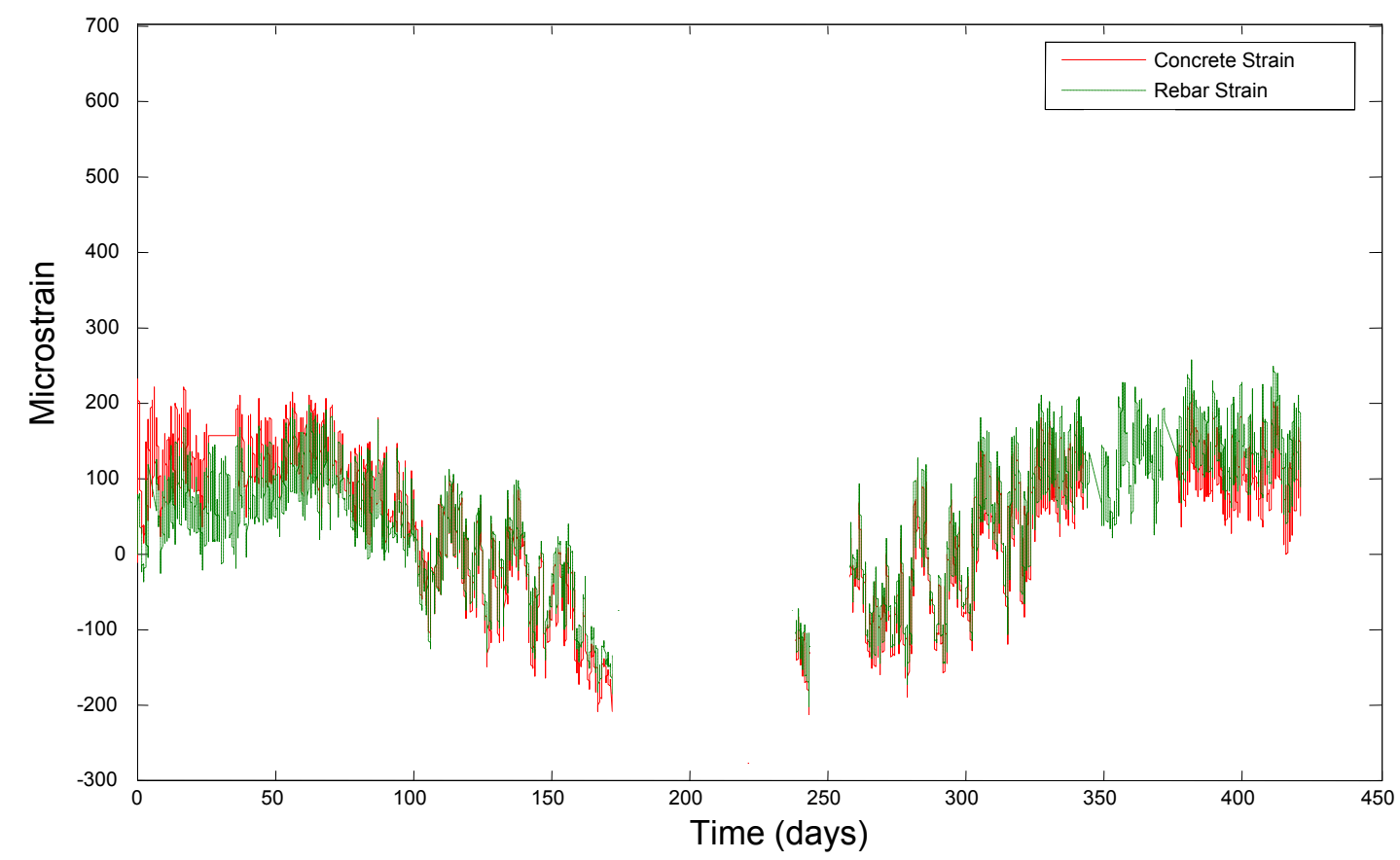

i) Strain in the Wheelpath Direction at Pier, Along Beam B

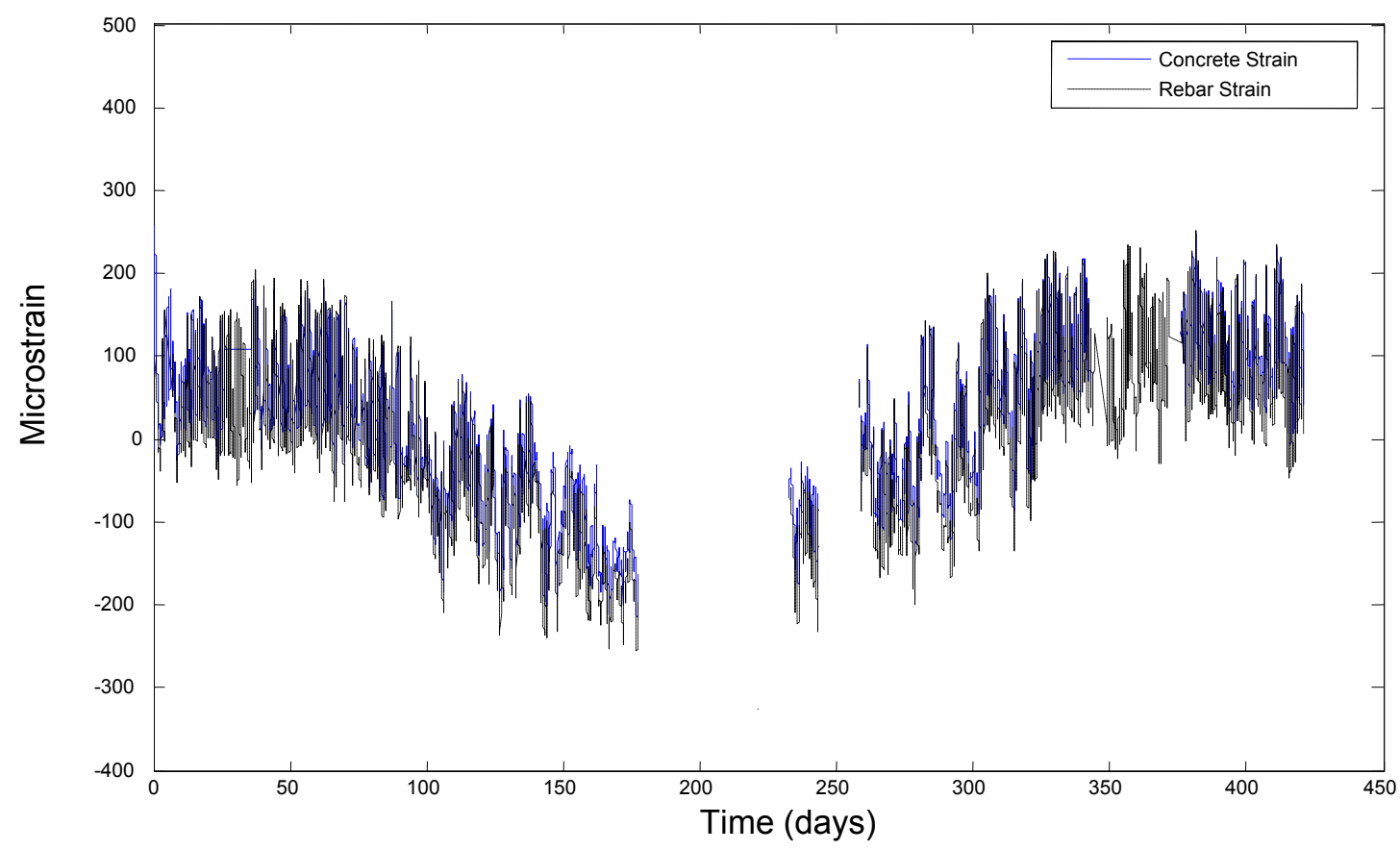

j) Strain in the Transverse Direction at Pier, Along Beam B 


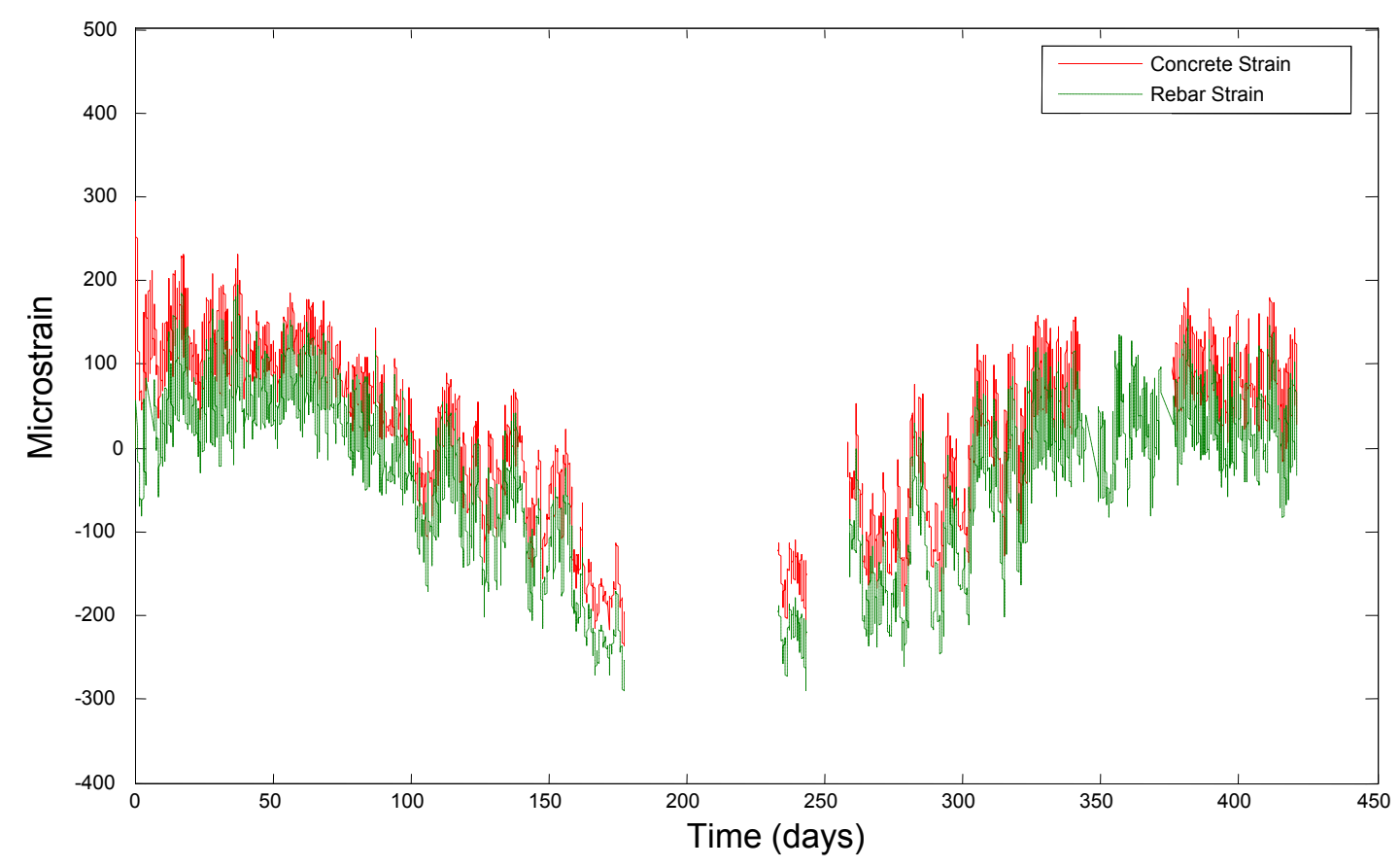

k) Strain in the Wheelpath Direction at Midspan, Along Beam C

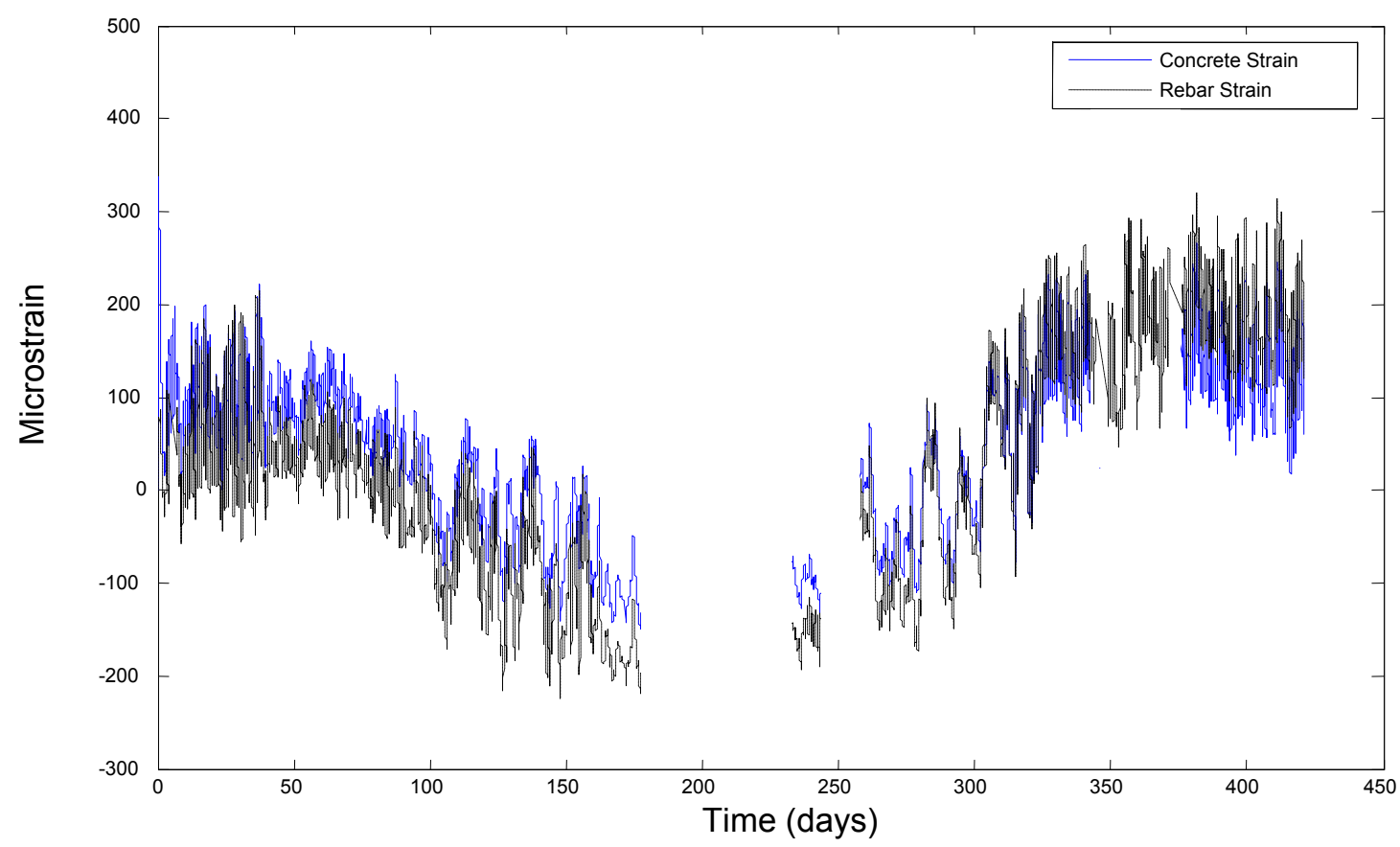

1) Strain in the Wheelpath Direction at Midspan, Along Beam C 


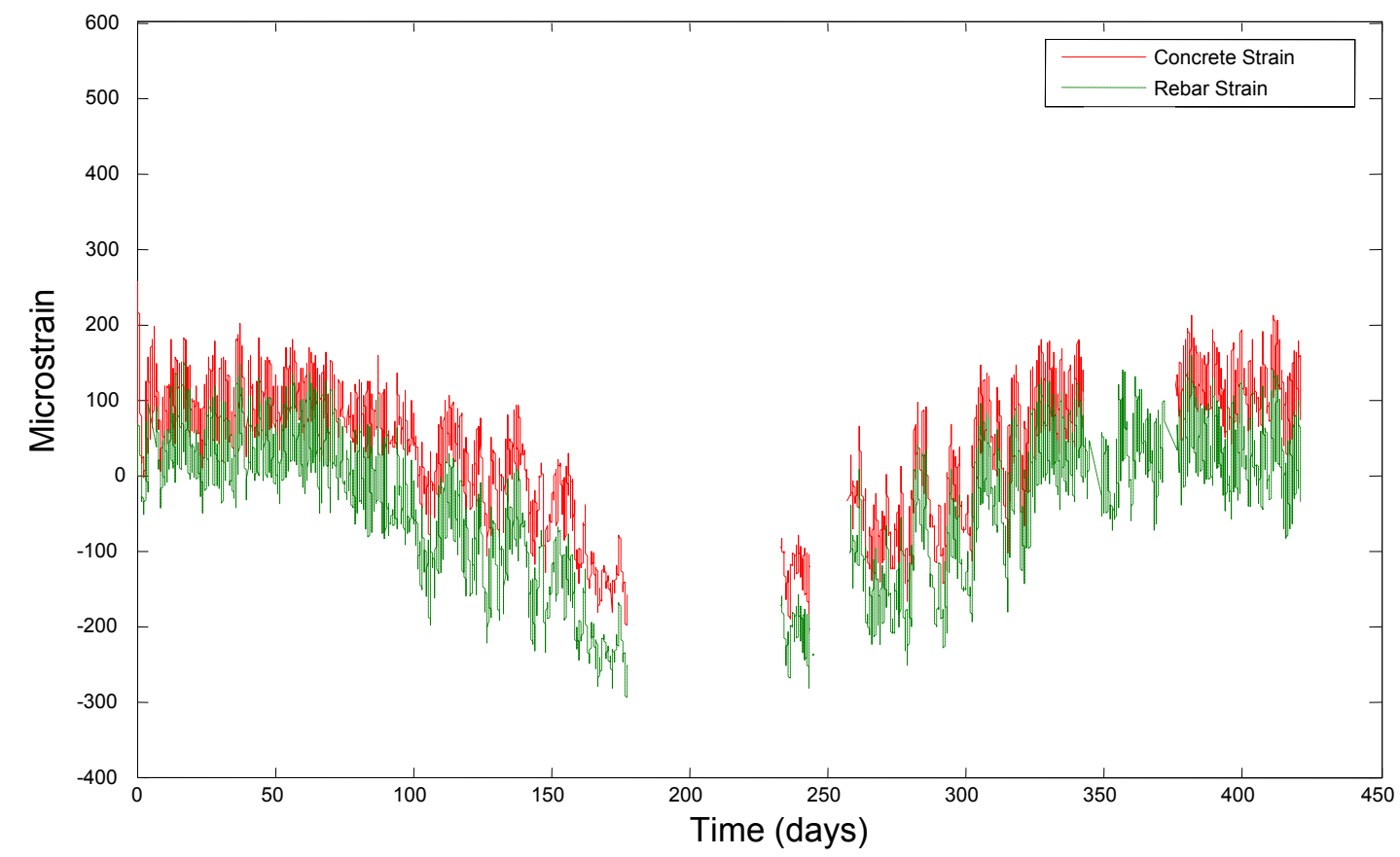

m) Strain in the Wheelpath Direction at Midspan, Along Beam C

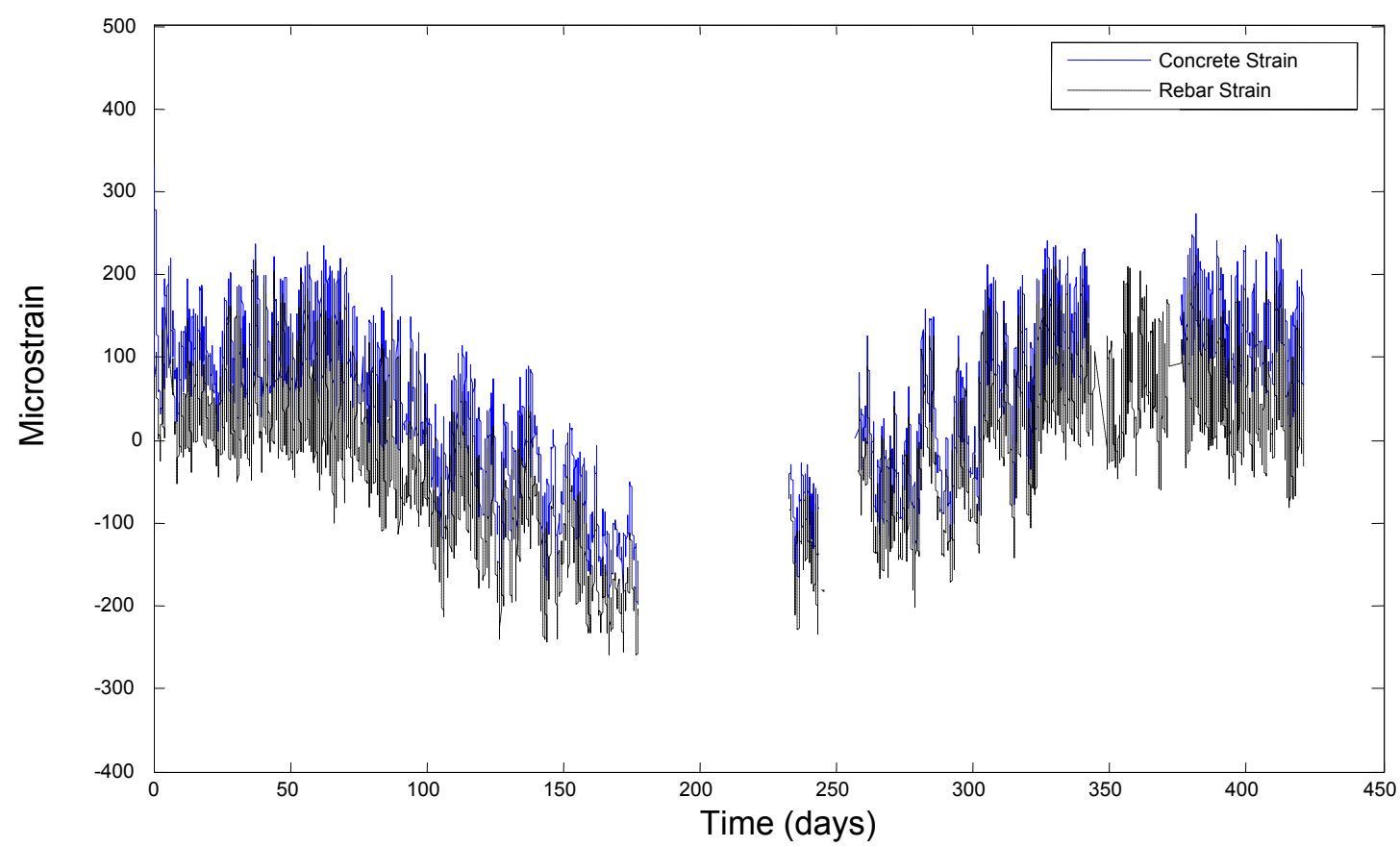

n) Strain in the Transverse Direction at Midspan, Along Beam C

Figures 6.1a- 6.1n Comparison of Strains in Reinforcement Steel and Concrete Deck 


\subsection{VERIFICATION OF RESULTS}

In order to verify that the bond between the reinforcement steel and the concrete of the deck has indeed weakened or slipped, it was necessary to examine the two strain histories statistically to determine if they differ significantly. In order to do this, correlation coefficients were computed between the two data sets. If the data is the same, and there is no loss of bonding, then the correlation between the two data sets will be high (correlation coefficient near one), and if the data differs significantly, the correlation will be relatively low. The correlation coefficients for each location are listed in table 6.2 .

Table 6.2: Correlation Between Strains in Rebar and Concrete

\begin{tabular}{|l|l|l|l|l|}
\hline Direction & $\begin{array}{l}\text { X } \\
\text { (in) }\end{array}$ & $\begin{array}{l}\text { Y } \\
\text { (in) }\end{array}$ & Location & $\begin{array}{l}\text { Correlation } \\
\text { Coefficient }\end{array}$ \\
\hline Wheelpath & 116.52 & 81 & $\begin{array}{l}\text { Abutment, } \\
\text { Beam B }\end{array}$ & 0.84638 \\
\hline Transverse & 116.52 & 81 & $\begin{array}{l}\text { Abutment, } \\
\text { Beam B }\end{array}$ & 0.95868 \\
\hline Wheelpath & 313.92 & 0 & $\begin{array}{l}1 / 2 \text { Span, } \\
\text { Beam C }\end{array}$ & 0.96541 \\
\hline Transverse & 313.92 & 0 & $\begin{array}{l}1 / 2 \text { Span, } \\
\text { Beam C }\end{array}$ & 0.84919 \\
\hline Wheelpath & 374.52 & 81 & $\begin{array}{l}1 / 2 \text { Span, } \\
\text { Beam B }\end{array}$ & 0.96979 \\
\hline Transverse & 374.52 & 81 & $\begin{array}{l}1 / 2 \text { Span, } \\
\text { Beam B }\end{array}$ & 0.92825 \\
\hline Wheelpath & 527.52 & 81 & $\begin{array}{l}1 / 2 \text { Span, } \\
\text { Beam C }\end{array}$ & 0.93842 \\
\hline Transverse & 527.52 & 81 & $\begin{array}{l}1 / 2 \text { Span, } \\
\text { Beam C }\end{array}$ & 0.92167 \\
\hline Wheelpath & 660.48 & 81 & $\begin{array}{l}\text { Pier, } \\
\text { Beam B }\end{array}$ & 0.89857 \\
\hline Transverse & 660.48 & 81 & $\begin{array}{l}\text { Pier, } \\
\text { Beam B }\end{array}$ & 0.95532 \\
\hline Wheelpath & 909.84 & 0 & $\begin{array}{l}\text { Midspan, } \\
\text { Beam C }\end{array}$ & 0.9674 \\
\hline Transverse & 909.84 & 0 & $\begin{array}{l}\text { Midspan, } \\
\text { Beam C }\end{array}$ & 0.92825 \\
\hline Wheelpath & 962.52 & 81 & $\begin{array}{l}\text { Midspan, } \\
\text { Beam B } \\
\text { Midspan, } \\
\text { Beam B }\end{array}$ & 0.95226 \\
\hline Transverse & 962.52 & 81 & 0.93294 \\
\hline
\end{tabular}


From the results shown in Table 6.2, it can be concluded that the results obtained from visual inspection of the plots are reasonably accurate. In particular, the wheelpath strains at the abutment along beam B appeared to be quite dissimilar and were proven so by the correlation analysis, as were those in the transverse direction at the abutment along beam C. 


\section{CHAPTER 7 \\ CONCLUSION AND RECCOMMENDATIONS}

\subsection{INSTRUMENTATION SYSTEM}

The instrumentation installed on Evansville Bridge has performed satisfactorily overall, with only a few minor setbacks, such as power outages and software problems. All of these problems were corrected with relative ease. The sensors have proven robust and reliable, with only a very small percentage of them being damaged during installation or while in service. In the future, instrumented monitoring of all bridge structures may be possible, allowing for quick diagnosis of problems and more efficient scheduling of repairs, as well as a better understanding of the real life field performance of a variety of bridge structures.

\subsection{BRIDGE STRUCTURE}

Even though the bridge structure does not appear to be in danger of failing, instrumented monitoring of its components has revealed numerous shortcomings in its design.

Extensive cracking of the concrete in the deck of Evansville Bridge occurred even before the bridge was opened to traffic. The primary causes of cracking are temperature changes and drying shrinkage. These conditions cause cracking because of elevated stresses, which are caused by the constraints placed on the deck by the stay-in-place forms, the shear studs, and the integral abutments. Under these constrained conditions, the stresses due to drying shrinkage exceed the modulus of rupture of the concrete during the first day. The differing thermal properties of different sections of the deck, which result in variations in material response to temperature changes, also contribute to cracking. In conjunction with the relatively deep concrete cover (3.25 inches) over the longitudinal reinforcement, the differential shrinkage and contraction of the deck that occurs as a result of the constraining effect of the stay-in-place forms contributes to the 
cracking that occurs at early age. The in plane temperature variations observed along the deck cause in-plane stresses that can contribute to early age cracking and delamination.

In order to alleviate the problem of early age cracking of bridge decks, it may be necessary to re-evaluate the use of traffic loads as the design loads for this type of integral abutment bridge, since the tensile stresses induced by constrained drying shrinkage and temperature changes (which are currently considered secondary effects) are relatively high, even in comparison with traffic loads. Early age cracking could be minimized by taking measures to reduce the stress due to shrinkage. Using concrete with low shrinkage and a high modulus of rupture is a means of achieving this. Adding fibers to concrete seems to be a good way of increasing its tensile strength, and minimizing the occurrence of early age cracking. Casting the deck with a small concrete cover of one inch, then later overlaying the deck with fine aggregate concrete would solve the problem of cracking induced by differential drying shrinkage in the presence of the stay-in-place forms.

Evansville Bridge did not exhibit composite action as expected. The lack of composite action was most likely brought on by cracking around the shear studs caused by drying shrinkage, and by the curling of the deck. Concrete with higher tensile stress and lower shrinkage would help to alleviate this problem, as would the use of a system similar to the post-rigid system (Kitagawa et. al.) mentioned in the literature review.

The measured variation between the strain in the reinforcement and the surrounding concrete shows that there may be some degree of slipping in the bond between the steel reinforcement and the concrete of the deck. Studies have revealed that cracking of the surrounding concrete is a precursor to pull-out of reinforcement steel (Weathersby, 2003, Haddad and Ashteyate, 2001). Clearly, reduction in the amount of cracking in the surrounding concrete would undoubtedly improve the bond between the concrete and the reinforcement steel. 


\section{REFERENCES}

1) Abdel-Qader, I., O. Abudayyeh, M.E. Kelly, (2003). Analysis of Edge Detection Techniques for Crack Identification in Bridges. Journal of Computing in Civil Engineering, October 2003, pp. 255-263.

2) Alageel, K., and I. Abdel-Qader, (2002). Haar Transform Use in Image Processing. Technical Report., Dept. of Electrical and Computer Engineering, Western Michigan University, Kalamazoo, Michigan.

3)American Association of State Highway and Transportation Officials (2002). Standard Specifications for Highway Bridges. $17^{\text {th }}$ Edition, Washington, D.C.

4) Brown, M.C., J.P. Gomez, T.E. Cousins, and F.W. Barton, (2003). Composite Action in a Steel Girder Span with Precast Panels: The I-81 Bridge Over the New River in Radford, Virginia. Final Report., Virginia Transportation Research Council, Charlottesville, Virginia

5) Campbell Scientific (1997). CR10X Measurements and Control Module Operator's Manual, Revision: 5/97, Campbell Scientific, Inc., Logan, Utah, USA

6) Canary systems (1997). MultiLogger Software User's Guide Version 2.0, Canary Systems, Inc., New London, NH, USA

7) Canary systems (1997). MultiSensor Interface User's Guide, Canary Systems, Inc., New London, NH, USA

8) Canny, J.F. (1986). A Computational Approach to Edge Detection. IEEE Trans. Pattern Anal. Mach. Intell., 8(6).

9) Civjan, S.A., S.F. Breńa, D.A. Butler, and D.S. Corvo (2004). Field Monitoring of an Integral Abutment Bridge in Massachusetts. TRB Annual Meeting CD-ROM.

10) Clemeńa, G.G., T.E. Freeman, D.S. Lane, M.G. Lozev, (2000). Evaluation of Nondestructive Evaluation Methods for Application of Early Detection of Deterioration in Concrete Pavements. Project Report, Virginia Transportation Research Council, Charlottesville, Virginia. 
11) Cooley, J.W., and J.W. Tukey (1965). An Algorithm for the Machine Calculation of Complex Fourier Series. Mathematical Computation., 19(90).

12) El-Salakawy, E, B. Benmokrane and G. Desgagné (2003). Fibre-reinforced polymer composite bars for the concrete deck slab of Wotton Bridge. Canadian Journal of Civil Engineering Vol. 30, pp 861-870

13) Geokon (1996), Installation Manual Models VCE-4200/4202/4210 Vibrating Wire Strain Gages.Geokon, The world Leader in Vibrating Wire Technology, Lebanon, NH, USA.

14) Geokon (1996), Installation Manual Models 4911 A/4911 VW Rebar Strain Meters. Geokon, The world Leader in Vibrating Wire Technology, Lebanon, NH, USA.

15) Geokon (1996), Instruction Manual Model VSM-4000 Vibrating Wire Strain Gage. Geokon, The world Leader in Vibrating Wire Technology, Lebanon, NH, USA.

16) Geokon (1996), Instruction Manual Model 4425 VW Convergence Meter.Geokon, The world Leader in Vibrating Wire Technology, Lebanon, NH, USA.

17) Geokon (1996), Instruction Manual Model 4430 VW deformation meter (crackmeter).Geokon, The world Leader in Vibrating Wire Technology, Lebanon, NH, USA.

18) Geokon (2001), Instruction Manual Model 8032 16/32 Channel Multiplexer.Geo Technical Instrumentation, Geokon, Inc., Lebanon, NH, USA.

19) Haddad, R.H., and Ashteyate, A.M. (2001). Role of synthetic fibers in delaying steel corrosion cracks and improving bond with concrete. Canadian Journal of Civil Engineering. Vol. 28, pp 787-793.

20) Halabe, U.B., K.R. Master, E.A. Kausel, (1995). Condition Assessment of Reinforced Concrete Structures using Electromagnetic Waves. American Concrete Institute (ACI) Materials Journal, Vol. 92, No. 5, pp. 511-523

21) Holmes, J.R., G.L. Downey, and R.E. Ekstrom (1974). Instrumentation for Long Term Field Structure and Model Structure Investigations (Interim Report). University of Nebraska Research Study 66-6.

22) Imbsen, R.A., D.E. Vandershaff, R.A. Schamber, and R.V. Nuutt (1985). Thermal Effects in Concrete Bridge Superstructures. National Cooperative Highway Research Program Report 276, Transportation Research Board, National Research Council, Washington, D.C.

23) Jajich, D. and A.E. Shultz (2003). Measurement and Analysis of Distortion-Induced Fatigue in Multigirder Steel Bridges. Journal of Bridge Engineering. Mar/Apr 2003, pp 84-91. 
24) Jewell Instruments, Manual for Jewell LCI Inertial Inclinometers, http://www.jewellinstruments.com.

25) Kitagawa, K., H. Watanabe, Y Tachibana, H. Hiragi, and Akimitsu Kurita (2001) Development of Innovative Composite System-Between Steel and Concrete Members. Technical Report, Kawada Industries, Japan.

26) Kuang, K.S.C, Akmaluddin, W.J. Cantwett, and C. Thomas (2003). Crack detection and vertical deflection monitoring in concrete beams using plastic optical fibre sensors. Measurement Science and Technology. Vol 14, pp 205-216.

27) Krauss, P.D. and E.A. Rogalla, (1996) Transverse Cracking in Newly Constructed Bridge Decks. National Cooperative Highway Research Program, Report 380, National Academy Press.

28) Lawver, A., C. Freanch, and C.K. Shield (2000) Field Performance of an Integral Abutment Bridge. Transportation Research Record. Vol. 1740, pp 108-117.

29) Levi, A, V.J. Hunt, A.J. Helmicki, and A.E. Aktan, (1999). Instrumentation, Testing, and Monitoring of a Newly Constructed Reinforced Concrete Deck-on-Steel Girder Bridge-Phases I and II. Report \#UC-CII 97/1, Cincinnati Infrastructure Institute, University of Cincinnati, Cincinnati, Ohio.

30) Lu, J.L., X. Mei, and M. Gunaratne (****), Development of an Automatic System for Measuring Pavement Crack Depth on Florida Roadways. Project Report Presented to Florida Department of Transportation, University of South Florida, Tampa, Florida.

31) Micro measurements, Manual for EGP-5-120 Embedment Strain Gages, http://www.vishay.com/brands/measurements_group/guide/500/lists/esg_list.htm

32) Nagy, Z. and I Szatmári, (1998). Composite Slab Design. $2^{\text {nd }}$ International PhD Symposium in Civil Engineering. Budapest, Hungary.

33) Nassif, H., N. Suksawang, M. Gindy, T. Abu-Amra, and J. Davis, (2003). Instrumentation and Testing of the Dormeus Avenue Bridge. TRB 2003 Annual Meeting CD-ROM.

34) Nawy E.G (1997). Concrete Construction Engineering Hand book , CRC press, Boca Raton, New York.

35) Parker, J.R. (1997). Algorithms for Image Processing and Computer Vision. Wiley, New York.

36) Petty, T.S. (2002). Permanent Instrumentation and Testing of I-15 Bridges. Master Thesis, Utah State University, Logan, Utah. 
37) Phares, B.M, D.D. Rolander, B.A Graybeal, G.A. Washer. (2001). Reliability of Visual Bridge Inspection. Public Roads, March/April 2001, pp. 22-29.

38) Roberts, E. and R. Shepard, (2000). Bridge Management for the $21^{\text {st }}$ Century. Transportation Research Record 1696, Transportation Research Board, Washington, D.C.

39) Shoukry, S.N., G.W. William, M.Y. Riad, (2005). Early Age Cracking in Concrete Bridge Decks. Draft Final Report No. T646-76-4.56 submitted to West Virginia Division of Highways.

40) Scheffy, C. N. Coetzee, and E. Diaz (1999). Asphalt Concrete Fatigue Crack Monitoring and Analysis Using Digital Image Analysis Techniques. Paper Submitted to Accelerated Pavement Testing 1999 International Conference, October 18-20, 1999 Reno, Nevada.

41) Scott, M., A. Rezaizadeh, and M. Moore, (2001). Phenomenology Study of HERMES Ground-Penetrating Radar Technology for Detection and Identification of Common Bridge Deck Features. Progress Report, Office of Infrastructure Research and Development, Federal Highway Administration, McLean, Virginia

42) Spiegel, L, and G. F. Limbrunner (1980). Reinforced Concrete Design. PrenticeHall, Inc., Englewood Cliffs, NJ.

43) Weathersby, J.H., (2003). Investigation of Bond Slip Between Concrete and Steel Reinforcement under Dynamic Loading Conditions. PhD Dissertation, Louisiana State University. 


\section{APPENDIX A: DATA ORGANIZATION}

The data acquired from the system of sensors installed at Evansville Bridge comes in the form of a raw data file in text form. Each Datalogger generates one data file each time data is collected. The data files are presented as plain text, delimited by commas. Each row of the data file represents one reading at a specific time. The first 11 columns of the data file contain the information shown in table A1.

Table A1: Data file contents for the first 11 Columns

\begin{tabular}{|c|l|}
\hline Column Number & Column Contents \\
\hline 1 & Datalogger ID Number \\
\hline 2 & Year \\
\hline 3 & Julian day \\
\hline 4 & Time HHMM \\
\hline 5 & Seconds \\
\hline 6 & Decimal Day \\
\hline 7 & Elapsed Hours \\
\hline 8 & Elapsed Minutes \\
\hline 9 & Elapsed Seconds \\
\hline 10 & Battery voltage \\
\hline 11 & Panel Temperature \\
\hline
\end{tabular}

The remaining columns (12 through 235) contain either a data point, or a blank column of zeros, depending upon whether a sensor is connected to that location or not. Table A2 shows the sensors connected to datalogger 1, and table A3 shows the sensors connected to datalogger 2. The key (a 5 character code was used to define the sensors) for both tables is shown below: 


\begin{tabular}{|l|l|l|l|l|}
\hline 1-Sensor Type & 2-Direction & 3-X position & 4- Y position & 5- Z position \\
\hline C- Crack Meter & W-Wheelpath & A- Abutment & 1- Beam A & 0- Top Slab \\
\hline I- Inclinometer & $\begin{array}{l}\text { P- Transverse } \\
\text { to } \\
\text { Wheelpath }\end{array}$ & B- 1/4 Span & 2- Beam B & 1- Bottom Slab \\
\hline S-Sister Bar & V- Vertical & H- 1/2 Span & 3- Wheelpath & $\begin{array}{l}\text { 2- Top Upper } \\
\text { Flange }\end{array}$ \\
\hline T- Thermistor & & T- 3/4 Span & 4- Line of Crack Meters & $\begin{array}{l}\text { 3- Bot. Upper } \\
\text { Flange }\end{array}$ \\
\hline $\begin{array}{l}\text { V- VW Strain } \\
\text { Gage }\end{array}$ & & P- Pier & 5- Beam C & 4- Top Web \\
\hline $\begin{array}{l}\text { W- Weldable } \\
\text { Strain Gage }\end{array}$ & & $\begin{array}{l}\text { Q- } 1 / 4 \\
\text { Midspan }\end{array}$ & $\begin{array}{l}\text { 6- Embeddment Strain } \\
\text { Gage }\end{array}$ & 5- Mid Web \\
\hline & M- Midspan & $\begin{array}{l}\text { 7- Sister Bar Abutment } \\
\text { Slab }\end{array}$ & 6- Bottom Web \\
\hline & & $\begin{array}{l}\text { 8- Crack Meter Abut. Slab } \\
\text { 7- Top Lower } \\
\text { Flange }\end{array}$ \\
\hline & & & & $\begin{array}{l}\text { 8- Bot. Lower } \\
\text { Flange }\end{array}$ \\
\hline
\end{tabular}


Table A2: Sensors Connected to Data Logger 1

\begin{tabular}{|c|c|c|c|c|c|c|c|c|c|}
\hline 12 & VWA10 & 59 & EMPTY & 106 & Mux_3CH_15Temp & 153 & VPA30 & 200 & Mux_6CH_13Temp \\
\hline 13 & VWA11 & 60 & Mux_2CH_1Temp & 107 & Mux_3CH_16Temp & 154 & VPA31 & 201 & Mux_6CH_14Temp \\
\hline 14 & VPA10 & 61 & Mux_2CH_2Temp & 108 & VWH20 & 155 & VVA30 & 202 & Mux_6CH_15Temp \\
\hline 15 & VPA11 & 62 & Mux_2CH_3Temp & 109 & VWH21 & 156 & Mux_5CH_1Temp & 203 & EMPTY \\
\hline 16 & VVA10 & 63 & Mux_2CH_4Temp & 110 & VPH20 & 157 & Mux 5 CH_2Temp & 204 & VWP30 \\
\hline 17 & VWB10 & 64 & Mux_2CH_5Temp & 111 & VPH21 & 158 & Mux_5CH_3Temp & 205 & VWP31 \\
\hline 18 & VWB11 & 65 & Mux_2CH_6Temp & 112 & VVH20 & 159 & Mux_5CH_4Temp & 206 & VPP30 \\
\hline 19 & VPB10 & 66 & Mux_2CH_7Temp & 113 & VVH21 & 160 & Mux_5CH_5Temp & 207 & VPP31 \\
\hline 20 & VPB11 & 67 & Mux_2CH_8Temp & 114 & VWT20 & 161 & Mux_5CH_6Temp & 208 & VVP30 \\
\hline 21 & VVB10 & 68 & Mux_2CH_9Temp & 115 & VWT21 & 162 & Mux_5CH_7Temp & 209 & VWQ30 \\
\hline 22 & VVB11 & 69 & Mux_2CH_10Temp & 116 & VPT20 & 163 & Mux_5CH_8Temp & 210 & VWQ31 \\
\hline 23 & VWH10 & 70 & Mux_2CH_11Temp & 117 & VPT21 & 164 & Mux_5CH_9Temp & 211 & VPQ30 \\
\hline 24 & VWH11 & 71 & Mux_2CH_12Temp & 118 & VVT20 & 165 & Mux_5CH_10Temp & 212 & VPQ31 \\
\hline 25 & VPH10 & 72 & Mux_2CH_13Temp & 119 & VWP20 & 166 & Mux_5CH_11Temp & 213 & VVQ30 \\
\hline 26 & VPH11 & 73 & Mux_2CH_14Temp & 120 & VWP21 & 167 & Mux_5CH_12Temp & 214 & VWM30 \\
\hline 27 & VVH10 & 74 & Mux_2CH_15Temp & 121 & VPP20 & 168 & Mux_5CH_13Temp & 215 & VWM31 \\
\hline 28 & Mux_1CH_1Temp & 75 & EMPTY & 122 & VPP21 & 169 & Mux_5CH_14Temp & 216 & VPM30 \\
\hline 29 & Mux_1CH_2Temp & 76 & VWM10 & 123 & VVP20 & 170 & Mux_5CH_15Temp & 217 & VPM31 \\
\hline 30 & Mux_1CH_3Temp & 77 & VWM11 & 124 & Mux_4CH_1Temp & 171 & Mux_5CH_16Temp & 218 & VVM30 \\
\hline 31 & Mux_1CH_4Temp & 78 & VPM10 & 125 & Mux_4CH_2Temp & 172 & VWB30 & 219 & VVM31 \\
\hline 32 & Mux_1CH_5Temp & 79 & VPM11 & 126 & Mux_4CH_3Temp & 173 & VWB31 & 220 & Mux_7CH_1Temp \\
\hline 33 & Mux_1CH_6Temp & 80 & VVM10 & 127 & Mux_4CH_4Temp & 174 & VPB30 & 221 & Mux_7CH_2Temp \\
\hline 34 & Mux_1CH_7Temp & 81 & VWA20 & 128 & Mux_4CH_5Temp & 175 & VPB31 & 222 & Mux_7CH_3Temp \\
\hline 35 & Mux_1CH_8Temp & 82 & VWA21 & 129 & Mux_4CH_6Temp & 176 & VVB30 & 223 & Mux_7CH_4Temp \\
\hline 36 & Mux_1CH_9Temp & 83 & VPA20 & 130 & Mux_4CH_7Temp & 177 & VWH30 & 224 & Mux_7CH_5Temp \\
\hline 37 & Mux_1CH_10Temp & 84 & VPA21 & 131 & Mux_4CH_8Temp & 178 & VWH31 & 225 & Mux_7CH_6Temp \\
\hline 38 & Mux_1CH_11Temp & 85 & VVA20 & 132 & Mux_4CH_9Temp & 179 & VPH30 & 226 & Mux_7CH_7Temp \\
\hline 39 & Mux_1CH_12Temp & 86 & VWB20 & 133 & Mux_4CH_10Temp & 180 & VPH31 & 227 & Mux_7CH_8Temp \\
\hline 40 & Mux_1CH_13Temp & 87 & VWB21 & 134 & Mux_4CH_11Temp & 181 & VVH30 & 228 & Mux_7CH_9Temp \\
\hline 41 & Mux_1CH_14Temp & 88 & VPB20 & 135 & Mux_4CH_12Temp & 182 & VWT30 & 229 & Mux_7CH_10Temp \\
\hline 42 & Mux_1CH_15Temp & 89 & VPB21 & 136 & Mux_4CH_13Temp & 183 & VWT31 & 230 & Mux_7CH_11Temp \\
\hline 43 & Mux_1CH_16Temp & 90 & VVB20 & 137 & Mux_4CH_14Temp & 184 & VPT30 & 231 & Mux_7CH_12Temp \\
\hline 44 & VWT10 & 91 & VVB21 & 138 & Mux_4CH_15Temp & 185 & VPT31 & 232 & Mux_7CH_13Temp \\
\hline 45 & VWT11 & 92 & Mux_3CH_1Temp & 139 & Mux_4CH_16Temp & 186 & VVT30 & 233 & Mux_7CH_14Temp \\
\hline 46 & VPT10 & 93 & Mux_3CH_2Temp & 140 & VWQ20 & 187 & EMPTY & 234 & Mux_7CH_15Temp \\
\hline 47 & VPT11 & 94 & Mux_3CH_3Temp & 141 & VWQ21 & 188 & Mux_6CH_1Temp & 235 & Mux_7CH_16Temp \\
\hline 48 & VVT10 & 95 & Mux_3CH_4Temp & 142 & VPQ20 & 189 & Mux_6CH_2Temp & & \\
\hline 49 & VWP10 & 96 & Mux_3CH_5Temp & 143 & VPQ21 & 190 & Mux_6CH_3Temp & & \\
\hline 50 & VWP11 & 97 & Mux_3CH_6Temp & 144 & VVQ20 & 191 & Mux_6CH_4Temp & & \\
\hline 51 & VPP10 & 98 & Mux_3CH_7Temp & 145 & VWM20 & 192 & Mux_6CH_5Temp & & \\
\hline 52 & VPP11 & 99 & Mux_3CH_8Temp & 146 & VWM21 & 193 & Mux_6CH_6Temp & & \\
\hline 53 & VVP10 & 100 & Mux_3CH_9Temp & 147 & VPM20 & 194 & Mux_6CH_7Temp & & \\
\hline 54 & VWQ10 & 101 & Mux_3CH_10Temp & 148 & VPM21 & 195 & Mux_6CH_8Temp & & \\
\hline 55 & VWQ11 & 102 & Mux_3CH_11Temp & 149 & VVM20 & 196 & Mux_6CH_9Temp & & \\
\hline 56 & VPQ10 & 103 & Mux_3CH_12Temp & 150 & VVM21 & 197 & Mux_6CH_10Temp & & \\
\hline 57 & VPQ11 & 104 & Mux_3CH_13Temp & 151 & VWA30 & 198 & Mux_6CH_11Temp & & \\
\hline 58 & VVQ10 & 105 & Mux 3CH_14Temp & 152 & VWA31 & 199 & Mux_6CH_12Temp & & \\
\hline
\end{tabular}


Table A3: Sensors Connected to Datalogger 2

\begin{tabular}{|c|c|c|c|c|c|c|c|c|c|}
\hline 12 & IW028 & 59 & CW1640 & 106 & Mux_3CH_15Temp & 153 & $\mathrm{~T} 13$ & 200 & EMPTY \\
\hline 13 & IW128 & 60 & Mux_2CH_1Temp & 107 & Mux_3CH_16Temp & 154 & $\mathrm{~T} 14$ & 201 & EMPTY \\
\hline 14 & IW228 & 61 & Mux_2CH_2Temp & 108 & CW1740 & 155 & $\mathrm{~T} 15$ & 202 & EMPTY \\
\hline 15 & IW328 & 62 & Mux_2CH_3Temp & 109 & CW1840 & 156 & $\mathrm{~T} 16$ & 203 & EMPTY \\
\hline 16 & IW428 & 63 & Mux_2CH_4Temp & 110 & CW1940 & 157 & EMPTY & 204 & VWZ20 \\
\hline 17 & IW528 & 64 & Mux_2CH_5Temp & 111 & CW2040 & 158 & EMPTY & 205 & VWZ21 \\
\hline 18 & IW628 & 65 & Mux_2CH_6Temp & 112 & CW2140 & 159 & EMPTY & 206 & VPZ20 \\
\hline 19 & WWA22 & 66 & Mux_2CH_7Temp & 113 & CW2240 & 160 & EMPTY & 207 & VPZ21 \\
\hline 20 & WWA28 & 67 & Mux_2CH_8Temp & 114 & CW2340 & 161 & EMPTY & 208 & VVZ20 \\
\hline 21 & WWH22 & 68 & Mux_2CH_9Temp & 115 & CW2440 & 162 & EMPTY & 209 & SWF30 \\
\hline 22 & WWH28 & 69 & Mux_2CH_10Temp & 116 & CW2540 & 163 & EMPTY & 210 & SW70 \\
\hline 23 & WWP22 & 70 & Mux_2CH_11Temp & 117 & CW2640 & 164 & EMPTY & 211 & EMPTY \\
\hline 24 & WWP28 & 71 & Mux_2CH_12Temp & 118 & CW2740 & 165 & EMPTY & 212 & EMPTY \\
\hline 25 & WWM22 & 72 & Mux_2CH_13Temp & 119 & CW2840 & 166 & EMPTY & 213 & EMPTY \\
\hline 26 & WWM28 & 73 & Mux_2CH_14Temp & 120 & CW2940 & 167 & EMPTY & 214 & EMPTY \\
\hline 27 & EMPTY & 74 & Mux_2CH_15Temp & 121 & CW3040 & 168 & EMPTY & 215 & EMPTY \\
\hline 28 & EMPTY & 75 & Mux_2CH_16Temp & 122 & CONVERGENCE_1 & 169 & EMPTY & 216 & EMPTY \\
\hline 29 & EMPTY & 76 & SWA20 & 123 & CONVERGENCE_2 & 170 & EMPTY & 217 & EMPTY \\
\hline 30 & EMPTY & 77 & SPA20 & 124 & Mux_4CH_1Temp & 171 & EMPTY & 218 & EMPTY \\
\hline 31 & EMPTY & 78 & SWA50 & 125 & Mux 4CH_2Temp & 172 & $\mathrm{~T} 2 \_0$ & 219 & EMPTY \\
\hline 32 & EMPTY & 79 & SPA50 & 126 & Mux_4CH_3Temp & 173 & $\mathrm{~T} 2 \_1$ & 220 & Mux_7CH_1Temp \\
\hline 33 & EMPTY & 80 & SWH20 & 127 & Mux_4CH_4Temp & 174 & $\mathrm{~T} 2 \_2$ & 221 & Mux_7CH_2Temp \\
\hline 34 & EMPTY & 81 & SPH20 & 128 & Mux_4CH_5Temp & 175 & $\mathrm{~T} 2 \_3$ & 222 & Mux_7CH_3Temp \\
\hline 35 & Mux_1CH_8Temp & 82 & SWH50 & 129 & Mux_4CH_6Temp & 176 & $\mathrm{~T} 2 \_4$ & 223 & Mux_7CH_4Temp \\
\hline 36 & Mux_1CH_9Temp & 83 & SPH50 & 130 & Mux 4CH_7Temp & 177 & $\mathrm{~T} 2 \_5$ & 224 & Mux $7 \mathrm{CH} 5 \mathrm{Temp}$ \\
\hline 37 & Mux_1CH_10Temp & 84 & SWT20 & 131 & Mux_4CH_8Temp & 178 & $\mathrm{~T} 2 \_6$ & 225 & Mux_7CH_6Temp \\
\hline 38 & Mux_1CH_11Temp & 85 & SPT20 & 132 & Mux_4CH_9Temp & 179 & $\mathrm{~T} 2 \_7$ & 226 & Mux_7CH_7Temp \\
\hline 39 & Mux_1CH_12Temp & 86 & SWP20 & 133 & Mux_4CH_10Temp & 180 & $\mathrm{~T} 2 \_8$ & 227 & EMPTY \\
\hline 40 & Mux_1CH_13Temp & 87 & SPP20 & 134 & Mux_4CH_11Temp & 181 & T2 9 & 228 & EMPTY \\
\hline 41 & Mux_1CH_14Temp & 88 & SWM20 & 135 & Mux_4CH_12Temp & 182 & $\mathrm{~T} 2 \quad 10$ & 229 & EMPTY \\
\hline 42 & Mux_1CH_15Temp & 89 & SPM20 & 136 & Mux_4CH_13Temp & 183 & $\mathrm{~T} 2 \_11$ & 230 & EMPTY \\
\hline 43 & EMPTY & 90 & SWM50 & 137 & Mux_4CH_14Temp & 184 & $\mathrm{~T} 2 \_12$ & 231 & EMPTY \\
\hline 44 & CW0110 & 91 & SPM50 & 138 & Mux_4CH_15Temp & 185 & $\mathrm{~T} 2 \_13$ & 232 & EMPTY \\
\hline 45 & CW0280 & 92 & Mux_3CH_1Temp & 139 & Mux_4CH_16Temp & 186 & $\mathrm{~T} 2 \_14$ & 233 & EMPTY \\
\hline 46 & CW340 & 93 & Mux $3 \mathrm{CH} 2 \mathrm{Temp}$ & 140 & T0 & 187 & $\mathrm{~T} 2 \_15$ & 234 & EMPTY \\
\hline 47 & CW0450 & 94 & Mux $3 \mathrm{CH} 3 \mathrm{Temp}$ & 141 & $\mathrm{~T} 1$ & 188 & T2 16 & 235 & EMPTY \\
\hline 48 & CW540 & 95 & Mux_3CH_4Temp & 142 & $\mathrm{~T} 2$ & 189 & Air temp1 & & \\
\hline 49 & CW640 & 96 & Mux_3CH_5Temp & 143 & $\mathrm{~T} 3$ & 190 & Air temp2 & & \\
\hline 50 & CW740 & 97 & Mux_3CH_6Temp & 144 & $\mathrm{~T} 4$ & 191 & EMPTY & & \\
\hline 51 & CW840 & 98 & Mux 3CH 7Temp & 145 & $\mathrm{~T} 5$ & 192 & EMPTY & & \\
\hline 52 & CW940 & 99 & Mux_3CH_8Temp & 146 & $\mathrm{~T} 6$ & 193 & EMPTY & & \\
\hline 53 & CW1040 & 100 & Mux_3CH_9Temp & 147 & $\mathrm{~T} 7$ & 194 & EMPTY & & \\
\hline 54 & CW1140 & 101 & Mux_3CH_10Temp & 148 & $\mathrm{~T} 8$ & 195 & EMPTY & & \\
\hline 55 & CW1240 & 102 & Mux_3CH_11Temp & 149 & T9 & 196 & EMPTY & & \\
\hline 56 & CW1340 & 103 & Mux $3 \mathrm{CH} 12 \mathrm{Temp}$ & 150 & $\mathrm{~T} 10$ & 197 & EMPTY & & \\
\hline 57 & CW1440 & 104 & Mux $3 \mathrm{CH} 13 \mathrm{Temp}$ & 151 & $\mathrm{~T} 11$ & 198 & EMPTY & & \\
\hline 58 & CW1540 & 105 & Mux $3 \mathrm{CH} 14 \mathrm{Temp}$ & 152 & $\mathrm{~T} 12$ & 199 & EMPTY & & \\
\hline
\end{tabular}


The data from each datalogger was initially downloaded onto a laptop computer at the site, but the system has since been upgraded to allow for remote downloading, which allows data to be downloaded with much greater regularity. After downloading, each set of data, corresponding to one to three weeks of elapsed time, is carefully inspected by plotting it using MATLAB software, and any data that is out of range is corrected by replacing it with an average of the data points immediately prior and immediately after it.

After correcting errors in the data, the new data is then added to the global data matrix, and saved as a MATLAB data file. After saving the matrix, individual MATLAB data files (afterwards referred to as matrices), are created for each type of sensor installed at Evansville bridge. The data in each of these matrices is manipulated as necessary to make it as easy as possible to work with. With the exception of temperature readings, all data is zeroed by subtracting the initial reading from each subsequent data point, and temperature compensation is applied as appropriate. In the case of the inclinometers, conversion from a reading in volts to angle in degrees is necessary. The crack meter reading is also converted to inches by multiplication by a gage factor. In each matrix, a time column is also created, which contains a column of time, in decimal days, starting at day zero. Day zero is taken as the day the sensor system was initially brought online, June 19, 2003. MATLAB data matrices were created for crack meter data (displacement and temperature), inclinometer data (angle), embedded vibrating wire strain gages (strain and temperature), weldable vibrating wire strain gages (strain and temperature), sister bars (strain and temperature), convergence meters (displacement and temperature), and thermistors (temperature). This arrangement makes it very simple to manipulate or examine the data and to perform calculations. MATLAB was used for all calculations since the data is already stored in the form of MATLAB data arrays. 